\title{
Impact of depression and antidepressant treatment in daily life : an experience sampling approach
}

Citation for published version (APA):

Barge-Schaapveld, D. Q. C. M. (2001). Impact of depression and antidepressant treatment in daily life : an experience sampling approach. [Doctoral Thesis, Maastricht University]. Datawyse / Universitaire Pers Maastricht. https://doi.org/10.26481/dis.20011221db

Document status and date:

Published: 01/01/2001

DOI:

$10.26481 /$ dis.20011221db

Document Version:

Publisher's PDF, also known as Version of record

\section{Please check the document version of this publication:}

- A submitted manuscript is the version of the article upon submission and before peer-review. There can be important differences between the submitted version and the official published version of record.

People interested in the research are advised to contact the author for the final version of the publication, or visit the DOI to the publisher's website.

- The final author version and the galley proof are versions of the publication after peer review.

- The final published version features the final layout of the paper including the volume, issue and page numbers.

Link to publication

\footnotetext{
General rights rights.

- You may freely distribute the URL identifying the publication in the public portal. please follow below link for the End User Agreement:

www.umlib.nl/taverne-license

Take down policy

If you believe that this document breaches copyright please contact us at:

repository@maastrichtuniversity.nl

providing details and we will investigate your claim.
}

Copyright and moral rights for the publications made accessible in the public portal are retained by the authors and/or other copyright owners and it is a condition of accessing publications that users recognise and abide by the legal requirements associated with these

- Users may download and print one copy of any publication from the public portal for the purpose of private study or research.

- You may not further distribute the material or use it for any profit-making activity or commercial gain

If the publication is distributed under the terms of Article $25 \mathrm{fa}$ of the Dutch Copyright Act, indicated by the "Taverne" license above, 


$$
\begin{gathered}
\text { IMPACT OF DEPRESSION AND } \\
\text { ANTIDEPRESSANT TREATMENT IN DAILY LIFE } \\
\text { AN EXPERIENCE SAMPLING APPROACH }
\end{gathered}
$$


Cower illustration: Agmes Chandemagne.

Edired and princed in the Netherlands by Darawyse, Mastricht.

ISBN 9052783314

(C) Copyrigh 2001 Daniela Barge-Schanpveld. All rights reserved. No part of this publication mal be reproduced in any form by any means without writen permission of the atuhor. 


\section{IMPACT OF DEPRESSION AND ANTIDEPRESSANT TREATMENT IN DAILY LIFE AN EXPERIENCE SAMPLUNG APPROACH}

\section{PROEFSCHRIFT}

ter verkrijging van de graad van doctor aan de Universiteit Maastricht, op gezag van de Rector Magnificus,

Prof.dr. A.C. Nieuwenhuijzen Kruseman volgens het besluit van het College van Decanen, in het openbaar te verdedigen op vrijdag 21 december 2001 om 14.00 uur

door

Daniela Quirina Carola Maria Barge-Schaapveld

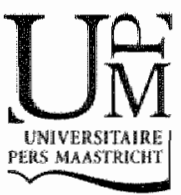


Promotor:

Prof.dr. M.W. deVries

Co-promotor:

Dr. N.A. Nicolson

\section{Beoordelingscommissie:}

Prof.dr. M. Maes (voorzitter)

Prof.dr. C.M.H. Hosman

Prof.dr. H. Katschnig (University of Vienna, Austria)

Prof.dr. J.A. Knottnerus

Prof.dr. H.F. Kraan (Universiteit Twente) 
Queer little twists and guivtes go into the making of an individuat.

To suppress them all and follow clock and alendar and creed until the individual is lost in the newatral gray of the

host is to be less than true to our inheritance..

Life, that gorgeous quality of life, is not acomplished by following another man's rules.

It is true we have the same bungers and thirsts, but they are for different things and in different ways and in different seasons...

Lay down your own day, follow it to its noon, your oun noon, or you would sit in an outer hall listening to the chimes but never reaching bigh enough to strike your own.

Essay by Angelo Patri, found in a scrapbook, kept by Virginias, mother of Jobn Nasb. 'A beautiful mind', Sylvia Nasar, 1998 


\section{TABLE OF CONTENTS}

PART I: $\quad$ INTRODUCTION

Based in part on an earlier publication by Barge-Schaapveld D.Q.C.M., Nicolson N.A., Delespaul P.A.E.G., deVries M.W., 1997. Assessing daily quality of life with the Experience Sampling Method. In: Katschnig H., Freeman H., Sartorius N., Quality of Life in Mental Disorders, John Wiley \& Sons, Chichester, UK.

CHAPTER 1 Depression and the Quality of Life (QoL)

CHAPTER 2 Use of the Experience Sampling Method (ESM) to assess daily QoL in clinical research

PART II: PRELIMINARY STUDY (STUDY 1)

CHAPTER 3 Changes in daily life experience associated with clinical improvement in depression Journal of Affective Disorders, 1995.34, 139-154

PART III: MAIN STUDY (STUDY 2)

CHAPTER 4 Using ESM to investigate QoL in clinical trials of antidepressants: A methodological overview

CHAPTER 5 QOL in depression: Daily life determinants and variability Psychiatry Research, 1999, 88, 173-189

CHAPTER 6 Effects of antidepressant treatment on the Quality of 111 Daily Life: An experience sampling study Journal of Clinical Psychiatry, under review 
CHAPTER 7 The everyday experience of two depressed patients: 131 A responder and a non-responder to treatment

PART IV: DISCUSSION

CHAPTER 8 The impact of depression and antidepressant treatment in daily life: Conclusions and general discussion

APPENDICES

APPENDIX 1 Study 1 ESM self-report (Dutch and English)

APPENDIX 2 Study 2 ESM self-report (Dutch and English) 

PART I

INTRODUCTION

\author{
CHAPTER 1 \\ Depression and \\ the Quality of Life (QoL)
}

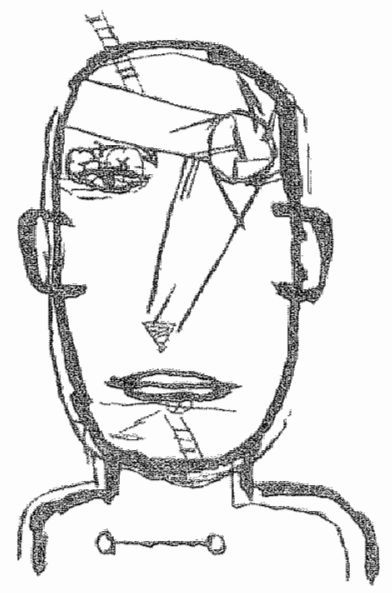




\section{Depression and the Quality of Life $(\mathrm{Q} o L)^{1}$}

At some point or other in our lives, we all experience what it is to be feeling down, to lack the energy to perform the activities we should do or normally do, and to be filled with pessimistic or gloomy thoughts about matters that concern us directly. Such states can occur in one person more often or longer than in the other. Usually these states do not exceed a certain level of severity, and they pass by because one has supportive friends or family, or simply because one can cope with them. In other cases, these stares are part of a pathological condition, namely major depression.

Major depressive disorder is an important diagnostic category in the two most widely used classification systems for psychiatric disorders: ICD-10 (World Health Organization, 1992) and DSM-IV (American Psychiatric Association, 1994). The DSM diagnostic criteria, used in this thesis ${ }^{2}$, include depressed mood, anhedonia, significant weight loss or gain, trouble wirh sleeping, psychomotor agitation or retardation, farigue, feelings of worthlessness, diminished ability to think, difficulty concentrating, and suicidal thoughts. Five or more of these symptoms are required to be present for a duration of at least two weeks for a 'case' definition, and one of the symproms must be either depressed mood or loss of interest.

Since the 1950s, with the appearance of new drugs for the trearment of depression and the refinement of the diagnostic systems in the decades thereafter, the scientific literature has shown an ever-increasing number of articles relating to this mood disorder. Why then, yer another study on depression and its treatment? Most of the available information concerns eriologic, nosological, pharmacological, and clinical perspectives. As a result, our understanding of the phenomenology, prevalence, course, and treatment of depression has dramatically increased. But our understanding of depression and its management is far from being complete, as evidenced by the fact that depression ranks fourth in terms of global burden of disease according to the World Bank (1993). And, as depression is expected to become the second most important cause of disability world wide in 2020 , additional research on depression is justifiable. In an attempt to obtain better insight into the burden of depression and its treatment on

1 This chapter is based in part on an carlier publication by Barge-Schapveld D. Q. C. M., Nicolson N A. Delespaul P. A. E. G., deVres. M. W. 1997 . Assessing daily quality of life with rhe Experience \$ampling Method. In: Kasschnig H.. Ereeman H., Sartorius N. (Eds.), Quality of Life in Mental Disorders, John Wiley \& Sons Lad, Chichester, pp.95-107.

2 Alshough DSM-IV is referred to in this introductory chapter, the prewious version of this diagnostic dassification system, namely DSM-IIL-R (American Psychiaric Association, 1987), is used in other chap. ters of this thesis. The diagnostic criteriat for major depression are identical in both versions. 
the parients rhemselves, clinical studies have introduced new ourcome measures, generally referred to as "Quality of Life" (QoL) measures. But as will be seen, little atrention has been given to the experiential aspects of depression and its treatment. That is to say, how do depressed persons experience their illness in daly life? In what kind of daily life siruations do they feel most depressed? Does their inability to enjoy life in general impact on all activities they engage in? How does anridepressant treament influence their daily life experiences? Is the improvement in mood related to specific contexts in their daily lives? How frequently during the day do treament side effects occur, and to what extent do they impact patients" quality of life? In order to answer these types of questions, this thesis will explore daily quality of life in depressed patients and changes in daily life experiences following pharmaco-rherapeutic interventions.

\section{BURDEN OF DEPRESSION}

Over the past rwo decades, major epidemiological studies have been conducted to determine the prevalence of depressive disorders. Although all agree that depression is a common condition, varying prevalence rates have been reported. Summarizing epidemiological studies performed since 1980, Wittchen er al. (1994) reported that the point-prevalence of major depression was about 3\% (range: 1.5\%-4.9\%); the 6-monch to 1 -year prevalence of major depression was about $6 \%$ (range: $2.6 \%-9.8 \%$ ) and the lifetime prevalence of major depression was about 16\% (range: $4.4 \%-18 \%$ ).

Depression was originally described as a primarily single episode disorder. In the past decades, it has been recognized as a recurrent psychiatric disorder, in which discrete episodes of illness alternate with clearly defined "well periods" during which patients return to their previous state of health (Keller, 1994). Expectations are that 50 to $85 \%$ of the parients experiencing a major depressive episode will experience at least one recurrence ( $T$ weed, 1993). The chances of occurrence of a second episode are estrimated at $50 \%$, whereas the chances that a second episode will be followed by a third rise to 85\% (Cassem, 1995). Angst (1988) followed patients with depression for 19 yoars and found that these patients spent as much as $23 \%$ of this period in depressive episodes.

Not only do the many investigations confirm that a significant number of depresed patients experience multiple episodes, but more recent results also indicate that a substantial number of depressed pacients do not return to the state of well-being they had prior to their illness. Longitudinal studies confirm that major depression is often a chronic condition. Many patients have subclinical depressive syndromes between episodes, in a scudy of patients who were high utilizers of primary care (Katonet al., 1992), half of the subjects who had experienced one or more lifetime episodes of major depression but no current major depression still had two or more depressive symptoms. In another study, in addition to the $20 \%$ of patients who did not respond to treatment, 
another 20 to $30 \%$ showed only a partial response to treatment (Fawcert, 1994). This implies that these patients continue to suffer significant psychological, physical and social impaiment beween episodes.

Finally, liferime suicide rates in individuals with major depression, in treatment or not, range between 15 and 20\% (Keller, 1994; Cassem, 1995; Goodwin, 1996), and the lethality of a suicide attempr increases with the severity of the depression (Malone er al., 1995). Recent epidemiological data indicate that suicide rates are often a consequence of poor diagnosis and treatment of depression and suggest that antidepressants may reduce suicide risk among depressives (Isacsson et al., 1996).

\section{Sacietal burden}

The magnitude of depression as a public health problem is reflected in the costs incurred by society. Although different estimates have been suggested, all represent a significant percentage of the GNP. In 1980, the total economic impact of depression in the US was estimated at more than $\$$ US 16 billion (Stoudemire et al, 1986). In 1990, Greenberg et al. (Greenberget al., 1993) estimated the annual cost of depression in the US at approximately $\$$ US 44 billion. Of these totals, only a small percentage (\$US2.1 billion and $\$$ US 12.3 billion, respectively) was spent on direct costs of diagnosis and treament. The remaining expenses were indirect costs associated with lost productivicy in the workplace. In a study of the medical and disability costs at the first Chicago Corporation (Conti and Burton, 1994), 3\% of total disability days were due to depressive disorders, and the average sick leave in employees with a diagnosis of depressive disorder was 40 work days (compared to an average work absence for somatic diagnoses of 29 days).

As a consequence of poor recognition and treatment of depression in medical serrings, in addition to high levels of both psychiatric and somatic comorbidity, another important contribution to the socictal burden of depression is the high level of medical utilization. In one study, the use of medical outpatient facilities was found to be subm stantially increased in parients with major depression (36\%) compared with patients with no mental disorder ( $8 \%$ ) (Cassem, 1995). Other studies have shown that even a minimal level of depressive symptoms was associated with increased rates of service utilization, but depressive disorders were clearly associated with the highest rates of service urilizarion (Johnson er al., 1992; Spitzer ct al., 1994). Likewise, elderly with depressive symptoms report the need for seeing a rrained counselor (Blazer and Williams, 1980) or actively seek help from health professionals (Henderson et al. 1993) more often than do their non-depressed peers.

Recognition and treatment of depression in medical sertings are all the more important given that untreated depression is associated with poor medical outcomes in several somatic disorders (Goodwin, 1996). In the elderly, untreated depression or inattention 
to important depressive symproms leads to needless emotional despair, psychosocial deterioration, economic loss, physical illness and institutionalization, as well as substantial rates of suicide (Kurlowicz, 1993).

\section{Familial burden}

Manifested less in economic terms, but more in terms of impairment, disability and disruption, the consequences of depression can dramatically affect the lives of those interacting with afflicted individuals (Tweed, 1993). Looking back on his own experience as a depressed inpatient, an anonymous psychiatrist described how difficult it is for staff and relatives to deal with a depressed person, mainly due to patients' indecisiveness and ambivalence (e.g. feeling guilty when people visit or phone but feeling rejected when they do not) (Anonymous, 1990). In a study of 42 adults living with a depressed patient, respondents felt burdened in numerous ways and were particularly upset by the patient's depressive symptoms, such as lack of interest in social life, fatigue, hopelessness, and worrying (Coyne et al., 1.987). In addition, $40 \%$ of these respondents were sufficiently distressed themselves to meet the criterion for needing psychological intervention. In another study (Fadden et al., 1987), spouses of 24 patients suffering from persistent depression were interviewed to find out how they were affected by the patient's illness. Results showed that the social and leisure activities of relatives suffered considerably as a consequence of the patient"s illness. Almost thalf of the spouses interviewed ( $45 \%$ ) felt that they had no idea what to do in a practical sense to deal with the mood disturbance of the patient and its consequences for their lives. However, the symptoms that relatives found most frequently burdensome were the "negative' ones, such as worrying, irritability, and nagging. Because they overlapped with normal parterns of behavior, these symptoms were frequently not seen by the relative as arising from the patient's depression. Maybe as a result of this lack of insight, family members may become irritared and direct hostile criticism at their depressed relatives, thereby also increasing marital problems (Dew and Bromet, 1991).

\section{Personal burden}

The personal burden is best described by the experience of feeling impaired, incompetent, and unable to handle stress or even the demands of everyday life, as expressed by the Swiss physician and natural scientist Albrecht von Haller (1708-1777), who is believed to have suffered from depressive episodes: 'I have felt wy heart succumb to its work, ready to surrender. ... My spirit which does not lack resilience, starts to succumb; the pleasure in my work is diminishing and my resources seem exhausted. '(van Lieburg, 1988, p.51). Becoming depressed is often seen by patients as a matter of their losing a balance in warious aspects of their lives (Coyne and Calarco, 1995). Depressed individuals fre- 
quently complain of poor memory and concentration. Counterintuitively, however, a direct relationship berween the severity of the depression and the occurrence of cognitive dysfunction has not been established (Brown et al., 1994). In addition, depressed individuals tend to appraise unpleasant events as more aversive than do non-depressed individuals (Lewinsohn and Amenson, 1978) and to attribute these negative events more often to internal causes than do parients with generalized anxiety disorder, for instance (Riskind et al., 1989). As already mentioned, depression is by definition characterized by a negative mood and an inability to enjoy life. Although this is widely accepted, it does not seem to be a sufficient basis, however, for differentiating clinical depression from ordinary blues. According to recovered patients, being depressed is different from being sad or blue because of the profound loss of energy and the disruption in everyday functioning that one experiences (Coyne and Calarco, 1995).

Indeed, having difficulties in everyday functioning is another important aspect of the personal burden experienced by depressed patients. In general, there is evidence that a low frequency of acriviries constitutes an extremely important clinical aspect of depression (Lewinsohn and Libet, 1972). The overall number of daytime acrivities depressed individuals engage in is only $70 \%$ of normal controls (Ehlers et al., 1988). Performance of daytime acrivities usually only occur when patients have sufficiently improved in their mood to take an interest in the activities (Anonymous, 1990). Similarly, Blazer et al. (Blazer and Williams, 1980) found a decrease in the activities of daily living in elderly depressed individuals, even though their physical health was nor substantially impaired. Specifically, depressed persons engage in fewer pleasant activities than nondepressed individuals (Lewinsoln and Amenson, 1978), and the frequency with which they engage in these activities is lower than in normal controls (Szuba er al., 1992).

Social relarionships in general and relationships with their families in particular become increasingly important as the social conrext of depressed individ uals narrows. Perceptions of inadequate support are associared with both the onset and conrinuation of depressive symptoms (Henderson and Moran, 1983), and high levels of spouses' expressed emorion are predictive of relapses (Hooley er al., 1986). In addirion, feelings of loneliness or the ending of an intimate relationship emerge regularly as precipitating factors for suicide artempts (O'Donnell er al., 1996). Although nor unique to depression, social support fulfils an essential role in depressed patients. They need to be understood by and useful to the members of their social network, they need to feel that significant others are available to talk to about problems, or in any case can becounted upon (George et al., 1989). Statements elicited in two focus groups of previously depressed persons showed that feelings of guilt toward one's family also play an important role (Coyne and Calarco, 1995). The aurhors found that even recovered depressed patients experience secondary guilt about having been depressed, they feel the need to conceal 
symptoms and impaiment from others in order to avoid criticism and rejection, they sense that they are a burden on orhers, and they feel stigmatized.

\section{Treatment iswes}

Nowadays, different alternatives are available for treating depressed patients, whereby a distinction is usually made berween psychotherapy and pharmacotherapy, even though a combination of both is also believed to be effective for major depression (de Jonghe et al., 2001). The various types of psychotherapy (e.g., cognitive-behavioral, interpersonal, psychoanalyrical) will not be described here, as they are not the focus of the current research. The available antidepressants can be categorized into different classes, of which the rwo best known - and also used in the present research - are: (1) twigh tic antdepressants (TCAs), with for example, impramine and amitriptine and (2) selective serotonin reuptake inbibitors (SSRIs), with for example, fluoxetine, ${ }^{3}$ paroxetine, and finoxamine ${ }^{5}$. In different meta-analytical reviews the rwo classes of drugs have not been shown to differ in efficacy (Kasper et al., 1992; Song et al., 1993). TCAs and SSRIs do differ in side effects profile as a consequence of their pharmacological actions. TCAs are known for their anticholinergic effects, which include dry mouth, constipation, and blurred vision, as well as autonomic effecrs, such as orthostatic hypotension, sweating, and palpitarions. SSRIs are known for their gastro-intestinal side effects, such as nausea and vomiting, and sexual dysfunction. Drugs in both classes have been extensively used over the years. At the outset of this research, "TCAs were still the 'first-line' treatment in many countries. Since then, most countries have turned to SSRIs as a first treatment option in view of a more favorable side effects profile. In light of still newer antidepressants (e.g. reboxetine ${ }^{(4)}$, suggestions have been made to revise the classification of antidepressants on the basis of ransmitter mechanism, for example (Healy, 1998).

Several studies conducted in the late 1980s (Regier et al., 1988; Klerman, 1989; Ormel et al. 1991) reported that among depressed patients who attend a general practicioner, some $50 \%$ of cases go unrecognised. In addition, wo-thirds of people identified in community surveys as suffering from major depression are not receiving adequate treatments (Keller er al., 1982; Regiereral., 1988; Katon etal., 1992). Only 11\% of patienrs evaluated as needing an antidepressant receive adequate dosage and duration of therapy (Katon et al. 1992). And when given treatment, 20 to $60 \%$ of primary care patients

Tofrail
2 Tryprizol
3 Prozac
4 Seroxat
5 Revarin
6 Edronax


stop taking antidepressant medication because of unpleasant side effects, early recovery or paradoxically, a worsening of depressive symproms (Johnson, 1973; Thomson et al., 1982). The number of safe and effective medication treatments for depression has increased significantly over the past 10 years. In spite of these benefits, and in spite of the exrensive and successful efforts that have been made to inform the general population abour the diagnosis and treatment of depression (for instance, the Defear Depression Campaign organized by the Royal Colleges of Psychiatrists and General Practitioners in the UK from 1992 to 1996, see Paykel et al., 1998), many patients still do not comply with treatment recommendations (Roose, 1999; Delgado, 2000). Currently, the treatment effect size of many antidepressants is modest, the burden of side effects they produce has never been established, and dara on the quality of life during treatment is absent' (Healy, 1999).

As outlined above, noc only is major depression a common illness in terms of prevalence rates but it is also a chronic illness, in the sense that individuals who are depressed will often remain so, at least intermittently, for the rest of their lives, if not commitring suicide at an earlier stage. The impact of this illness is therefore immense. The burden of depression on sociery as a whole, but also on the families involved and the parients themselves, is huge in both economic and social terms. Still recognition of depression is far from adequare. Several treatments are available, but none is withour side effects. In addition, many patients strill do not comply with treatment recommendations. Therefore, our understanding of how patients experience their illness and treatment has room for much improvement. The development of QoL as an outcome measure in clinical research has offered new opportunities to shed light on the parient's perspective.

\section{DEVELOPMENT OF QOL AS AN OUTCOME MEASURE IN} DEPRESSION TRIALS

Over the second half of the twentieth century, evolving medical, governmental and industrial perspectives on health care have encouraged an optimization of treatment that reaches beyond standard medical outcome variables. Traditional indicators of the severity of illness have helped to clarify the disease parhophysiology and effects of therapy, but they do not provide insight into whether or not a particular treatment helps from the patient's perspecrive (Read et al., 1987). To meer these needs, QoL has developed as an outcome measure in clinical research.

Current methods of assessing QoL have developed out of three main research traditions: 'happiness', 'social indicarors' and 'health status'. Each tradition has placed a different emphasis on affective, cognitive-appraisal, and behavioral components. In this section, the three QoL conceptualizations are briefly reviewed (for more derailed 
reviews see Wilson, 1967; Diener, 1984; de Neeling, 1991), and the influences on the use of QoL in clinical research, in depression in parricular, are outlined.

\section{Different research traditions}

The 'happiness' research tradition developed primarily out of the interests of psychologists and personalicy researchers; here, QoL is defined subjectively as 'feeling happy' (see, e.g. Gurin et al., 1960; Bradburn and Caplovitz, 1965; Costa and McCrae, 1980; Diener et al., 1991). 'Happiness' was first defined as a psychological construct in the 1950 s (Jones, 1953), opening the way for research into its nature and determinants. In 1960, the first national study to assess the happiness of the population was carried our in the US (Gurin et al., 1960). Later it became clear that the concept of well-being should not be restricted to the extent of positive mood one feels. There is increasing agreement on the relevance of negarive affect as a second independent dimension (Bradburn, 1969). Evidence for the independence of positive and negative affects stems from findings that both constructs correlate wirh different variables (Costa and McCrae, 1980; Abbey and Andrews, 1985): positive affect with internal control, performance, social support and extraversion, and negative affect with stress and neuroticism. Another current discussion focuses on the importance of discinguishing between short-and long-term components of happiness in models of subjective well-being (Kozma et al., 1990).

'Social indicarors' research originated at the beginning of this century and reflects the interest of social scientists in economic and social determinants of well-being. The measurement of material well-being dates back to 1930, when King (1930) produced the first rough estimates of National Product to compare the living standards of different countries. In the following three decades, the definition of well-being using material indicators was refined (see, e.g. Kuznets, 1941). In the 1950s, the term "quality of life" was introduced for the first time in this context (Ordway, 1953, p.52). Even more influ* ential was the use of the term by President Johnson during the election campaign of 1964: "These goals cannot be measured by the size of our bank balances. They can only be measured in the quality of life that our people lead' (Rescher, 1972). These political statements were confirmed in several studies that found little or no relationship between objective indicators and subjective appraisals in terms of satisfaction with life (e.g. Cantril, 1965; Rodgers and Converse, 1975; Andrews and Withey, 1976; Campbell, 1976). This led to a divergence into two lines of research. One group continued with the idea that objective indicators such as use of time (time-budgets) could also be used as social indicators of well-being (Robinson, 1977; Juster er al., 1981; Grønmo, 1982; Milbrath, 1982; Robinson, 1987). Others focused on subjective indicators; Cantril (1965), for example, asked subjects to evaluate their current life siruation on a ladder from 1 (worst possible) to 10 (best possible). The idea was that QoL reflects the 
size of the gap berween an individual's actual situation and that to which (s)he aspires. In other words, perceived QoL is thought to result from a cognitive-appraisal process and reflects current life satisfaction. Whether this satisfaction should be measured globally or with respect to specific life domains is still the subject of debate (Lance et al., 1989; Headey et al., 1991; Feist et al., 1995).

"Health status" QoL research originated in the World Health Organization Charter of 1948. Healch was defined as 'a state of complete physical, mental and social well-being and not merely the absence of disease or infirmity'. Traditionally, the health status of a population was measured by the mortality rate or life expectancy. However, in the 1950 s, the mortality rate reached a balance in Western countries, mainly due to a decrease in life-threatening diseases. It was therefore no longer a sensitive measure to differentiate the health starus of different countries. On the orher hand, due to the growing proportion of individuals with chronic diseases and the development of medical rechnology that diminished pain and discomfort without extending life, other sensitive outcome measures were needed. This led to the development of integrated and comprehensive health starus indices in the late 1970 s (e.g. the Notringham Health ProFile, Hunt and McEwen, 1980; the Sickness Impact Profile, Bergner et al., 1981; the SF-36, Ware et al., 1981). The 'health status' tradition has contributed a behavioral dimension to the concept: QoL represents the effect of an illness and its consequent therapy upon the patient's ability to function in daily life circumstances (Schipper, $1990)$.

\section{Use of QoL in clinical research}

According to some, the goal of medical interventions is not so much to decrease mortality and morbidity as to enhance the quality of life of those treated (Levine, 1987). In this sense, QoL. has always been an essential outcome measure in clinical research. Although the introduction of QoL measures in clinical research is often atributed to the 'social indicators" research tradition (see Najman and Levine, 1981 ), there were some investigations into related concepts in clinical research prior to this date that are worth mentioning. For instance, following the introduction of nitrogen mustards in the palliative reatment of cancer, Karnofsky et al. (1948) published an article on the effects of this treatment on patients with lung cancer, measured in terms of 'subjective improvement' and 'performance status'. They developed an instrument for this purpose, the 'Kamofsky-index', which has often been referred to in later clinical trials. In 1963 , independently of the three QoL research traditions, Katzet al. (1963) developed an index of independence in Activities of Daily Living (the ADL-index). It was presented as a measure of biological and psychosocial functioning for estimating the results of health care interventions in the elderly. In 1966, probably inspired by President Johnson's speech, the term 'Quality of Life" appeared for the first time in the medicalliterature in an edito- 
rial of the 'Annals of Internal Medicine' (Elkinton, 1966, p.711). In the following two decades, the 'social indicators' tradition (e.g. Andrews and Withey, 1976; Campbell, 1976) played an increasingly influential role in QoL investigations in clinical research. The influences of the 'social indicators' research were both conceptual and methodological in nature. In the first place, the importance of the QoL concept became widely recognized (Najman and Levine, 1981; de Haes and van Knippenberg, 1985). And, despite the intangible nature of the concept, the idea that QoL can be operationalized and measured gained acceptance. QoL was acknowledged as essentially subjective and therefore only measurable by asking a judgement of the patients themselves. Popularity of the term increased, as evidenced by the introduction of 'quality of life' as a keyword in the Index Medicus in 1977. Since the mid-1980s the emphasis has shifted from a 'social indicators' approach to a 'health status' approach to QoL. By 1986, use of the terms QoL and health status had become interchangeable (Spitzer, 1987). The years thereafter have been characrerized by the introduction of health status measures in clinical trials: first in somatic illnesses and more recently in psychiatric disorders. The main influences of the 'health status' tradition on QoL investigations in clinical research have been the emphasis on the importance of psychometric properties of instruments and the introduction of more functional-oriented measures. The 1990 s have been marked by the development of disease-specific QoL instruments in clinical research. These instruments are often based on ideas derived from the 'social indicators' and 'health status' research traditions. With a few exceptions (e.g. de Haes et al., 1992), the 'happiness' research tradition appears to have had no influence in clinical research.

Parient's QoL, defined as a sense of well-being and ability to function in important life domains, is now commonly accepted as a (secondary) ourcome measure in clinical trials.

\section{QoL measures in depression trials}

As recently summarized by Katschnig and Angermeyer (Karschnig and Angermeyer, 1997), using QoL measures in depression poses a specific conceptual problem. Intuitively, the concepts of QoL and depression are two different sides of a same coin. Indeed, suffering from psychic and somatic complaints seerns to exclude someone from experiencing a high level of QoL (de Jong and Verhage, 1987). High negative correlarions between measures of depression and anxiety with well-being found in some studies (Kammann and Fletr, 1983; Abbey and Andrews, 1985) have led some researchers to go so far as to call depression and anxicty scales 'measures of ill-being' as opposed to well-being (Kammann and Flett, 1983). However, the relationship between the rwo concepts becomes more complex when time is taken into account. A depressed person may at times experience moments of high levels of QoL even though feeling depressed overall. Similarly, a non-depressed person may experience depressive states even though reporting high levels of QoL. Invesrigarions into the relarionships between QoL and depression 
so far suggest that the two concepts may be related but are distinct, like measures of quantitarive and verbal ability in intelligence tests (Headey et al., 1984).

In spite of these conceptual difficulties, a number of scales have been developed and used for the purpose of measuring QoL in depression trials. These instruments can be separated into two categories: generic and disease-specific. Generic QoL instruments are measures designed to cover a wide variety of domains that are relevant to QoL. They allow for comparisons to be made across condicions, but may not address sufficiently the areas relevant to depression. Some examples of generic scales used in depression trials are the Short-Form Survey (SF-36 or SF-20, Ware et al., 1994) and the Sickness Impact Profile (SIP, Bergner et al., 1981). The SF-36 was originally developed as a survey of general health status. All bur one of the 36 items (self-reported health transition) are used to score eight modules (physical functioning, role-physical, bodily pain, general health, vitality, social functioning, role-emotional and mental health). These eight modules are hypothesized to form two distinct higher-ordered clusters (physical and mentall health). It has been included in various clinical trials of antidepressants (Heiligenstein etal., 1995; Philipp et al., 1999). The SIP has also been used in part or as a whole in antidepressant clinical trials (Sechter et al., 1999). This instrument consists of 12 modules of daily life activities, which can be clustered in a psychological module (emotional behavior, social interaction, alertness behavior and communication) and in a physical module (body care/movement, mobility and ambulation). The five remaining modules (sleep/rest, eating, home management, work and recreation/pastimes) are independent. Other type of generic instruments used in depression trials include objective indices of work performance, e.g. 'number of days lost from work' or 'absentecism' (Beuzen et al., 1993), and VAS mood ratings for subjective feelings (Wheatley et al., 1998). Disease-specific scales are instruments that include all essential aspects of depression and, as such, are expected to detect any small, bur clinically meaningful change in depressed parient's QoL. Although several depression-specific scales have been developed and published (e.g. SBQOL, Dunbar et al., 1992), only two have been commonly used in published trials. The first is the Quality of Life in Depression Scale (QLDS, Hunt and McKenna, 1992). The instrument is based on the theory that life gains its quality from the ability of the individual to satisfy his or her needs, with items derived from qualitative interviews with depressed or recently recovered patients. The QLDS has been used in several studies investigaring the effects of fluoxetine on QoL (e.g. Mesters et al., 1993; Dam et al., 1998). The second is the Quality of Life and Enjoyment Questionnaire (Q-LES-Q, Endicott et al., 1993), designed to obtain sensitive measures of the degree of enjoyment and satisfaction experienced by subjects in various areas of daily functioning. It has mainly been used to assess the effects of the newer generation of antidepressants on QoL (Lydiard et al., 1997; Wheatley et al., 1998; Leinonen et al., 1999). 
In summary, major depression is a common and chronic disease with a huge personal, familial, and societal burden. Since the 1950 s, the advent of pharmacological drugs has provided new opportunities for depressed patients and over the years much effort has been made to increase the awareness of depression and its treatment. In spite of these advancements, the World Bank estimates depression to rank second in global burden of disease in 2020. Our understanding of the impact of depression and its treatment on patients' lives is far from complete. Many questions relating to how the illness is experienced in daily life or how antidepressants impinge on daily life aspects remain umaddressed or unanswered. Born out of different research traditions, the use of QoL as an ourcome measure in clinical research has been steadily increasing in the past decades. In spite of conceptual difficulties with the use of QoL in depression, both generic and disease-specific scales have been applied in depression trials.

In light of the extent and burden of depression, we argue that current research approaches should be supplemented by ecological valid methods that go beyond the nosological and clinical perspectives to address the impact of depression and antidepressant treatment in the context of daily life as it is experienced. In the following chapter, an ecologically valid method will be presented. QoL approaches derived from the three research traditions and operationalized within more dynamic models of daily life experience will be described. Lastly, the potential issues arising as a result of integrating such a method in a clinical trial in order to assess the impact of antidepressants on daily life experiences will be addressed. 


\section{REFERENCES}

Abbey, A., Andrews, F. M., 1985. Modeling the psychological determinants oflife qualicy. Social Indica rors Researdn $16,1-34$.

Andrews, F. M., Withey, S. B., 1976. Chapter 1. Introducrion. In: Andrews, F. M., Withey, S. B. (Eds.), Social Indicarors of Well-Being Plenum Press, New-York, pp. 1-24.

Angsw, J. 1988. Clinical course of affective disorders. In: Helgson, T., Daly, R. J. (Eds.), Depressive Illness: I’rediction of Course and Outcome. Springer, Berlin, pp. 1-44.

Anonymous, 1990. View from the botrom. Psychiatric Bullerin 14, $452-454$.

American Psychiatric Association, 1987. Diagnostic and Statistical Manual of Mental Disorders, Third Edition, revised. American Psychiatric Association, Washington, DC.

American Psychiatric Association, 1994. Diagnostic and Statistical Manual of Mental Disorders. Fourrh Edition. American Psychiatric Assaciation, Washington, DC.

Bergner, M., Bobbitr, R. A., Carter, W. B., Gilson, B.S., 1981. The Sickness Impact Proflle: development and final revision of a health status measure. Med Care 19(8), 787-805.

Beuzen, J. N., Ravily, V. E., Soucere, E. J., Thomander, L., 1993. Impact of fluoxetine an work loss in depression. Internarional Cinical Psychopharmacology 8, 319-321.

Blazer, D., Williams C. D., 1980. Epidemiology of dysphoria and depression in an elderly population. Am J Psychiarry $137(4), 439-444$.

Bradburn, N. M., 1969. The Strueture of Psychological Well-Being. Aldine Publishing Company, Chicago.

Bradburn, N. M. Caplovita, D., 1965. Reports on Happiness. Aldine, Chicago.

Brown, R. G., Scon, L. C., Bench, C. J., Dolan, R. J., 1994. Cognitive function in depression: irs relarionship to the presence and severity of intellectual decline. Psychological Medicine 24, 829-847.

Campbell A. 1976. Subjective measures of well-being. American Psychologist (February), 117-124.

Canril, H., 1965. The Pattern of Human Concerns. Rutgers Universiry Press, New Brunswick, New Jersey.

Cassem, E. H. 1995. Depressive disorders in the medically ill: an overview. Psychosomatics 36, S2-S10.

Conti, D. J., Burton. W. N., 1994. The economic impact of depression in a workplace. J. Occup. Med. $36(9), 983-988$

Costa, P." T... McCrac, R. R., 1980. Influence of extraversion and neurocicism on subjective well-being: happy and whappy people. I Pers Soc Psychol 38(4),668-678.

Coyne, J., Kesster, R., Tal, M., Turnbull, J., Wortman, C., Greden, J., 1987. 1.iving with a depressed person.] Consult Clin Psychol 55(347), 347-352.

Coyne, J. C. Calarco, M. M., 1995. Effects of the experience of deptession: application of fochs group and surwey methodologies. Psychiarty $58,149-163$.

Dam, J. Ryde, L.. Svejso, N. Lauge, B., Lauritsen, B., Bech, P., 1998. Moming fluoxetine plus evening mianserin versus morming fluoxerine plus evening placebo in the acure treatment of major depression. Phatruacopsychiar $31,48-54$.

de Haes, J. C. J. M., de Ruiter, J. H. "Tempelat, R., Pennink, B. J. W., 1992. The distinction berween affec and cognirion in the qualiry of life of cancer parients - sensirvity and stability. Qualing of Life Research 1, 315-322.

de Hacs, J.C. J. M., van Knippenberg, F. C. E., 1985. The quality of life of cancer parients: a review of the literature. Soc. Sei. Med. 20(8), 809-817.

de Jong, R. D. Verhage, J. 1987. Quality of life and depression in entrepreneurs and managers. J Hum Bellar Learn 4(2), 46-53.

de Jonghe, F., Kool, S., wan Aalst, G. Dekker, J., Peen, J., 2001. Combining psychorherapy and antidepressants in the trearment of depression. J Affect Disord 64(2-3), 217-229. 
de Neding, I. N. D. 1991. Quality of Life: Het Onderzok naar Welzinsefferen van Medische Handelingen, Wetenschappelijke Uirgeverij Bunge, Utrecht.

Delgado, P. L., 2000. Approaches to the enhancement of patient adherence to antidepressant medication treatment. ] Clin Psychiarry 61 (Suppl 2), 6-9.

Dew, M. A., Bromer, E. J., 1991. Effects of depression on supporr in a communiry sample of women. In: Eckenrode, J. (Ed.), The Social Context of Coping. Plenum Press, New York, pp. 189-211.

Diener, E, 1984. Subjective well-being. Psychological Bullerin 95(3), 542-575.

Dienter, E., Sandvik, E., Pavor, W., 1991. Chapter 7. Happiness is the frequeno, not the intensiry, of posirive versus negative affect. In: Strack, F., Arghle, M. Schwar, N. (Eds), Subjecrive Well-being; an Interdisciplinary Perspective. Pergamon Press, New.York, pp. $119-139$

Durbar, G. C., Stoker, M. J., Hoddges, T. C. P., Beamont, G., 1992. The development of SBQOL: a unique scale for measuring quality of life. British Journal of Medical Fconomics $2,65-74$.

Ehlers, C. L., Frank, E. Kupfer, D. J. 1988. Social zeirgebers and biological rhythms. Archives of Gencral Psychiarry 45, 948-952.

Elkinwon, J. R., 1966. Medicine and the quality of life. Annals of Internal Medicine 64, $7111-714$

Endicort, J., Nee, J., Harrison, W., Blumenthal, R., 1993. Quality of Life Enipyment and Satisfaction Questionnaire: a new measure. Psychopharmacology Bulletin 29(2), 321-326.

Fadden, G., Bebbington, P., Kuipers, L., 1987. Caring and its burdens: a study of the spouses of depressed patients. British Journal of Psychiatry 151, 660 667.

Fawcett, I, 1994. Antidepressans: partial response in chronic depression. British Journal of Psychiatry 165(Suppl. 26), 37-41.

Feist, G. J., Bodner, T. E., Jacobs, J. F., Miles, M., Tan, V., 1995. Integrating rop-down and botrom-up structural models of subjective well-being: a longirudinal investigation. Journal of Personality and Social Psychology 68(1), 138-150.

George, L. K, Blazer, D. G., Hughes, D. C., Fowler, N., 1989. Social support and the outcome of major depression. British Joumal of Psychiatry $154,478-485$.

Goodwin, F., 1996. A 47-year-old man with chronic depression. JAMA 275(6), 479-485.

Greenberg, P. E., Stiglin, L. E., finkelstein, S.N., Berndt, E. R., 1993. Depressiona a neglected major illness. J Clin Psychiarry 54(11), 419-424.

Gronmo, S., 1982. Use of time and quality of life: dimensions of welfare related to specific acrivities. In: Staikov, Z. (Ed.). It's abour time. The Institute of Sociology at the Bulgarian Academy of Science \& The Bulgarian Sociological Association. Sofia, pp. 97-117.

Gurin, G., Veroff, S., Feld, S., 1960. Americans view their mental health. Basic Books, New York.

Headey, B., Holmstrom, E., Wearing, A., 1984. Well-being and ill-being: different dimensions? Social Indicators Research 14, 115-139.

Headey, $B$, Veenhoven, R., Wearing, A, 1991. Top-down wersus botrom-up theorics of abbective well-being. Social Indicarors Research 24(1),81-100.

Healy, D., 1998. Reboxetine, Iuoxetine and social functioning as an outcome measure in antidepressant trials: implicarions. Primary Care Psychatry 4(2), 81-85.

Healy, D., 1999. The three faces of the antidepressants: a critical commentary on the clinicateconomic context of diagnosis. I Nerv Ment Dis $187(3), 174-180$.

Heiligenstein, J. H., Ware. J. E., Beusterien, K. M. Roback, P. I., Andrejasich, C., Wollefson, G. D. 1995. Acute effects of fuoxerine versus placebo on functional health and well-being in late-life depression. In Psychogeriatrics 7(suppl.), 125-137.

Henderson, A. S., Jorm, A. F., Mackinnon, A., Chrisicnsen, H., Scot, L. R, Kotten, A. E, Doyle, C., 1993. The prevalence of depressive disorders and the distribution of depressive symptoms in later life a survey using Draft TCD-10 and DSM-III-R. Psychological Medicine 23, 719.729.

Henderson, A. S. Moran, P. A. P., 1983. Social relationships during the onset and remission of neurotic symptoms: a prospective community study. Brit. ]. Psychiat. 143,467-472. 
Hooley, J. M., Orley, J., Teasdales J. D., 1986. Levels of expressed emotion and relapse in depressed parients. British Joumal of Psychiatry 148,642-647.

Hunt, S. M., McEwen, I., 1980. The development of a subjective health indicator. Sociology of Health and Illness 2, 231-246.

Hunt, S. M. MCKenna, S.P.,1992. The QLDS: A scale for the measurement of qualing oflife in depression. Healte Policy 22, 307-319.

Isacsson, G., Bergman, U., Rich, C. L., 1996 . Epidemiological data suggest antidepessants reduce suicide ristk among depressives. Journall of Affective Disorders 41, 1-8.

Johnson, D. A. W., 1973. Treament of depression in general practice. Brirish Medical Journal 2, 18-20.

Johnson, J., Weisman, M. M., Klerman, G. L., 1992. Service utilization and social morbidiry associared with depressive symptoms in the communiry. JAMA 267(11), 1478-1483.

Jones, H. M., 1953. The Pursuit of Happiness. Harward Universiry Pwess, Cambridge, MA.

Juster, F. T., Courant, P. N., Dow, G. K, 1981. A theoretical framework for the measurement of well-being. The Review of Income and Wealth 27(1), 1-31.

Kammann, $\mathbb{R}$, Flett, R, 1983. Affectometer 2: a scale to measure current llevel of general happiness. Australian Journal of Psychology 35(2), 259-265.

Karnofsky, D. A., Abelman, W. H., Craver, In. F., Burchenal, J. H., 1948. The use of nitrogen mustards in the palliative treatment of carcinoma. Cancer 1, 634-656.

Kasper, S., Fuger, J., Moller, H. J., 1992. Comparative efficacy of antidepressants. Drugs 43(Suppl. 2), 11-23.

Katon, W., Korff, w. M., Lin, E., Bush, T., Ormel, J., 1992. Adequacy and duration of antidepressant treatment in primary care. Med Care $30(1), 67-76$.

Katschnig, H., Angermeyer, M. C., 1997. Quality of life in depression. In: Katschnig, H., Freeman, H., Sartorius, N. (Eds), Quality of Life in Mental Disorders. John Wiley \& Sons Lrd, Chichester, pp. $137-147$.

Katz. S, Ford, A. B., Moskowitz, R. W., Jackson, B. A., Jaffe, M. W., 1963. Studies of illnes in the aged. The index of ADL: a standardized measure of biological and psychosocial function. JAMA Sept 21. $914-919$.

Keller, M. B., 1994. Depression: along-term illness. British Journal of Psychiatry 165(Suppl. 26), 9-15.

Keller, M. B., Kerman, G. L., Lavori, P. W., Fawcett, I. A., Coryell, W., Endicott, J., 1982. Treatment received by depressed patients. JAMA 248(15), 1848-1855.

King, W. I. 1930. The National Income and its purchasing power. NBER. New York.

Klerman, G. L. 1 1989. Depressive disorders: furcher evidence for increased medical morbidiry and impairment of social functioning. Arch. Gen. Psychiatry $46,856-860$.

Kotma, A., Stone, S., Srones. M. J., Hannah, T. E., 1990. Long- and short-term affective states in happiness: Model, paradigm and experimental evidence. Social Indicators Research 22(2), 119.138.

Kurlowicz, L. H. 1993. Social factors and depression in Jate life. Archives of Psychiatric Nursing 7(1), $30-36$.

Kuznets, S. 1941. National income and its composition, 1919-1938. NBR, New York.

Lance, C. T., Latuenschlager, G. J., Sloan, C. E., Varea, P. E., 1989. A comparison between botrom-up, top-down, and bidirectional models of relationships berween global and life facet satisfaction. Joumal of Personality $57(3), 601-624$

Leinonen, E., Skarstein, J., Behnke, K., Agren, H., Helsdingen, J. T., 1999. Efficacy and rolerability of mirtazapine versus cicalopram: a doubje-blind, randomized study in parients with major depressive disonder. Nordic Antidepressane Study Group. Inr Clin Psychopharmacol 14(6), 329-337.

Levine, $\mathrm{S}$, 1987 . The changing terains in medical sociology: emergent concern with quality oflife. Journal of Healch and Social Behavior 28(March), 1-6.

Lewinsohn, P. M. Amenson, C. S., 1978. Some relarions between pleasant and unpleasant mood-related evenrs and depression. Joumal of Abnormal Psychology 87(6), 644-654. 
Lewinsohn, P. M., Liber, J., 1972. Pleasant events, activity schedules, and depressions. Journal of Albnormal Psychology 79(3). 291-295.

Lydiand, R. B., Stahl, S. M., Hertzman, M., Harrison, W. M., 1997. A double-blind, plactbo-controlled study comparing the effects of sertraline versus anitriptyline in the treatment of major depresion. $J$ Clin Psychiatry 58(11), 484-491.

Malone, K. M. Haas, G. L., Sweeney, J. A., Mann. J. J., 1995. Major depression and the risk of atrempted suicide. Journal of Affective Disorders 34, 173-185.

Mesrers, P., Cosyns, P., Dejaiffe, G., Fanielle, J., Gilles, C., Godderis, I. Grezgoire, J., De Leval, N., Meire, P., Mesorten, F., Reynaert, C., Rosillon, D., Seghers, S., Stellamans, G., Van Moltaert, M., 1993. Assessment of quality of life in the treatment of major depressive disorder with fluoxerine, $20 \mathrm{mg}$, in ambularory parients aged over 60 years. International Clinical Psychopharmacology $8,337-340$.

Milbrath, L. W., 1982. A conceptualization and research strategy for the study of ecological aspects of the quality of life. Social Indicators Research 10, 133-157.

Najman. J. M., Levine, S., 1981. Evaluating the impact of medical care and technologies on the quality of life: a review and cricique. Soc. Sci. \& Med. 15F, 107-1.15.

O'Donnell, I., Farmer, R., Catalan, J., 1996. Explaining suicide: the views of survivors of serious suicide attempts. British Joumal of Psychiatry 168, 780-786.

Ordway, S. H., 1953. Resources and the american dream. The Ronald Press Company, New York.

Ormel, J., Koerer, M. W. J., wan den Brink, W., van de Willige, G., 1991. Recognition, management, and course of anxiety and depression in general pracrice. Arch Gen Psychiary 48, 700-706.

Paykel, E. S., Hart, D., Priest, R. G., 1998. Changes in public attitudes to depression during the Defeat Depression Campaign. Br J Psychiarry 173, 519-522.

Philipp, M., Kohnen, R., Hiller, K. O., 1999. Hypericum extract versus innipramine or placebo in patients with moderate depression: randomised multicentre study of rrearment for eight weeks BM. $319(7224), 1534-1538$.

Read, J. L., Quinn, R. J., Hoefer, M. A., 1987. Measuring overall health: an evaluation of three important approaches. J. Chron. Dis. 40(Suppl, 1), 7S-21S.

Regier, D. A., Hirschfeld, R. M. A., Goodwin, F. K., Burke, J. D.s Lazar, J. B., Judd, L. L., 1988. The NIMH depression awareness, recognition, and treatment program: structure, aims, and scientific basis. Am J Psychiarry $145(11), 1351-1357$.

Rescher. N., 1972. Welfare. The social issues in philosophical perspective. Uniwersity of Pitrshurgh Press, Pirtsburgh.

Riskind, J. H., Castellon, C. S. Beck. A. T., 1989. Spontaneous causal explanations in unipolar depression and generalized anxiety: content analysis of dystunctional-thought diaries. Cognitive Therapy and Research 13(2), 97-108.

Robinson, 1., 1977. How Americans use time: a social-psychological analysis of everyday behaviout. Praeger, New York.

Robinson, J. P., 1987. Microbehavioral approaches to monitoring human experience. 』Nerv Ment Dis $175.514-518$

Rodgers, W. L., Converse, P. E., 1975. Measures of the perceived overall quality of life. Sociall Indicators Research 2, 127-152.

Roose, S. P., 1990. Tolerabiliry and patient compliance. I Clin Psychiatry 60(Suppl 17). 14-17; discussion $46-48$.

Schipper, H., 1990. Guidelines and caveats for quality of ife measurement in clinical practice and research. Oncology Williston Park 4(51), 51-57.

Sechrer, D., Troy, S. Parement, S., Boyer, P., 1999. Adouble-blind comparison of sertraline and fluoxetine in the reatment of major depressive episode in outparients. Eur Psychiatry 14(1), 41-48.

Song. F. Freemande, N., Sheldon, T. A., House, A., Watson, P., Long, A., Mason, J., 1993. Sellective serow tonin reuptake irhthibitors: meta-analysis of efficacy and acceptability. BM] 306(683), 683-687. 
Spitzer, R. L., Williams, J. B. W., Kroenke, K., Linzer, M., Verloin deGruy, F., Hahn, S. R., Brody, D., Johnson, ]. G., 1994. Utilliry of a new procedure for diagnasing mental disorders in primary care. JAMA $272(22), 1749-1756$

Spirzer, W. O, 1987. State of science 1986: qualicy of life and functional status as rarget variables for rescarch. I Chronic Dis $40(6), 465-471$.

Stoudemire, A, Frank, R., Hedemark, N., Kamlet, M., Blazer, D., 1986. The econonic burden of depression. General Hospial Psychiatry 8(6),387-394.

Szuba, M. P., Yager A., Guze, B. H. Allen, E. M. Baxrer, L. R., 1992. Disruption of social circadian rhytums in major depression: a preliminary report. Psychiary Research 42, 221-230.

Thomson, J., Rankin, H. Ashcroft, W., Yates, C. M., McQueen, J. K., Cummings, S. W., 1982. The treatment of depression in general practicen a comparison of L-tryprophan, amitriptyline, and a combinawion of L-tryprophan and amitriptyline with placebo. Psychological Medicine 12, 741-751.

Tweed, D. L., 1993. Depression-related impaimencestimating concurrent and lingering effecrs. Psychological Medicine $23(2), 373-386$.

wan Lieburg. M. J., 1988. Famous Depressives: Ten Historical Skerches. Organon Internarional bw., Oss, The Nethertands.

Ware, I. E., Brook, R. H., Dawies, A. R., Lohr, K. N., 1981. Choosing measures of health status for individuals in general populations. Am. J. Public Health 71, 620-625.

Ware, J. E., Gardek, B., group, I. p., 1994. The SF-36 health survey: development and use in mental health research and the $100 L A$ project. Int. I. Ment. Health 23(2), $49-73$.

Whearley, D. P., Van Moffaerr, M., Timmerman, L., Kremer, C. M. E., Group, M.-F. S., 1998. Mirtazapine: efficacy and tolerability in comparison with fluoxetine in patients with moderate to severe major depressive disorder. J Clin Psychiary 59(6), 306-312.

Wilson, W., 1967. Correlates of avowed happiness. Psychological Bullerin 67(4), 294-306.

Wituchen, H. U., Knauper, B., Kessler, R. C., 1994. Lifetime risk of depression. British Journal of Psychiatry 165(Suppl. 26), 16-22.

World Bank. 1993. World Development Report-Investing in Health. Oxford University Press, Oxford.

World Health Organizarion, 1992. The ICD-10 Classificarion of Mental and Behavioural Disorders: Clinical Descriptions and Diagnostic Guidelines. World Health Organization, Geneva. 


\author{
PART I \\ INTRODUCTION
}

CHAPTER 2

Use of the Experience Sampling Method (ESM) to assess daily QoL in clinical research

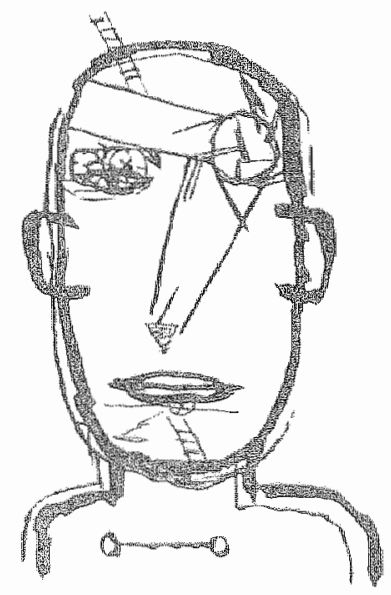




\title{
Use of the Experience Sampling Method (ESM) to assess daily QoL in clinical research ${ }^{1}$
}

\author{
EXPERIENCE SAMPLING METHOD (ESM)
}

ESM is a time-sampling merhodology designed to study subjective experience in the natural context of daily life. It provides a description of mental states across situations, time, and places. An electronic device is used to cue subjects to report their activities, thoughts and moods at semi-random time points throughout the day. The ESM self-report, the electronic device, and the sampling frequency used may vary depending on the objective of the study (Csikszentmihalyi and Larson, 1987; Delespaul, 1995).

\section{Development and applications of ESM}

In the past 20 years, ESM has been applied by different research groups in a large number of studies addressing a variety of clinical questions (for an overview, see deVries, 1992a). Originally starring in developmental psychology as a method to obtain data on daily activities and experiences of adolescents (Csikszentmihalyi et al., 1977), sampling techniques such as ESM have subsequently been used to investigate, for example, the stream of conscious thought in daily life (e.g., Klinger et al., 1980), the effect of urbanization on daily life (e.g., Hormuth, 1986), thought content (e.g., Hurlburt and Melacon, 1987), optimal experience (e.g., Massimini and Carli, 1988), stress (Nicolson, 1992; van Eck, 1996), and the experience of psychopathology in natural settings (deVries, 1987; deVries, 1992a; deVries, 1997). In Maastricht, a broad range of psychiatric and psychosomatic disorders have been studied to dare, including pain (Portegijs, 1996), heroin addiction (Kaplan, 1992), anxiety (deVries et al., 1987; Dijkman-Caes, 1993), depression (Kraan et al., 1992; Wilson et al., 1992; Barge-Schaapveld et al., 1999), and schizophrenia (Delespaul and deVries, 1987; Delespaul, 1995: Myin-Germeys et al., 2000). These studies provide evidence for the utility of ESM in describing clinically significant within-day variations in experience and symptoms, in identifying contributions of context and setting to illness or well-being, in refining current diagnostic categories, and in delineating time use patterns of psychiatric and non-psychiatric groups.

1 This chapter is based in part on an earlicr publication by Barge-Schaapreld D. Q. C. M., Nicolson N. A., Delespaul P. A. E. G. deV ries. M. W., 1997. Assessing daily quality of life with the Experience Sampling Merhod. In: Katschnig H., Freeman H., Sarrorius N. (Eds.), Quality of Life in Mencal Disorders, John Wiley \&e Sons ltd, Chichester, pp.95-107. 


\section{ESM in practice}

A typical ESM period consists of three parts: a briefing interview (lasting 1 hour) the day before sampling begins, a sampling period of 6 days, and a final interview, or 'debriefing (lasting $1 / 2$ hour).

During the briefing session, which is usually carried out by a research nurse trained in ESM, the subject is instructed about the sampling procedures and the use of the signalling device, a digital wristwatch. The subject practices complering an ESM form. Anticipated difficulties in the use of ESM in daily life (e.g., taking a shower, driving a car) and possible solutions are discussed. Subjects are allowed to turn off the signalling device in situations when the signal would be unduly disruptive (e.g., a daytime nap), but are asked in these cases to document the time period elapsed and the reason for turning off the watch. Finally, the subject is instructed to contact the research nurse at a telephone number listed in the booklet, in case of any questions or problems with either the self-report form or the watch.

During the sampling days the subject completes self-reports (see for examples, Appendices $1 \& 2$ ), collated per day in a booklet, at semi-random time points throughout the day, typically from 7:30 in the morning to 10:30 in the evening. Additional information is recorded each day immediately after waking (sleep quality, duration of sleep, delay in falling asleep, and number of awakenings) and again before going to sleep (timing of meals, timing of switching off the watch, effects of participation in the study).

At the debriefing session, the wristwatch and the booklets are returned. The research nurse reviews the booklets and discusses all responses that are missing, illegible, unclear, or inconsistent. This is done in order to limit potential coding problems of open-ended questions (e.g, where are you?). Subsequently, the subject is asked in a structured interview about the possible impact the study might have had on mood, thoughts, and activities in daily life.

ECOLOGICALLY VALID METHODS TO INVESTIGATE QOL.

\section{Rationale}

Across the three research traditions that have played an important role in the operationalization of the QoL concept (see Chapter 1), a number of issues appear to be unresolved or unaddressed. The first controversy concerns the stability of QoL over time - more specifically, whether QoL reflects a top-down or a botrom-up process (Lance et al., 1989; Headey et al., 1991; Feist et al., 1995). If we are interested in changes in QoL resulting from either the natural course or the trearment of an illness, 
we would like to understand, for example, how the illness impinges on daily experiences of positive emotions, rewarding situations and the satisfying use of productive and leisure time - inherently a bortom-up approach. However, while such daily experiences are made up of states that vary from moment to moment, it is clear that a QoL index should be a summary measure of experiences over some representative period of time.

A second issue concerns the reliability of the available QoL measures. In 'health status' studies, individuals are asked to evaluate how the illness and its therapy affect their lives. However, traditional retrospective assessments of objective as well as subjective QoL dimensions are prone to a number of potential biases. Prospective monitoring of behaviors in time budget research allows more accurate measures of frequencies and duration of activities than is possible with retrospective questionnaires (Juster and Stafford, 1985). For subjective QoL data (emotions), retrospective bias has been wel] documented, and effects of social desirability (Milbrath, 1982; Diener et al., 1991; Veenhoven, 1991) and recall errors (Lehman and Burns, 1990) have been reported.

The third issue is ecological validity (Bronfenbrenner, 1979). Beyond the reliability issues involved, the emotional states elicited during traditional assessment situations such as clinical interviews are not necessarily the same as those occurring in natural environments. Lack of ecological validity may occur as a consequence of office-based reports bias (e.g., white coat hypertension), subject manipulation (e.g, pain reports biased by desire to influence the treating physician) or failure to sample patients' typical roles, activities, and settings (e.g., symptom report influenced by whether patient is at work or at leisure) (Stone et al., 1999).

\section{Models of daily QoL}

The problems described in the previous section have stimulated a search for new models and methods for assessing daily QoL. For example, paramerers of daily life experience such as the diversity of different activities or the variability of behaviors carried out from moment to moment have been related to QoL(Delespaul, 1995). According to this formulation, QoL, will be higher when individuals have contact with a variety of different persons and carry out a wider variety of acrivities. QoL is also expected to be higher when social contacts are distributed over time, instead of being concentrated all in one day, with social isolation the rest of the week. Similarly, QoL. will be low when the same activiries have to be performed for extended periods of time withour a break. But QoL is not an objective state. While it might be true that most people prefer variability to continuously performing the same task, the concept of QoL points to the crucial role of subjective experience. Daily QoL is not then restricted to what subjects actually do in reference to some absolute norm, but incorporates the concurrent assessment of the individual's mood state. For example, 'being alone' most of the time is only a problem if a person experiences his worst mental states in that context. Nor, obviously, does being 
in social contexts improve $Q \mathrm{~L} L$ if these are experienced as negative. Knowledge of individual preferences and experiences is thus vital for understanding QoL.

'Objective happiness' was introduced by Kahneman (1999) as a bottom-up approach to the analysis of well-being, derived from a record of the quality of experience at each 'point-instant utility'. Instant urility is an attribute of experience (being pleased or distressed) at a particular moment and is defined as the strength of the disposition to continue or to interrupt the current experience. Objective happiness is therefore the average of utility over a period of time and contrasts with "subjective happiness", which is assessed by asking respondents to state how happy they have been throughout that same period of rime.

The "Flow' model conceptualizes oprimal experience as a state in which positive mood, motivation, alermess, concentration, and control are high while negative mood is low. According to the theory, this state is most likely to be attained in the context of activities that are challenging and in which the individual is skilled (Massimini and Carli, 1988; Csikszentmihalyi, 1990). The subjects of studies contriburing to the development of 'Flow' theory were primarily artists, mountain climbers, and high achievers in school. One might question whether mentally ill patients pursue optimal experience by maximizing 'Flow'. Escaping stagnation, boredom, and negative feelings may represent an equally great improvement in daily QoL in many psychiatric patients (Massimini et al., 1992).

Bringing daily life in line with personal tasks as suggested by Cantor et al. (Cantor et al., 1991) may also be regarded as a daily QoL model. Indeed, individuals who find ways to work on their most important or most rewarding rasks in their day-to-day life may experience increased emorional involvement, positive affect, and satisfaction in daily life.

Finally, according to a daily QoL model formulated by Brandstätter (1994), an important determinant of well-being may be the adequacy of the fit between person and environment. Here, states of well-being are hyporhesized to be dependent on the correspondence between an individual's goals, or motives, and the gratification provided by the environment in terms of specific behavior setrings.

In summary, we propose that the QoL approaches derived from 'happiness', 'social indicators' and 'health status' traditions may be operationalized within more dynamic models of daily life experience. New data and models that include the frequency of and variability in doing activities one likes, a dense record of the quality of experience at each point-instant utility, the experience of well-being that comes about when challenges and skills are in optimal balance, the time spent on tasks that are relevant and rewarding for the individual, and the goodness of fit between an individual and his environment form a starting point for operationalizing and further exploring QoL in real life setrings. 
The objective of this research is to investigate the contribution of dynamic models of daily life experience to the field of clinical research in depression.

\section{APPLICATION OF ESM IN CLINICAL RESEARCH}

In clinical research, the randomized controlled trial (RCT) has evolved as a major research methodology for the rigorous evaluarion of new medical interventions and therapies. RCT requires an appropriately selected control treatment, randomization to the treatments, and 'blinded' assessments of response (Schatzbergand Kraemer, 2000). The typical depression trial is designed simply to determine whether a drug, in comparison with a placebo control and/or a standard antidepressant, can significantly reduce the severity of, or completely resolve a depressive disorder (Katz, 1998).

\section{Rationale}

In recent years, the increasing occurrence of 'failed' clinical studies (either negative or inconclusive) in psychiatric disorders in general, and in depression in particular, has triggered major discussions at international level among industry, academia, and regulatory agencies about the adequate use of placebo, the true drug effect of antidepressants, the choice of outcome measures, and the design of RCTs in depression'.

In spite of numerous clinical studies that are performed throughout the different phases of a drug's development process as required for the approval of a New Drug Applicarion (NDA), it is striking how little clinicians know about a new antidepressant at the time it is first approved for general use (Thase, 1999). Effects of drugs are estimated as the difference berween the drug response and the placebo response. But because the nature of the placebo response is not fully understood and may vary according to the characteristics of the depressed group selected, concerns have been raised about the "true" antidepressant drug effect (Kirsch and Sapirstein, 1998; Antonuccio et al., 1999). Substantial placebo response is quite common in major depression, with average placebo response rates across studies in the order of 30 to $40 \%$ (Trivedi and Rush, 1994) and some individual studies reporting rates as high as $70 \%$ (Brown et al., 1988). On average, drug-placebo differences in global response in RCTs are believed to be in the order of onlly 18 to $20 \%$, with one third of all published RCTs of proven anti-

I for example: ECNP Consensus Meering on 'Alternacives to placebo-controlled trials in psychiatry', Seprember 26.1996. Ansterdam; ACNP sarellite symposium on "Multi-site clinical trials: can they be improved?", 1997. Hawaii; ECNP Consensus Meering on "The failure of placebo-controlled studies", September 13, 1997, Vienna; conference organized by the Narional Depressive and Manic-Depressive Association on 'Clinical trials in mood disorders: the use of placebo ...past, present, and furure", September
14-15, 1999, Washington, DC. 
depressants failing to show drug-placebo differences (Thase, 1999). In over 30 years of double-blind placebo-controlled antidepressant trials, the most widely used primary outcome measure has been the Hamilton Rating Scale for Depression (HDRS, Hamilton, 1960), even though it was never developed with that intent and despite questions raised as to whether the HDRS can accurately measure change in the severity of meaningful depressive symptoms (Gibbons et al., 1993). The main focus of pharnaceutical industries throughout the clinical development process of an NDA in depression, in all these years, was and still is on differentiating the antidepressant compound from placebo by at least 4 points on the HDRS (which is regarded to be a clinical significant difference) at the end of treatment, on the basis of an intent-to-treat analysis (an analysis that includes all drop-outs on treatment). Little or no attention has been given ro obtain a deeper understanding of the treatment effects found (e.g., do treatment effects vary during the day, or according to activities?) so as to inform clinicians more adequately on the potential use of the new antidepressant. Approaches such as ESM that generate experiential information may contribute substantially to a better understanding of these trearment effects.

The model for the typical depression trial was designed in the 1960s. The first FDA guidelines for such trials were proposed in the 1970s and revised in the late 1980s and early 1990s (Thase, 1999). This model is still recommended by the Food and Drug Administration (FDA) in the US as well as the European Agency for the Evaluation of Medicinal Products (EMEA) as the 'gold standard'approach to the evaluarion of treatments, despite serious questions about the integrity of the double-blind procedure (Antonuccio et al., 1999) and suggestions for new paradigms (Katz, 1998; Montgomery, 1999; Thase, 1999). A fundamental concern in the design of a RCT is to ensure adequate statistical power, meaning that if a treatment difference exists that is clinically meaningful, it is detected. There are two ways of increasing the power of a test: increasing sample size or increasing effect size. In an attempt to address the issues surrounding the placebo response, the strategy over the past decades has been to increase the sample size at a cost of additional time and expense, from typically $N=30$ per treatment arm in the early years to $N=100$ in more recent years. However, in an attempt to shorten drug development rime, the focus is shifring from increasing sample size to increasing effect size (Leon et al., 1993; Scharzberg and Kraemer, 2000), and a search for more sensitive and reliable instruments as outcome measures is ongoing (Leon et al., 1995; Faries et al., 2000). In this respect, outcome measures based on repeated measurements may turn out be more sensitive than the conventional retrospective questionnaires used thus far. ESM provides a potential means for reducing the number of subjects required, thereby reducing rreatment research burden and number of subjects exposed to placebo, without decreasing the statistical power needed to detect a true treatment difference. 


\section{Methodological and practical issues}

In applying ESM to the context of clinical trials, several methodological and practical issues can be anticipated. These issues need to be addressed during the design of a clinical trial.

Research alliance. ESM demands a look into the private world and experience of the subject over a prolonged period of time. In addition, more effort and time is required from the subject than for a questionnaire or interview. In order to obtain good compliance and accurate reporting, special care must be taken in creating a research alliance and a mutual understanding abour the procedures and aims of the study. Even though in clinical trials a similar alliance would be required berween patient and physician to ensure treatment adherence, the alliance for an ESM study should be even stronger, as the patient is asked to disclose personal experiences.

Subject recruitment. Subject recruitment is always a critical issue in the conduct of commercial RCT's, as any delay occurring in the development of a compound represents less return on investments. ESM is a very demanding assessment method. The additional burden imposed on subjects by ESM may reduce the number of potential candidates for the study and as such may introduce a selection bias, endangering thereby the generalizability of the study findings. In addition, some potential candidates may not be able to comply with ESM. Previous ESM studies have encountered difficulties in sampling elderly subjects with dementia, individuals with severe melancholia, acurely psychotic patients, and recently treated alcoholics (deVries, 1992b; Kraan et al., 1992; Wilson et al., 1992; Litt et al., 1998). Also, little information is available on compliance of subjects who participate in more than one sampling period in a short timeframe, as would be the case in the context of RCT.

Sampling strategy. The main focus of RCT is the comparison between pre- and post-treatment depressive states. Within this framework, the sampling strategy, in rerms of frequency and density, is a compromise between compliance and sampling requirements (Delespaul, 1992). Too many sampling moments may lead to low compliance with ESM, whereas too few sampling moments may jeopardize the representativeness of daily life.

Interpretation of results. Traditional primary outcome measures used in RCTs in depression are clinician ratings such as the HDRS, often assessed on a weekly basis. In the interpretarion of results, it should be taken into account that any discrepancies found between clinician and ESM measures may be the result of having: (1) observer-ratings 
versus self-ratings, (2) one-time measurement versus repeated measurement, (3) retrospective versus prospective ratings, and (4) clinical versus QoL measures.

Study conduct. As was seen in the previous section, the clinical research realm is one of regularions and strict guidelines. As a consequence, the conduct of RCT is labortous and highly precise. In applying ESM to such a context; the researcher adds logistical challenges to the study conduct. In a standard clinical trial, the researcher needs to educate the physician; adding ESM, the researcher needs to educate the patient on top of that"

\section{PRESENT RESEARCH: AIMS AND STUDY QUESTIONS}

As ESM had not previously been used in the context of a clinical trial", we conducted a pilot study (Study 1), which was a 6-week, single-blind investigation of the effects of two active treatments (fluwoxamine and amitriptyline, known to differ in side effects profile) on the daily life experiences of major depressed patients. In addition, it provided an opportunity to address issues such as compliance with ESM, ease of use, and design of the ESM form (see Appendix 1). Results of this study are presented in Chapter 3. The main study (Study 2) was set up based on the experience of the pilot study. Several changes were made in the design: (1) inclusion of a healthy control group, (2) inclusion of a placebo-treated group, (3) double-blind design, (4) addition of a sampling period in the first week of treatment to better capture the experience of side effects, and (5) longer-term follow-up. The ESM form (see Appendix 2) was also adapted, as described in Chapter 4. In Study 2, depressed patients were randomized to either imipramine or placebo, which they could receive for up to 6 weeks, with a possible prolongation to 18 weeks. In addition, healthy controls participated in ar least one ESM period. Chapter 4 provides a methodological overview of the use of ESM to investigate QoL in dinical rrials of antidepressants. Chapter 5 compares the daily life experiences of depressed patients prior to treatment to the group of healthy controls similar in sociodemographic characteristics. In Chapter 6 the effects of antidepressant treatment, both in terms of side effects and efficacy, on daily life experiences are investigated. Finally, in Chaprer 7 , wo case studies are presented as an illustration of results.

1 Since then, a non-pharmacological incervention study has been published that used ESM measures to evaluate the effect of a tape-recorded relaxation intervencion on well-being, seffereported symptoms, and pulmonary funcrion in adule asthmarics (Smyth et al, 1999). More recently, Shiffman ef al. (2000a; 2000b) published two studies that used ISSM to investigate the effects of pharmacological reatments on nicorine craving and withdrawal symptoms during smoking cessacion. To our knowledge, thesc three studies are the only other applicarions of ESM in intervencion studies that have been published to dare. 
The aim of the present tesearch was to assess the impact of depression and antidepressant treatment in daily life. To thisend, an ecologically valid method, such as ESM, was needed that captures subjective experiences prospectively in real-life setrings. Such a method had not been applied to a clinical trial context at the outset of the current research. Therefore, the issues exploted throughout these two studies and across the different chapters reflect two central goals:

1. To determine the feasibility and utility of ESM in studying the impact of depression and antidepressant treatment in daily life.

- Is ESM well accepted by patients participating in the context of a clinical drug trial? (Chapters 3 \& 4)

- How stable are ESM data over time? (Chapter 4)

- Can ESM pick up changes in daily life domains following treatment that traditional measures (generic or disease-specific QoL scales) fail to pick up? (Chapter 3)

- Does ESM improve statistical power? (Chapter 4)

II. To obtain new insights into the impact of depression and antidepressant treatment (both in terms of efficacy and side effects) on daily life. More specifically:

- What is the general impact of depression on daily mood states, physical complaints, activity patterns and enjoyment of activities? (Chapter 5)

- What are the effects of concurrent daily life experiences (negative and positive affect, physical complaints and enjoyment of acriviries) on QoL as it is experienced from moment to moment? (Chapter 5)

- Is instability in QoL levels characteristic for depressed patients and does antidepressant treatment reduce instability? (Chapters $5 \& 6$ )

- How is clinical improvement following antidepressant therapy reflected in aspects of depressed patients" daily life experiences? (Chapters 3 \& 5)

- How does the experience of side effecrs in daily life impact depressed patients" QoL? (Chapter 6)

- Does antidepressant treatment effectively improve QoL in daily life to what can be regarded as "normal" levels and patterns? (Chapter 6)

- How do group results translate to the individual patient? (Chapter 7)

Chapter 8 summarizes the main research findings with respect to the above topics and atrempts to place them in a larger perspective. In addition it discusses limitations of the studies and possible future research directions. 


\section{REFERENCES}

Antonuccio, D. O., Danron, W. G., DeNelsky, G. Y., Greenberg, R. P., Gordon, J. S. 1999. Raising questions about ancidepressanss. Psychonther Psychosom 68(1), 3-14.

Barge-Schapveld, D. Q. C. M., Nicolson, N. A., Berkhof, J., deVries, M. W. 1999. Qualiry oflife in depression: daily life determinants and variabiliry. Psychiar Res 88, 173-189.

Brandstatter, H., 1994. Well-being and motivational person-environment fit: a cime-sampling study of emotions. European Journal of Personality $8,75-93$.

Bronfenbrenner, U., 1979. The ecology of human developmene. Harvard Universiry Press, Cambridge, MA.

Brown, W. A., Dornseif, B. E., Wernicke, J. F., 1988. Placebo response in clepression: a search for predictors. Psychiatry Research 26, 259-264.

Cantor, N., Norem, ]., Langstom, C., Zirkel, S., Fleeson, W., Cook-Flanmagan, C. 1991. Life takks and daily life experience. Journal of Personality 59(3), 425-45i.

Csilszentmilhalyi, M, 1990. Flow: the psychology of optimal experience. Steps toward enhancing the quality of life. Harper Perennial, New York.

Csikszentmihalyi, M., Larson, R., 1987. Validityand reliability of the Experience Sampling Metzod. J Nerw Ment Dis $175(9), 526-537$.

Csikszentmithalyi, M., Larson, R., Irescott, S., 1977. The ecology of adolescent acrivity and experience. Journal of Yourh and Adolescence 6,281-294.

Delespaul, P. A. E. G., 1992. Technical note: devices and time-sampling procedures. In: deVies, M. W. (Ed.), The Experience of Psychoparhology: Investigating Mental Disorders in Their Natural Settings. Cambridge Universiry Press, Cambridge, pp. 363-373.

Delespaul, P. A. E. G. 1995. Assessing Schizophrenia in Daily Life: The Experience Sampling Method.. Ph.D. Dissertation, Mastrich University, Universitaire Pers, Maastricht.

Delespaul, P.A. E. G., deVries, M. W., 1987. The daily life of ambulatory chronic mental parients ل Journall of Nervous and Mencal Disease 175(9), 537-544.

deVries, M. W. 1987. Investigating mental disorders in their narural settings. Dournal of Nervous and Mental Discase 175(9), 509-513.

deVries, M. W., 1992a. The Experience of Psychopathology: Investigating Mental Disorders in Their Natural Sertings. Cambridge University Press, Cambridge.

deVries, M. W. 1992b. Practical issues in psychituc applications of ESM. In deVrics. M. W. (Ed.), The Experience of Psychopathology: Inwestigang Mental Disorders in Their Narunal Sentings. Cambridge University Press, Cambridge, pp. 317-323.

deVries, M. W., 1997. Recontextualizing psychiaryctoward ecologically wald mental heal wh research. Transcultural Psychiatry 34(2), 185-218.

deVries, M. W., Delespaul, P. A. E. G., Dijkman-Caes, C. I. M., 1987. Affect and anxicty in daily life. In: Racagni, G. Smeraldi, E. (Eds.), Anxious depression: assessment and treatment. Rawen Press, New-York. Pp. $21-32$.

Diener, E., Sandwik, E., Pavot, W., Gallagher, D., 1991. Response artifacts in the measurement of subjective well-being. Social Indicators Research $24,35-56$.

Dijkman-Caes, C. I. M. (1993). Panic disorder and agoraphobia in daily life. Ph. D. Dissertation, Maastricht Universiry, Universitaire Pers, Mastricht.

Faries, D., Herrera, J, Rayamajhi, J., DeBrota, D., Demitrack, M., Porter, W. Z., 2000. The responsiveness of the Hamilon Depression Rating Scale.J Psychiat Res 34(1), 3-10.

Feist, G. I., Bodner, T. E., Jacobs, J. F., Miles, M., Tan, V., 1995. Integrating rop-down and bortom-4p structural models of subjective well-being: a longitudinal invesrigation. Joumal of Personality and Social Psychology 68(1), 138-150. 
Gibbons, R. D. Clark, D. C. Kupfer, D. J, 1993. Exactly what does the Hamilton Depression Raring Scale measure? J Psychiatr Res 27(3), 259-273.

Hamilon, M. 1960. A rating scalc for depression. Neurol Neurosurg Psychiar 23, 56-62.

Headle, B., Vechhoven, R., Wearing, A., 1991. Top-down versus bortom-up theories of subjective well-being. Social Indicators Research 24(1),81-100.

Hormuth, S. E., 1986. The sampling of experience in situ. Journal of Personaliry 54(1), 262-293.

Hurburt, R. T., Melacon, S. M., 1987. Goofed-up images: thought sampling with a schizophrenic woman. Journal of Nerous and Mencal Disense 179), 575-578.

Juster, F. T. Stafford, F. P., 1985. Time, goods and well-being. Instirute for Social Research, The Universicy of Michigan, Ann Arbor.

Kalmeman, D., Diener, E, Schwarz, N., 1999. Well-being: The foundarions of hedonic psychology. Russell Sage Foundation, New York.

Kaplan, C. D., 1992. Drugcraving and drug use in the daily life of heroin addicts. In: deVries, M. W. (Ed.). The Experience of Psychopachology: Investigating Mental Disorders in Their Narural Serrings. Cambridge Uniwersity Press, Cambridge, pp. 193-218.

Karz, M. M. 1998. Need for a new paradigm for the dinical trials of antidepressants. Neuropsychoptiamacol 19(6), 517-522.

Kirscli, 1., Sapirstein, G., 1998. Listening to Prozac but hearing placebo: a meta-analysis of antidepressant medication. Prevention \& "Treatment 1(Artide 0002a).

Klinger, E., Barta, S. Maxeimer, M., 1980. Motivarional correlates of thought content, freguency and commitment. Joumal of Personality and Social Psychology 39, 1222-1237.

Kraan, H., Meertens, H., Hilwig, M., Volowics, L., Dijkman-Caes, C. L. M., Portegijs, P., 1992. Selecting measures, diagnostic yalidity and scaling in the study of fepression. In deVries, M. W. (Ed), The Experixence of Psychoparthology: Investigaring Mental Disorders in Their Natural Serrings. Cambridge University Press, Cambridge, pp. 324-338.

Lance, C. E., Lautenschlager, G. J., Sloan, C. E., Varca, P. E., 1989. A comparison berween botrom-up, top-down, and bidirecrional modets of relarionships between global and life facet sarisfaction. Joumal of Personality $57(3), 601-624$.

Lehman, A. F., Burns, B., 1990. Severe mental illness in the community. In: Spilker, B. (Ed.), Qualiry of Life Assesmenes in Clinical 'Trials. Raven Press, New York, pp. 357-366.

Leon, A. C. Marzuk, P. M., Porrera, L., 1995. More reliable outcome measures can reduce sample size requirements. Arch Gen Psychiacry 52(10), 867-871.

Leon, A. C., Shcar, M. K., Portera, L., Klerman, C. L., 1993. Effect size as a measute of symprom-specific drugg change in dinical riats. Psychophar ruacol. Bull. 29(2), 163-167.

Lirt, M. D. Cooncy, N. L.. Morse, P., 1998. Ecological momentary assessment (EMA) with treated alcoholics: methodological problems and potencial solutions. Health $\mathbb{I}_{3 y \text { chol } 17(1), 48-52 .}$

Massimini, F., Carti, M., 1988. The systematic assessment of flow in daily bife experience. In: Csikszentmihalyi, M., Csikszentmihalyi, I, (Eds), Optimal experience: psychological studies of flow in consciousness. Cambridge University Press, New-York, pp. $266-287$.

Massimini, F., Csikszentmithaly. M., Carli, M., 1992. The montoring of optimal experience: at tool for psychiarric rehabilitation. In: deVries, M. W. (Ed.), The Experience of Psychopathology: Investigating Men at Disorders in Their Narural Setrings. Cambridge University Press, Cambridge, pp. 270-279.

Milbath, L. W., 1982. A conceptualization and rescarch strategy for the study of ecological aspects of the qualiry oflife. Social Indicators Research $10,133-157$.

Montgomery, S. A., 1999. Alternatives to placebo-controlled rials in psychiatry. ECNP Consensus Mcering, September 26, 1996. Amsterdam. European College of Neuropsychopharmacology. Eur Neuropsychopharnacol 9(3). 265-269.

Myin-Germeys, L. Delespatul, P. A. deVries, M. W., 2000. Schizophrenia pariens are more emotionally acrive than is assumed based on cheir behavior. Schizophr Bull 26(4), 847-854. 
Nicolson, N. A, 1992. Stress, coping and corcisol dyamicsin daily life. In: deVues, M. W. (Ed.), The experience of psychopathology: investiganing mental disorders in their narural servings. Cambridge Universiry Press, Cambridge, pp. $219-232$.

Portegijs, P.I. M. 1996. Somanzation in frequent artenders of general practice. Unpublished PhD disseration, University Madstrichr.

Schatzberg. A. F., Kraemer. H. C., 2000. Use of placebo control groups in evaluating efficacy of trearment of unipolar major depression. Biol Psychiary 47(8), 736-744.

Shiffman, S. Elash, C. A., Paton, S. M., Gwaltney, C. J., Pary, J. A., Cark, D. B., Liu, K. S., Di Marino, M. E. 2000a. Comparative efficacy of 24 -hour and 16-hour transdermal nicotine pathes for relief of morning craving. Addiction 95(8), 1185-1195.

Shiffman, S., Johnston, J. A., Khayrallah, M., Elasty, C. A., Gwalmey, C. J., Pary, J. A. Gnys, M., Evoniuk, $G_{.,}$DeVeaugh-Geiss, J., 2000b. The effecr of bupropion on nicotine craving and withdrawal. Psychopharmacology (Berl) $148(1), 33-40$.

Smyth, I. M. Soefer, M. H., Hurewitz, A., Stone, A. A., 1999. The effect of tape-recorded relaxation training on well-being, symproms, and peak expiratory flow rate in adult asthmatics: a pilot study. Psychology and Health 14,487-501.

Stone, A. A., Shiffman, S. S., DeVries, M. W., 1999. Ecological Momentary Assessment. In: Kahneman, D., Diener, E., Schwar, N. (Eds.), Well-being: the foundations of hedonic psychollogy. Russell Sage Foundation, New York, pp. 26-39.

Thase, M. E., 1999. How should efficacy be evaluated in randomized clinical rrals of treatments for depression? J Clin Psychiarry 60(Suppl 4), 23-31; discussion 32.

Trivedi, M. H. Rush, H., 1994. Does a placebo run-in or a placebo rreatment cell affect the efficacy of antidepressant medications? Neuropsychophamacology 11(1), 33-43.

van Eck, M. 1996. Stress, Mood, and Cortisol Dynamics in Daily Life. Ph.D. Dissertation, Mactricht University, Universitaire Pers, Maastricht.

Veenhoven, $R_{\text {. }}$, 1991. Is happiness relative? Social Indicators Research 24(1), 1-34.

Wilson, K. C.M., Hopkins, R., deVries, M. W., Copeland, J. R. M., 1992. Research alliance and the limic of compliance: Experience Sampling with the depressed elderly. In: deVries, M. W. (Ed.), The Experience of $\int^{2}$ sychopathology: Investigating Mental Disorders in Their Natural Sertings. Cambridge University Press, Cambridge, pp. 339436. 



\title{
PART I]
}

PRELIMINARY STUDY (STUDY 1)

\author{
CHAPTER 3
}

Changes in daily life experience associated with clinical improvement in depression

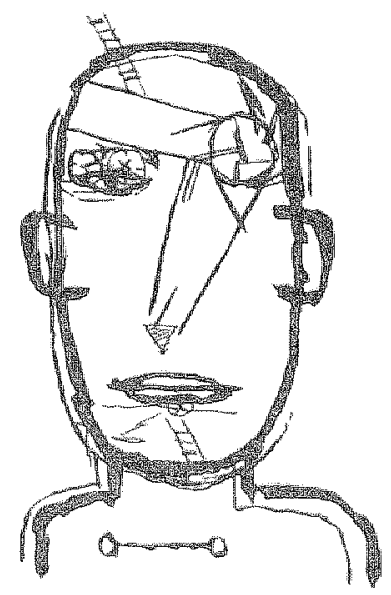

Barge-Schaapveld, D. Q. C. M., Nicolson, N. A., Gerritsen van der Hoop, R., deVries, M. W., 1995. Changes in daily life experience associated with clinical improvement in depression. Journal of Affective Disorders 34, 139-154. 


\title{
Changes in daily life experience associated with clinical improvement in depression
}

\begin{abstract}
Changes in depressed outpatients experience of daily actwities after 6 weeks of antidepressant treatment were assessed with the Experience Sampling Method (ESM). On the Sickness Impact Profille, theatment responders (HDRS $\leq 7, N=12)$ improved more than non-responders $(N=9)$ in the domains of household chores, leisure and social activities. On ESM measures completed $10 \times$ each day for 6 days pre- and postreatment, responders showed greater increases in time spent in chores and greater decreases in passive leisure time than non-responders. Responders showed greater increases in positive affect and greater decreases in negative affect during all activities. Thus, ESM provides quantitative evidence of changes in reall life time use and subjective experience accompanying clinical improvement.
\end{abstract}

\section{INTRODUCTION}

All though the symptoms of depression have been discussed for centuries (Hare, 1991), it is only in the last decades that the impact of these symptoms on the everyday functioning and well-being of the patient has been recognized (Hammen, 1990; Revicki and Murray, 1994). In recent years the burden of this mood disorder has been well documented for several life domains such as social, productive and leisure activities. Impaired social functioning, such as reduction in frequency and intensity of social contacts, has been reported extensively in depressed parients (De Lisio et al, 1986; Gotlib, 1990; Agosti et al., 1991). This social maladjustment has been viewed as a common consequence of depression, which may persist long after patients are symptomarically recovered (Paykel er al.. 1978; Tweed, 1993). Depression is also associated with pronounced disturbances in work (De Lisio et al., 1986; Mintz et al., 1992). In a prospecrive epidemiological survey, Broadhead er al. (Broadhead et al., 1990) found that major depression carries a high risk of disability days and days lost from work. Although less systematic information is available on impairment in unpaid work such as household 
chores and maintenance, it appears that performance of household roles is also disturbed as a consequence of depression (De Lisioet al., 1986). Finally, maladjustment is evident in leisure activities. The performance of leisure requires the exertion of personal initrative and may reflect central hedonic function, which may explain why impairments in this domain are especially likely to persist after clinical remission (De Lisio et al., 1986).

In spite of the numerous antidepressant drug trials conducted, lirtle is known about how clinical improvement is reflected in daily functioning and well-being. In an attempt to address this issue, recent studies have incorporated questionnaire measures of well-being or life satisfaction (Revicki et al., 1992; Rost et al., 1992; Stoker et al., 1992; Tuynman-Qua et al., 1992; Endicott er al., 1993). A major limitation of such cross-sectional measures is that they are unable to obtain unbiased quantitative information on daily life contexts and acrivities, which may be fundamental for an understanding of patients' subjective experience. In this regard, a time-based method such as the Experience Sampling Method (ESM) may have more potential. ESM uses repeated self-assessments to study the variability of patients' thoughts, mood, morivarion, physical symproms and acrivities in their natural settings (deVries, 1987). By collecting self-reports from subjects immediately after repeated, randon signals, ESM has important advantages over cross-sectional instruments (Verbrugge, 1980; Wheeler and Reis, 1991). First of all, a time-based method reduces recall errors, a particularly important advantage in depression, where retrospective memory bias has been documented (McLeod et al., 1990). Another advantage of a rime-based method is its ability to elicit reports of symptoms that are too minor or transient to be captured in a cross-sectional report later, but that may nevertheless be significant to the patient at the time of occurrence. Finally, by providing a longitudinal series of data for each individual, a rime-based method offers a rich porential for the analysis of individual variability and change over time.

ESM has been applied in a variety of psychiatric populations (deVries, 1992). Information concerning compliance, reliability and validity of ESM have been reported elsewhere (Csikszenmihalyi and Larson, 1987; deVries, 1987). Previous studies in depression have shown ESM to distinguish between depressed adolescents and their non-depressed peers on time-budgets, mood lability and reactivity to daily life contexts (Merrick, 1992), and to differentiate between groups with different levels of depression severity on measures of mood states (Kraan et al., 1992). The current study is the first application of ESM in the context of a clinical drug trial.

This paper describes how clinical improvement, possibly accompanied by side effects, following antidepressant therapy (fluvoxamine or amitriptyline) is reflected in aspects of depressed patients" daily life experience. In order to berter contrast the effects of dinical improvement, we distinguish two groups of patients: responders to treatment and non-responders. We first identify the life domains in which changes in sick- 
ness impact as measured with a cross-sectional instrument, the Sickness Impact Profile $(\mathrm{SIP})$, differentiate treatment responders from non-responders. A second question focuses specifically on these life domains and examines the pre- to post-treatment changes in daily life experience associated with clinical improvement. For this purpose, ESM measures of time use, positive and negative affect in daily life are first defined. A third question addresses whether responders to treatment show any changes in daily life domains as assessed with ESM that the SIP fails to pick up. A final question addresses the relationships between SIP life domains and ESM measures of daily life experience.

We hypothesized that improvement in a SIP life domain would be associated with increased time spent (during ESM sampling) in demanding activities and decreased rime spent in non-demanding activities relared to this domain. Since depression is not only characterized by a persistent and pervasive low mood (American Psychiatric Association, 1987) but also by 'anhedonia", the absence of positive affect (Tellegen, 1985; Clark and Watson, 1988; Watson et al., 1988; Snaith, 1993), we hypothesized that improvement in a life domain as identified by the SIIP would be associated with both higher positive affect and lower negative affecr during these activiries. Furthermore, we hypothesized that ESM measures would be able to identify more subtle changes in daily life experience than a cross-sectional measure, the SIP. Finally, we hypothesized that, since the SIP purports to measure behavior rather than mood (Bergner et al., 1981), ESM time use would be more highly associated with SIP measures than would ESM mood measures.

\section{METHODS}

\section{Study derign}

The study was conducted in five primary care practices in the Nerherlands. Subjects, who ranged in age from 18 to 65 years, met DSM-III-R criteria for Major Depressive Disorder (American Psychiatric Association, 1987) and were free of other major psychiatric or medical conditions. For inclusion, patients had to score at least 18 on the 17-irem version of the Hamilton Depression Rating Scale (HDRS, Hamilton, 1960) and 4 on the Clinical Global Impression (CGI, Guy, 1976) severity score at Baseline. Ethical committee approval was obtained prior to patient entry. The physicians and the research nurse were trained in diagnosing Major Depressive Disorder, in administering the scales and in using ESM. The study procedures were explained to all patients and their informed consent to participate obtained. Following a one-week placebo run-in period, patients were randomized and tapered-on to either fluvoxamine (first week 50 $\mathrm{mg}$ once daily, thereafter $50 \mathrm{mg}$ b.i.d.) or amitriptyline (first week $75 \mathrm{mg}$ once daily, thereafter $75 \mathrm{mg}$ b.i.d.), which they received, single-blind, during six weeks. Two treat- 
ments known to differ in side effects profile (Nierenberg and Cole, 1991; Tollefson: 1991; Kasper er al., 1992) but not in efficacy were included in the design in order to increase the variability in daily life measures. Because this study focuses explicitly on self-report measures, a double-blind design was nor considered to be necessary.

\section{Instruments}

Cross-seccional measures were adiministered as follows: the HDRS was used to measure clinical improvement and was assessed by the physicians on a regular basis. Ar each visit, the physicians asked their patients whether or not they had experienced any unusual or unwanted signs or symptoms. Only pre-and post-trearment (Day 43) measures are used here. The SIP (Bergner et al., 1981; Read et al., 1987) was administered by the research nurse as a generic Quadity of Life (QoL) scale, intended to measure subject's health status independently of the specific disease or condition, at Baseline and at the end of the study. The SIP consists of 12 modules of daily life acriviries, which can be clustered in a psychological module (emotional behavior, social interaction, alertness behavior and communication) and in a physical module (body care/movement, mobility and ambulation). The five remaining modules (sleep/rest, eating, home management, work and recreation/pastimes) are independent. All scores are given in percentages. Based on all modules, a total score is calculated, which indicates the level of impact the illness has on a parient's life. The higher the score, the higher the impact of the illness and thus the lower the QoL.

ESM was conducted 'pre-treatment' during 6 consecutive days of the placebo week and 'post-treatment" during 6 days of the last ( $6 \mathrm{th}$ ) week of active treatment. The wrist-watch was programmed to signal subjects 10 times a day, between $7.30 \mathrm{am}$ and $10.30 \mathrm{pm}$. At each signal, which will be referred to as a 'beep', subjects were asked to report their thoughts, current activity, physical and social context by way of open questions. Seven-point Likert scale items (with endpoints: $1=$ "not at all' and $7=$ 'extremely") were used to assess subjective experience. Mental states were assessed by asking patients to rate current thoughts with the irems 'brooding' or "pleasant", and to indicate to what extent they could concentrate on their current activity. Mood states were assessed with 14 items. Regarding their physical disposition, patients were asked to rate the items 'thirsty', 'hungry', 'sleepy', 'agitated' and 'feeling well'. Satisfaction with activity and social context was measured by questions such as 'Would you prefer to be doing something else (than the activity you were doing)?' or 'Would you prefer to be alone (when in a social context)"? To derermine the elapsed time between the 'beep' and the ESM report (response time), subjects also recorded the time at which the self-report form was completed.

In addition, patients completed short questionnaires concerning sleep parterns each morning, upon waking. This information included the time they went to bed on the 
prior evening, the rime they required to fall asleep, the number of times they awoke during the night and the time they got up. Patients were also asked to rate on a Likert scale

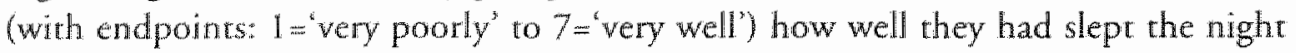
before.

Each sampling period was preceded by a briefing session, during which the research nurse instructed the parient on the sampling procedures and the use of the warch. At the end of each sampling period a debriefing session was held during which the research nurse obtained information from the patient as to the representativeness of the sampled days as well as any experimental effects or annoyance ESM might have caused.

\section{Analysis}

Definition of clinical improvement. The aim of this study was to describe the relationship between clinical improvement and changes in daily experience. Due to large individual differences in clinical improvement during the study, we chose to contrast two groups in the analysis. Clinical improvement was therefore defined by a conservative post-treatment HDRS criterion: patients who scored 7 or less on the HDRS at Day 43 were classified as responders and those with a higher post-treatment HDRS score were classified as non-responders (Murphy et al., 1985).

Analysis of ESM data. ESM self-reports completed more than 15 minutes afrer the signal (4\%) were discarded prior to analysis. ESM time use was defined as the percentage of total beeps engaged in each caregory of activity. Responses to the open question about current activity were first coded into one of 48 caregories (e.g. shopping, child care, conversarion). In other ESM studies, inter-coder reliability of these activity codings has been found to be acceptable. Activities were subsequently grouped into five larger categories: chores, leisure, social, work and orher time use. The category 'chores' consisted of activities such as 'household maintenance' and 'shopping'. 'The category 'leisure' was differentiated in two sub-categories: active (e.g. sports, hobbies) and passive (e.g. T.V. watching, reading) leisure activities. Social time use included activities such as conversation and visits to and from others. Work consisted of both paid and voluntecr work as well as study, whereas the remaining rime use category 'other' comprised acriviries such as transportation and personal hygiene.

In accordance with current models of mood (Tellegen, 1985; Watson and Tellegen, 1985) and supported by principal components analysis with varimax rotation over the averaged mood item scores per subject as well as over total mood item beep scores, two affect scales were formed. Ratings on the Likert-scale items 'happy', 'satisfied', 'relaxed', 'calm', 'energetic' and 'enthusiastic' were averaged to form a posirive affect (PA) scale (over all beeps; Cronbach's alpha = 88). The items 'angry', 'irritated', 'anxious', 'sad', 'depressed' and 'lonely' were averaged to form a negative affect (NA) scale (over all 
beeps; Cronbach's alpha $=.87$ ). Scores were computed as the sum of all irems divided by the number of items in the scales and, thus, ranged from 1 to 7 .

PAduring daily activities was defined in two ways. First, PA scores were averaged for each subject and for each period (pre-and post-treatment) per main activity caregory. Second, PA during daily activities was assessed by the frequency of highly positive affective states ( $P A \geq 5$ on the 7-point scale). The frequency of these beeps was then calculated per activity as a percentage of the subject's total number of beeps spent in that activity. NA during daily activities was similarly measured in two ways: average NA and the frequency of highly negative affective states (NA $\geq 5$ ). Here again, the frequency of these states was calculated per activity as a percentage of the subject's total number of beeps spent in that activity.

Based on the sleep information collected each morning, four additional ESM measures were defined: duration of sleep (the interval between the time the patient went to bed the prior evening and the time he/she gor up the following morning), sleep latency (the interval between going to bed and falling asleep), the number of times the patient awoke during the night and the quality of the patient's sleep. For each subject, a pre-treatment and a post-trearment mean were calculated for each of the above measures, over the 6 days sampled in each period.

Statistical tests. Only subjects who completed both pre- and post-treatment sampling periods were included in the analysis (see 'Patient characteristics' below for information concerning drop-outs).

Within-subject pre- to post-treatment change was tested using the Wilcoxon signed rank sum test. Differences between responders and non-responders were tested with the Mann-W/himey $U$ test for the continuous variables and with the Fisher's exact test for the categorical variables. For the relationships between the SIP life domains and ESM daily life measures, as well as for the associations between the ESM time use and mood measures, Spearman correlations were calculated. All statistical tests were two-tailed. Analyses were performed with SPSS.

\section{RESUL'T'S}

\section{Patient characteristics}

Of the 25 patients screened, 21 completed the study. Two patients dropped out after the pre-trearment sampling period due to adverse events not related to trearment and two due to difficulties complying with ESM procedures during the first sampling period. Drop-outs were significantly older than completers, with a mean age of 50.5 versus 36.4 years (Mann-Whitney, $p \leq 01$ ), but did not differ on other 
socio-demographic parameters. Although no statistical difference in severity of depression was found between completers and drop-outs, the two subjects who had difficulties with ESM procedures scored relatively higher on the HDRS (26 and 34) at Screening.

Eleven of the 21 completers received fluvoxamine and ten received amitriptyline. No statistically significant differences were found between the two treatment groups on any socio-demographic characteristics, or on any pre- or post-treatment clinical measures (HDRS and CGI). Five out of the ten patients who received amitriptyline reported side effects at some point in the first 4 weeks of treatment (four in Week 1, five in Week 2 and one during Weeks $3-4)$ with complaints of dry mouth $(N=3)$, dullness or fatigue $(N=4)$, depersonalization $(N=1)$, or headache $(N=2)$. Three out of the eleven parients who were rreated with fluvoxamine reported side effects at some time in the first 4 weeks of trearment (one in Week 1 , three in Week 2 and two during Weeks 3-4) with complaints of nausea or vomiting $(N=2)$, headache $(N=1)$, dry mouth $(N=$ 1) or transpiration $(N=1)$. During Weeks $5-6$ (including the ESM sampling period in Week 6), no subjects reported side effecrs to the physicians. Thus, no differential effects of treatment on daily life measures were to be expected. Therefore we felt justified in combining the two treatment groups in the analysis.

Based on the criterion for treatment response (post-treatment HDRS $\leq 7$ ), twelve completers were classified as responders and nine as non-responders to treatment. No significant difference was found in the sex distribution of the two groups ( 8 out of 12 responders versus 4 out of 9 non-responders were female). Responders were older than non-responders (mean age: 39.6 versus 32.3; Mann-Whitney, $p \leq .05$ ) and tended more often to be married (Fisher"s exact test, $p=.06$ ). Responders and non-responders had received similar levels of education. No differences were found in employment status; of the total sample, $43 \%$ received either unemployment or sickness benefits, $38 \%$ had paid employment, and $19 \%$ were housewives.

Pre- and post-treatment HDRS ratings for all subjects are shown in Figure 1. Responders and non-responders to treatment did not differ in severity of depression at Baseline; responders had a mean HDRS score of 24.8 and non-responders of 25.7 . After 6 weeks of treatment, HDRS scores had decreased on average by 20.4 to 4.4 for responders and by 9.8 to 15.9 for non-responders, a significant improvement (Wilcoxon, $p \leq .01$ ) in both cases. However, the improvement was significantly greater in responders than non-responders (Mann-Whitney, $p \leq .001$ ).

\section{Changes in SIP life domain measures}

Changes in SIP modules were first examined to determine which life domains were most relevant to explore with ESM data. As shown in Table 1 , responders' overall qual- 


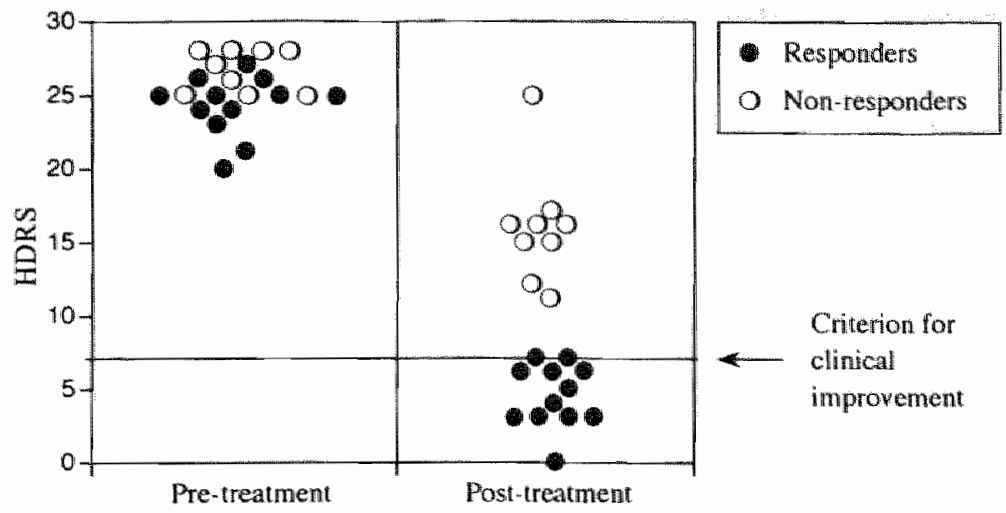

FIGURE 1. Distribution of pre- and postuentment HDRS scores.

TABLE 1. SIP scores for responders and non-responders pre-and post-treatment.

\begin{tabular}{|c|c|c|c|c|c|c|c|}
\hline \multirow[t]{2}{*}{ SIP modules } & \multicolumn{3}{|c|}{$\begin{array}{l}\text { Responders } \\
(N=12)\end{array}$} & \multicolumn{3}{|c|}{$\begin{array}{l}\text { Non-responders } \\
(N=9)\end{array}$} & \multirow{2}{*}{$\begin{array}{l}\text { Change in } \\
\text { responders > } \\
\text { change in } \\
\text { non-responders }\end{array}$} \\
\hline & Pre & Post & $\begin{array}{l}\text { Significance } \\
\text { of change }\end{array}$ & Pre & Post & $\begin{array}{l}\text { Significance } \\
\text { of change }\end{array}$ & \\
\hline Total & 26.2 & 6.9 & $* *$ & 25.4 & 15.7 & $* *$ & * \\
\hline $\begin{array}{l}\text { Psychological impact } \\
\text { module }\end{array}$ & 43.2 & 8.5 & $* *$ & 45.4 & 27.1 & $* *$ & $*$ \\
\hline Emorional behavior & 45.7 & 6.8 & *** & 55.1 & 31.4 & * & -- \\
\hline Social interaction & 47.4 & 8.0 & *** & 43.9 & 29.5 & * & *.*. \\
\hline Alertness behavior & 61.9 & 12.5 & $* *$ & 69.0 & 36.8 & * & - \\
\hline Communication & 12.5 & 6.8 & - & 13.5 & 7.6 & * & - \\
\hline $\begin{array}{l}\text { Physical impact } \\
\text { module }\end{array}$ & 5.5 & $\mathbb{1 1 . 5}$ & $* *$ & 6.0 & 2.4 & $*$ & - \\
\hline Body care/movement & 3.7 & 0.9 & - & 4.6 & 1.3 & $*$ & - \\
\hline Mobility & 13.5 & 4.3 & $*$ & 15.2 & 8.3 & - & - \\
\hline Ambularion & 2.8 & 0.5 & - & 1 & 0.0 & - & - \\
\hline $5 \mathrm{lecp} / \mathrm{rest}$ & 43.0 & 8.0 & $* *$ & 36.5 & 25.8 & - & $p \approx .06$ \\
\hline Faving & 10.4 & 1.6 & $*$ & 6.0 & 3.6 & - & - \\
\hline Home management & 19.0 & 3.3 & *** & 8.1 & 7.7 & - & a... \\
\hline work & 54.2 & 46.7 & - & 57.4 & 40.9 & - & - \\
\hline Recreation/pastimes & 37.4 & 4.2 & $* *$ & 24.5 & 20.5 & - & $* *$ \\
\hline
\end{tabular}

"p $\leq .05 * * 0.01$ 
iry of life, as measured by the SIP total score, improved significantly following the six weeks of antidepressant treatment. Non-responders' total SIP scores also improved, but significantly less so than those of responders. For the psychological impact modules, similar patterns were observed: both responders and non-responders showed improvement, but, for the rotal psychological module score as well as for the social interaction sub-module, positive change was significantly greater in responders than in non-responders. In contrast, no differences between responders and non-responders were found in the physical modules (total or sub-modules). For the remaining SIP modules, responders improved significantly more than non-responders in home management chores and leisure activity domains. Between-group differences in 'sleep/rest' improvement failed to reach significance. No differences in improvement were found between responders and non-responders for "work" or 'eating" modules. In the case of work, it should be noted that a minority of subjects ( $38 \%$ ) had paid employment and therefore no differences between responders and non-responders were expected.

To summarize, clinical improvement was most clearly reflected in the domains of social interaction, home management and recreational activity. These areas were therefore selected for further investigation with ESM data.

\section{Changes in ESM measures}

\section{Compliance and patient evaluation of ESM}

Of the maximum possible 2520 ESM self-reports for these 21 subjects, $81 \%$ were completed, with no significant difference between responders ( $84 \%$ ) and non-responders $(77 \%)$. There were no differences either pre-versus post-treatment in the average number of beeps completed. The lowest number of beeps was 28 in the first sampling period and 33 in the second sampling period. Furthermore, responders and non-responders to treatment did not differ in the first sampling period as to the mean delay between the beep and the response time ( 3.56 versus 4.44 minutes, $n s$ ). Nevertheless, responders showed a significant decrease in the mean delay in the second sampling period $(3.56$ pre-versus 2.87 minutes post-treatment, Wilcoxon, $p \leq .05)$. No significant change was found in non-responders ( 4.44 pre-versus 4.08 minutes post-treatment).

Information collected during the debriefing interview suggested that the ESM procedure had relatively little effect on patients' daily experience during eirher of the two sampling periods. A few subjects reported that participation in the study had some effect on their mood (pre-, post-treatment: 5,4 subjects), activities $(2,2)$, social contacts $(5,4)$, or thoughrs $(9,5)$. Pre-rreatment, 11 subjects reported that the ESM procedure was to some extent disruptive or annoying; this was reported by only 6 subjects post-treatment. There were no differences between responders and non-responders on any of the above evaluations. 
TABLE 2. Time use (expressed as \% of toral ESM repors) for responders and non-responders prem and pose-treatment.

\begin{tabular}{|c|c|c|c|c|c|c|c|}
\hline \multirow[t]{2}{*}{$\begin{array}{l}\text { Acriviry } \\
\text { aregoty }\end{array}$} & \multicolumn{3}{|c|}{$\begin{array}{l}\text { Responders } \\
(N=12)\end{array}$} & \multicolumn{3}{|c|}{$\begin{array}{l}\text { Non-responders } \\
(N=9)\end{array}$} & \multirow{2}{*}{$\begin{array}{l}\text { Change in } \\
\text { responders } \\
\text { change in } \\
\text { non-tesponders }\end{array}$} \\
\hline & Pre & Post & $\begin{array}{l}\text { Significance of } \\
\text { change }\end{array}$ & Pre & Past & $\begin{array}{l}\text { Significance of } \\
\text { change }\end{array}$ & \\
\hline Chores & 29.6 & 34.3 & - & 28.1 & 22.4 & - & $*$ \\
\hline Leisure & 31.0 & 23.7 & $p=.06$ & 28.1 & 34.9 & - & * \\
\hline Active leisure & 10.6 & 10.2 & 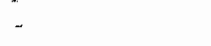 & 4.5 & 7.5 & - & - \\
\hline Passive leisure & 20.4 & $\mathbb{1 3 . 5}$ & $*$ & 23.5 & 27.4 & - & * \\
\hline Social & 19.0 & 19.1 & - & 23.8 & 16.2 & - & - \\
\hline
\end{tabular}

$* 0.05$

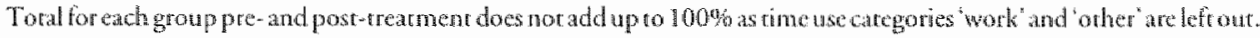

\section{ESM time use}

We first tesred whether the improvements found with the SIP for household chores, leisure acrivities and social interactions were reflected in changes in time spent in these activities as estimated with the ESM data. As shown in Table 2, responders increased the time they spent on household chores by $5 \%$ following treatment while non-responders decreased their household acrivities by $6 \%$. Furthermore, responders showed a rendency to decrease the rime spent in leisure activities, which differed from the pattern of change observed in non-responders.

A further breakdown into active and passive leisure time revealed that responders spent significantly less time in passive leisure activities, such as doing norhing, watching T.V. or reading a newspaper, following the 6 weeks of treatment in both absolute terms and in comparison to non-responders. The percentage of time spent in acrive leisure, on the other hand, remained more or less constant over the two sampling periods for both groups. Finally, the percentage of time spent in social interacrions, comprising activities such as conversations, visits to and from farnily and meals with friends, did not change significantly for either responders or non-responders from pre- to post-treatment, and no significant between-group difference was found.

\section{ESM mood measures}

Positive affect. No difference was found between responders (mean $=2.86, S D=.75$ ) versus non-responders (mean $=2.66, \mathrm{SD}=.58$ ) during the first sampling period in average PA over all acrivities. Following the six weeks of treatment, responders had higher PA (change: $+1.30, p \leq .01$ ), whereas change in PA in non-responders $(+0.17)$ was not significant. 
The average PA calculated separately for each type of activity increased significantly in responders compared to non-responders during all three main activity caregories: chores $(p \leq .05)$, leisure $(p \leq .05)$ and social acrivities $(p \leq .01)$. These data are shown in the top half of the graphs in Figure 2. Within leisure activities, PA improvement was significantly greater in responders than non-responders for passive $(p \leq .05)$ but not for active leisure.

Negative affect. Pre-treatment, responders (mean $=2.53, \mathrm{SD}=1.01$ ) did not differ from non-responders (mean $=3.06, \mathrm{SD}=.93)$ in average NA over all activiries. Following the six weeks of treatment, responders had lower NA (change: $-1.15, p \leq .01$ ), whereas change in NA in non-responders $(-0.16)$ was not significant.

Average $N A$ in responders decreased significantly when compared to non-responders (chores: $p \leq .05$; leisure and social: $p \leq .01$ ). These data are shown in the bottom half of the graphs in Figure 2. Again a breakdown of leisure activities revealed greater NA improvement in responders than non-responders for passive but not for acrive leisure.

Highly positive states. Both responders and non-responders had $1 \%$ of highly positive states during the first sampling week pre-rreatment. Although it remained at this level for non-responders post-treatment, this percentage increased significantly to $34 \%$ (Wilcoxon, $p \leq .01$; Mann-Whitney, $p \leq .05$ ) in responders following the 6 weeks of treatment.

Results found for the frequency of highly positive states during the various acrivities were similar to the results found with the mean PA. Although the rate of occurrence of highly positive srares pre-treatment was about $1 \%$ for both responders and non-responders during the various activities (top half of graphs in Figure 3), it increased in tesponders to $34 \%$ for chores, to $42 \%$ for leisure activities and to $31 \%$ for social interacrions. These changes were all significant (leisure: $p \leq .05$; chores and social: $p \leq .01$ ) when compared to non-responders, who remained around the $1 \%$ level for all three activities. Here again, within leisure activities, responders experienced a highly posirive state significantly more frequently during passive (but not during active) leisure than non-responders.

Highly negative states. No difference was found in the percentage of highly negative affective states responders ( $4 \%$ ) and non-responders (10\%) experienced over all activities pre-treament. Nor was there a group difference in the change in percentage of highly negative states following treatment (responders: $-4 \%$; non-responders: $+1 \%$ ).

The pre- to post-rreatment change in the percentage of highly negative states parients experienced during each particular acrivity was not significant in either responders or non-responders. Although the percentage of highly negative states experienced by responders was already low pre-treatment, individuals in this group showed no highly negative states at all post-treatment. 


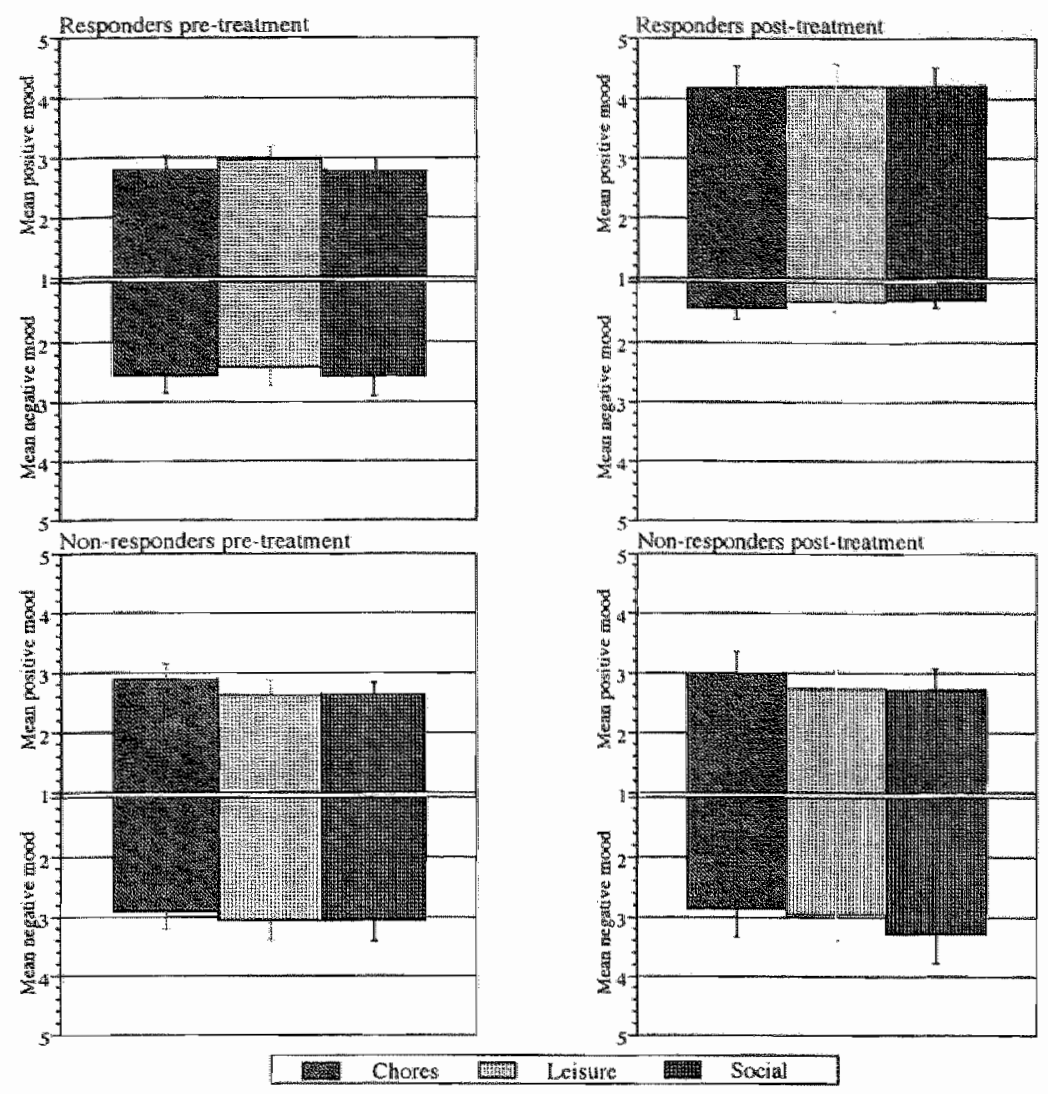

FIGURE 2. Mean posirive and negative mood scale scores in responders and non-rcsponders prem and postreatment. Euror bars, SEM.

Correlations between ESM measures over all stbjects. Changes in average PA and average NA showed a negarive association $(r=-.61, p \leq .01)$. An increase in average PA was accompanied by a greater frequency of high positive states $(r=.81, p \leq .001)$ and, although an increase in average NA was also accompanied by a greater frequency of high negative states, the latter association was weaker $(r=.51, p \leq .05)$. Patients who experienced an increase in the frequency of high positive states did not experience a decrease in the frequency of high negative states $(r=.03, n s)$. Increases in time spent in one activity category did nor auromatically result in decreases in another caregory, in that the analysis did not add up to $100 \%$. Patients who showed the greatest increases in chore time did, however, show the greatest decreases in passive leisure $(r=-.76, p \leq .001)$ and the greatest increases in social interactions $(r=.52, p \leq .05)$. Changes in social interaction time were negatively associated with changes in active leisure $(r=-.46, p \leq .05)$. 


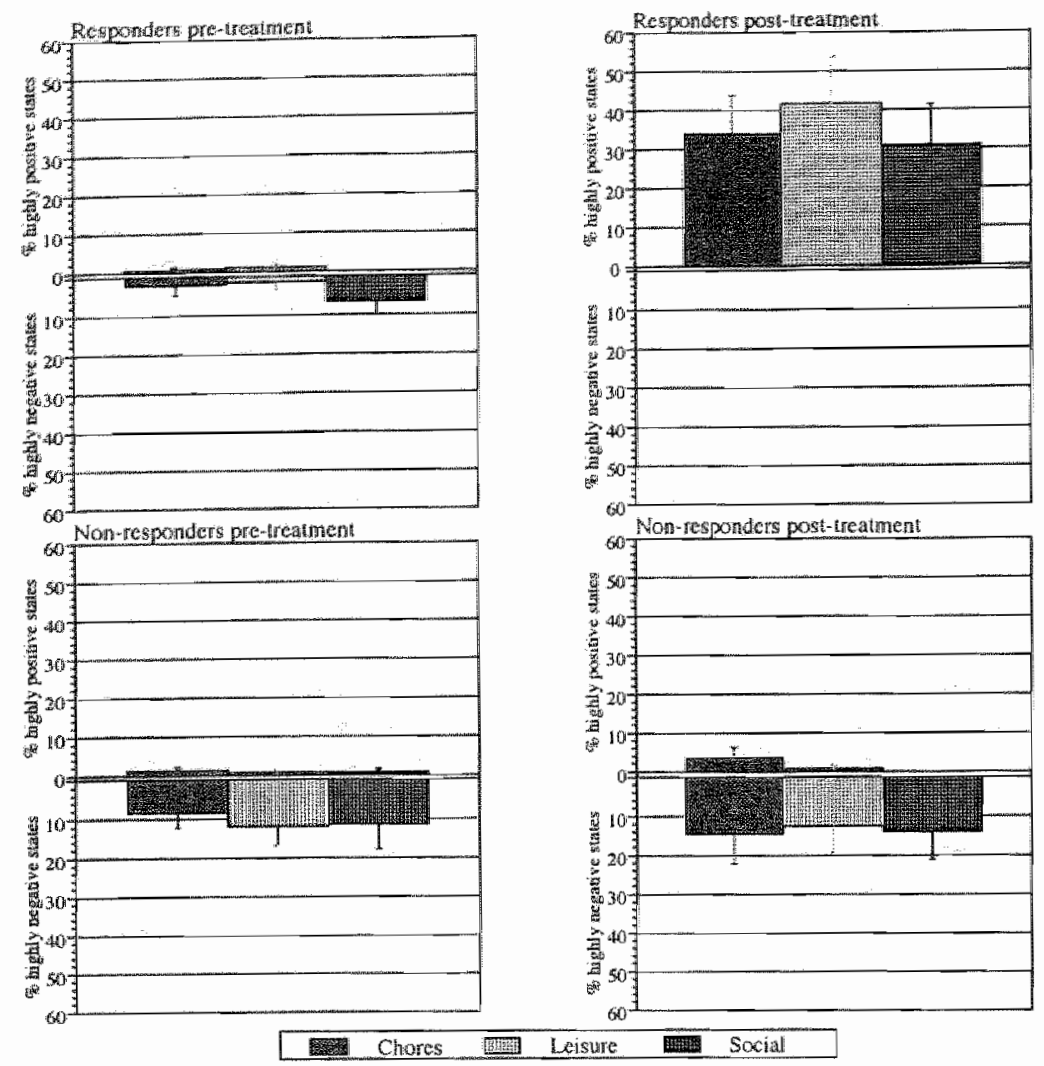

FIGURE 3. Mean \% of highly positive and highly negarive states in responders and non-responders prem and postreatment. Error bars, SEM.

The remaining correlations were not significant (changes in passive versus active leisure: $r=.23$; chores versus active leisure: $r=-.36$; passive leisure versus social interaction: $r=-40$ ). With the exception of a significant association between general increases in $\mathrm{PA}$ and increased time spent in chores post-treatment $(r=.48, p \leq .05)$, changes in ESM affect measures were not associated with changes in time use.

\section{Sleep}

In order to assess whether responders to reatment showed any changes in daily life domains as assessed with ESM that the SIP failed to pick up, we tested the changes in ESM sleep measures. Average duration of sleep, delay in falling asleep and number of awakenings during the night did not change significantly following the six weeks of treatment in either responders or non-responders. However, responders rated the quality of their sleep to be higher post-treatment $(5.3$ versus 4.5 pre-treatment, Wilcoxon, $p \leq .05)$. This change was significant $(p \leq .05)$ when compared to the change in 
non-responders" quality of sleep (from 3.8 pre-rreatment to 3.4 post-treatment), although the two groups did not differ on this aspect pre-treatment.

\section{Relationship between SIP and ESM medures}

In an artempt to identify the relationships between SIP life domains and ESM measures of daily life experience, Spearman correlations between the pre- ro post-treatment change scores of the SIP modules (household chores, leisure and social interactions) and the pre-to post-treatment change scores of the logically related ESM variables, namely the estimated time use, the rwo measures of PA felt during daily activities as well as the rwo measures of NA were calculated. All correlations between the SIP and the ESM positive affecr measures were expected ro be negarive, as higher SIP scores reflect poorer quality oflife. Consequently, correlarions between the SIP and the ESM negarive affect measures were expected to be posirive. The highest correlations, negative in direction, were expected to occur between the SIP modules and ESM estimated time use, as most SIP items asked specifically about the frequency of activities performed (e.g. "I am going out for entertainment less').

The correlations revealed a pattern of negative associations between the SIP scores and the ESM positive affect measures, with significant correlations found for mean PA. As predicted, measures of negative affect in daily activities were positively associated with SIP scores, and highly significant for mean NA. However, contrary to expectarions, no or low associations were found between SIP module scores and ESM estimated time use. As predicted, these associations were negative for demanding activities such as chores, social interactions and active leisure and positive for non-demanding activities such as passive leisure.

Correlations between the SIP "sleep/rest" module and the four ESM sleep measures were expected to be positive for sleep latency and number of awakenings and negative for sleep duration and quality of sleep. All correlarions were in the expected direction, except for sleep latency $(r=-.04, n)$. The correlations were low (sleep duration: $r=-.25, n s$ ) to moderave (number of awakenings: $r=.44, p \leq .05$; qualicy of sleep: $r=-.55, p \leq 01)$.

\section{DISCUSSTON}

In this sample of depressed outpatients, individuals who demonstrated the greatest clinical improvement following 6 weeks of acrive pharmacological treatment showed greater changes in daily life experience than individuals who improved less. On the SIP, a cross-sectional instrument widely used as a QoL measure, responders improved rela- 
TABLE 3. Spearman correlations berween change scores on SIP modules and ESM measures $(N=21)$.

\begin{tabular}{|c|c|c|c|c|c|}
\hline \multirow[b]{3}{*}{$\begin{array}{l}\text { Sip } \\
\text { modules }\end{array}$} & \multicolumn{5}{|c|}{ ESM metasures } \\
\hline & \multirow[b]{2}{*}{$\begin{array}{l}\text { Time spent } \\
\text { in activity }\end{array}$} & \multicolumn{2}{|c|}{ Positive mood } & \multicolumn{2}{|c|}{ Negative mood } \\
\hline & & Mean level & $\begin{array}{l}\text { \% highly } \\
\text { positiwe states }\end{array}$ & Mean level & $\begin{array}{l}\% \text { highly } \\
\text { negarive states }\end{array}$ \\
\hline Chores & -10 & -.39 & -.28 & $.55^{*}$ & .26 \\
\hline Leisure & .23 & $-.45^{*}$ & -.31 & $.69 \%$ & .40 \\
\hline Social & -.08 & $-47^{*}$ & -.37 & $.67^{* *}$ & .24 \\
\hline
\end{tabular}

" $p \leq .05, * p \leq 01$; Spearmian correllations berween sIp leisure module and ESM time spen in active leisure: -04 $(N=15, n s)$. Spearman correlarions berween SIP leisure module and ESM tine spent in passive leisure: $36(N=21, n s)$.

tive ro non-responders in the domains of household maintenance, leisure and social activities. ESM results clarify the nature of the changes in these three aspects of daily life in terms of quantitative estimates of time actually spent in these activities and accompanying mood states. With respect to time use, trearment responders increased time spent on chores and reduced time spent on passive leisure. Contrary to expectation, responders showed no significant increase in social interaction time. Across all activities except active leisure, responders experienced greater increases in average positive mood and greater decreases in average negative mood than non-responders. Furthermore, during these same activities, responders reported highly positive mood states more ofren than non-responders; the frequency of extremely negative mood states did not differ between the two groups. Finally, clinical improvement was associated with an increase in daily self-rated sleep quality, whereas differences between responders and non-responders on the SIP sleep module had failed to reach significance.

Time use patterns have been related to well-being (Juster and Stafford, 1985) and would also seem to be relevant to the concept of QoL, in that they reflect the extent to which an individual is incerested in and capable of engaging in normal daily acrivities. In contrast to physician ratings of psycho-social adjustment in various activity domains (e.g. De Lisio et al., 1986; Agostiet al., 1991), time use can be objectively defined and measured in real life. Some existing QoL questionnaires attempr to assess time use indirectly, wirh global items like 'I sit during much of the day" (SIP) or "During the past 4 weeks, have you cut down on the amount of time you spent on work or other activities?' (SF-36, Medical Outcomes Study). Studies have shown, however, that retrospecrive estimates of personal time use are highly inaccurate, even over time periods as short as the past 24 hours (Bernard et al., 1984). Reliable self-report information can only be obtained from time diaries, such as those used in survey research (Szalai et al., 1972; Robinson, 1987), or from time-sampling methods like ESM. 
To date, only a few studies (all using ESM) have systematically investigated time use in psychiatric disorders. Previous studies, like our own, suggest that rime spent in productive activities and social activities and the balance between active and passive leisure time may be particularly sensitive indicators of clinical state. For example, the within-subject changes in time use we observed following clinical improvement (increased household chore time, decreased passive leisure) are similar to patterns reported by Merrick (Merrick, 1992) in a study comparing daily life experience in currently depressed, previously depressed, and a control group of adolescents. Currently depressed youngsters spent significantly less time on average in productive activities such as schoolwork or a job than either recovered or control subjects. Furthermore, although the three groups did not differ in total leisure time (about $44 \%$ of all ESM reports), currently depressed adolescents spent dramatically more time in passive leisure activinies (watching television, reading, thinking) and less time in socialising than adolescents in the orher two groups. Similarly, in a case study of a woman being treated successfully for agoraphobia, time use patterns derived from nine separate ESM sampling periods over the course of a year showed a gradual decrease in T.V. watching (from $45 \%$ to less than $15 \%$ ), paralleled by an increase in active leisure and social acrivities (Delle Fave and Massimini, 1988). Due to the infuences of a multitude of social and demographic factors on time use, within-subject research designs can be expected to be more sensitive to clinical improvement than between-group comparisons. The fact that significant changes could be detected in our small sample of patients following only 6 weeks of trearment suggests that time use measures may be a feasible and worthwhile addition to standard assessments in clinical trials.

Interpretation of the clinical significance of the time use changes we found in improved depressed outpatients is limited by borh the short duration of the study and the lack of normarive data. It is thus unclear whether further change might have occurred with more prolonged treatment and whether post-treatment time budgets resembled those of healthy individuals. An accurate general picture of time use patterns in the larger population can be obtained from surveys. From recent Durch survey data, for example, the average percentage of total (non-sleep) time spent in household chores and passive leisure can be estimated as $23 \%$ and $21 \%$, respectively (Netherlands Central Bureau of Statistics, 1988); these figures are roughly comparable to the ESM estimates we obtained for these activities in responders post-treatment (Table 2). Differences in methods of dara collection, activity codes, and subject socio-demographic characteristics, however, make meaningful direct comparisons impossible.

Both average positive affect and the frequency of high positive affect states increased significantly in clinically improved versus unimproved subjects. PA increased during. activities that became more frequent (i.e., chores), but also during activitics that declined in frequency (passive leisure). In the case of chores, patients with the greatest 
improvements in positive affect were those most likely to show post-treatment increases in chore rime. Although the causal relarionship between changes in mood and changes in behavior cannor be determined in a naturalistic study, it seems intuitively more likely that an increase in energy, enthusiasm, and happiness (PA) would precede rather than follow a greater participation in household maintenance. Given the salience of low positive affect in the phenomenology of depression, in particular (Clark and Warson, 1988), and the relevance of both positive and negative affect to the concept of well-being, in general (Diener, 1984), current psychological models of affect should be more widely incorporated into clinical rrial and quality of life research designs.

Surprisingly, neither positive nor negative affect varied significantly in relation to the current activiry, in either responders or non-responders, pre- or post-treatment. Based on the results of borh diary and ESM studies, we had expected to find higher positive and lower negative affect during leisure activities and social interactions than during chores, at least in subjects who showed clinical improvement. Previous studies of healthy individuals report an association between activities and subjective states, ranging from self-esteem (Wells, 1988), motivation (Csikszentmihalyi and Larson, 1987), challenge and skills (Massimini et al., 1987), enjoyment (Robinson, 1977) to affect (Kubey and Csikszentmihalyi, 1990). It is possible that the absence of activity-specific mood variability in our study reflects an aspect of depression that failed to normalize after 6 weeks of treatment. Alternatively, the activity categories we used may have been too broad, or the sample size too smali, for detecting associations with mood. Future studies incorporating normal control subjects will help clarify this issue.

Daily ESM assessments of sleep were related to the SIP sleep module but were apparently more sensitive to changes associated with clinical improvement. Other SIP measures were either conceptually too difficult to relate to ESM variables (e.g. mobility), or were not relevant for a sufficient number of subjects in this outpatient sample (e.g. work). The potential advantages of ESM, in terms of greater sensitivity, over cross-sectional measures in psychiatry needs to be further examined. It should also be noted that many aspects of the ESM data, such as cognition, motivation and social context, remain to be investigated. These are areas where ESM data may eventually be able to expand our understanding of clinical improvement.

We hypothesized that improvement in a SIP life domain, that is a decrease in the SIP score, would be associated with increased time spent (during ESM sampling) in demanding activities and decreased time spent in non-demanding activities related to this domain. In addition, because many of the SIP items are phrased in terms of time use, we expected the SIP scores to correlate more highly with the ESM time use measures than with the ESM measures of affect. Although all correlations were in the expected direction, only the correlations between changes in SIP scores and changes in 
average mood measures were significant, while those between SIP scores changes and ESM time use changes were not. A possible explanarion is that the mood typically experienced during an activity is both more salient and easier to recall than the frequency with which the acriviry is performed.

In interprecing these results, it is important to note that the number of subjects in this study was small and that the standard cut-off-point used to classify responders and non-responders was relatively arbitrary as almost all patients improved. Thus, responders and non-responders were part of a continumm, rarher than two distinct groups. In addition, it must be stated that the single-blind design may have introduced biases in both clinical assessment measures (HDRS) and in clinician-rated side effects; however, no differences between the two treatment groups on these measures were found. Moreover, the main results reported here concern self-report measures, which would not be subject to this source of possible bias. Due to the nature of the study design, changes in daily life experience associated with clinical improvement can not be definitely attributed to pharmacological treatment, since a spontaneous remission may have occurred. This emphasizes the need for a placebo-controlled study to analyse the effects of pharmacological treatment on daily life experience. Finally, given the small sample size and the single-blind design, this study cannot adequately distingush the effects of different pharmacological treaments on daily life experience. We had expected that the two treatments, because of the differences in described side effects profiles (Nierenberg and Cole, 1991; Tollefson, 1991; Kasper er al., 1992), might be associated with different measures of daily life experience. However, the side effects appeared to have largely disappeared by Week 6. Future studies should include ESM sampling periods at an earlier stage in the treatment in order to better address the effects of anridepressant side effects on patients' daily life experience.

Although cross - sectional measures can detect QoL changes in life domains, the current evidence suggests that a method such as the ESM is required to describe trearment impact in terms of daily life experience. Based on acceprable levels of compliance and procedure effects on mood and behaviour, the current study has shown that depressed ourpatients are willing and able to use ESM. While parients were (equally) able to comply both pre-and post-treatment, the finding that responders decreased the response time significantly post-treatment may reflect improvement in concentration or cognitive performance in this subgroup. Although the scope of this paper has been essentially limited to the description of changes in daily life experience associated with clinical improvement in those life domains that show significant changes on the SIP, it has shown that ESM is also capable of revealing subtle changes in daily life experience that are not picked up by a cross-sectional measure such as the SIP. 


\section{REFERENCES}

Agosti, V., Stewart, J. W., Quitkin, F. M., 1991. Life satisfaction and psychosocial functioning in chronic depression: effect of acute treatment with antidepressants. Journal of Affeccive Disorders $23(1), 35-41$.

American Psychiatric Association, 1987. Diagnostic and Statistical Manual of Mental Disorders, 3rd ed.

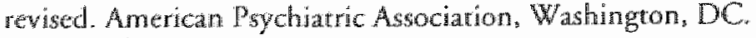

Bergner, M., Bobliati, R. A., Carter, W. B., Gilson, B. S., 1981. The Sickness Impace Profille: development and final revision of a health status measure. Med Care 19(8), 787-805.

Bernard, H. R, Killworth, P., Kronenfeld, D. Sailer, L., 1984. The problem of informant accuracy: the validity of retrospective data. Annual Review of Anthropology 13,495-517.

Broadhead, W. E., Blazer, D. G. George, L. K., Tse, C. K., 1990. Depression, disabiliry days, and days lost from work in a prospective epidemiologic survey. J. Am. Med. Ass. 264(19), 2524-2528.

Clark, L. A., Watson, D., 1988. Mood and the mundane: relations batween daily life events and self-reported mood. Journal of Personalicy and Social Psychology 54(2), 296-308.

Csilkszencmihalyi, M., Larson, R., 1987. Validicy and reliability of the Experience Sampling Method. J Nerv Ment Dis 175(9), 526-537.

De Lisio, G. Marenmani, I., Pentgi, G., Cassano, G. B., Deltiro, J., Akiskal, H. S., 1986. Impairment of work and leisure in depressed outparients: a preliminary communication. J Affect Disord 10,79-84.

Delle Fave, A. Massimini, F, 1988. Modernizarion and the changing contexts of flow in work and leisure. In: Csikszentmihalyi, M., Csikszentmihalyi, II, (Eds.), Oprimal experience: psychologicat studies of flow in consciousness. Cambridge University Press, New-York, pp. 193-213.

deVries, M. W., 1987. Investigating mental disorders in their natural setrings. Journal of Nervots and Mental Diserse $175(9), 509-513$.

deV ries, $M$. 1992. The experience of psychopachology in natural setcings: introduction and illustration of variables. In: deVries, M. W. (Ed.). The Experience of Psychopathology: Investigaring Mental Disorders in Their Natural Settings. Cambridge University Press, Cambridge, pp. 3-26.

Diener, E, 1984. Subjective well-being. Psychological Bulletin 95(3), 542-575.

Endicotx, J., Nee, J., Harrison, W., Blumenthal, R., 1993. Quality of Life Enjoyment and Satisfacrion Questionnaire: a new measure. Psychopharmacology Bulletin 29(2), 321-326.

Gotlib, I. IH., 1990. An interpersonal systems approach to the concepiualization and trearment of depression. In: Ingram, R. E. (Ed.), Contemporary Psychological Approaches to Depression. Plenum Press, Now-York, pp. 137-154.

Gay. W., 1976. ECDEU Assessmenr Manual for Psychophamacology. US Deparment of Healrh, Education and Welare, Rockville, MD, pp. 59-70.

Hamiton, M., 1960. A rating scalle for depression. J Neurol Neurosurg Psychiat 23, 56-62

Hammen, C., 1990. Vutherability to depression: personat, situational and family aspects. In: Ingram, R. E. (Ed.). Contempratry psychological approaches to depiession. Plenum Press, New-York, pp. 59-70.

Hare. E. 1991. The history of "Nervous Disorders" from 1600 to 1840 and a comparison with modem views. Br. J. Psychiatr. 159, 37-45.

Juster, F. T, Srafford, F. P., 1985. Time, goods and well-being Institute for Social Research, The University of Michigan. Ann Arbor.

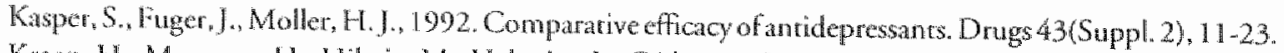

Kram, H., Meertens, H., Hilwig, M., Volovics, L., Dijkman-Caes, C. L. M., Portegijs, P., 1992. Selecring measures, diagnostic watidiry and scaling in the study of depression. In: deVries, M. W. (Ed), The Experience of Psychopathology: Investigating Mental Disorders in Their Natural Settings. Cambridge Universiry Press, Cambridge. pp. $324-338$

Kubey, R., Csikszentmihalyi, M. 1990. Television and the Quality of Life how viewing shapes everyday experience. Lawrence Erlbaum Associates, Publishers, Hilisdale, New Jersey. 
Massimini, F., Csilkszentmihalyi, M., Carli, M., 1987. The monitoring of oprimal experience A tool for psychiatric rehabilitation. IN Nerv Ment Dis $175(9), 545-9$.

McLeod, I. D., "Turnbull, I E. Kesster, R. C., J.M., A., 1990. Sources of discrepancy in the comparison of a lay-administered diagnostic instrument with clinical diagnosis. Psychiatry Research 31 (2), 145-159.

Merrick, W. A., 1992. Dysphoric moods in depressed and non-depressed adolescents. In: deVries, M. W. (Ed.), The Experience of Psychopathology: Invesrigating Mental Disorders in Their Natural Sertings. Cambridge University Press, Cambridge, pp. 148-156.

Mintz, J., Mintz, L. I., Arruda, M. J., Hwang, S. S., 1992. Trearments of depression and the functional capacity to work. Arch. Gen. Psychiatry 49(10), $761-768$.

Murphy, G. E., Simons, A. D., Wetzel, R. C., 1985. Plasma nortriptyline and clinical response in depression. J. Aff. Disorders 9, 123-129.

Netherlands Central Bureau of Staristics. (1988). A Survey on Time Use in The Netherlands. [In Dutch; wirh English summary.] .

Nierenberg, A. A., Cole, J. O., 1991. Anridepressant adwerse drug reactions. J. Clin. Psychiatry $52(6$ (Suppl.)), 40-47.

Paykel, E. S., Weissman, M. M., Prusoff, B. A., 1978. Social maladjuscment and severiry of depression. Comprehensive Psychiatry 19(2), 121-128.

Read, J. L., Quinn, R. J., Hoefer. M. A., 1987. Measuring overall health; an evaluation of three important approaches. J. Chron. Dis. 40(Suppl. 1), 75-215.

Revicki. D. A., Murray, M., 1994. Assessing health-related quality of life outcomes of drug treatments for psychiarric disorders. CNS Drugs 1(6), 465-476.

Revicki, D. A., Tumer, R., Brown, R., Martindale, J. J., 1992. Reliability and validiry of a health-related quality of life battery for evaluating outpatient antidepressant treatment. Quality of Life Research 1(4), $257-266$.

Robinson, J., 1977. How Americans use rime: a social-psychological analysis of everyday behaviour. Praeger, New York.

Robinson, If P.. 1987. Microbehavioral approaches to monitoring human experience. I Nerv Ment Dis $175,514-518$.

Rost, K., Sinith, G. R., Burnman, M. A., Burns, B. J., 1992. Measuring the outcomes of care for mental health problems: the case of depressive disorders. Med. Care 30(Suppl. 5), \$266-\$273.

Snairth, P., 1993. Anhedonia: a neglected symptom of psychoparhology. Psychological medicine 23,957-966.

Stoker, M. J. Dunbar, G. C., Beamont, G., 1992. The SmirlaKline Beecham "Quality of Life" scales a validation and reliabilicy study in patients with affective disorder. Quality of Life Research 1 (6), 385-395.

Szalai, A., Conwerse, P., Feldheim, P.. el al., 1972. The Use of Time. Mouton, The Hague.

Tellegen, A. 1985. Strucrures of mood and personality and their relevance to assessing anxiety, with an emphasis on self-report. In: Tuma, A. H., Maser, J. D. (Eds.), Anxiery and the anxiery disorders. Erilbaum, Hillsdale, NJ, pp. $681-706$.

Tollefson. G. D., 1991. Antidepressant treatment and side effect considerations. I. Clin. Psychiatry 5215 (Suppl.), 4-13.

Tuynman-Qua, H., Jonghe de, F. Mckenna, S., Hunt, S., 1992. Schaal woor de mering van de kwaliteir van her leven bij depressie. Bero Publikaties, Houren.

Tweed, D. L., 1993. Depression-related impaiment: esrimating concurrent and lingeringeffects. Psychom logical Medicine 23(2), 373-386.

Verbrugge, L. M., 1980. Health Diaries. Medical Care 18(1), 73-95.

Warson, D., Clark, L. A. Cary, G., 1988. Positive and negative affectivity and their relation to anxiety and depressive disorders. Journal of Abnormal Psychology $97(3), 346-353$.

Watson, D., Tellegen, A., 1985. Toward a consexsual structure of mood. Psychol Bull 98, 219-235.

Wells, A. J., 1988. Variations in mathers' self-esteem in daily life. J Pers Soe Psychol 55 (4), 661-668.

Whecler, L., Reis, H. T., 1991. Self-recording of everyday life cverts: origins, types, and uses. Joumal of Personality 59(3), 339-354. 

PART IIII

MAIN STUDY (STUDY 2)

CHAPTER 4

Using ESM to investigate QoL in clinical trials of antidepressants: A methodological overview

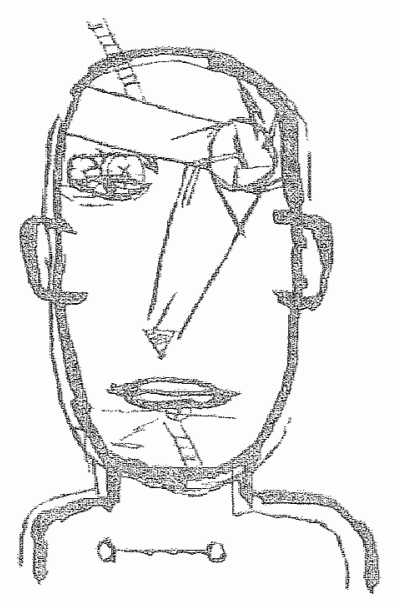




\section{Using ESM to investigate QoL in clinical trials of antidepressants: A methodological overview}

Study I data showed that, with the exception of two subjects (somewhat older and more depressed than the rest), compliance with ESM was high, and the ESM procedure had little effect on patients ${ }^{2}$ daily experience during either of the two sampling periods (see Chapter 3). In addition, results showed that positiwe mood increased, negarive mood decreased, and patterns of time use changed following successful treatment with fluvoxamine or amitriptyline. However, due to the nature of the study design, these changes in daily life experiences could not be definitely atributed to pharmacological treatment, since a spontaneous remission or placebo effects could have occurred. Therefore, Study 2 was initiated with a view to build on the experience and to resolve many of the limitations of Study 1 . In the first section the study objectives are described and the differences in design with respect to Study I are highlighted. Both the measures and the procedure used in Study 2 are described in a second section, again highlighting the changes made on the basis of the experience obtained in the previous study. Finally, results concerning the use of ESM to investigate QOL in clinical trials of antidepressants are presented.

\section{STUDY OBJECTIVES AND DESIGN}

Study 2 investigated the effects of depression and antidepressant treatment (imipramine) on determinants and variability of QoL in daly life, as assessed with ESM. The focus in the current chapter is on the feasibility and utility of ESM in achieving this aim. Two objectives are defined, as follows:

- To assess the feasibility of using ESM in clinical trials in depression by invesrigating how well depressed patients comply with repeated sampling periods over 18 weels of treament.

- To investigate the utiliry of ESM in clinical trials in depression. In order to be useful in such a context, ESM must yield valid and reliable information about QoL in daily life of depressed parients and about daily life effects of antidepressant treatment. In addition, ESM should be more sensitive to treatment effects than traditional retrospective questionnaires. Sensitivity can be investigated in two ways:

- Quantitatively. By how much can ESM, through repeated measurements, increase the statistical power, and thereby reduce the number of subjects required for detecting treatment eflects? 
- Qualitatively: Can ESM deliver new insights about QoL in daily life of depressed patients and daily life effects of antidepressant treatment not obtainable via conventional research methods? (This question is largely addressed in Chapters 5, 6 and 7 , and is discussed in Chapter 8 . It will not be considered in the current chapter).

In contrast to Study 1, the current study was double-blind and placebo-controlled, so that observed changes in daily life experiences could be attributed with more confidence to the active drug. In addition, time sampling was done more extensively to better assess the impact of side effects on daily life experiences as well as conrinued improvement of QoL during exrended treatment. Finally, a control group was included in this study so that the extent to which daily life experiences were normalized after trearment could be assessed.

\section{METHODS}

\section{Subjects}

In order to be feasible and useful in the context of clinical trials, ESM should be fully integrated in the logistics surrounding the conduct of trials. Hence, in addition to the usual selection criteria used for the selection of participating sites (i.e., experience with the conduct of depression trials), two aspects were kept in mind: (1) the GP had to be part of a local research network, and (2) location had to be geographically near Maastricht. The first aspect was necessary in order to ensure that the research nurse, who was employed by the research network and trained in ESM, could conduct the briefing and debriefing sessions that were required prior and at the end of each sampling period. The second aspect was regarded as useful in the sense that technical support for the programmed watches was available in Maastricht. Moreover, the timing of the different sampling periods were chosen in such a way that patients were not required to have more GP visits than would usually be the case in such a depression trial. Thus, briefing and debriefing sessions took place at scheduled GP wisits.

\section{Depressed patients}

Participating patients met criteria for primary moderate or severe Major Depressive Disorder according to DSM-III-R (American Psychiatric Association, 1987), single or recurrent episode, as assessed by the GPs. At the baseline visit, depressed patients had to score 18 or higher on the 17-item version of the HDRS (Hamilton, 1960) and 4 on rhe CGI severity of illness scale (Guy, 1976). Patients were randomized if they had completed a minimum of 30 ESM self-reports - thus $50 \%$ of the maximum possible - during the baseline (pre-treatment) sampling period. 


\section{Healthy controls}

On the basis of the distribution in socio-demographic characteristics (sex, age, work status, and living circumstances) of each block of four depressed patients included in the study, two healthy controls were recruited. This procedure allowed for a control group that was comparable in socio-demographics to the patient group and comparable in size to each of the two treatment groups. Healthy controls were selected by the same GPs as the patient group, with later exclusion of any with either a current psychiatric disorder or a lifetime history of major depressive disorder, as determined with the Diagnostic Interview Schedule (Dingemans et al., 1985).

\section{Measures}

\section{Retrospective measures}

Most conventional questionnaires are global and retrospective, in that subjects are asked usually to summarize their experiences or feelings over some period of time, for example the past week or month. The retrospective measures used in Study 2 were chosen on the basis of their conceptual relationship with ESM derived measures. All retrospective measures had a one-week timeframe. In instances where no adequate measure was available, retrospective measures were specifically designed for this study and, thus, no prior data were availlable on their sensitivity. Measures are listed in Table 1a.

Subjects were asked to rate the quality of their life in the previous week on a visual analogue scale ( $Q 0 L V A S$ ), a $100-\mathrm{mm}$ line with endpoints the worst quality of life you can imagine for yourself and 'the best qualicy of life you can imagine for yourself' (Andrews and McKennell, 1980). In addition, patients were asked to complete the Durch version of the Positive Affect and Negative Affect Schedule (PANAS, Peeters et al., 1996), containing two scales, Positive Affect $(P A)$ and Negative Affect $(N A)$ of 10 irems each. The $P A$ scale reflects one's level of pleasurable engagement with the environment, whereas the NA scale is a general factor of subjective distress (Watson et al., 1988). All items are scored on a 5-point Likert-type scales ranging from (1) "very slightly or not at all' to (5) 'very much'. Furthermore, based on previous imipramine studies (e.g., Cassano et al., 1994), a list of 10 of the most frequently encountered side effecrs of imipramine was generated (see Table 1a). For each complaint, subjects were asked ro indicare how freguently it had occurred in the previous week ( 1 'not at all' to 5 "several times a day') and, if it had occurred, how troublesome it was (1 'not at all' to 5 'very'). Finally, patients rated the frequency and enjoyment they experienced in performing different rype of activities. All activities reported in Study 1 (see Chapter 3) were ranked per sampling period according to the average frequency with which they were reported across individuals. The 15 most frequently reported activities were the same in the rwo periods, so that these were chosen to form a list of activities for the current study (see Table la). Regarding the previous week, subjects were asked how often they had 
TABLE 1. Description of the measures used.

\section{A. Retrospective measures - Self-report}

QOL WAS

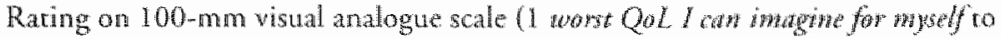
100 bes QoL I can imagine for myself

PANAS

Selfrating of affect on two dimensions:

Posirive Affect = PA (athonthe, interested, alent exctied, enthusiastic, inspired, proud, determined, strong, antite)

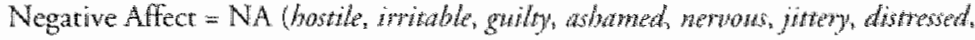
apses, afratd, sacared)

All items are scored on 5 -point scales ( 1 wot at all to 5 very)

Complaints List of 10 most frequent side effects of imipramine: headude, dizzines, dry mow h, nausea, heart palpitations, drowsines, wimary problems, blanred wisions, suedang, comstipation

Severity: 5-point scale ( 1 not at all to 5 yery)

Frequency: 5-point scale (1 mot at all to 5 several times at doy?

Acrivities List of 15 most frequenty occurring accivities in daily life: bowsehold dowes,

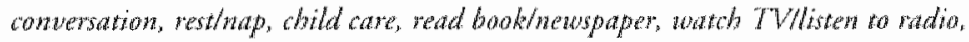

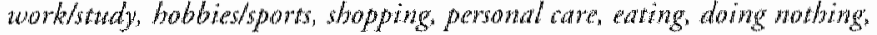
wisthrecente wisit, taking at wowk, going out

Enjoyment: 5-point scale (I not at all ro 5 wery muth)

freguency: 5-point scale ( 1 not at all co 5 several twhes a day)

\section{B. ESM beep measures}

mQol.

$\mathrm{PA}$

NA

Complaints

Curitent acriviry

Disturbance

Valid self-report
'In general, how is it going with you right now?' (rated -3 very bad to 3 very good) Mean of items energetic, cheerful, satisfed, alert, calm, chthwsiastic, strong, and hatppy (rated 1 not at all to 7 extrexnely)

Mean of items hostile, depressed, tense, lowely, anxiows, insecure, grilty, hamied, and iwritable (rated 1 not at all to 7 extrewnely)

Five 7-point Likert scales for beadache, dizziness, dy mouth, droveriness, and nansea (rated I not at all to 7 extremety)

Severity: mean rating on the five scales

Frequepary, percentage of ESM records with mean sewerity $\geq 2$

Subject's writen response coded and collapsed into 8 categorics:

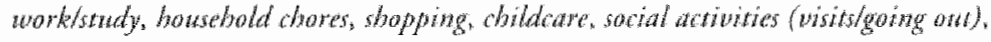

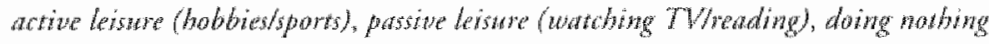
Enjoyment. "How much are you enjoying this acrivity?" (1 nat at all to 7 extremely)

Frequency: percentage of ESM records in which an activity was reported Level of disturbance by the 'beep' (I not at all to 7 extremely) Self-report with response time berween $(-5 ; 15)$ mintutes 
TABLE 1. Contrinued.

C. ESM day measures Missing self-report Representaviveness

Method reactiwity
Self-reporr which was expected but not filled in.

Self-rating on 7 -point Liker scale (1 wor at all to 7 extremely) of how usual each day was in terms of:

mood

thoughts

activities

Self-rating on 7 -point Likert scale (1 not at all to 7 extremely) of possible effects the sampling might have had on:

mood

thoughts

activinies

\section{ESM debriefing measures}

Disturbance

Subject's response ro categorical question (yes/no) on disturbance to the sampling

Difficultics Subject's response to categorical question (yes/no) on difficulites encountered in filling out the self-report forms

Representativeness ${ }^{\text {b }}$ Subject's response to categorical question (yes/no) on how ustual the sampling period was in rerms of:

mood

thoughts

activities

Method reactivity Subjecr"s response to categorical question (yes/no) on possible effects the sampling might have had on:

mood

thonglits

attivities

"See parallet with LSM debrichong measures: "See paralle! with ESM day measures.

performed each activity ( 1 "not at all' to 5 'several times a day') and, if at all, how much they had enjoyed engaging in it ( 1 'not at all' to 5 'very much').

\section{ESM measures}

ESM self-reports collected at each signal consisted of 48 items, of which 36 were Likert scales (see Appendix 2.a for the original Dutch version, and see Appendix 2.b for the English ranslation). In comparison to the self-reports used in Study 1, two significant modificarions were made. First, a general question about momentary QoL ('In general, how is it going with you right now?') was added at the beginning of each self-report. This inclusion was required in order to study variability of QoL in dailly life and to identify factors that influence momentary QoL. Second, a module on complaints was included to betrer rack potenrial side effecrs of treatment. Based on the list of complaints described under 'Retrospecrive measures', the five most frequently associated 
with imipramine (Cassano et al, 1994) that were most likely to fluctuate from moment to moment (i.e., headache, dizziness, dry mouth, nausea, and drowsiness) were identified.

Beep level measures. (see Table 1 b) Based on the time recorded when the self-report form was completed and the programmed time of the watch, a valid self-reportwas defined as any with a response time of minimally -5 to maximally 15 minutes (Delespaul, 1995). The level of disturbance generared by the ESM procedure was reported on a 7-point Likert scale at the end of each self-report. At each signal, subjects also rared momentary QoL ( $m$ QoL, see above), current mood, physical complaints, and enjoyment of activities on 7-point Likert scales. Mood items were combined into separate scales for positive and negative affective states $(P A, \alpha=0.95 ; N A, \alpha=0.92$, for more details see Chapter 5). Physical complaints included five common side effects of imipramine, mentioned above. Subjects also provided a brief description of their current activity, which was later coded into eight categories (i.e., doing nothing, work or study, household chores, shopping, childcare, active leisure, passive leisure, and social activities).

Day level measures. (see Table 1c) Several questions were asked at the end of each sampled day. To assess reasons for missing self-reports, subjects were asked to report all times during the day at which they had switched off the watch and the reason for doing so (e.g. personal, social). In addition, subjects were asked to rate on 7-point scales how usual (representative) their day had been, and whether the sampling had had any effects on their mood, thoughts, or activities during the day.

Debriefing meastures. (see Table $1 \mathrm{~d}$ ) Ar the end of each sampling period a debriefing session was held. Subjects were asked to indicate whether they experienced any disturbance from the sampling or wherher they encountered any difficulties in filling out the self-report forms. Subjects also reported bou representative their sampled period was in terms of mood, thoughts, and activities in daily life, and whether they felt that the sampling had any effects on their mond, thoughts, and activities.

\section{Procedure}

Following one week with no treatment (baseline), patients were randomized to either $50 \mathrm{mg}$ imipramine or placebo. Imipramine was tapered on in the course of a week to $200 \mathrm{mg}$ a day, in a twice-daily dosing regimen, and kept at this dose for the remainder of the study. In case intolerance of the drug occurred, the GP could decrease dose to a minimum of $100 \mathrm{mg}$ a day. Continuing intolerance led to withdrawal from the study. At the end of 6 weeks of treatment, a decision was taken, based upon the judgement of the GP and the wish of the patient, as to further prolongation of double-blind treatment for another 12 weeks (see Figure 1). Patients were scheduled to visit the physicians at regu- 
Depresed patients

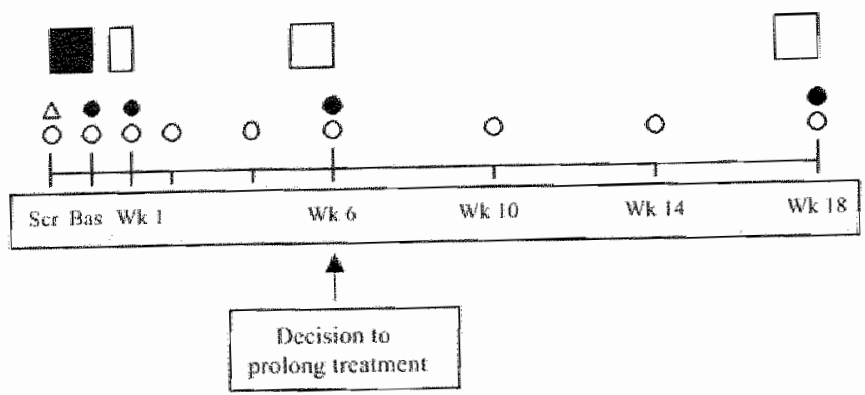

Healthy controls

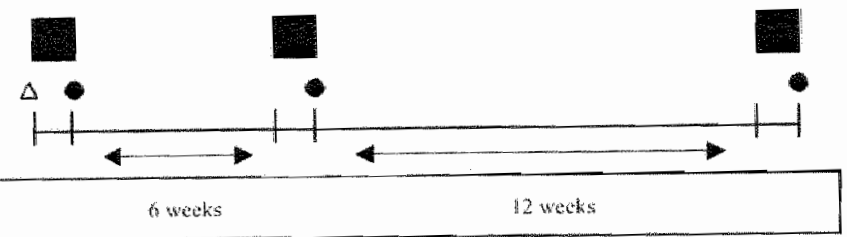

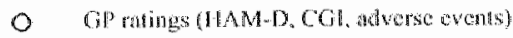

DSM sampling withou trastrom

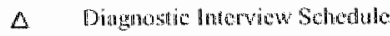

ESM sampling during double-blind itcatsment (imiprentus of placebo)

PCORE ? .SM sampling periods during Study 2 .

Lar intervals (Screening, Baseline, and weeks 1,2,4, and 6; if trearment was extended, also weeks 10, 14, and 18) for assessment of clinical symptoms (using HDRS and CGI) and potencial adverse events.

As in Study 1, patients were sampled for 6 days pre-treatment and 6 days in the $6^{\mathrm{th}}$ week of treatment. In the current study, parients were also asked to fill out ESM forms for 3 days at the end of the first week of double-blind treatment. Furthermore, patients who decided to prolong trearment were sampled for another 6 days in the $18^{\text {th }}$ week of treatment. Questionnaires (QOL VAS, PANAS, complaints, activities, and ESM debriefing) were completed at the end of each sampling period. 
Healthy controls were asked to fill out ESM self-report forms for 18 days in total ( 3 periods of 6 days). The first rwo periods of 6 days were separated by 6 weeks, and the last sampling period took place 12 weeks after the second sampling period (see Figure 1). Questionnaires were completed, as with the patients, ar the end of each ESM period.

\title{
Statistical tests
}

Within-group changes over time were tested with paired t-tests of wirh analysis of variance (ANOVA) with repeated measures. Differences between groups (ESM compliant versus non-compliant patients, depressed versus control subjects) were tested with $t$-tests for two samples, using a Satterthwaite approximation for the degrees of freedom, and $\chi^{2}$-rests for the categorical variables. For the relationships berween ESM aggregated measures and the conceptually related retrospective measures and the rest-retest reliability scores, Pearson correlations were calculated. Cronbach's alpha was calculated as a measure of split-half reliability. All statistical tests were two-tailed. An alpha level of .05 was used.

\author{
RESULTS
}

\section{Feasibility of applying ESM in clinical trials in depression}

Although a clinical trial can be designed and set-up in such a way as to fully integrare ESM, the feasibility of using ESM in clinical trials in depression can still be jeopardized by patients not complying with the method.

\section{Compliance}

According to the sampling schedule shown in Figure 1, depressed subjects who completed 18 weeks of trearment could have filled in a maximum of 210 ESM self-report forms (beeps), and healthy controls a maximum of 180 beeps. Based on previous experience (Delespaul, 1995), an ESM self-report was considered 'valid' if it was completed in less than 15 minutes after the signal. As subjects can use a different time reference (e.g., a kitchen clock) than the programmed watch ro report the time at which the self-report is complered, reports filled in up to 5 minutes before the signal were also considered valid (see also Delespaul, 1995). Of the 83 depressed patients screened, nine subjects had protocol deviations and were excluded from further analyses. Of the 29 control subjects screened, six were found to have had depression (lifetime) or another current psychiatric condition and were therefore excluded from further analyses. The remaining 97 subjects completed 4.145 valid reports in the first sampling period within the acceptable time-window, which is $72 \%$ of the maximum possible reports. This percentage is com- 
parable to what has previously been found in ESM studies using the same time-window (73\% in blue-collar workers, see Csikszentmihalyi and Larson, 1987; e.g., 74\% in anxiety disorders, see Dijkman-Caes, 1993).

\section{ESM non-compliant subjects}

Prospectively, a minimum of 30 valid beeps ( $50 \%$ of total expected) in the first sampling period was set as a criterion for inclusion in the analysis. Eleven depressed subjects and one control (14.9\% versus $4.4 \%$ of the participants in the respective groups, $\chi^{2}=$ $1.8, n 5)$ did not meet this requirement. ESM non-compliance in the depressed group was studied in three ways: (1) did non-compliant subjects express more disturbance or difficulties with ESM than complianr subjects? (2) did non-compliant subjects differ from compliant subjects in socio-demographic characteristics?, and (3) were non-compliant subjects more likely to be non-compliant with ESM in subsequent sampling periods than compliant subjects?

At the debriefing, a similar number of compliant and non-compliant subjects reported disturbance from ESM and difficulty in completing the self-reports. Average ratings of disturbance across self-reports were also similar for the two groups.

As noted in Chapter 2, more severe illness may prevent adequate compliance with ESM. The eleven depressed subjects who did not comply adequately with ESM in Study 2 reported greater depressive symptomatology, were younger, and were more likely to be living allone than patients with adequate ESM data (see Chapter 5).

As expecred, non-compliant subjects in the first sampling period were more likely than compliant subjects to deliver insufficient ESM dara in subsequent sampling periods (of the non-compliant subjects who participated in a second sampling week, $50 \%$ remained non-compliant versus $1.7 \%$ of compliant subjects; of the non-compliant subjects who participated in a third sampling week, $60 \%$ remained non-compliant versus $16.3 \%$ of compliant subjects; and all non-compliant subjects who participared in a fourth sampling week remained non-compliant versus $14.3 \%$ in the fourth sampling week; all $p$ 's <.05).

In summary, in comparison to subjects with adequate ESM data, non-compliant subjects are more likely to be younger and living alone, to report greater depressive symptomatology, and to be non-compliant in subsequent sampling periods.

\section{Completion rates}

Across all sampling periods, $75 \%$ of self-reports from compliant subjects were valid (range: $70.1 \%-77.9 \%$, see Table 2). About two-thirds of all ESM reports were completed within 5 minutes. Unexpectedly, compared to the imipramine group, the placebo group completed a greater percentage of reports in less than 1 minute in the first sampling period $(t=-2.7, d f=61, p<.01)$ and kept this tendency in subsequent sampling periods $(p<s<16$, see Table 2$)$. In spite of randomization, patients in the placebo 
TABLE 2. Mean \% of valid, out of valid time range, and missing responses for depressed and control groups.

\begin{tabular}{|c|c|c|c|c|c|c|c|}
\hline & \multicolumn{4}{|c|}{ Cumulative \% walid responses within } & \multirow[b]{2}{*}{$\begin{array}{l}\text { Out of } \\
\text { rime } \\
\text { range }\end{array}$} & \multirow[b]{2}{*}{ Missing } & \multirow[b]{2}{*}{$\begin{array}{l}\text { Number of } \\
\text { programtmed } \\
\text { reporrs }\end{array}$} \\
\hline & $1 \min ^{3}$ & $5 \mathrm{~min}$ & $10 \mathrm{~min}$ & $15 \mathrm{~min}$ & & & \\
\hline \multicolumn{8}{|l|}{ Deprewed } \\
\hline Baseline $^{\text {b }}(N=63)$ & $26.9 \%$ & $65.5 \%$ & $75.2 \%$ & $77.6 \%$ & $4.1 \%$ & $18.3 \%$ & $3790^{\circ}$ \\
\hline \multicolumn{8}{|l|}{ Weck $1 \mathrm{~d}$} \\
\hline $1 \operatorname{mic}(N=29)$ & $27.1 \%$ & $66.3 \%$ & $75.4 \%$ & $77.5 \%$ & $5.70 \%$ & $16.8 \%$ & 870 \\
\hline $\mathrm{Pl}_{2}(N=30)$ & $38.1 \%$ & $70.3 \%$ & $76.3 \%$ & $77.4 \%$ & $3.1 \%$ & $19.4 \%$ & 900 \\
\hline \multicolumn{8}{|l|}{ Week $6^{\text {l }}$} \\
\hline $\operatorname{Imi}(N=23)$ & $28.0 \%$ & $59.1 \%$ & $68.0 \%$ & $71.3 \%$ & $8.6 \%$ & $20.1 \%$ & 1380 \\
\hline $\operatorname{Pla}(N=26)$ & $39.6 \%$ & $65.4 \%$ & $68.9 \%$ & $70.1 \%$ & $3.9 \%$ & $26.0 \%$ & 1560 \\
\hline \multicolumn{8}{|l|}{ Week $18^{b}$} \\
\hline $\operatorname{Imin}(N=17)$ & $24.2 \%$ & $56.2 \%$ & $66.7 \%$ & $70.2 \%$ & $8.1 \%$ & $21.7 \%$ & 1020 \\
\hline $\operatorname{Pla}(N=11)$ & $45.8 \%$ & $70.3 \%$ & $72.9 \%$ & $74.4 \%$ & $5.2 \%$ & $20.5 \%$ & 660 \\
\hline \multicolumn{8}{|l|}{ Controls } \\
\hline Baseline $^{b}(N=22)$ & $41.3 \%$ & $74.4 \%$ & $77.0 \%$ & $77.9 \%$ & $3.9 \%$ & $18.2 \%$ & 1320 \\
\hline Week $6^{\mathrm{b}}(N=21)$ & $38.3 \%$ & $70.6 \%$ & $72.9 \%$ & $73.5 \%$ & $6.7 \%$ & $19.8 \%$ & 1260 \\
\hline Week $18^{b}(N=13)$ & $40.5 \%$ & $72.8 \%$ & $74.5 \%$ & $75.6 \%$ & $8.7 \%$ & $15.6 \%$ & 780 \\
\hline TOTAI NUMBERS & & & & 10,138 & 735 & 2,667 & 13,540 \\
\hline
\end{tabular}

ancluding responses filled in up to 5 minutes before the signal; "Sanpling period of 6 days; ${ }^{\circ}$ One parient was sampled

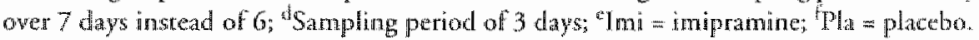

group were faster than parients in the imipramine group in completing ESM self-reports even though both groups had equal percentages of yalid reports. Completion rates were furrher investigated by: (1) time of day, (2) day of the week, and (3) day within the sampling period. As there were no significant differences between eirher groups or sampling periods, all valid beeps were combined in these analyses.

As found with other ESM studies (e.g., Delespaul, 1995), more than two-thirds of the beeps were valid at all diumal sampling times, except for the first beep (see Figure 2). Significant lower numbers of valid reports were found for the first beep of the day as compared to the orher beeps ( $F=45.9, p<.001)$. Seventy-four percent of missing first beeps of the day could be related to the fact that subjecrs were still asleep. 


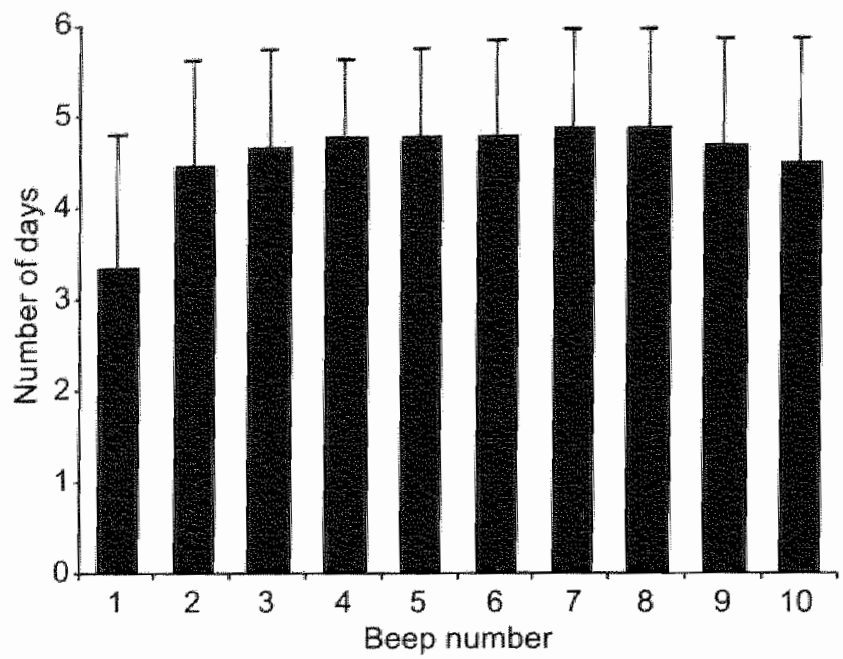

FIGURE 2. Number of wallid. ESM responses by cime of the day. Relationship between beep number and time of the day: $\mathrm{I}=7: 30-9: 00 \mathrm{am}, 2=9 ; 000-10: 30 \mathrm{am}$, $3=10: 30-12: 00 \mathrm{am}, 4=12: 00-1: 30 \mathrm{pm}, 5=1: 30 \mathrm{~m}, 3: 00 \mathrm{pm}, 6=3: 00-4: 30 \mathrm{pm}$, $7=4: 30-6: 00 \mathrm{pm}, 8=6: 00-7: 30 \mathrm{pm}, 9=7: 30-9: 00 \mathrm{pm}, 10=9: 00-10: 30 \mathrm{pm}$.

Analyses done over the days of the week showed that subjects (depressed and controls alike) completed fewer valid responses in the weekend compared to weekdays $(F=7.7$, $p<.01$ ) (see Figure 3). In the weekend, more than half of all missing responses could be related to the fact that subjects were asleep. These results are in line with previous ESM studies in anxiety disorders (Dijkman-Caes, 1993) and white-collar workers (van Eck, 1996).

The percentage of valid responses on different research days did not show much variation (see Figure 4). As with other ESM studies (Dijkman-Caes, 1993; Delespaul, 1995; van Eck, 1996), there was no significant decay in response frequencies over the six days sampled $(F=0.6, n s)$.

In sumnary, $75 \%$ of expected reports from compliant subjects were valid. Most missing responses occurred at the beginning of each day (i.e. first beep of the day, between $7: 30$ and 9:00 a,m.), and in the weekends.

\section{Reasons for missing responses}

At the end of the day, subjects could indicate time periods during which the warch was turned off and the reasons. Of the 13,540 programmed beeps, $19.7 \%(2,667)$ of the responses were missing. The most common reason was that subjects were still asleep or 


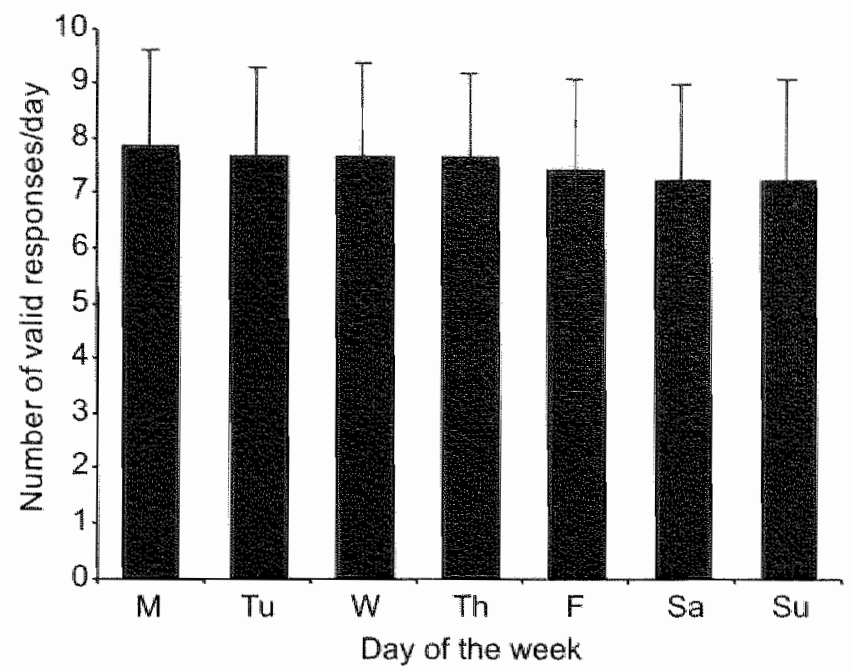

FIGURE 3. Number of valid ESM responses by day of the wed.

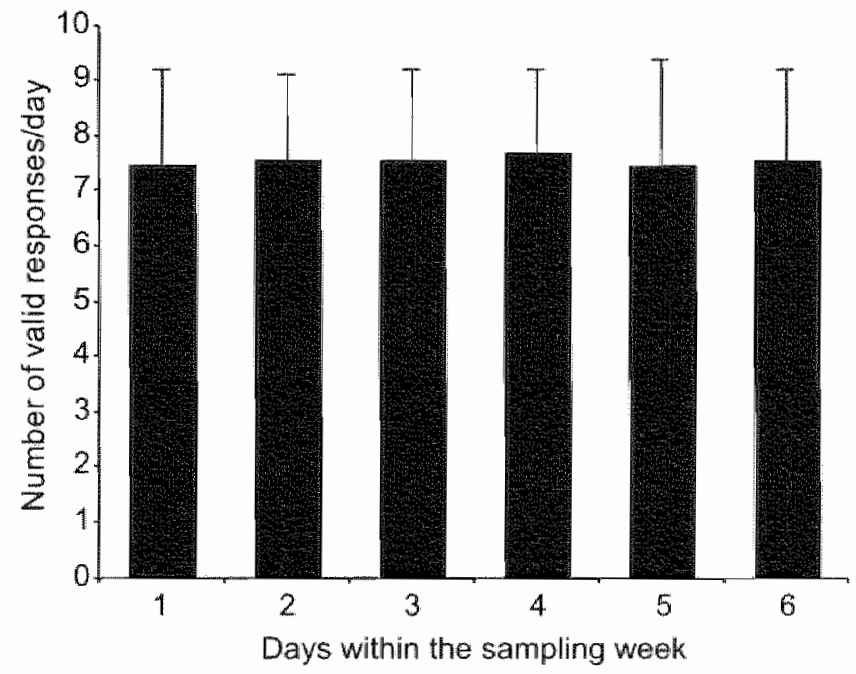

FIGURE 4. Number of walid ESM responses by research day within the sampling week. 
had already gone to bed. Other reasons were of social, personal, or technical nature. For $34 \%$ of missing responses, no reason was specified.

\section{Method chatacteristics}

\section{Method acceptability}

The method acceptability was investigated in the following ways: (1) did depressed parients have more difficulties with ESM self-reports than controls?, (2) did depressed patients express more disturbance from ESM than controls?, (3) did those depressed patients who experienced the highest levels of difficulties, also express the highest levels of disturbance from ESM?, and (4) did depressed subjects who participated in all sampling periods experience less difficulty and disturbance from ESM in the first sampling period than those who did not; in other words, could initial difficulty or disturbance with ESM be a reason for nor completing all subsequent sampling periods?

Across all sampling periods, depressed subjects required on average 1 minute more than conrrols to fill in the self-report form $(2.6 \pm 2.1$ versus $1.6 \pm 1.4, F=3.7, p=.06)$. One would therefore expecr depressed patients to express more difficulties in completing the self-report forms than controls. Differences between the two groups were found in the first sampling period only ( $34.9 \%$ of depressed versus $9.1 \%$ of controls reported difficulties, $\chi^{2}=5.4, p<.05$ ).

At the end of each ESM report, subjects were asked how much they had been disturbed by the interruption of the beep. Results showed that depressed subjects had a tendency, al though not statistically significant, to report more disturbance than heal thy controls across all sampling periods $(2.5 \pm 1.5$ versus $1.7 \pm 1.0$ respectively on a 7 -point scale, $F=2.6, p=.11$ ). However, the numbers of subjects reporting disturbance at the debriefing session were equally distributed across groups for each sampling period (depressed: $58.7 \%, 47.9 \%$, and $42.9 \%$; controls: $54.5 \%, 50.0 \%$, and $23.1 \%$ for baseline-, $6^{\text {th }}$, and $18^{\text {th }}$-week, respectively). In both depressed and control groups, the number of subjects reporting disturbance decreased over time, but again not significantly $\left(\chi^{2}=\right.$ $5.0 . p=.08$ ).

In the depressed group, the relationship between mean disturbance level and speed of response in the first sampling period was negative, but not statistically significant $(r=$ $-.23, N=63, p=.08$ ). There was no difference in disturbance level in the first sampling period between depressed subjects who had difficulties with ESM and those who did not $(2.3 \pm 1.1$ versus $2.6 \pm 1.5$ respecrively, $t=-.66, d f=61, p=.51)$. Therefore, the higher disturbance levels reported could not be attribured to difficulties with ESM perse.

Patients who completed both the 18 weeks of treatment and the four sampling periods did nor differ from the other parients in either disturbance levels $(2.5 \pm 1.4$ versus $2.5 \pm 1.3$ respectively, $t=-.02, d f=61, n s)$ or response time $(3.1 \pm 2.0$ versus $2.4 \pm 2.2$ respectively, $t=-1.3, d f=61, n s)$ in the first period. During the debriefing session at the 
end of the first sampling period, equal numbers of completers and non-completers expressed having difficulties with $\operatorname{ESM}\left(32.1 \%\right.$ versus $37.1 \%$ respectively, $\left.\chi^{2}=.17, n s\right)$, but non-completers were somewhat more likely to report disturbance from ESM $\left(68.6 \%\right.$ versus $46.4 \%$ of completers, $\left.\chi^{2}=3.2, p=.08\right)$.

In summary, depressed patients expressed more difficulties with ESM than healthy individuals, and took more rime to fill in the self-report forms. In addition, depressed patients had a tendency to report slightly greater disturbance from ESM than healthy individuals, which may have been a reason in some individuals - although this was not explicitly mentioned - for not completing all subsequent sampling periods.

\section{Method reactivity}

At the end of the day, subjects were asked to rate on 7 -point scales the extent to which ESM had any effects on their thoughts, mood, or activities during that day. Thoughts were most likely influenced by the ESM procedure, in both depressed and control groups, with no difference in the extent of reactivity between the two groups (2.4 1.0 versus $1.8 \pm 1.0$ respectively, $F=0.1, n s$ ). Depressed and healthy subjects also reported equal influence of ESM with respect to activities ( $2.2 \pm 1.2$ versus $1.5 \pm 1.0$ respectively, $F=0.5, n s)$. However, depressed subjects reported more influence on their moods than healthy individuals ( $2.2 \pm 1.2$ versus $1.3 \pm 0.5$ respectively, $F=4.0, p<.05$ ). Method reactiviry was highest in the first sampling period and decreased over time for thoughts $(F=9.2, p<.001), \operatorname{mood}(F=4.7, p<.01)$, and acrivities $(F=3.7, p<.05)$ in both groups (see Table 3 ).

TABLE 3. ESM reacriviry on thoughts, mood, and activities by sampling period as assessed at the end of the day for depressed and control groups combined.

\begin{tabular}{lccc} 
& Thoughts & Mood & Acrivitics \\
\hline Baseline week & $2.6 \pm 1.2$ & $2.1 \pm 1.3$ & $2.1 \pm 1.3$ \\
Week 6 & $1.9 \pm 1.1$ & $1.7 \pm 1.0$ & $1.8 \pm 1.2$ \\
Week 18 & $1.4 \pm 0.9$ & $1.4 \pm 0.9$ & $1.5 \pm 0.8$ \\
\hline
\end{tabular}

During the debriefing at the end of the first sampling period, more depressed than healthy subjects reported experimental effects with respect to their moods $(39.7 \%$ versus $13.6 \%$ respectively, $\left.\chi^{2}=5.0, p<.05\right)$ and to some extent with respect to their thoughts $(63.5 \%$ versus $40.9 \%, \chi^{2}=3.4, p=.06$, but not with respect to their activities $(30.2 \%$ versus $\left.22.7 \%, \chi^{2}=0.4, n s\right)$. In subsequent periods, no differences were found between the wo groups in experimental effects on moods, thoughts, or activities. 
In summary, depressed patients reported greater experimental effects with respect to their moods than healthy individuals. Whether these influences were positive or negative remains unknown, as this was not specifically asked. In general, method reactiviry decreased in subsequent sampling periods.

\section{Representatizeness}

At the end of each day, subjects were asked how 'usual' their day had been on a Likert scale ranging from 1 (nor usual) to 7 (very usual). Overall, ESM days were reported to be fairly representative for daily life (mean: 3.8). Across all periods, depressed subjects reported days to be less usual on average than controls $(F=9.3, p<.01)$, but the difference between the two groups diminished over time (as evidenced by a significant Group by Period interaction term; $F=5.5, p<.01$ ).

However, subjects were asked during the debriefing session at the end of each sampling week whether they felt the sampled days to be representative with respect to their thoughts, mood, and activities. Here, there were no significant differences berween the two groups in the percentage of subjects reporting each sampling period to be representative of their daily lives.

In summary, it is feasible to apply ESM in clinical trials in depression. ESM compliance rates in depression were comparable to rates found in other patient populations and controls. Young parients living alone and with severe depression were most likely non-compliant with ESM and remained non-compliant during subsequent sampling periods. In compliant patients, $75 \%$ of self-reports were valid. Because patients were often still asleep, significantly fewer ESM reports were obtained at the beginning of the day and in the weekends. Depressed patients experienced more difficulty with the method, and reported somewhat more disturbance than controls, which might in some ases have discouraged depressed patients from participating in subsequent sampling periods even though 'disturbance from ESM' was never reported as a reason for dropping-out of the study. Depressed patients reported greater method reactivity with respect to moods than healthy individuals and found days to be less usual than healthy individuals. This suggests either, that the parients may not have considered life in the depressed condition as representative, or that patients' ratings are more likely affected. by their depressive state.

\section{Utility of ESM for ase in clinical trials in depression}

The urility of ESM in the context of depression trials depends in the first place on whether the merhod yields reliable and valid information - as far as this can be investigated - abour QoL in daily life of depressed pacients and about daily life effects of antidepressant treatment. In the second place, the urility of ESM for depression trials depends 
on whether ESM can be shown to be more sensirive-quantitatively or qualitarively - to treatment effects than conventional research methods.

\section{Reliability}

Reliability refers to the degree that a test outcome is reproducible under similar conditions. One way of investigating the reliability of ESM is by looking ar the stability of measures over time when no systematic change is expected. First, test-retest reliability scores were calculared: (1) by correlaring mean levels of ESM measures at baseline and week 6 for controls, and (2) by correlating mean levels of ESM measures at baseline and week 1 for depressed patients, based on the expectation that rhe clinical state, but nor the side effects, during the first week of treatment would have remained unchanged compared to baseline. Secondly, split-half reliability scores were calculated for both groups for the first sampling period. The first half consisted of the uneven sampled days (day numbers 1,3 , and 5), whereas the second half consisted of the even sampled days (day numbers 2,4 , and 6).

Test-retest reliablity. Mean levels of mQoL, PA, NA, severity of complaints, and enjoymenc of activities were stable over a period of six weeks in healthy individuals $(r$ 's $>.69$, see Table 4). Correlations between mean levels of ESM measures at baseline and the first week of treatment were also high in depressed patients ( $r$ 's $>.75$, see Table 4$)$, suggesting that ESM measures are stable over time periods during which no systematic changes in clinical state are expected. As the majority of side effecrs were expected and also occurred in the first week of treatment, current reliabiliry ratings can be underestimates of the real reliability of the ESM measures.

Split-half reliability. Cronbach's alpha between subjects' means on even sampled days and on uneven sampled days were all above. 90 , indicating that ESM measures reflect fairly stable individual characteristics (see Table 5).

In summary, on the basis of test-retest and splir-half reliability, ESM measures in borth depressed patients and healthy controls showed high levels of temporal stability (in mean levels).

\section{Validity}

Validiry refers to the degree that a test measures what it is intended to measure. As it is subject to the purpose of the use in a specific situation, validity of a test can never be fully demonstrated. However, there are several types of validiry (e.g., face validity, construct validity) which may provide for a certain level of confidence in the validity of the rest. In this section, a specific form of construct validicy (i.e., concurrent validity) is investigated, where ESM measures were expected to correlate positively with conceptually related retrospective measures. 
Chapter 4

TABLE 4. Test-retert reliability scores in depressed parients (correlation between baseline and week 1) and in controls (correlation berween baseline and week 6 ).

\begin{tabular}{lll}
\hline Correlation & Depressed & Controls \\
cofficient for & $(N=59)$ & $(N=21)$ \\
\hline MQoL & $.81^{* * * *}$ & $.74^{* * * *}$ \\
$\mathrm{PA}$ & $.83^{* * *}$ & $.88^{* * * *}$ \\
NA & $.88^{* * * *}$ & $.89^{* * * *}$ \\
Severity of complaints & $.75^{* * * *}$ & $.77^{* * *}$ \\
Enjoyment of activities & $.89^{* * *}$ & $.69^{* * * *}$ \\
\hline
\end{tabular}

${ }^{* * 4} p<.001$. "Number of convtrols for NA: $N=20$.

TABLE 5. Split-half reliability in depressed and healthy individuals on the basis of the first sampling period.

\begin{tabular}{lll}
\hline Cronbach's alpha for: & $\begin{array}{c}\text { Depressed } \\
(N=63)\end{array}$ & $\begin{array}{l}\text { Controls } \\
(N=22)\end{array}$ \\
\hline mQoL & .93 & .90 \\
PA & .97 & .99 \\
NA & .97 & $.89^{\mathrm{a}}$ \\
Severity of complaints & .90 & .93 \\
Enjoyment of activities & .90 & .90 \\
\hline
\end{tabular}

$N=21$.

TABLE 6. Correlation coefficients berween ESM and conceprually related retrospective measures by group on the basis of the erst sampling period.

\begin{tabular}{lll} 
& $\begin{array}{l}\text { Depressed } \\
(N=63)\end{array}$ & $\begin{array}{l}\text { Controls } \\
(N=22)\end{array}$ \\
\hline mQol & $.42^{* * *}$ & $.58^{* *}$ \\
PA & $.76^{* * * *}$ & $.64^{* * *}$ \\
NA & $.64^{* * *}$ & $.50^{* *}$ \\
Complaints & & \\
Severitya & $.30^{*}$ & .40 \\
Frequency & $.71^{* * * *}$ & $.56^{* *}$ \\
Enjoyment of activities & $.65^{* * *}$ & $.48^{* *}$ \\
\hline
\end{tabular}

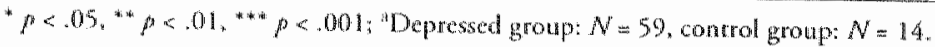


In borh groups, mean levels of ESM measures (mQOL, PA, NA, and enjoyment of activiries) were significantly associated with their conceptually relared retrospective measures ( $r$ 's $>.42, p$ 's $<.05$, see Table 6 ). In both groups, a lower association was found between ESM and retrospective measures for severity of complaints than for frequency of complaints (see Table 6).

\section{Sensitivity}

Sensitivity is defined, here, as the degree to which a measure can detect differences between two treatment groups. In the context of a clinical trial, the sensitivity of a measure is regarded as an imporrant aspect as ir determines, together with the sample size, the chances of finding true treatment differences (see also Chapter 2). The greater the sensitiviry and the greater the sample size, the greater the chance of detecting treatment differences. The sensitivity of a measure can be defined as the standardized treatment effect size (STES, also 'standardized difference', see Whitehead, 1992), which is the ratio of the treatment group mean difference $\Delta$ to the pooled standard deviation $\sigma$. Thus, the smaller the pooled standard deviation, the larger the standardized treatment effect size.

The sensitivity of the sampling strategy in Study 2 was investigated by taking the STES in the $6^{\text {th }}$ week of treatment and addressing the following questions: (1) by what percentage did the current sampling straregy increase STES for ESM measures when compared to one-time measurements, and how did this percentage gain affect the chances of detecting a treatment difference?, (2) what would have been the most efficient sampling strategy to obtain the greatest possible STES for the ESM measures (used as outcome measures) with the smallest number of sampling moments possible?, and (3) how did STES for ESM measures compare with STES for the conceptually related retrospective measures? As similar results were found for all ESM measures (mQoL, PA, NA, severity of complaints, enjoyment of activity), only data on $\mathrm{mQoL}$ are shown.

In general, as repeated observations decrease the measurement error, a time sampling strategy is not expected to change the treatment group mean difference $\Delta$, but it is expected to decrease the pooled standard deviation $\sigma$ of the mean. As a result, STES is expected to increase as a function of the number of observations. In case of $m$ sampled days with $n$ beeps per day, the decrease in variance $\sigma^{2}$ is:

$$
g=\left(1-\left(\sigma_{S}^{2}+\sigma_{D}^{2} / m+\sigma_{B}^{2} 2 / m n\right) /\left(\sigma_{S}^{2}+\sigma_{D}^{2}+\sigma_{B}^{2}\right)\right) \times 100 \%
$$

where: $\left(\sigma_{S}^{2}+\sigma_{D}^{2}+\sigma_{B}^{2}\right)$ is the variance of a one-time measurement $\left(\sigma_{S}^{2}+\sigma_{D}^{2} / m+\sigma_{B}^{2} / m n\right)$ is the variance of the mean of $m n$ replications $\sigma_{5}{ }^{2}$ is the variation berween subjects $\sigma_{D}^{2}$ is the variation between days within a subject 
$\sigma_{\|}^{2}$ is the variation between beeps within a day $m$ is the number of sampled days $n$ is the number of beeps within a day.

STES for mQoL, considered as a one-time measurement ( $m=1, n=1$ ), was compared with $\mathrm{mQoL}$ as measured throughout the sampling period $(m=6, n=10)$. Results showed that the sampling strategy currently used decreased the variance $\sigma^{2}$ by $(g) 26 \%$ compared to a one-rime measurement of $\mathrm{MQOL}$, which led to an increase in STES of $18 \%$ (see Table 7). The larger STES was reflected in a smaller $p$-value for detecting a difference between the two treatment groups, although in this case neirher of the two $p$-values was significant.

In Srudy 2, the choice for the number of sampled days (6) and the number of beeps (10) was a pragmaric one, based on previous experiences (Delespaul, 1995). Whether this choice was effective and efficient depends on two factors: (1) Was the maximum STES obtained?, and (2) Was the maximum STES obtained with the smallest number of sampled days and beeps?

In Figure 5, STES is displayed as a function of the number of days (lines) and the number of beeps ( $X$-axis). As can be seen, STES varied more as a function of the sampled days than as a function of beeps. In general, the greater the number of days and the greater the number of beeps, the greater STES. However, increases of STES occurred as a function of number of days and number of beeps until a certain limit was reached. This limit, the maximum STES (0.332), was determined under the assumption that the number of sampled clays $m$ and the number of sampled moments per day $n$ are so large that $\left(\sigma_{D}{ }^{2} / m\right)$ and $\left(\sigma_{i j}{ }^{2} / m n\right)$ can be assumed to be negligible.

The STES found in Study 2 for mQoL (0.328) was at $98.7 \%$ of the maximum, so thar the current sampling strategy (i.e. 10 times/day for 6 days) was effective in obtaining the highest level of sensitivity for $\mathrm{mQOL}$. In other words, a more intensive sampling regimen would not have led to higher STES. With the aim of obtaining the grearest STES with the fewest sampling moments, the current sampling strategy was not the most efficient. A similar STES for MQOL could also have been obtained with a smaller number of beeps per day $(\geq 7)$, but probably not with a smaller number of sampled days (see Figure 5).

In summary, the sampling strategy used in Study 2 was effective, but not the most efficient, in obtaining the greatest level of sensitivity for $\mathrm{mQOL}$ as an outcome measure.

Finally, STES for mQOL was compared with STES for the conceptually related retrospective measure QoL VAS (correlarion in the $6^{\text {th }}$ week of treatment for the impramine group: $x=.69, p<.001, N=23$; for the placebogroup: $r=.65, p<.001, N=$ 26). To allow comparison of group mean differences and variances of the two measures, 
TABLE 7. Observed group mean difference, variance, STES, and related p-value for mQoL, one-ume measurement versus based on the current sampling strategy (t.e 10 thimes a day for 6 days).

\begin{tabular}{lll}
\hline & $\begin{array}{l}\text { One-rime } \\
\text { measurement }\end{array}$ & $\begin{array}{l}\text { Current sampling } \\
\text { strategy }\end{array}$ \\
\hline$\Delta$ & 0.38 & 0.38 \\
$\sigma^{2}$ & 1.78 & 1.32 \\
STES & 0.28 & 0.33 \\
$p$-value & 0.33 & 0.26 \\
\hline
\end{tabular}

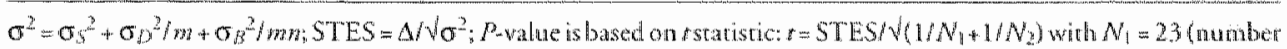
of subjects in the imipranine group) and $N_{2}=26$ (number of subjects in the placebogroup).

TABLE 8. Group mean difference, wariance, and STES for mQoL versus QoL VAS, transformed wa scalle $(-3,3)$

\begin{tabular}{lll}
\hline & mQOL & QoLVAS \\
\hline$\Delta$ & 0.38 & 0.83 \\
$\sigma^{2}$ & 1.32 & 1.79 \\
STES $^{*}$ & 0.33 & 0.62 \\
$(95 \%$-confidence interval $)$ & $(-0.23,0.89)$ & $(0.06,1.18)$ \\
\hline
\end{tabular}

$\sigma^{2}=\sigma_{S^{2}}+\sigma_{2^{2}}^{2} m+\sigma_{1}^{2} / m m$. STES $=\Delta / \sqrt{ } \sigma^{2}$.

"As the imipramine patients differed significantly trom placebo patients on the QoL VAS at baseline (39.4 16.1 versus $30.7 \pm 15.7, t=2.2, d f=61, p<.05)$ but not in ratings of mQoL $(0.2 \pm 1.0 \times \mathrm{ercus}-0.1 \pm 0.9, t=1.2 . d f=61 . \mathrm{m})$, we adjusted STES for baseline differences. Again, no difference was found between STES for mQOL (0.10) and STES for QoL VAS $(0.23)$ as the $95 \%$-confidence intervals overlapped: $(-0.50,0.62)$ versus $(-0.47,0.65)$ respectively.

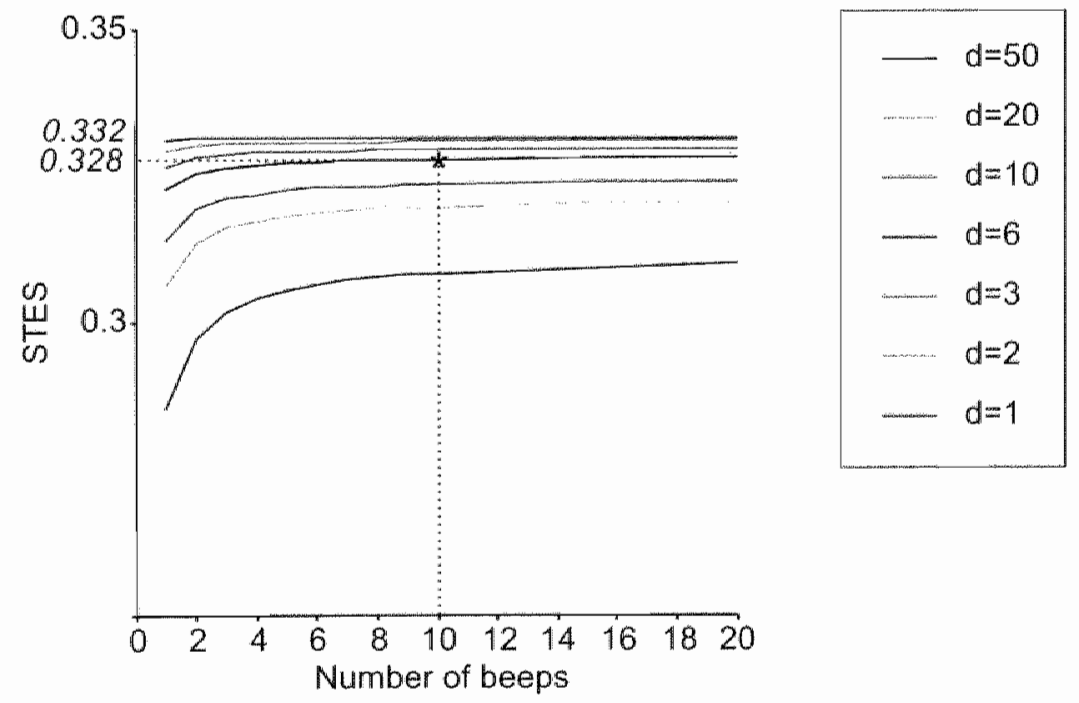

FUGEE 5. Standardized treatment effect size for nQL by number of sampled days and number of sampled beeps. $d=$ number of sampled days. * STES for mQoL with sampling straregy used in Sudy $2=0.328$. Maximum STES for $\mathrm{MQoL}=0.332$. 
QoL VAS was tratusformed to a scale ranging from -3 to 3 . The transformation was deemed justified as 7 -point Likert and vistall analogue scales are known to show comparable responsiveness and validity in a randomized trial setting (Jaeschke et al., 1990). Re-scaling the scores for QoL VAS was done as follows:

$$
X_{r}=3 \times \frac{(X-50)}{50}
$$

where: $X_{r}$ is the re-scaled QoL VAS score

$X$ is the original QoL VAS score.

Contrary to expectations, STES for mQOL was not significantly greater than STES for QoL VAS, as the 95\%-confidence intervals overlapped (see Table 8). Thus, a single ESM item (repeatedly scored) was not found to be more sensitive than a retrospective assessment of a similar item in this study. Although the variance of $\mathrm{mQOL}$ was, as expected, smaller than the variance of QoL VAS, the group mean difference for $\mathrm{mQoL}$ was, unexpectedlly, also smaller.

To summarize the main findings concerning sensitivity, the sampling strategy used in Study 2 (i.e., 10 times a day for 6 days) was effective in attaining the maximum STES for mQOL. Ir increased STES by $18 \%$ over a one-time measurement of mQoL. However, in order to obtain a $\mathrm{mQoL}$ measure with the highest level of sensitivity possible, the sampling strategy could have been restricted in the number of beeps per day, to a minimum of 7. Contrary to expectations, $\mathrm{mQOL}$ (repearedly scored) was not found to be more sensitive than a retrospective assessment of a similar irem in this study.

\section{DISCUSSION}

With the exception of a small number of severely depressed individuals, patients were able to comply with ESM and did so as well as healthy individuals, even though they had more difficulties in completing the self-reports and reported somewhat more disurbance from ESM. In general, those who complied with one sampling period complied equally well with subsequent sampling periods. Over time, initial difficulty and disturbance with ESM in depressed patients subsided, so that the application of ESM to clinical trials can be regarded as feasible and appears promising for long-term clinical trials.

Concurrent validity was high for ESM and the conceptually related retrospecrive measures for QoL, PA, NA, enjoyment of activities, and frequency of complaints. On the basis of resr-retest and split-half reliability analyses, ESM measures were found to be stable over time. By using repeared measurements over the day and across days instead 
of one-time measurement, the current sampling strategy (i.e. 10 times a day for 6 days) increased the standardized trearment effect size, thereby increasing the likelihood of detecting true treatment differences. Although the chosen sampling straregy was effective in that it achieved the maximum STES for MQoL, it was not the most efficient choice, as the maximum STES for mQoL could also have been obtained with fewer beeps per day. Another recent application of ESM in a nicotine-parch trial has used a sampling strategy of 8 to 10 beeps a day for 21 days and found differences in nicotine craving and withdrawal symptoms between rwo different nicotine patches (Shiffman et al., 2000). With only a few experiences to date in applying ESM in clinical trials, it is clear that the design of optimal sampling strategies should be studied more thoroughly, as an objective in itself. Surprisingly, mQoL was not found to be more sensitive than the conceptually related retrospective measure QoL. VAS in detecting differences between drug and placebo, in spite of decreasing the error measurement. Comparisons berween the two scales on a range from -3 to 3 showed that the group mean difference was greater for QoLVAS than $\mathrm{mQoL}$. Although this outcome is difficult to interpret, two possible explanations are proposed. First, the correlation between the two scales was possibly not sufficient to make such a comparison. In orher words, retrospective and moment-to-moment assessments may measure intrinsically different concepts (see discussion of 'subjective happiness' versus 'objective happiness' respectively, in Kahneman, 1999 and see also Chapter 2). Second, in the current debate on the integrity of the double-blind procedure in depression trials due to side effects (Greenberg and Fisher, 1997; Quitkin et al., 2000), some authors suggest that patients report en hanced improvement as a result of experiencing anticipated side effects (Antonuccio et al., 1999). Such a cognirive judgmental process is more likely to affect a retrospecrive assessment than moment-to-moment reports. It should be said, however, that the comparisons made in terms of the sensitivity of the measures were possibly limited by the choice of the measures used (single-item, self-constructed scales). Futtre ESM application in depression trials should address the question of whether a relevant ESM index can be developed which is more sensitive in detecting treatment differences than a commonly used primary outcome measure such as HDRS. Interesting as this might be, such an investigarion lies beyond the focus of the present research.

As indicated at the beginning of this chapter, the utility of ESM in the context of clinical trials also depends on whether ESM can deliver new insights (not amenable to assessment by other means) into the effects of drug treatments by virtue of measuring prospectively in real-life settings. This objective will be investigated in Chapters 6807 . Chapter 5 will first address the differences in daily QoL between depressed and healthy subjects. 


\section{REFERENCES}

American Psychiatric Association, 1987. Diagnostic and Stariscical Manual of Mental Disorders, Third Edition, revised. American Psychiaric Association, Washingron, DC.

Andrews, F. M. Mckennell, A. C., 1980. Measures of self-reported well-being: their affective, cogninive, and other components. Social Indicators Research $8.127-155$.

Antonuccio, D. O. Danton, W. G., DeNelsky, G. Y. Greenberg, R. P., Gordon, J. S., 1999. Raising quesvions about antidepressants. Psychorher Psychosom 68(1), 3- 14 ,

Cassarno, G. B. Toni, C., Petracca, A., Deltito, J., Benkert, O., Curris, G. Hippius, H., Maier, W., Shera, D. Kleman, G., 1994. Adverse effects associated with the short-term treatment of panic disorder with imipramine, alprazolam or placebo. Eur Neuropsychopharmacol 4, 47-53.

Csikszentmihalyi, M., Larson, R, 1987 . Validiry and reliabil ity of the Experience Sampling Method. J Nerw Ment Dis 175(9), 526-537.

Delespaul, P. A. E. G.s 1995. Assessing Schizophrenia in Daily Life: The Experience Sampling Method. Ph.D. disseracion, Manstricht University, Universitaire Pers, Maastricht.

Dijkman-Caes, C. I. M. 1993. Panic disorder and agoraphobia in daily Life. Ph. D. dissercarion, Maastricht University, Universicaire Pers, Maastricht.

Dingemans, D., wan Engeland, H., Dijkhuis, J. H., Blecker, J., 1985. De 'Diagnostic Interview Schedule' (DIS). Tijdschrift woor Psychiatric 27(5), 341-359.

Greenberg, R. P., Fusher, $S_{n, 1}$ 1997. Mood-mending medicines: probing dug, psychotherapy, and placebo solutions. In: Fisher, S., Greenberg, R. P. (Eds.), From Placebo to Panacea: Putring Psychiarric Drugs to we Test. Wiley \& Sons, New York, pp. 115-172.

Guy, W., 1976. ECDEU Assessment Manual for P'sychopharmacology. US Department of Heallth, Education and Welfare, Rockville, MD, pp. 59-70.

Hamilton, M., 1960. A rating scalle for depression. J Neurol Neurosurg Psychiar 23, 56-62.

Jaeschke, R., Singer, J., Guyart, G. H., 1990. A comparison of seven-point and visual analogue scales. Data from a randomized trial. Controlled Clin Trials $11,43-51$.

Kahneman, D., 1999. Objecrive happiness. In: Kahneman, D., Diener, E, Schwarz, N. (Eds.), Well-being: the foundations of hedonic psychology. Russell Sage Foundation, New York, pp. 3-25.

Peeters, F. I. M. L., Ponds, R. W. H. M., Vermeeren M. T. G., 1996. Affectiviteit en zelfbeoordeling van depressie en angst. Tijdschrift voor Psychiatrie 38(3), 240-250.

Quitkin, F. M., Rabkin, J. G., Gerald, J., Davis, J. M., Klein, D. F., 2000. Validity of clinical trials of antidepressans. An J Psychiatry 157(3), 327-337.

Shiffman, S., Elash, C. A. Paton, S. M., Gwalney, C. J., Paty, I. A, Clark, D. B., Liu, K. S., Di Marino, M. L., 20000. Comparative efficacy of 24-hour and 16-hour transdermal nicotine patches for relief of morning craving. Addiction 95(8), 1185-1195.

van Lek, M., 1996. Stress. Mood, and Cortisol Dynamics in Daily Life. Ph.D. dissertation, Masasticht Uniwersity, Universiatre Pers, Maastriche.

Warson, D., Clark, L. A., Tellegen, A., 1988. Development and validation of brief measures of posirive and negative affec: the PANAS scales. Journal of Personaliry and Social Psychology 54(6), 1063-1070.

Whirehend, J. 1992. The design and analysis of sequential clinical trials, Second edicion. Ellis Horwood Lid, Chichester, UK. 


\title{
PART I\| \\ MAIN STUDY (STUDY 2)
}

\author{
CHAPTER 5 \\ Quality of life in depression: \\ Daily life determinants and variability
}

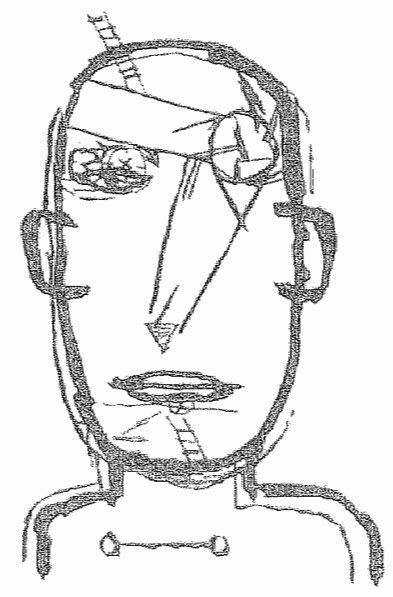

Barge-Schaapweld, D. Q. C. M. Nicolson, N. A., Berkhof, J., deVries, M. W., 1999. Quality of life in depression: daily life determinants and variability.

Psychiatry Research 88, 173\%189. 


\section{Quality of life in depression: Daily life determinants and variability}

Identifying dally intuences on subjective well being can be helpfut in understanding the burden of depression This study used expenience sampling methodology (ESM) to examine the contribution of mood states physical complaints and enjoyment of activities to a momentany measure of quality of life (mOol) assessed by responses to the question "In general, how is 11 going with you right now?". Sixty three depressed and 22 healthy control subjects completed ESM self-reports during dailly activities, 10 times per day for 6 days. In comparison to control subjects, depressed subjects had lower levels of mQol, positive mood, and enjoyment of activity, higher negative mood, and more frequent and severe complaints. Depressed subjects were more likely than control subjects to be doing nothing and less likely to be engaged in work. Multilevel regression analysis showed that positive mood and enjoyment of the current activity were associated with higher $\mathrm{mQOL}$, whereas negative mood and complaints were associated with lower mQol, In depressed subjects, mQoL was more variable over time than in control subjects. In contrast to the ESM results, only negative mood and depression were significant predictors of global measures of Qol. We conclude that Qol has important situational determinants that can in part explain the impact of depression on daily functioning and well-being.

\section{INTRODUCTION}

Depressive illness leads to pronounced decrements in the quality of life (QoL), as reflected in subjective well-being and the performance of rourine activities and social roles. QoL is a broad construct, encompassing affective, cognitive, behavioral, and physical components (Spilker, 1990). Depression is characterized by disturbances in many or all of these areas, which may explain why QoL is even lower in depression than 
in serious somatic disorders like diabetes or arthritis (Wells et al., 1989). Recognition of the burden that depression creares in major life domains has led to increased efforts to assess QoL in clinical research. In addition to clarifying the impact of the illness on patients' lives, QoL instruments provide a way of determining the value of new and existing therapies, beyond their ability to relieve depressive symproms,

The first studies of QoL in depression employed generic instruments (e.g., Markowirz et al., 1989; Wells et al., 1989). In recent years, new instruments have been developed specifically for use in assessing QoL in depression and other affective disorders (Hunt and McKenna, 1992; Stoker et al., 1992; Endicott et al., 1993; for an overview, see Lehman, 1997). Results indicate that QoL is influenced by affecr (Dunbar er al., 1992; Hunt and McKenna, 1992; Corrigan and Buican, 1995), physical symptoms (Markowitz et al., 1989; Endicott et al., 1993; Pyne et al., 1997), and satisfaction with daily activities (Wells et al., 1989; Endicott et al., 1993; Goethe and Fischer, 1995). Clearly, these are influences that will vary from moment to moment throughout the day, reflecting internal states as well as shifting environmental contexts. This means that, in addition to a global lowering of QoL in depression, daily fluctuations in QoL will occur that may be relevant for clinical practice. Because dynamic processes of the sort cannor be studied with existing instruments, new research approaches are needed.

To determine how daily experience contribures to short-term fluctuations in QoL in depressed parients compared to healthy individuals, we used the experience sampling method (ESM). ESM was developed to investigate subjective experience over time and across naturally occurring situations (Csikszentmihalyi and Larson, 1987; deVries, 1992a). Responding to signals at frequent, semi-random intervals, subjects complete brief self-reports concerning their current mental and physical stare, activity, location and social context. In the current study, subjects were also asked to evaluate their general well-being at that moment, in response to the question: "Jn general, how is it going with you right now?". We refer to this measure as momentary QoL ( $\mathrm{mQoL}$ ). The prospective nature of ESM assessments offers an advantage over questionnaire measures, which typically summarize experiences over the past week or longer. Retrospective measures are vulnerable to influences of current affective state, forgetting, cognirive re-framing, and other sources of bias (Diener, 1994), which can pose particular problems in depression research (Adkinson et al., 1997). For overviews of previous ESM research on well-being and QoL, with particular reference to mental disorders, see (Barge-Schaapveld et al., 1997) and (deVries er al., 1999).

In the present study, we first use aggregated ESM data to assess the general impact of depression on mQoL, daily mood states, physical complaints, activity patterns, and enjoyment of acrivities. Results of an earlier study (Barge-Schaapveld et al., 1995) showed that posirive affect increased, negative affect decreased, and patterns of time use changed (time spent in chores increased and time spent in passive leisure decreased) following successful treatment of depression. As there was no control group, however, it is 
not clear whether these patterns differed, either before or after treatment, from those of healthy individuals.

Next, we develop a multilevel regression model to test the effects of concurrent daily life experiences (negative and positive affect, physical complainrs, and enjoyment of acrivities) on $\mathrm{mQoL}$. There is evidence that these predictors are themselves interrelated; for example, positive correlations have been reported between negative affect and physical complaints (Verbrugge, 1985; Watson, 1988) and between positive affect and enjoyable activities (Watson et al., 1992). The current analysis therefore estimates the relative magnitude of the contribution of each predictor variable, controlling for the others.

Comparing moment-to-moment, day-to-day, and person-to-person variance components of $\mathrm{mQOL}$ in the multilevel model can shed new light on the issue of trait versus state aspects of QoL. Traits refer to relatively stable individual differences, whereas states refer to fluctuations within individuals, in response to changing internal conditions and environmental influences. In addition to their widespread usage in psychology, concepts of trait and state have important implications for psychiatric research methodology (Kraemer er al., 1994). Up until now, the few studies that have examined intraindividual fluctuations in QoL in depression have been limited to treatment-related changes (Agosti et al., 1991). A number of studies provide evidence, however, that instability in well-being or in other positive self-evaluations may be more important as markers of vulnerability to depression than low levels of these characteristics per se. For example, recent studies indicate that self-esteem is more unstable (Roberts and Kassel, 1997) and Jabile to the influence of daily events (Butler et al., 1994) in depressed than in non-depressed individuals, and that within-individual variability in measures of well-being is greater in persons with a high risk for depression (Gable and Nezlek, 1998). We therefore expected that mQoL would fluctuate more widely in depressed individuals than in healthy controls. To test this hypothesis, we compare berween-and within-person variance estimates obtained separately in the mulrilevel model for each of the two groups.

Finally, we compare the ESM results to those obtained with more standard questionnaire measures, to determine whether daily life experiences that are relevant to $\mathrm{mQoL}$ can also be identified retrospectively. Results of an earlier study of depressed outparients (Barge-Schaapveld et al., 1995) showed that ESM was capable of revealing subrle changes in daily life experience following clinical improvement that were not identified by a retrospective QoL instrument. Comparison of the results obtained with ESM versus standard questionnaire measures provides a perspective on the unique contributions of a daily life approach to understanding quality of life in depression. 
METHODS

Pariolpants

\section{Diagnosis and screening}

After the study was approved by a medical ethics committee, subjects were recruited in eight primary care practices in The Netherlands. During a training session, general practitioners (GPs) were given detailed instructions and practice in diagnosing major depressive disorder according to DSM-III-R criteria (American Psychiatric Association, 1987) by means of a semi-structured interview. They also received training in administration of the Hamilton Depression Rating Scale (HDRS, Hamilton, 1960). Research nurses were trained to administer the Diagnostic Interview Schedule (DIS, Dingemans et al., 1985; Robins et al., 1985) to screen control subjects.

\section{Depressed patients}

All patients in the study had a primary diagnosis of current major depressive disorder, as assessed by the GPS. The research nurses later obtained DIS diagnoses for descriptive purposes, but these were not used for inclusion or exclusion of patients. To participare in the study, patients had to meet the following criteria: age 18 to 65 years, free of major somaric illness (including abnormal ECG), scoring $\geq 18$ on the 17 -item version of the HDRS and $\geq 4$ on the Clinical Global Impression severity score (CGI, Guy, 1976). Except for the occasional use of temazepam, no current psychotropic medications were allowed. Of the 83 patients screened, five did not meet all of the above criteria (two had HDRS $<18$, one used prohibited psychotropic medication, one had an abnormal ECG, and one was lost to follow-up) and were therefore excluded. Patients received no treatment (pharmacological or other) for depression during the baseline week in which the current data were collected.

\section{Control group}

Each individual in The Netherlands is registered as a client of a particular general medical practice. Healthy subjects were recruired from the participating practices to form a control group similar to the patient group in age and sex distriburion, employment status, and living circumstances (alone or not). The research nurses administered the DIS to exclude individuals meeting diagnostic criteria for depression (lifetime) or orher current psychiatric conditions. Of the 29 control subjects screened, 6 were therefore excluded. 


\section{Procedure}

During the screening session, study procedures were explained to all subjects and informed consent obtained. The SF-36 Health Survey (SF-36, Ware, 1996), added to the measures after the study began, was completed by a subset of 42 depressed and 18 control subjects. In a separate briefing session, a research nurse explained details of the ESM procedure. Subjects then completed ESM reports for six days, in response to signals from a programmed wristwatch at ten semi-random intervals per day, between $7: 30 \mathrm{a} \cdot \mathrm{m}$. and $10: 30 \mathrm{p} . \mathrm{m}$. In a final session, the research nurse interviewed subjects as to the representativeness of the sampled days and influences the ESM procedure might have had on daily experiences. Subjects then completed a battery of global, retrospective questionnaires.

\section{Assessments}

\section{ESM measures}

ESM self-report forms were collated into a booklet for each day. Subjects were instructed to complete all irems with reference to the moment at which they received a signal (beep). ESM forms used in the current study are reproduced in (deVries et al., 1999). Measures derived from ESM questionnaires are summarized in the top half of Table 1.

At each beep, subjects rated $\mathrm{mQoL}$, current mood, physical complaints, and enjoyment of activity on 7-point scales. Based on a factor analysis of the 17 mood items, two mood dimensions were identified: positive affect (PA; $\alpha=0.95)$ and negarive affect (NA; $\alpha=0.92$ ). Subjects also provided a brief description of their current activity. Responses were later coded by a trained research assistant. The 57 original codes were collapsed into 8 broader activity categories for the current analysis. Interrater agreement for ESM activity codes is high (van Eck, 1996).

\section{Global measures}

Questionnaires completed retrospectively, with reference to the past week, provided global measures of quality of life, mood, physical complaints, enjoyment of daily activities, and depressive symproms. The measures we used are summarized in the bottom half of Table 1. Subjects were asked to rate the quality of their life on a $100-\mathrm{mm}$ visual analogue scale (Andrews and McKennell, 1980) and to complete the validated Dutch version of the SF-36 (van der Zee et al., 1996). Positive and negative affect were rated by subjects on two 10-item scales (PANAS, Watson et al., 1988). For the five somatic complaints also assessed with ESM (headache, dizziness, dry mouth, drowsiness, and nausea), subjects indicated how frequently the complaint had occurred in the previous week (1 not at all to 5 several times a day) and, if it had occurred, how bothersome it was ( 1 not at 
TABLE $\mathbb{1}$. Description of the measures used.

ESM measures

mQoL

$P A$

'In general, how is it going with you right now?' (rated -3 sery bad to 3 trey good)

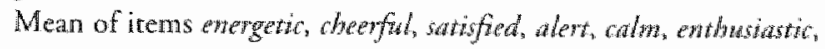

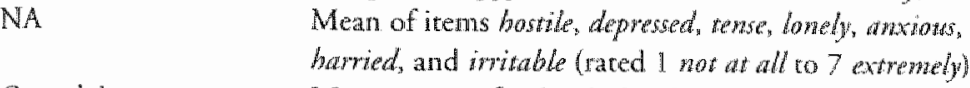
strong, and happy (rared 11 not at all ro 7 extremely)

Complaines Mean severicy for beadache, dizziness, dry wowth, drowsines, and wasued (rated 1. wot at all to 7 extremely)

Enjoyment of activity

Current activity

'How much are you enjoying this activity?' (1 nor ar all to 7 extremely)

Subject's written response coded in eight categories: work or stady, howehold dhore, shopping, childare, social awivities (pisith and going out), acrive leisure (e.g., hobbies, sports, taking a walk), passive leisure (e.g., watching $T V$, reading) or doing nowing

Global measures:

QOL VAS

Rating on 100-mm visual analogue scale 11 towst QoL l cam imatgine for myself to 100 best QoL I can imagine for myself)

$S F-36$

Self-rating of global functioning, with two summary scores:

MCS = Mental Heath Component scale

PCS = Physical Health Component scale

PANAS

Self-rating of affect on cwo dimensions:

$P A=$ Posirive Affect

$\mathrm{NA}=$ Negariwe Affect

Complaints

Average product of the frequency $x$ sewericy rarings for the five symptoms (see above)

Enjoyment of activities Average product of the frequency $x$ enjoyment ratings for the eiglt categories of activity (see above)

all to 5 very). A summary measure was calculared as the average product of the frequency and severity ratings for the five complaints. Finally, for the 15 most common categories of daily activities identified in a previous ESM study of depressed outpatients (Barge-Schaapveld et al., 1995), subjects were asked to report how frequently they had performed each activity in the previous week ( 1 not at all to 5 several times a day) and, if performed, how much pleasure they had experienced in that acrivity (1 none to 5 very much). As noted above for ESM assessments, wre limited the current analysis to eight categories of activity, computing a global measure of enjoyment as the average product of frequency and enjoyment ratings. 


\section{Statistical Analysis}

\section{Agrregated data}

MQol, PA, NA, and enjoyment of activiry scores were averaged across all ESM records for each subject. Severity ratings of physical complaints were averaged for each subject across records for which some level of complaint was reported. Mean severity rarings were then transformed to a scale ranging from 1 mild to 6 severe. The frequency of physical complaints was defined as the number of rimes that a subject reported a physical complaint (complaint score $\geq 2$ ), expressed as a percentage of total valid ESM records for that subject. Finally, the time spent in each category of activity was defined as the number of records in which that activity was reported, as a percentage of total valid records.

The significance of differences between depressed and control groups was assessed with two-sample $t$-tests which use a Satterthwaite approximation for the degrees of free$\mathrm{dom}$, and with $\chi^{2}$-tests for the categorical variables. Multiple regression and correlation analyses were performed to invesrigate relationships between global measures and aggregated ESM measures. An alpha level of .05 was used.

\section{Multilevel model}

To estimate the effecrs of mood states, physical complaints, and enjoyment of acrivities on momentary QoL, we used multilevel or hierarchical linear modelling (Goldstein, 1995; Kreft and de Leeuw, 1998; Sullivan et al., 1999). The hierarchical linear model is a variant of the multiple regression model, appropriate for datasets with a multilevel structure. In our case, three different levels (beep, day, and person) can be distinguished. The response variable $(\mathrm{mQOL})$ is assumed to be related to its determinants by the regression equation:

$$
\begin{aligned}
\mathrm{mQOL}= & \beta_{0}+\beta_{1} \times \mathrm{PA}+\beta_{2} \times \mathrm{NA}+\beta_{3} \times \mathrm{COMPL}+\beta_{4} \times \mathrm{ACT}+\beta_{5} \times \mathrm{GROUP}+ \\
& \beta_{6} \times \mathrm{PA} \times \mathrm{GROUP}+\beta_{7} \times \mathrm{NA} \times \mathrm{GROUP}+\beta_{8} \times \mathrm{COMPL} \times \mathrm{GROUP}+ \\
& \beta_{9} \times \mathrm{ACT} \times \mathrm{GROUP}^{2}+r_{10}+r_{\mathrm{C}}
\end{aligned}
$$

The predictors PA, NA, COMPL, and ACT refer ro vectors of standardized scores (mean 0, variance 1) for positive affect, negative affect, physical complaints, and enjoyment of acrivities reported at the beeps. The variable GROUP indicates whether an individual belongs to the depressed of to the control group (dummy coded as 1 or 0 , respectively). The $\beta^{\prime}$ 's are the fixed regression coefficients of the predictors.

Each of the residual vectors $r_{\mathrm{D}}$ and $r_{\mathrm{C}}$ (for depressed and control subjects, respectively) can be decomposed in to three terms: a person level random effecrs vector $\left(r_{3 D}\right.$ or $\left.r_{30}\right)$, a day level random effects vector $\left(r_{21}\right.$ or $\left.r_{2 \mathrm{C}}\right)$, and a beep level residual vector $\left(r_{10}\right.$ or $r_{1 C}$. The entries for $r_{3 D}$ (or $r_{3 C}$ ) represent the variability in the $\mathrm{mQOL}$ averages per 
person that is not explained by the predictors; the entries for $r_{2 D}$ (or $r_{2 C}$ ) represent the variability in the mQL averages per day within a person that is not explained by the predictors; the entries for $r_{10}($ or $m$ ) represent the residual variability among the $\mathrm{mQOL}$ scores of the beeps within a day. The decompositions of $r$, and $r$ can be represented by the equations:

$$
r_{\mathrm{D}}=r_{3 \mathrm{D}}+r_{2 \mathrm{D}}+r_{\mathrm{BD}} \text { and } r_{\mathrm{C}}=r_{3 \mathrm{C}}+r_{2 \mathrm{C}}+r_{1 \mathrm{C}}
$$

The entries of $r_{30^{*}} r_{20}$, and $r_{10}$ are normally distributed with mean zero and person level variance $\sigma_{3 D}^{2}$, day level variance $\sigma_{2 D}^{2}$, and beep level variance $\sigma_{11}^{2}$. Likewise, the entries of $r_{3 C}, r_{2 C}$ and $r_{1 C}$ are normally distributed with mean zero and person level variance $\sigma_{3 c}^{2}$, day level variance $\sigma_{2 c}^{2}$, and beep level variance $\sigma_{1,2}^{2}$. The different variances express the size of residual variability at the three levels. For instance, if the person variance is large, there is large variability in the $\mathrm{mQoL}$ averages per person. As in ordinary linear regression, the variances decrease when additional predictors are included in the model. The entries of $r_{1 D}$ (or $r_{1 C}$ ) are assumed to follow a first-order autoregressive AR (1) process. Disregarding the autocorrelation berween consecutive beeps biases the standard errors of the fixed regression coefficients downwards.

Significance of the regression coefficients was tested by dividing the estimated effect by its standard error. This ratio is approximately normally distributed. Tests were two-tailed, even when hypotheses were directional. For testing the significance of the residual variances and the autocorrelation, we used the likelihood ratio test (Bryk and Raudenbush, 1992). We estimated the model parameters (the fixed regression coefficients, the variance components, and the autocorrelation) with the staristical software program MLn (Prosser et al., 1996), which produces maximum likelihood estimates.

\section{RESULTS}

\section{Excluded subjects}

Four depressed subjects were excluded from the analysis for the following reasons: no data on global questionnaires ( 2 patients), randomized to double-blind medication during the baseline week ( 1 patient), and no ratings on $\mathrm{MQoL}$ (1 patient). Another reason for exclusion was insufficient ESM data. An ESM self-report was considered valid if it was complered less than 15 minutes after the signal. Eleven depressed subjects and one control (14.9\% versus $4.4 \%$ of the participants in the respecrive groups, $\chi^{2}=1.8$, nis) completed fewer than 30 valid beeps, the minimum criterion for inclusion in the analysis. These excluded patients were younger $(35.5 \pm 8.8$ years versus $43.4 \pm 9.2$ years respecrively, $t=2.7, d f=14, p<.05)$ and more likely to be living alone $(12.4 \%$ versus 
TABLE 2. Sociodemographic data for depressed and healthy subjecrs.

\begin{tabular}{|c|c|c|}
\hline & $\begin{array}{l}\text { Depressed } \\
N=63\end{array}$ & $\begin{array}{l}\text { Controls } \\
N=22\end{array}$ \\
\hline Age (nean \pm SD) & $43.4 \pm 9.2$ & $42.0 \pm 11.5$ \\
\hline \multicolumn{3}{|l|}{ Gender } \\
\hline male & $17(27.0 \%)$ & $5(22.7 \%)$ \\
\hline female & $46(73.0 \%)$ & $17(77.3 \%)$ \\
\hline \multicolumn{3}{|l|}{ Work status } \\
\hline working & $28(44.40 \%)$ & $12(54.5 \%)$ \\
\hline nor working & $35(55.6 \%)$ & $10(45.5 \%)$ \\
\hline \multicolumn{3}{|l|}{ Living alone } \\
\hline yes & $8(12.7 \%)$ & $2(9.1 \%)$ \\
\hline no & $55(87.3 \%)$ & $20(90.9 \%)$ \\
\hline \multicolumn{3}{|l|}{ Psychiatric diagraseses (DIS) } \\
\hline Major Depression Disorder (MDD) only & $7(11.1 \%)$ & $0(0.0 \%)$ \\
\hline MDD + other affective disonden & $7(11.1 \%)$ & $0(0.0 \%)$ \\
\hline MDD + anxiety disorder & $27(42.9 \%)$ & $0(0.0 \%)$ \\
\hline MDD - affective + anxiety disorders & $16(25.400)$ & $0(0.0 \%)$ \\
\hline no MDO & $6(9.5 \%)$ & $22(100.0 \%)$ \\
\hline \multicolumn{3}{|l|}{ Depressive symptoms } \\
\hline Zung (mean $\pm S D)^{\prime}$ & $68.0 \pm 10.8$ & $37.3 \pm 8.3$ \\
\hline \multicolumn{3}{|l|}{ Current depressive eppisode } \\
\hline first episode & $36(57.1 \%)$ & $0(0.0 \%)$ \\
\hline recurrence & $27(42.9 \%)$ & $0(0.0 \%)$ \\
\hline
\end{tabular}
$p<.001$.

$6.4 \%, \chi^{2}=3.9, p<.05$ ) than patients with adequate ESM dara. In addition, patients with inadequate ESM compliance reported greater depressive symptomarology (Zung scale: $73.5 \pm 6.2$ versus $68.0 \pm 10.8$ respectively, $t=-2.3, d f=19, p<.05)$. They did not, however, score higher on the HDRS (24.1 44.0 versus $23.8 \pm 3.1, t=-0.3, d f=12, n s)$, and the percentage of parients with recurrent major depression did not differ in the wo groups $\left(36.4 \%\right.$ of the non-compliant versus $57.1 \%$ of the compliant patients, $\chi^{2}=1.6$. n). In the total parient sample, Zung scores were negatively associated with age ( $r=$ $-0.27, p<.05$ ), which suggests that the poorer ESM compliance in younger patients may in part reflec their greater illness severiry.

\section{Characteristics of patient and control groups}

As a result of the procedure for recruiting control subjects (see Methods), there were no differences between the two groups in mean age, sex distribution, living situation (alone or not), or work status (see Table 2). As expected, patients had significantly higher levels 
TABLE 3. Descriptive statistics and correlations between ESM aggregated measures.

\begin{tabular}{|c|c|c|c|c|c|c|c|c|c|}
\hline & \multicolumn{2}{|c|}{$\begin{array}{l}\text { Depressed } \\
(N=63)\end{array}$} & \multicolumn{2}{|c|}{$\begin{array}{l}\text { Controls } \\
(N=22)\end{array}$} & \multirow[b]{2}{*}{$t$} & \multicolumn{4}{|c|}{$\begin{array}{l}\text { Pearson } r \\
(N=85)\end{array}$} \\
\hline & Mean & $S D$ & Mean & $S D$ & & 2. & 3. & 4 & 5. \\
\hline 1. $\mathrm{mQOH}$ & 0.08 & 0.92 & 2.07 & 0.47 & $9.7^{60}$ & $0.77^{\circ *}$ & $-0.76^{42}$ & $-0.60^{\circ}$ & 0.61. \\
\hline 2. $\mathrm{PA}$ & 2.23 & 1.08 & 4.67 & 1.21 & $8.8^{\circ \cdot 0}$ & - & $-0.54^{\circ}$ & $-0.43^{\circ}$ & $0.69^{\circ}$ \\
\hline 3. NA & 2.29 & 0.98 & 1.08 & 0.11 & $-5.7^{2 \ldots}$ & - & - & $0.47^{\circ}$ & $-0.43^{* *}$ \\
\hline 4. Complaints & 1.87 & 0.71 & 1.11 & 0.16 & $-5.0^{* * *}$ & - & - & - & $-9.47^{n+}$ \\
\hline $\begin{array}{l}\text { 5. Enjoyment of } \\
\text { acrivity }\end{array}$ & 420 & 0.96 & 5.26 & 0.68 & $48^{* \ldots}$ & - & - & - & - \\
\hline
\end{tabular}

of depressive symptoms than controls (Zung scale: $t=13.8, d f=48, p<.001$ ). For 36 $(57.1 \%)$ of the patients, the current major depressive episode was a first occurrence. DIS results indicated that the majority of the patients ( 54 out of 63) had a secondary, comorbid psychiatric disorder; as shown in Table 2,68\% of the depressed patients also met criteria for an anxiety disorder. Although all patients were diagnosed by trained physicians as meeting DSM III-R criteria for current major depression, six patients did not meet these criteria as assessed with the DIS; an earlier report has shown, however, that the DIS may underdiagnose major depression in community samples (Helzer et al., 1985). With one exception (obsessive compulsive disorder, never treated) on the basis of DIS results, control subjects were free of current psychiatric disorder and had no lifetime history of depressive disorder.

\section{QoL in daily life}

\section{ESM compliance}

The 85 subjects ( 63 patients and 22 controls) completed a total of 3966 valid reports (77.8\% of the maximum possible), with no difference in the average number of valid ESM reports completed by subjects in either group (depressed: $46.6 \pm 7.4$ reports; controls: $46.7 \pm 7.9$ reports; $t=-0.1, d f=35, n s)$. However, depressed subjects rook longer on average to complete a report $(2.7 \pm 2.1$ minutes $w s .1 .6 \pm 1.4$ minutes for controls, $t=$ 2.7. $d f=56, p<.01$ ).

\section{Aggregated ESM measures}

As expected, depressed individuals experienced lower average levels of mQL than control subjecrs (see Table 3). These levels of $\mathrm{mQoL}$ were negatively associated to Zung scores in borh groups, but only significant in the depressed group $(r=-0.59, p<.01$ versus $r=-0.32$, ns in controls). No other socio-demographic characteristic stated in 


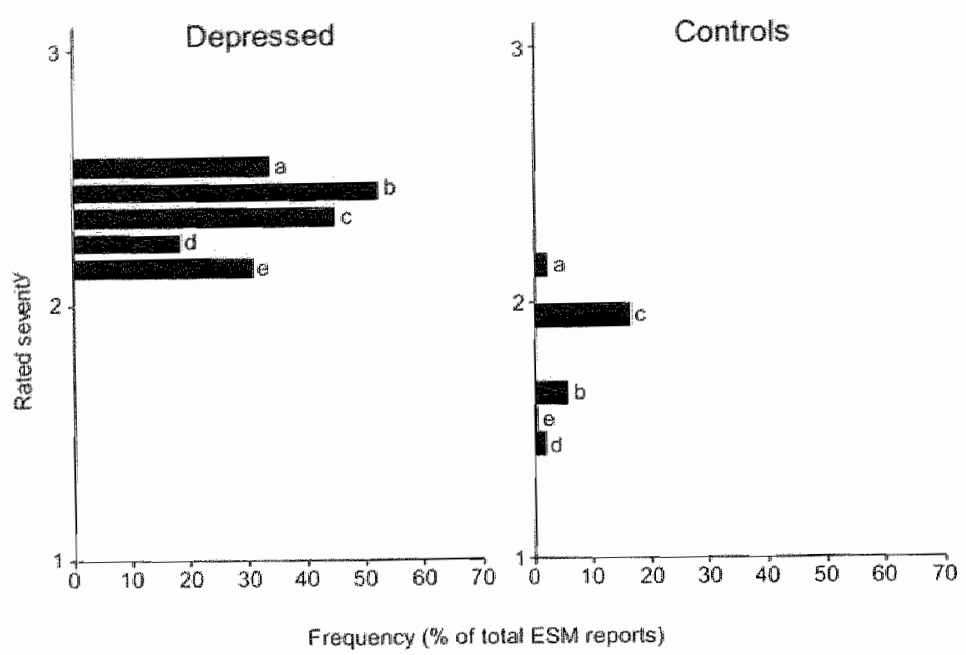

FIGURE 1. Frequency and severity of each type of physical complaine. $a=d r y$ mouth; $b=d$ trowsiness; $c=$ headache; $c=$ nausea; $e=$ dizziness. $X$ axis: Frequency of ESM reports mentiouing each complaint, expressed as a percentage of toral valid reports, was first calculated for each subject. The lengh of a batr tepresents the mean frequency of that complain over all subjects in each group. Depressed: $N=63 ;$ controls: $N=22$. $Y$-axis: A mean severity rating was first calculated for each subject's physical complaints, induding only those ESM reports in which the specific complaint was recorded. Iflacement of the bars indicates the man severity rating for each complaint in the subser of subjects who reporred that complaint. Depressed: ${ }^{2} N=48,{ }^{\circ} N=54, " N=57,{ }^{4} N=45$, " $N=51$; conrols: " $N=6, " N=8,{ }^{\circ} N=14, " N=3,{ }^{c} N=1$.

Table 2 (i.e. age, gender, work status, living circumstances, current depressive episode) was significantly associated with $\mathrm{MQOL}$ either in the control or the depressed groups. Furthermore, patients reported higher NA, lower PA, more physical complaints, and less enjoyment of the current acrivity. Overall, correlations between the measures were statistically significant and in the expected direction. When calculated separately, similar correlational patterns (not shown) were found in both groups.

Figure 1 shows average frequency of ESM complaint reports ( $x$-axis), and mean severtity ratings for physical complaints for subjects who reported a particular complaint ( $y$-axis) in the two groups. Over all ESM reports, each of the five physical complaints was reported by more than $70 \%$ of the depressed subjects. In contrast, complaints were rare in the control group: significantly fewer control subjects than patients ever experienced dizziness $\left(\chi^{2}=40.1\right)$, nausea $\left(\chi^{2}=22.2\right)$, dry mouth $\left(\chi^{2}=16.8\right)$, or drowsiness $\left(\chi^{2}=20.1\right.$; all $\left.p^{\prime} s<.001\right)$. Headache was relatively common in the control group, but still occurred in significantly fewer subjects than in the depressed group $\left(\chi^{2}=\right.$ $8.5, p<.01)$. Each complaint occurred with a greater frequency throughout the ESM sampling period in depressed than in control subjecrs (headache: $t=-4.1, d f=42$; dizziness: $t=-6.8, d f=63$; dry mouth: $t=-6.7, d f=71$; nausea: $t=-4.9, d f=77$; drowsiness: 


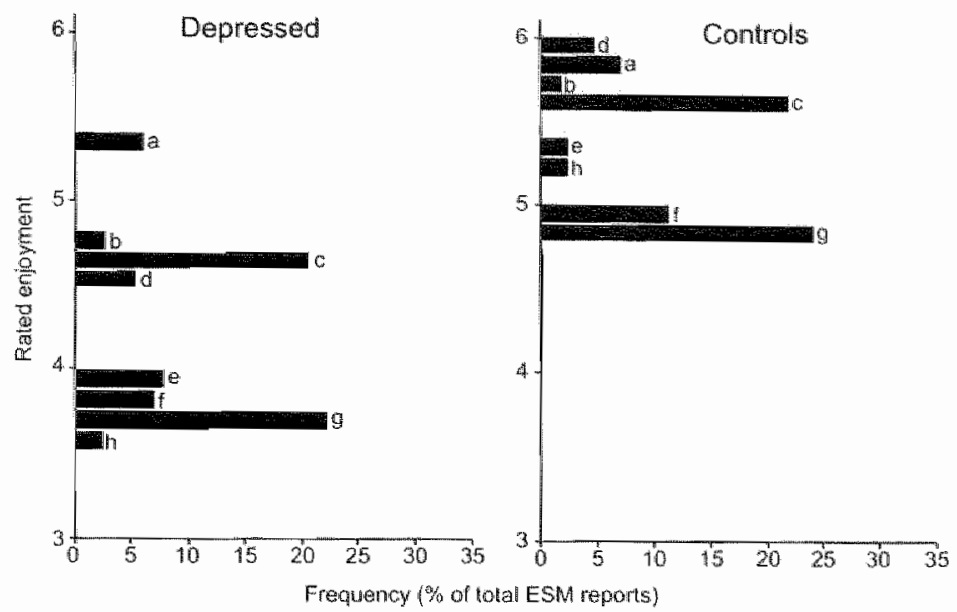

FICURE 2. Frequency and enjoyment of each category of activity. $a=$ active leisure $b=$ child care; $c=$ passive leisure; $d=$ social activities; $e=$ doing nothing; $f=$ work or study; $g=c_{\text {chores }}$ h $h=$ shoppirg. $X$-axis: Frequency of ESM reports mencioning each activity, expressed as a percentage of total valid reports "was first calculated for each subject. Length of rhe bars represents the mean frequency over all stubjects in each group. Depressed: $N=63 ;$ controls: $N=22$. Yaxis: A mean enjoyment rating was frist calculated for each subject's activities, including only those ESM reports in which the specific activity was recorded. Placement of the bars indicanes the mean enjoyment rating for each acrivity in the subser of subjects who reported that acriviry.

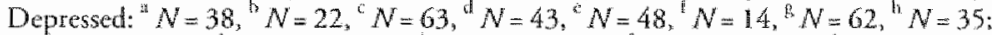
controls: ${ }^{\mathrm{a}} N=17,{ }^{\mathrm{b}} N=12,{ }^{c} N=9{ }^{\mathrm{d}} \mathrm{d} N=22,{ }^{\mathrm{c}} N=10,{ }^{\mathrm{f}} N=11,{ }^{\mathrm{g}} \mathrm{b} N=12,{ }^{\mathrm{h}} \mathrm{h}=22$.

$t=-8.7, d f=82$; all $\left.p^{3} s<.001\right)$. Complaints were also rated as more severe in the depressed than in the control group, with statistically significant differences observed for drowsiness $(t=-3.1, d f=13, p<.01)$, headache $(t=-2.8, d f=47, p<.01)$, and nausea $(t=-3.7, d f=5, p<.05)$.

With regard to reported activities, more depressed than control subjects reported at times to be doing nothing $\left(\chi^{2}=7.9, p<.01\right)$ and fewer depressed parients engaged in work activities $\left(\chi^{2}=8.0, p<.01\right)$, even though the two groups did not differ in employment status. As shown in Figure 2, there were few differences between the rwo groups in the frequency of performing various activities. Depressed subjects spent a greater percentage of time in doing nothing than controls $(t=-4.7, d f=77, p<.001)$. In contrast to the small differences in ime use, the groups differed markedly in the level of enjoyment experienced in daily acrivities, with depressed individuals reporting significantly less enjoyment than controls in all activities (doing nothing: $t=3.6$, df $=22$; work, sudy: $t=3.2, d f=24$; chores: $t=3.7, d f=38$; shopping: $t=3.8, d f=36$; passive leisure: $t=4.6, d f=60$; social acrivities: $t=3.9, d f=46$; all $\left.p^{\prime} s<.01\right)$, except child care $(t=1.6$, $d f=15, n s)$ and active leisure $(t=1.3, d f=22, n s)$. 
TABLE 4. Mulritevel model estimates for monentary QoL (mQoL).

\begin{tabular}{|c|c|c|c|}
\hline Variable & $B$ & $\operatorname{SE} B$ & $Z^{b}$ \\
\hline \multicolumn{4}{|l|}{ (a) Main effects model } \\
\hline Intercepr & .76 & .09 & $8.5^{* * * * * * *}$ \\
\hline \multicolumn{4}{|l|}{ Beeplevel } \\
\hline $\mathrm{PA}$ & .56 & .03 & $17.4^{\text {*ankin:*x}}$ \\
\hline$N A$ & -.47 & .03 & $-18.9^{*}$ \\
\hline Complants & -.34 & .02 & 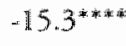 \\
\hline Enjoyment of activity & .05 & .01 & $3.5^{* * * * *}$ \\
\hline \multicolumn{4}{|l|}{ Person lewel } \\
\hline Group $^{4}$ & .29 & .12 & $2.5^{*}$ \\
\hline
\end{tabular}

\section{(b) Full model with interation terms}

Beep level by person level

\begin{tabular}{lccc} 
PAx Group & -.02 & .07 & -.27 \\
NA X Group & -.19 & .10 & -1.85 \\
Complaints x Group & .25 & .09 & $2.92^{* *}$ \\
Enjoyment of activity x Group & -.00 & .03 & -.04 \\
\hline
\end{tabular}

${ }^{a}$ Depressed $=1$; Control $=0$; $2 Z$-values are calculated by divading the estimatred regression coefficienr: $(B)$ by irs standard

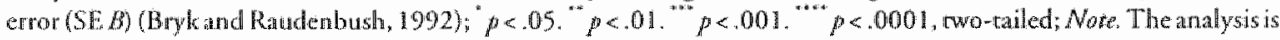
based on 3966 ESM reports. For the full model, at tocorrelations berween successive mQoL observations were escimated as 0.400 in the depressed group and 0.272 in the control group, both $p$ s $s<.0001$, likelihood ratio test.

TABLE 5. Explained variance in MQL at each level of the multilevel model.

\% Explained variance*

Main effects Full model

model

$\begin{array}{lll}\text { Depressed group } & & \\ \text { Person level } & 63.1 & 63.2 \\ \text { Daylevel } & 51.1 & 51.1 \\ \text { Beep level } & 41.2 & 41.2 \\ \text { Control group } & & \\ \text { Person level } & 38.9 & 34.3 \\ \text { Day level } & 42.8 & 46.9 \\ \text { Beeplevel } & 26.7 & 27.3\end{array}$

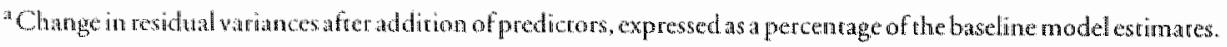




\section{Daily life influences on $m Q 0 L$}

We performed multilevel regression analysis to clarify the contriburion of daily life experiences to the overall decrement in $\mathrm{mQOL}$ in depression. The first model estimated the main effects of predictor variables, prior to the addition of interacrion terms. As shown in Table 4a, all four beep level variables had significant main effects on mQoL. Positive mood states and enjoyment of the current activity were clearly associated with a higher mQoL, whereas negative mood states and physical complaints were associated with lower $m Q$ oL. The small but significant effect of the person level variable Group confirms that $\mathrm{mQOL}$ levels were lower on average in the depressed group. Notably, when the beep level predictors PA, NA, complaints, and enjoyment of current activity were removed from the model, Group had a much larger effect $(B=-1.9, Z=-12.7, p<$ .0001 ), which indicates that the effect of a major depression on $\mathrm{mQoL}$ was largely mediated by these other variables.

Interaction terms were next added to the model to test for differences between depressed and control groups in the importance of the beep level predictors. All main effects that were found in the first model (Table 4 a) remained significant. Table $4 \mathrm{~b}$ therefore presents only results for the interaction terms in the full model. Physical complaints had a significantly less negative effect on $\mathrm{mQoL}$ in the depressed than in the control group. NA, on the other hand, tended to have a more negarive influence on mQoL in the depressed group $(p<.10)$.

The strength of these findings can be evaluated by examining how much of the variance in $\mathrm{mQOL}$ is explained by each model (i.e., the main effects model and the full model with interaction effects). As independent variables are added to a model with only the fixed effect of Group (which we will refer to as the baseline model), the residual mQoL variances observed at each level in the model decrease; these changes in variance components can be used to estimate the percentage of baseline variance in mQol. that is explained, at each level, by the chosen set of predictor variables (for further details, see Kreft and de Leeuw, 1998). In Table 5, explained variances are shown, expressed as percentages of baseline variances. In the main effects model, beep and person level variables togerher accounted for a considerable percentage of the variability in $\mathrm{mQOL}$ at all three levels in the control group, with an even better fit in the depressed group. It is clear that the addition of interaction terms (full model) did little to improve the model, as the percentages of overall explained variance did not increase. For this reason, the group by complaint effect (see'Table 4), although significant, should be interpreted with caution.

\section{Variability in $m Q o L$}

To test the hypothesis that $m$ QoL would show greater variability in depressed than in control subjects, we estimated the variances of the baseline model as shown in Table 6. As predicted, $\mathrm{mQoL}$ was less stable within depressed than within control subjects. Beep level variance was significantly larger in the depressed group (likelihood ratio test, $p<$ 
TABLE 6 . mQL variance components in the multilevel reference model.

\begin{tabular}{lc} 
& Variance estimate \\
\hline Depressed group & .76 \\
Person level & .18 \\
Day lewel & .71 \\
Beep level & 1.65 \\
TOTAL. & .18 \\
Control group & .33 \\
Person level & \\
Day level & .66 \\
Beep level & \\
TOTAL &
\end{tabular}

Notc. All variance cstimates are statistically significant, p < .0001, likelihood ratio rest (Bryk and Raudenbush, 1992).

$.00001)$. In addition, the significant $(p<.05)$ difference between the two groups in person level variance indicates greater heterogeneity in average $\mathrm{mQoL}$ levels among subjects in the depressed group. Differences between depressed and control groups in day level variability, on the other hand, were not significant.

Examining the contributions of person, day, and beep level variance components to total variance provides information about the relative importance of intraindividual ('state') versus interindividual ('trait') variability in $\mathrm{mQoL}$. Based on the data in Table 6 , person level variance in the depressed group represented $46 \%$ of the total variance; day level, $11 \%$; and beep level, $43 \%$. In the control group, the distribution of variance components was $27 \%$ at the person level, $23 \%$ at the day level, and $50 \%$ at the beep level. Thus, there was substantial intraindividual (beep level and day level) as well as interindivicual (person level) variability in $\mathrm{mQoL}$ in both groups. Beep level variance was larger than day level variance, indicating that mQoL fluctuated more widely within than between days.

\section{Predictors of global QoL}

How do the ESM findings correspond to global assessments made at the end of the week? First, we examined the correlations between each of the ESM aggregated measures (mQoL, PA, NA, complaints and enjoyment of activities) and its related global assessment. All correlation coefficients were statistically significant $(r \geq 0.70$, all $p$ s $<$ .01 , one-tailed), except for the correlation between mean mQoL (aggregated per subject $)$ and SF-36 PCS $(r=0.12, n s ;$ one-tailed). Similar patterns were found in both 
TABLE 7. Summary of regression analysis for global measures predicting QOL VAS and $5 \mathrm{~F}-36 \mathrm{MCS}$ scores $(N=85)$.

\begin{tabular}{|c|c|c|c|c|c|c|}
\hline \multirow[b]{2}{*}{ Variables } & \multicolumn{3}{|l|}{ QOL VAS } & \multicolumn{3}{|c|}{ SF-36 MCS } \\
\hline & $B$ & $\operatorname{SE} B$ & $\beta$ & $B$ & SE $B$ & $\beta$ \\
\hline \multicolumn{7}{|l|}{ Global measures } \\
\hline PA & .36 & .25 & .14 & .28 & .15 & .18 \\
\hline NA & -.68 & .22 & $-.27^{* *}$ & -.41 & .14 & $-.27^{* *}$ \\
\hline Complaints & -.36 & .46 & -.06 & -.27 & .27 & -.08 \\
\hline Enioyment of acrivity & 1.03 & .73 & .13 & .27 & .46 & .06 \\
\hline Group & -21.70 & 5.19 & $-39^{* * *}$ & -14.59 & 3.15 & $-.45 *$ \\
\hline
\end{tabular}

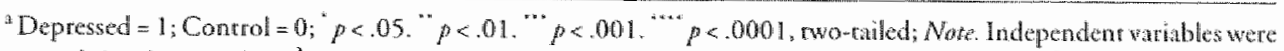
entered simultaneously. $R^{2}=.68(F=33.0, p<.0001)$ for the equation predicting QoL VAS; $R^{3}=.79(F=39.3, p<$ .0001) for SF-36 MCS.

groups, except for the correlation between mean $\mathrm{mQoL}$ and SF-36 MCS, which was positive in the depressed group only (depressed: $r=0.29, p<.05$; controls: $r=-0.12, n s$; one-tailed).

Next, multiple regression analyses were conducted with the global assessments $\mathrm{QOL}$ VAS and SF-36 MCS as dependent variables and retrospective measures of PA, NA, complaints, and enjoyment of activities as independent variables. Results are shown in Table 7. In contrast to the multilevel resullts for ESM measures, although depression (the variable Group) was again a good predictor of QoL measures, only NA had a significant added effect.

\section{DISCUSSION}

This study used experience sampling methodology (ESM) to investigate wo aspects of the quality of life in depression: subjective well-being and daily functioning. Well-being, or momentary QoL (mQoL), was assessed wirh the question 'In general, how is it going with you righr now?". As expected, depressed subjects experienced lower levels of $\mathrm{mQoL}$ than healthy controls. Results of mulrilevel regression analysis indicated that positive affect, negative affect, and physical complaints had large independent effects on $\mathrm{mQoL}$, with enjoyment of activiries making a small bur significant addirional contriburion. Although depression had a major effect on mQoL when it was the only predictor, its estimated effect decreased markedly after the addition of the daily experience variables to the model. In other words, these variables partially mediated the effect of depression on $\mathrm{mQoL}$. On the other hand, the finding that depression continued to have a significant effect on mQoL after controlling for mood, physical complaints, and enjoyment of activities means that orher, unmeasured aspects of depression 
had an impact on self-assessed well-being. These could include, for example, cognitive disturbances, negative social interactions, or difficulty in coping with daily stressors. Finally, it is important to note that the same variables were predictors of $\mathrm{mQOL}$ in healthy control subjects as in depressed subjects. The total percentage of mQoL variance explained was clearly less in the control than in the depressed group, however. We speculate that environmental contexts (social and work activities, for example) may have had larger infuences on $\mathrm{mQoL}$ in healthy individuals, and that these effects were not mediated by the predictor variables in our model.

Depressed subjects were much more likely to report frequent and/or severe physical complaints than control subjects were. Because the complaints we assessed (dry mouth, dizziness, drowsiness, nausea, and headache) are considered to be common side effects of antidepressants (Cassano et al., 1994), it was surprising to find that the majority of patients experienced these symptoms prior to any treatment. A recent study of untreated depressed patients in primary care, however, confirms that symptoms resembling side effects are very common (Rollman et al., 1997). The fact that negative mood states can trigger physical symptoms (Verbrugge, 1985) may provide some explanation. Although aggregated ESM measures of NA and complaints were indeed positively correlated, both variables made independent contributions to $\mathrm{mQOL}$ in the current model.

Variance component estimates in the multilevel model confirmed the importance of both trait and state aspects of mQoL. The finding that more than half of the total variance represented intraindividual fluctuations (beep and day level) points to a large influence of transient situational factors on $\mathrm{mQoL}$ in both groups. As hypothesized, depressed subjects showed grearer within-person variability in $\mathrm{mQoL}$, from moment to moment and from day to day, than controls. This instability in subjective well-being could be a temporary phenomenon, related to a depression-induced dysregulation of normal oscillations in mood (see, for example, Hall et al., 1991), or it could be related to a pre-existing trait (like neuroticism, Eid and Diener, 1999) associated with greater vulnerability to negarive daily experiences (Gable and Nezlek, 1998). This remains an important question for future longitudinal studies. Interindividual variability was also greater in the depressed than in the control group; we speculated that differences in $\mathrm{mQoL}$ levels among depressed patients might correlate with symptom severity (Zung score), which they did $(r=-0.59, p<001)$. This was not the case in the control group ( $r$ $=-0.32, n s)$. We found no association, however, berween within-subject variability in mQoL and Zung scores in either the depressed group $(r=0.05, n s)$ or in the controls $(r=$ $0.18, n s)$.

A second aspect of QoL, daily functioning, was operationalized as the frequency with which an individual engaged in productive, social, and leisure activities, in conrrast to inactivity, over the six days of experience sampling. Analysis of time use patterns showed that fewer depressed individuals reported work or study activities. In addition, a greater proportion of the depressed group reported daily periods of "doing nothing", 
and this activity state represented a greater percentage of the daily time budger for depressed than for control subjects. Previous research on QoL in depression has mentioned reducrions in productive, social or leisure activities (for a recent review, see Katschnig and Angermeyer, 1997). We, however, found no significant differences between depressed and control groups in time spent in social, leisure, or maintenance activities. An earlier ESM study of time use in psychiatric and psychosomatic disorders and healthy controls showed that percentages of time spent doing nothing was higher in severe psychiatric disorders (including major depression); furthermore, doing nothing was associated with low PA and high NA, suggesting that this state may be a behavioral marker of low QoL (Barge-Schaapveld et al., 1997). Due to the poor reliability of retrospective estimates of time use (Bernard et al., 1984), time-sampling methods like ESM may be especially valuable in assessing illness-related reductions in productive and enjoyable activities. Although it may be impossible to unravel the causal connection between activities and psychopathological symptoms, case studies provide some evidence that therapeutic attempts to influence parterns of time use can be effective in improving mental status (Delle Fave and Massimini, 1992; Barge-Schaapveld et al., 1997).

Ratings of $\mathrm{mQOL}$ averaged over the sampling period were highly correlated with global assessments of QoL. Whereas ESM measures of NA, PA, physical complaints, and enjoyment of activities were highly associated with mQoL, however, only NA was a significant predictor of global QoL in a regression analysis using aggregated or questionnaire measures of the same variables. The greater sensitivity of $\mathrm{mQoL}$ to transient states and daily experiences underscores the porential value of the ESM approach as a tool in understanding changes in QoL during the course of depression and its treatment.

Whether an ESM approach to QoL assessment is 'better' than validated questionnaire or interview measures, however, will depend on the research questions, the setting, and the resources. A drawback of ESM is that it is relatively time-consuming for both the participant and the researcher. The demands of repeatedly completing ESM forms over several days may prove too great for some depressed patients, especially individuals with limited education, cognitive disturbances, or the elderly (Kraan et al., 1992; Wilson et al., 1992). To the extent that these factors result in refusal to participate or drop-outs during ESM, they could bias results. Whereas drop-outs in the current study were not significantly more common among patients than controls, the finding that parients who did not adequately complete the ESM study had higher Zung scores and were somewhat younger than patients included in the analysis does suggest that the sample may not have been completely representative of the population of depressed patients in primary care settings. However, the ability of the majority of the participants to complete the study, as well as successful previous applications of ESM in psychiarric disorders (deVries, 1992 a; Barge-Schaapveld er al., 1995; Delespaul, 1995), shows that the method is feasible in major depression. 
Beyond research applications, ESM has potential for use in clinical practice. Individualized profiles of quantitative ESM results and qualitative information obtained during the debriefing session can, in our experience, provide patients and therapists with valuable insights (deVries, 1992b; Donner, 1992). Individual therapies could be tailored to promote situations or states associated with maximum $m Q O L$ and to reduce exposure to or improve coping with situations that have negative effects on $\mathrm{mQOL}$. ESM could also be adapted for monitoring treatment adherence, or performance and response to homework assignments in cognitive or behavioral interventions (Donner, 1992). Future studies are needed to supplement descriptive case studies, which are currently the only source of information about clinical applications of ESM in psychiatric disorders.

The study had a number of limitations. Firstly, we assessed momentary quality of life with a single item ( $\mathrm{mQOL})$, which has psychometric disadvantages compared to multi-item measures (see Diener, 1984). In favor of the measure, the strong correlations berween average mQoL scores and the mental component of the SF-36, a widely accepted multi-item measure, support the construct validity of $\mathrm{mQoL}$, and the frequendly repeated measurements of $\mathrm{mQoL}$ can also be expected to increase the reliability of the results (Kraemer et al., 1994). More work is needed, however, to develop a valid and reliable multi-item $\mathrm{mQoL}$ scale. Secondly, several variables that are likely to have important influences on QoL were not examined; these include daily events (Emmons, 1991) and the quality of social interactions (Gannon et al., 1992), trait characteristics such as neuroticism (McCrae and Costa, 1991), and long-term influences, such as life satisfaction (Barry, 1997) or the quality of the living environment (e.g., employment, housing, social networks) (Katschnig and Angermeyer, 1997). Finally, interpretation of the state versus trait aspects of $\mathrm{mQoL}$ is limited by the short time-frame (six days) of the study. Longitudinal follow-up through treatment and clinical recovery, using the same measures, will be necessary to determine whether decreased mQoL levels and increased lability of mQoLare state characteristics of current depression or whether residual symptons or 'scars' remaining after a depressive episode result in persistent, traitlike changes in mQoL and its components. Similarly, follow-up data are needed to assess whether ESM measures can help predict short-term compliance with treatment, early response to treatment, or longer-term clinical outcome.

\section{REFERENCES}

Agosti, V., Stewart, J. W., Quitkin, F. M., 1991. Life satisfaction and psychosocial functioning in chronic deptession: effect of acute treatmen with antidepressants. Journal of Affective Disorders $23(1), 35-41$.

American Psychiatric Associanion, 1987. Diagnostic and Staristical Manual of Mental Disorders, 3rd ed. rewised. American Psychiatric Association, Washingron, DC. 
Andrews, F. M. McKennell, A. C., 1980. Measures of selfreported well-being their affective, cognirive. and other components. Social Indicators Research 8, 127-155.

Axkinson, M., Zibin, S., Chuang, H., 1997. Characterizing quality of life among patients with chronic mental illness: a critical examination of the self-report methodology. American Joumal of Psychiatry $154(1), 99-105$.

Barge-Schapveld. D. Q. C. M., Nicolson, N. A., Delespaul, P. A. E. G., deVries, M. W., 1997. Assessing daily qualiry of life with the Experience Sampling Method. In: Katschnig, H., Freenan, H., Sartorius, N. (Eds.), Quality of Life in Menral Disorders. John Wiley \& Sons Lud, Chichester, pp. 95-10\%.

Barge-Schaapweld, D. Q. C. M., Nicolson, N. A. Gerritsen wan der Hoop, R., deVries, M. W. 1995. Changes in daily life experience associared with clinical improvement in depression. Journal of Affective Disorders 34, 139-154.

Barry, M. M. 1997. Well-being and life sat isfaction as components of quality of life in mental disonders. In: Karshnig, H., Freeman, H, Sartorius, N. (Eds.), Quality of Life in Mental Disorders. John Wilcy \& Sons, Chichester, pp. 31-42.

Bernard, H. R., Killworth, P., Kronenfeld, D., Sailer, L., 1984. The problem of informant accuracy the validity of retrospective data. Annual Review of Anthropology 13,495-517.

Bryk. A. S., Raudenbush, S. W., 1992. Hierarchical Linear Models: Applications and Dara Analysis Merhods. Sage Publications, London.

Butler, A. C., Hokanson, J. E., Flynn, H. A., 1994. A comparison of self-esteem lability and low rrait self-esteem as vulnerability factors for depression. Journal of Personality and Social Psychology 66, $166-177$.

Cassano, G. B., Toni, C., Petracca, A., Deltito, J., Benkert, O., Curtis, G., Hippius, H., Maier, W., Shera, D. Klerman, G., 1994. Adwerse effects associated with the short-term treatment of panic disorder with imipramine, alprazolam or placebo. European Neuropsychopharmacology 4, 47-53.

Corrigan, P. W., Buican, B., 1995. The construct validity of subjective quality of life tor the severely mentally ill. Joumal of Nervous and Mental Disease 183,281-285.

Csikszentmihalyi, M., Larson, R., 1987. Validity and reliability of the Experience Sampling Method. Joumal of Nerwous and Mental Disease 175(9), 526-537.

Delespaul, P. A. E. G., 1995. Assessing Schizophrenia in Daily Life: The Experience Sampling Merhod, Ph.D. dissertation, Maastricht Unjversiry, Universitaire Pers, Maastricht.

Delle Fave, A., Massimini, F., 1992. The ESM and the measurement of clinical change: a case of anxiety disorder. In: deVries, M. W. (Ed.), The Experience of Psychopathology" Invesuigating Mental Disorders in Their Narural Setrings. Cambridge University Press, Cambridge, pp. $280-289$.

deVries, M. W., 1992a. The Experience of Psychopathology: lnwestigating Menal Disorders in Thoir Natural Setrings. Cambridge University Press, Cambridge.

deVries, M. W, 1992b. The uses of the ESM in psychatherapy In: deVries, M. W. (Ed), The Expericnee of Psychopathology: Investigating Mental Disorders in Their Natural Setrings. Cambridge Universing Press, Cambridge, pp. 255-259.

deVries, M. W. Delespaul, P. A. E. G., Nicolson, N. A., 1999. Experience Sampling Merhod (ESM). In: Salek, S. (Ed.), Compendium of Quality of Life Instruments. John Wilcy \& Sons, Chichester, pp. 2L:6; 2L:6a.

Diener, E., 1984. Subjective well-being. Psychological Bulletin 95(3), 542-575.

Diener E, 1994. Assessing subjecrive well-being: progress and opportunities. Social Indicators Research $31.103-157$.

Dingemans, P., wan Engeland. H., Dijkhuis, J. H., Bleker, J., 1985. De Diagnostic Interview Schedule" (DIS). Tijdschrift woor Psychiatrie 27(5), $341-359$.

Donner, E, 1992. Expanding the experiential parameters of cognitive therapy. In: deVries, M. (Ed), The Experience of Psychopathology: Investigating Mental Disorders in Their Natural Setrings. Cambridge University Press, Cambridge, pp. 260-269. 
Dubbar, G. C., Stoker, M. J., Hodges, T. C. P., Beaumont, G. 1992. The development of SBQOL: a unique scale for measuring quality of life. Brirish Journal of Medical Economics 2, 65-74.

Eid, M., Dienter, E, 1999. Intraindividual wariability in affect: reliability, validity, and personality correlates. Journal of personality and Social Psychology $76,662-676$.

Emmons, R. A., 1994. Personal srrivings, daily life evercs, and psychological and physical well-being. Joumal of Personality $59(3), 453-472$.

Enadicon, J. Wee, I., Harrison, W., Blumenthal, R, 1993. Quality of Life Enjoyment and Sarisfacion Questionnaire; new measure. Psychophamacology Bulletin 29(2), 321-326.

Gable, S. L., Nealek, J. B. 1998. Level and instabilicy of day-to-day psychological well-being and risk for depression. Journal of Personaliry and Social Psychology 74(1), 129-138.

Gannon, L., Vaux, A., Rhades, K., Lucherta, T., 1992. A wo-domain model of well-being: everyday events, social supporn and gender-relared personality factors. Journal of Research in Personality 26(3), 288 $80 \%$

Goethe ${ }_{\text {. }}$. W. Fischer, E. H. 1995. Funcrional impairment in depressed inparients. Journal of Affective Disorders 33, 23-29.

Goldstein, H., 1995. Mulrilevel Statistical Models, 2nd ed. Arnold, London.

Guy, W. 1976. ECDEU Assessment Manual for Psychopharmacology. US Department of Health, Educarion and Welfare, Rockille, MD, Pp. $59-70$.

Hall, D. P. Jr., Sing, H. C., Romanoski, A. J., 1991 . Identificarion and characterization of greater mood variance in depression. American loumal of Psychiarry 148, 1341-1345.

Hamilton, M., 1960. A rating scale for depression. I Neurol Neurosurg Psychiat 23, 56-62.

Helzer, J. E, Robins, L. N., McEvoy, L. T., Spirznagel, E. L., Stoltzman, R. K., Farmer, A., Brockingron, I. F., 1985. A comparison of dinical and diagnostic interview schedule diagnoses. Archives of General Psychiarry $42,657-666$.

Hunt, S. M., Mckenna, S. P., 1992. The QLDS: A scale for the measurement of quality of life in depression. Healch Policy 22, 307-319.

Katschnig, H., Angermeyer, M. C., 1997. Quality of life in depression. In: Katschnig, H., Freeman, H., Sartorius, N. (Eds.), Quality of Life in Mental Disorders. John Wiley \& Sons Lrd, Chichester, pp. $137-147$

Kraan, H., Meertens, H., Hilwig, M., Volovics, L., Dijkman-Caes, C. I. M., Portegijs, P., 1992. Selecting measures, diagnostic validiry and scaling in the study of depression. In: deVries, M. W. (Ed.), The Experience of Psychopahology: Investigating Mental Disonders in Their Natural Setrings. Cambridge University Press, Cambridge, pp. 324-338.

Kratemer H. C., Gullion, C. M. Rush, A. I. Frank, E. Kupfer, D. J., 1994 . Can state and trair wariables be disentangled? A methodological framework for psychiatric disorders. Psychiarry Research 52,55-69.

Kreft, I., de Leeww, J., 1998. Introducing Multilevel Modeling. Sage Publications, London.

Lehman, A.F., 1997. Instruments for measuring qualiny of life in mental illnesses. In: Katschnig, H., Erectuan, H. Sartorius, N. (Eds.), Quallity of Life in Mental Disorders. John Wiley \& Sons Lud, Chichester, pp. 79-94.

Markowitz, J. S., Weissman, M. M., Ouellere, R. Lish, J. D. Klerman, G. L., 1989. Quality of life in panic disorder. Archives of General Psychiary 46, 984992.

MeCrue, R. R., Costa, IP. T. 1991. Adding Liebe und Arbeit: The full rve-factor model and well-being. Personaliry and Social Psychology Bulletin 17(2), 227-232.

Prosser, R., Rasbach,J., Goldstein, H., 1996. MLn User's Guide. Insticute of Educarion, London.

Pyne, I. M. Patrerson, T. L.. Kaplan, R. M., Gillin, I. C., Koch, W. L.. Grant, I., 1997. Assessment of the quality of life of pacients with major depression. Psychiartic Services $48(2), 224-230$.

Roberts, J. E., Kassel, J. D. . 1997. Labile self-esteem, life stress, and depressive symptoms: Prospecrive data resting a model of vulneabiliry. Cognitive Therapy and Research $21,569-589$. 
Rabins, L. N., Helzer, I. E., Orvaschel, H., Anchony, J. C., Blater, D. G., Burnam, A., Burke, I. D., 1985. The Diagnostic Interwiew Schedule. In: Eaton, W. W. Kessler, L. G. (Eds.), Epideniologic Field Methods in Psychiatry: The NIMH Epidemiologic Catchment Area Program. Academic Press, Orlando, pp. $143-170$.

Rollman, B. L., Block, M. R., Schulberg, H. C., 1997. Symproms of major depression and rricyclic side effects in primary care patients. Jourmal of General Internal Medicine 12(5), 284-291.

Spilker, B, 1990. Quality of Life Assessments in Clinical Trials. Raven Press, New York.

Stoker, M. J., Dunbar, G.C., Beaumont, G., 1992. The SmithKline Beecham 'Quality of Life' scalle: a validation and reliability study in parienes with affectivedisonder. Quality of Life Research 1(6),385-395.

Sullivan, L. M., Dukes, K. A., Losina, E., 1999. An introduction to hierarchical linear modelling. Stanistics in Medicine 18, 855-888.

wan der Zee, K. L, Sanderman, R. Heyink, ]. W., de Haes, H. 1996. Psychomerric qualities of the RAND 36-irem health survey 1.0: a multidimensional measure of generat health status. International Joumal of Bellavioral Medicine 3(2), 104-122.

van Eck, M., 1996. Stress, Mood, and Cortisol Dymamics in Daily Life, Ph.D. dissertation, Maastricht University, Universitaire Pers, Maastrichr.

Verbrugge, $\mathbb{L}$. M. 1985. Triggers of symproms and health care. Social Science and Medicine 20(9), 855-876.

Ware, J. E., 1996. The SF-36 Healch Survey. In: Spilker, B. (Ed.), Quality of Life and Pharmacoeconomics in Clinical "Trials, 2nd ed. Lippincort-Raven Publishers, Philadelphia, pp. $337-345$.

Warson, D., 1988. Intraindividual and interindividual analyses of positive and negarive affect their relation to heal th complaints, perceived stress, and daily acrivities. Journal of Personality and Social Psychology 54(6), 1020-1030.

Watson, D., Clark. L. A., Mclntyre, C. W., Hamaker, S. 1992. Affect, personallicy, and social acriviry. Journall of Personality and Social Psychology 63(6), 1011-\$1025.

Warson, D., Clark, L. A., Tellegen, A., 1988. Development and validation of brief measures of positive and negative affect: the PANAS scales. Journal of Personaliry and Social Psychology 54(6), 1063-1070.

Wells, K. B., Stewwrt, A., Hays, R. D., Bumam, M. A., Rogers, W., Daniels, M., Berry, S., Greenfield, S., Ware, J. 1989. The functioning and well-being of depressed patients. Results from the Medical Outcomes Sudy. Journal of the American Medical Association 262(7), 914-919.

Wilson, K. C. M. Hopkins, R, deVries, M. W., Copeland, I. R. M., 1992. Research alliance and the limit of compliance: Experience Sampling with the depressed elderly. In: deVries, M. W. (Ed.), The Experience of Pychoparhology: Jnvestigating Mental Disorders in Their Natural Settings. Cambridge University Press, Canbridge, pp. 339-346. 



\section{PART III \\ MAIN STUDY (STUDY 2)}

CHAPTER 6

Effects of antidepressant treatment on the quality of daily life: An experience sampling study

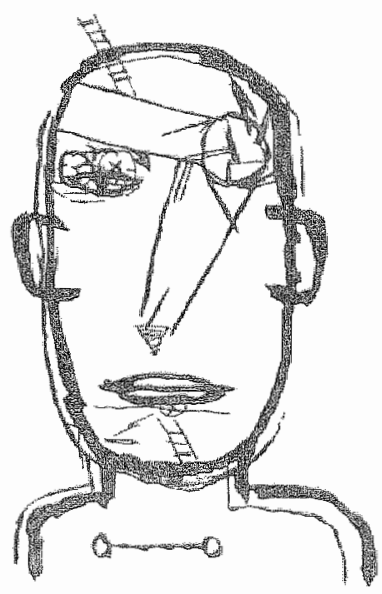

Barge-Schaapveld, D. Q. C. M., Nicolson, N. A. Effects of antidepressant treatment on the quality of daily life: an experience sampling study. Journal of Clinical Psychiatry, under review. 


\section{Effects of antidepressant treatment on the quality of daily life: An experience sampling study}

Background: Although some depression trials have included quality of life (OoL) as an outcome meaw sure, assessments were retrospective and relatively infrequent. Because Qoll varies in relation to everyday experience, intensive time-sampling approaches may be useful.

Method: The Experience Sampling Method (ESM) was used to assess effects of antidepressant treatment on the quality of life, as measured from moment to moment in daily life (mQoL), and related aspects of daily experience. Primary care patients with major depression $(N=63)$ were randomly assigned to imipramine (IMI) or placebo (PLA) treatment for 6 weeks, with possible prolongation to 18 weeks. A healthy control group $(N=22)$ provided normative data.

Results: Treatmentrelated increases in frequency or severity of physical complaints, including those not reported to the general practitioner as side effects, were associated with lowered $\mathrm{mQoL}_{\text {; }}$ increased complaints were especially prominent in treatment drop-outs. Despite greater clinical improvement at week 6, IMI patients did not report greater increases than PLA patients in mean mQoL. However, IMI treatment stabilized mQot fluctuations and led to reductions in time spent 'doing nothing'. Pattients' decisions to prolong treatment depended on clinical improvement, mQol changes, and specific early side effects. At 18 weeks, remitted patients still showed deficits on ESM daily life measures relative to healthy controls, even though Qol. had returned to normal on retrospective measures.

Conclusion: ESM provides new insights in the effects of antidepressant treatment on daily life experiences and should therefore be considered as a supplement to conventional instruments in clinical trials. 


\section{INTRODUCTION}

Quallity of life (QoL) has become an accepted outcome measure in clinical drug trials, going beyond measures of symprom reduction. The acknowledged importance of QoL is reflected in an increasing trend over the past two decades to use QoL measures in clinical trials in all medical subdisciplines (Sanders et al., 1998). The same period has also seen a growing interest in the effects of drug treatments on QoL in depressive disorders. There are several reasons for this interest. First, depression has been recognized as a debilitating disorder with significant impairments in many areas of daily life (De Lisio et al., 1986; Wells et al., 1989), and treatment-related improvements in these areas are not adequately reflected in clinical rating scales. Another reason is that available antidepressant treatments, although comparable in terms of efficacy, may have different effects on QoL by virtue of their divergent side effect profiles (Song et al., 1993; Anderson and Tomenson, 1994). Finally, QoL evaluations assess the global impact of aspects related to side effect profile from the viewpoint of the patient and, hence, may provide better insight in to the effects of different antidepressants than efficacy measures alone.

Following the approach taken by Sanders et al. (1998), we conducted a literature search over the period 1980-2000 and identified 42 randomized, controlled trials (RCTs) of pharmacological treatments in unipolar depressive disorders that included QoL assessments. Although only a small minority of these studies included a placebo $\mathrm{atm}$, the nine studies that did reported significant differences between active and placebo groups on various dimensions of QoL, such as social relationships, life satisfaction, and leisure activities (Lydiard, 1994; Kocsis et al., 1997), thus supporting the hyporhesis that antidepressants improve QoL in depressed patients. A number of questions remain, however.

Firstly, although side effecrs of antidepressants are widely believed to have a negative impact on the quality of life, research findings on this relationship are relatively meager (Healy, 1999). Because QoL is generally assessed at the end of treatment, when most side effects have subsided, information on the influence of early-appearing side effects is particularly scarce. Physical complaints experienced during the first week or two of treatment can contribute to poor compliance and early termination of treatment (Blackwell, 1982; Cookson, 1993), and it is thus important to investigate the frequency, severity, and QoL impacr of early side effects as they are experienced in daily life.

Secondly, certain features of the QoL measures typically used in such studies place limitations on their ability to capture the full impact of the illness and its treatment on QoL.

All QoL measures, whether generic (e.g. SIP, Sechter et al., 1999) or depression-specific (e.g. Q-LES-Q, Leinonen et al., 1999), assess patients' QoL retrospectively, usually over the past week. In general, but even more so in depression research (Atkinson et al., 1997), retrospective measures are vulnerable to influences of current 
affective state, forgetting, cognitive re-framing, and other sources of bias (Diener, 1994). This problem is compounded by the fact that most studies rely on single preand post-treatment measures. Both retrospective bias and infrequent measurement can reduce the reliability of QoL assessments.

A related limitation of conventional QoL measures is that they summarize average levels of well-being and thus cannot reveal how QoL varies in relation to everyday contexts and experiences. QoL is influenced by affect (Corrigan and Buican, 1995), physicall symptoms (Pyne et al., 1997), and sarisfaction with daily activities (Goethe and Fischer, 1995), all of which vary within the course of a single day. In orher words, QoL has state as well as trait properties. Moreover, there is evidence that variability in QoL, from moment-to-moment or from day-to-day, is heightened in individuals most vulnerable to depression (Gable and Nezlek, 1998). Whether pharmacological treatment stabilizes QoL is as yet unknown, but this could prove to be a useful outcome measure.

Finally, RCTs have not yet clarified the time course over which aspects of QoL recover to 'normal' levels during antidepressant treatment. Six of the identified papers compared post-treatment findings to normative data; results indicated, for example, that QoL levels remained lower in clinically improved depressed patients than in a normative sample of the US (Walker et al., 1995) or Finland (Lonnquist et al., 1994). However, the trearment duration in these studies ranged from 6 to 12 weeks, which might have been too short for QoL aspects to normalize. In addition, in only one study (Ravindran et al., 1999) was a group of healthy subjects recruited for direct comparison; in the other studies, differences in demographic characteristics, location, and time could have biased the comparisons with the controls.

\section{The current study}

To redress some of the limitations of earlier studies, the current study of the effects of pharmacological treatment on QoL used an intensive time-sampling approach. The experience sampling method (ESM) was developed to measure subjective experience over time and across situations (Csikszentmihalyi and Larson, 1987). During their normal daily routines, subjects complete frequent self-reports with respect to their mood, activity, location, and social context, in response to signals they receive at frequent but unpredictable intervals over a period of several days or a week. Advantages of the method include greater ecological validity and increased reliability, due to the repeated measurements and reduction in retrospective bias through time-sampling. Among many other applications, ESM has been used in research on psychiatric and psychosomatic disorders (deVries, 1992), including studies of QoL (Barge-Schaapveld er al., 1997; Barge-Schaapveld et al., 1999; deVries et al., 1999). To date, however, applications of ESM in the context of a clinical trial have been limited to a handful of studies: our initial study in a small sample of depressed outpatients treated with amitriptyline or 
fluvoxamine (Barge-Schaapveld et al., 1995), a pilot investigation of the effect of relaxarion training on asthma symptoms (Smyth et al., 1999), and two recent studies that used ESM to evaluate the effects of pharmacological treatments on nicorine craving and withdrawal symptoms during smoking cessation (Shiffman et al., 2000a; Shiffman er al. $2000 \mathrm{~b}$ ). Results obtained so far in ESM studies suggest that applying an intensive time-sampling approach in the context of a clinical trial may provide a better and more reliable understanding of the effects of treatment on the quality of daily life experience. In a previous analysis of ESM data collected in the same sample of depressed outparients prior to treatment (Barge-Schaapveld et al., 1999), we found that self-reports of general well-being ('momentary $\mathrm{QoL}$ ', or $\mathrm{mQoL}$ ) showed considerable variation over the course of a day, with significantly greater within-person variability in depressed patients than in healthy controls. In borth groups, positive and negative mood stares, enjoyment of daily activities, and physical complaints had independent influences on mQoL. As expected, depressed patients had more negative (or less positive) scores on all of these variables than controls. In a different sample of depressed outpatients, we found that positive mood increased, negative mood decreased, and patterns of time use changed (time spent in chores increased and time spent in passive leisure decreased) following successful treatment with fluwoxamine or amitriptyline (Barge-Schaapveld et al., 1995).

The current study was designed to extend these findings in a number of ways:

(1) Inclusion of assessments during the first week of treatment in the longitudinal design of the study allows investigation of the relarionship between early side effects, $\mathrm{mQoL}$, and subsequent termination of treatment. Patients with side effects were expected to experience lower levels of $\mathrm{mQoL}$ than patients without side effects (assuming that the positive effects of active treatment would not yer be apparent) and, as a consequence, be more likely to withdraw from treatment.

(2) In contrast to an earlier ESM study (Barge-Schaapveld et al., 1995), the current study was placebo-controlled, so thar observed changes in daily measures of Qol. during treatment can be attributed with more confidence to the acrive drug (in this case, imipramine), and not (only) to spontaneous remission, placebo effects, or the effects of the ESM procedure itself. Imipramine was chosen as the active treatment because imipramine and related tricyclics remain the 'gold standard' for antidepressant efficacy (Gumnick and Nemeroff, 2000).

(3) To determine whether $\mathrm{mQoL}$ stabilizes following active treatment, we compared intraindividual variability in $\mathrm{mQoL}$ from pre- to post-treatment in imipramine versus placebo groups. In the same sample, prior to trearment (Barge-Schaapveld et al., 1999), the magnitude of intraindividual variability was unrelated to the severity of depression, which would suggest that any decrease in variability found is more 
likely to reflect an actual change in subject's experience of QoL than an increased reliability of the methodology in higher functioning individuals.

(4) To obtain a better picture of the effects of extended treatment, additional sampling was done at 18 weeks. Comparison of ESM measures in patients treated for 18 weeks with those of healthy controls provides a measure of the efficacy of antidepressant treatment in normalizing QoL.

\section{METHODS}

\section{Study design}

The study was conducted in a primary care setting, in a sample of depressed outpatients presenting for treatment to their own general practitioners. During an initial baseline week, participants received no treatment of any form. Thereafter, patients were randomly assigned to twice-daily, double-blind treatment with either imipramine (starting dose of $50 \mathrm{mg} /$ day, increased to $200 \mathrm{mg} /$ day over the first week of treatment) or placebo (starting with one capsule per day, increased to 4 capsules over the first week of treatment). In cases of intolerance, the dose could be decreased to either $100 \mathrm{mg} /$ day of imipramine or 2 placebo capsules per day. After 6 weeks, a decision was made concerning prolongation of double-blind treatment to 18 weeks, based on consensus between physician and patient. The possibility that some patients might thereby continue placebo trearment for up to 18 weeks was considered acceptable for the following reasons: (1) informed consent, (2) relatively mild symptomatology, (3) intensive clinical monitoring, (4) freedom to drop our, and (5) post-study access to standard treatment and continued follow-up. The study was approved by a medical ethics committee.

\section{Subjects}

Eighty-three patients with a DSM-III-R/DSM-IV diagnosis of current major depressive disorder were recruited in eight primary care practices in the Netherlands (for details concerning diagnosis and screening, see Barge-Schaapweld et al., 1999). Inclusion criteria were age between 18 and 65 years, a score at entry of $\geq 18$ on the 17 -item Hamilton Depression Rating Scale (HDRS) (Hamilton, 1960), and a score $\geq 4$ on the Clinical Global Impression (CGI) (Guy, 1976). Exclusion criteria included current use of psychotropic medications and major medical disorders. All subjects gave written informed consent.

After exclusion of subjects who either did not meet all of the above criteria $(N=9)$ or had insufficient data during the ESM baseline sampling period $(N=11), 63$ patients were included in the current analysis: 32 in the imipramine group (IMI) and 31 in the 
placebo group (PLA) (for details abour exclusion criteria and differences between included and excluded subjecrs, see Barge-Schaapveld et al., 1999). One PLA patient withdrew consent and three IMI patients dropped out due to adverse events during the first week of treatment. Of the 63 patients randomized, $49(77.8 \%)$ completed the first 6 weeks of treatment. Subsequently, 35 patients agreed to prolong trearment, of whom $22 \mathrm{IMI}$ and 13 PLA subjects $(95.7 \%$ versus $50.0 \%$ of patients at week 6 , respectively, $\left.\chi^{2}=12.5, p<.001\right)$. Eighty percent of these patients $(N=28: 17$ IMI and 11 . PLA $)$ completed the prolongation phase through 18 weeks.

A control group of 22 healthy individuals, similar to the patient groups in sociodemographic characteristics, was recruited to provide normal reference values for ESM measures (for details, see Barge-Schaapveld et al., 1999).

\section{Assessments}

\section{Clinical monitoring: efficacy and tolerability}

The HDRS was administered by the treating physician (GP) at screening, baseline, and weeks $1,2,4,6,10,14$, and 18. At each visit, the GP asked wherher the patient had experienced any unusual or unwanted signs or symptoms since the last visit. If so, start and stop dates were recorded as well as the severity of the symptom.

\section{Retrospective QoL measures}

Questionnaires completed with reference to the past week provided retrospective measures of quality of life. At the end of each sampling period, subjects were asked to rate the qualiry of their life on a $100-\mathrm{mm}$ visual analogue scale (Andrews and McKennell, 1980) and to indicate their global life satisfaction on the Satisfaction with Life Scale (SWLS, Diener et all., 1985), which consists of five items (rated from 1 'strongly disagree' to 7 'strongly agree'). The validated Dutch version of the SF-36 Healch Survey (van der Zee et al., 1996) was completed by a subser of 42 depressed subjects at some point during the baseline week.

\section{ESM monitoring}

After a briefing session in which a research nurse explained the procedure, parients completed ESM reports in response to signals from a programmed wristwatch at 10 semi-random intervals per day, between $07: 30$ and 22:30. ESM was conducted during 6 consecutive days during the baseline week, again during the last 3 days of the first week of treatment, and for 6 consecutive days in the sixth week of trearment. Finally, patients who remained in the treatment prolongation phase completed 6 consecutive days of ESM in week 18. An ESM self-report was considered valid if completed within 15 minutes after the signal. The protocol allowed only patients with a minimum of 30 valid reports to be randomized, so that by definition all subjecrs fulfilled this criterion in 
the baseline week. ESM compliance remained acceptable throughout the study, with more than $80 \%$ of subjecrs in each of the repeated sampling periods completing valid reports in response to half or more of all signals.

Subjects were asked to complete ESM items with reference to the moment at which they received a signal (beep). At each beep, subjects rated their momentary QoL ( $\mathrm{mQoL}$ ) in response to the question 'In general, how is it going with you right now?? Responses ranged from -3 ('very bad') to +3 ('very good'). In addition, subjects rated current mood, and enjoyment of the present activity on 7-point scales. Mood items were combined into separate scales for positive affective states (PA: irems energetic, cheerful, satisfied, alert, calm, entbusiastic, strong, and happy) and negative states (NA: items hostile, depressed, tense, lonely, anxious, insecure, guilty, harried, and irritable). Physical complaints included three common side effects of imipramine: dry mouth, dizziness, and nausea (Cassano et al., 1994). In response to an open question, subjects provided a descriprion of their current activity, which was later coded and collapsed into 8 categories. Only the category 'doing nothing' was used in the current analysis. The ESM procedure, quesrionnaire, and derived measures are described in greater detail elsewhere (Barge-Schaapveld et al., 1999; deVries et al., 1999).

\section{Definition of measures}

For each sampling week, ESM measures were averaged across all valid ESM records for each subject to obtain mean levels of $m Q 0 L, P A, N A$, and exjoyment of activities. At baseline, mean $\mathrm{mQoL}$ was significantly associated with the other ESM measures (PA: $r=$ 55, NA: $r=-.67$, enjoyment of activities: $r=.46 ; N=63$; all $p$ 's $<.001$; one-tailed tests). Mean $\mathrm{mQoL}$ also showed positive associations with all retrospective measures ( $\mathrm{mQoL}$. wirh QoL VAS: $r=.42, p<.001$; mQoL wirh SWLS: $r=.33, p<.01 ;$ mQoL with SF-36 mental subscale: $r=.29, p<.05$; one-tailed tests). These correlations support the construct validity of $\mathrm{mQoL}$. Amount of rime spent doing nothing was defined as the percentage of valid ESM records in which "doing nothing" was specifically reported as the current activity. Mean severity of each ESM complaint (i.e., dry mouth, dizziness, and nausea) was obtained by averaging across all ESM records for each subject per sampling week. The frequency of each ESM complaint was defined as the percentage of records in which the complaint was reported present. Patients who showed an increase from pre-treatment baseline in eirher the mean severity or the frequency of a complaint were considered to have experienced a side effect of trearment ( $E S M$ side effect). Side effects reported to the general practitioner ( $G P$ side effect) as occurring in the same period over which ESM side effects were recorded were identified according to indicated start and stop dates. 


\section{Statistical analyses}

Descriptive statistics are presented as means and standard deviations. Differences in continuous measures berween groups over time were tested with ANOVA for repeated measures. Comparisons between groups at specific points in time were performed with two-sample $t$-rests for continuous variables and with $\chi^{2}$-tests for categorical variables. The Kappa statistic was calculated to assess agreement berween GP and ESM side effecr reports. Pearson correlations were used to assess the relarionship between early-appearing side effects and changes in mQoL. To test the hypothesis that intraindividual variability in $\mathrm{mQoL}$ would stabilize following active trearment, we compared within-subject variance components estimated in a multilevel regression model (Barge-Schaapveld et all., 1999; Snijders and Bosker, 1999) for IMI and PLA patients at baseline and at week 6 , and for controls. Unless otherwise noted, statistical tests were two-tailed, with alpha $=.05$.

\section{RESULTS}

\section{Patient characteristics}

Patients ranged in age from 25 to 59 years (mean $=43.4 y)$. The majority were women $(73 \%)$ and married $(68 \%)$. Most had a regular job (44\%) or were housewives $(25 \%)$. There were no significant differences between the two treatment groups on either sociodemographic characteristics or initial HDRS ratings (IMI: 24.0 3.5 , PLA: 23.5 $\pm 2.6 ; t=-0.6, d f=61, n s)$. Patients randomized to IMI $(N=32)$ were less likely to have had a previous episode of depression than those randomized to PLA $(N=31)(25.0 \%$ vs. $61.3 \%, \chi^{2}=8.5, p<.01$ )

\section{Side effects of treatment}

\section{Differences between GP and ESM reports}

More than $75 \%$ of all side effects reported to the GP occurred in the first week of treatment. Among the side effects most frequently reported to the GP during the three days at the end of the first week of treatment (corresponding to the ESM sampling period) were dry mourh, nausea, and dizziness, with all except dizziness reported by more IMI than PLA patients (see Table 1). Of the three complaints assessed with ESM, dry mouth and dizziness were reported by significantly more IMI than PLA patients.

The overall degree of agreement between GP and ESM assessments of side effects was surprisingly low (kappa's< 30). However, in ar least half of the cases (Table 1, last column), GP ratings and ESM reports were in agreement on the presence or absence of 
TABLE 1. Percentages of parients with specific side effects present in the first week of treament.

\begin{tabular}{|c|c|c|c|c|c|}
\hline & \multicolumn{4}{|c|}{ Watients with } & \multirow[t]{3}{*}{$\begin{array}{l}\% \text { agrecmenc berween GP } \\
\text { and ESM measures }\end{array}$} \\
\hline & \multicolumn{2}{|c|}{ QP side effects } & \multicolumn{2}{|c|}{ ESM side effects } & \\
\hline & $\begin{array}{l}\text { IMI } \\
N=29\end{array}$ & $\begin{array}{l}P L A \\
N=30\end{array}$ & $\begin{array}{l}I M I \\
N=29\end{array}$ & $\begin{array}{l}\text { PLA } \\
N=30\end{array}$ & \\
\hline Dry mouth & $41.4^{\circ}$ & 16.7 & $86.2^{n \cdots}$ & 46.7 & 59.3 \\
\hline Nausea & $20.7^{*}$ & 3.3 & 41.4 & 36.7 & 62.7 \\
\hline Dizziness & 13.8 & 10.0 & $72.4^{\circ}$ & 46.7 & 49.2 \\
\hline
\end{tabular}

Differences between IMI and PLA groups $\left(x^{2}-t e s t s\right): " p<.05, " p<01$.

TABLE 2. Correlations beween ESM side effects (severity and frequency) and changes in mQoL (week 1) in treatment completers $(N=49)$ versus drop-outs $(N=10)$ (week 6$)$.

\begin{tabular}{|c|c|c|c|c|}
\hline & \multicolumn{2}{|c|}{ Side effect severity } & \multicolumn{2}{|c|}{ Side effect frequency } \\
\hline & Completers & Drop-outs & Completers & Drop-outs \\
\hline Dry mouth & -.16 & $-.84^{\circ}$ & .02 & -.51 \\
\hline Nausea & -.27 & -.22 & $-.29^{\circ}$ & -.39 \\
\hline Dizziness & -16 & -20 & -.08 & -.20 \\
\hline
\end{tabular}

"p<.05," $p<.01$

side effects. In general, more patients reported ESM side effects than GP side effects, with increased dizziness, for example, experienced by 5 times as many subjects according to ESM reports ( 35 patients with ESM versus 7 with GP side effects). In general, ESM side effects were also reported as GP side effects when an increase from baseline occurred in the percentage of time spent with a complaint (see Figure 1a). Dry mouth was also more likely to be reported to the GP when a significant increase from baseline had occurred in the ESM-rated severity (see Figure 1b). However, parients with borh ESM and GP side effecrs showed no greater decreases in mQoL than patients with ESM side effecrs only (dry mouth: $F=1.8$, nausea: $F=2.2$, dizziness: $F=0.0$, all $n s$ ); in other words, a decrease in $\mathrm{MQoL}$ was no reason for patients to report side effects to the GP.

\section{ESM side effects, $n Q$ QL , and early termination}

To datify the clinical relevance of the ESM side effects in the first trearment week, we examined their relationship to subsequent treatment drop-out. Of the 59 patients in the first week of trearment, 10 did not complete the entire 6-week treatment period (6 IMI and 4 PLA subjects). Associations berween $\mathrm{mQoL}$ and both frequency and severity of complaints were greater in the drop-ours than in completers (see Table 2). In addition, drop-outs tended to report greater decreases in $\mathrm{mQoL}$, from baseline to week 1 , 
a) Frequency

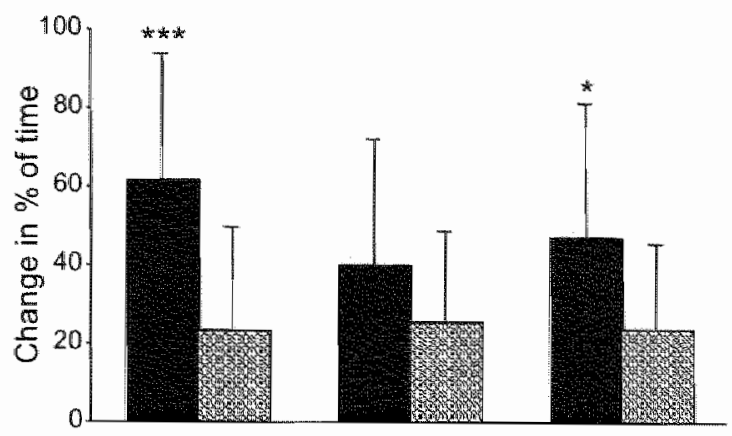

b) Severity

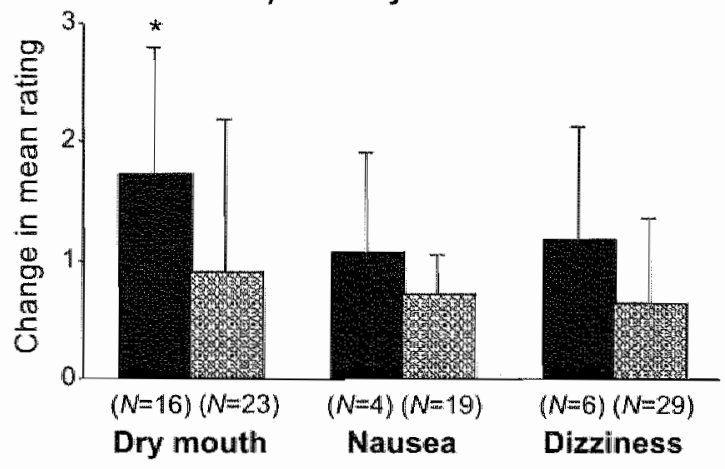

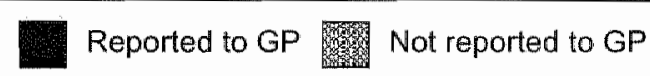

FIGURE 1. Change from baseline to week $\mathbb{1}$ in ESM physical complaints. Parients who expericnoed an increase in ESM complannts and reported the same side effect to the GP are contrasued to parients who did not report ESM complaints as side effects ro the Cil" (a) Frequency of ESM complaints, (b) Severity of ESM complaints. Teses of group differences: $*$ \& $<.05$; $^{* * *} p<.001$.

TABLE 3. Intraindividual variance components for mQL in the multilevel regression model.

Variance estimates

Bepplevel Dayleve:

$\begin{array}{lll}\text { Depressed } & & \\ \text { Imipramine } & & \\ \text { Baseline } & .57 & .30 \\ \text { Week } 6 & .22 & .10 \\ \text { Placebo } & & \\ \text { Baseline } & .58 & .31 \\ \text { Week 6 } & .36 & .26 \\ \text { Controls } & .28 & .20\end{array}$


than patients who subsequently completed 6 weeks of treatment $(-.33 \pm 0.9$ versus .00 $\pm 62, F=2.1, p=15)$. This suggests that the impact of ESM side effects - including those nor reported to the GP - on $\mathrm{mQoL}$ led patients to withdraw from treatment.

\section{Changes at 6 weeks}

\section{Clinical efficacy, retrospective QoL and $m$ QoL}

At 6 weeks, both IMI and PLA groups showed clinical improvement (repeated measures ANOVA. Time effect: $F=194.8, p<.001$ ), with HDRS scores declining on average to $8.9 \pm 6.2$ and $12.5 \pm 6.3$, respectively. The IMI group showed significantly greater improvement than the PLA group (Group by Time effect: $F=4.9, p<.05$ ). Despite greater clinical improvement, IMI parients did not report larger QoL increases than PLA patients on either QoL VAS (change: $27.3 \pm 21.5$ versus $21.0 \pm 28.9, F=0.7$, $n s$ ) or $\mathrm{MQoL}$ (change: $0.7 \pm 0.7$ versus $0.5 \pm 1.0, F=0.7, n s$ ). However, IMI parients did show grearer increases in life satisfaction than PLA patients (increase in SWLS: $6.7 \pm$ 7.8 versus $1.6 \pm 6.3, F=6.3, p<.05$ ).

\section{mQoL variability}

Active treatment was expected to decrease intraindividual fluctuations in mQoL. Results of the multilevel regression analysis supported this hypothesis. At week 6, variances in $\mathrm{mQOL}$ ar both beep and day levels had significantly decreased from baseline in the combined parient groups (likelihood ratio tests, $p .0001$ ). As shown in Table 3 , active treatment had a stronger stabilizing effect, with greater decreases in beep level $(p<$ $.001)$ and day level $(p<.05)$ variances in IMI than in PLA parients. At week $6, \mathrm{mQoL}$ remained relatively unstable in PLA patients, as evidenced by significandly greater beep level variance in PLA than in controls $(p<.001)$. In contrast, mQoL in the IMI group had stabilized by week 6 , with both beep level $(p<.001)$ and day level $(p<.01)$ variance estimates even smaller than in healthy controls.

\section{Other daily life measures}

By week 6 , significant changes from baseline in PA (repeated measures ANOVA, Time effect: $F=16.6, p<.001)$ and $\mathrm{NA}(F=19.5, p<.001)$, but not in enjoyment of the current activity $(F=.01, n)$, were observed in both groups. The two trearment groups did not differ significantly from each other on any of these measures (Group by Time effect for PA: $F=.33, \mathrm{NA}: F=.21$, and enjoyment of activiries: $F=.84$, all $n s$ ).

\section{Time spent 'doing nothing'}

Previous ESM studies showed a link berween inactivity and low mQoL (Barge-Schaapveld et al., 1997; Barge-Schaapveld et al., 1999). The percentage of patients who reported 'doing nothing' as their current activity at some point during 
ESM sampling decreased significantly from baseline to week 6 in the IMI $(87.5 \%$ versus $43.5 \%$ respectively, $\left.\chi^{2}=12.1, p<.001\right)$ but not in the PLA group $(74.2 \%$ versus $61.5 \%$ respectively, $\chi^{2}=1.1$, ns). In order to compare the magnitude of these changes, we identified the percentage of patients per treatment group who reported some inactivity at baseline but no inactivity at week 6 ; this percentage was twice as high in the IMI as in the PLA group (52.2\% vs. $26.9 \%$ respectively, $\left.\chi^{2}=2.0, p=.07\right)$. In other words, more IMI than PLA patients neduced their level of inactivity to $0 \%$ over the course of 6 weeks. There was, however, no significant difference in the reduction in percentage of time spent doing nothing between IMI and PLA groups $(-2.1 \% \pm 6.6$ versus $-3.7 \% \pm$ $6.0, F=0.8, n s)$.

\section{Changes with prolonged treatment (18 weeks)}

\section{Factors related to prolongation}

As expected, the 35 patients who entered the treatment prolongation phase had shown greater decreases in HDRS scores than patients who stopped at 6 weeks $(-15.7 \pm 5.1$ versus $-6.5 \pm 6.5, F=27.8, p<.001)$. Prolongers had also experienced a greater increase from baseline in levels of $\mathrm{mQoL}$ than non-prolongers $(0.8 \pm 0.8$ versus $0.1 \pm 0.8, F=$ $7.9, p<.01)$. Contrary to expectation, prolongers had experienced greater increases than non-prolongers in the ESM complaint 'dry mouth' during the first week of treatment (increase in frequency: $31.0 \% \pm 39.2$ versus $7.4 \% \pm 32.6, F=5.9, p<.05$; increase in severity: $1.0 \pm 1.4$ versus $0.2 \pm 1.2, F=4.7, p<.05$ ). This was specifically rue for prolongers relative to non-prolongers on imipramine (frequency: $F=5.3$, severity: $F=5.1$, both $p$ "s $<.05$ ), but not on placebo (frequency: $F=0.4$, severity: $F=0.1, n s$ ). Experience of other side effects did not differentiate prolongers from non-prolongers. Taken together, these results suggest that degree of clinical improvement, mQoL changes, and specific side effects may all have influenced the decision to prolong treatment.

\section{Normalization}

There was no difference in clinical severiry between IMI and PLA groups at week 18 (HDRS: $4.9 \pm 6.7$ versus $3.8 \pm 5.3, F=.03, n, s)$. Of the 28 patients who completed treatment, 23 were considered to be clinically remitted at 18 weeks (HDRS $\leq 7$ ) (IMI: $14 / 17$, PLA: $\left.9 / 11 ; \chi^{2}=0.0, n_{s}\right)$. To determine wherher quality of life measures achieved normal levels, measures in the remitred patients were contrasted to those in the healthy control group.

Remitred patients and controls reported similar levels of QoL VAS $(75.0 \pm 19.1$ versus $76.5 \pm 15.6, t=0.3, d f=43, n s)$ and SWLS $(25.6 \pm 7.3$ versus $27.5 \pm 6.8, t=0.9$, $d f^{\prime}=43, n s$ ). However, remitted patients still had significantly lower mQoL (see Figure 2). Only 10 of the 23 patients in remission ( 5 in each treatment arm) had mean $\mathrm{mQoL}$ 


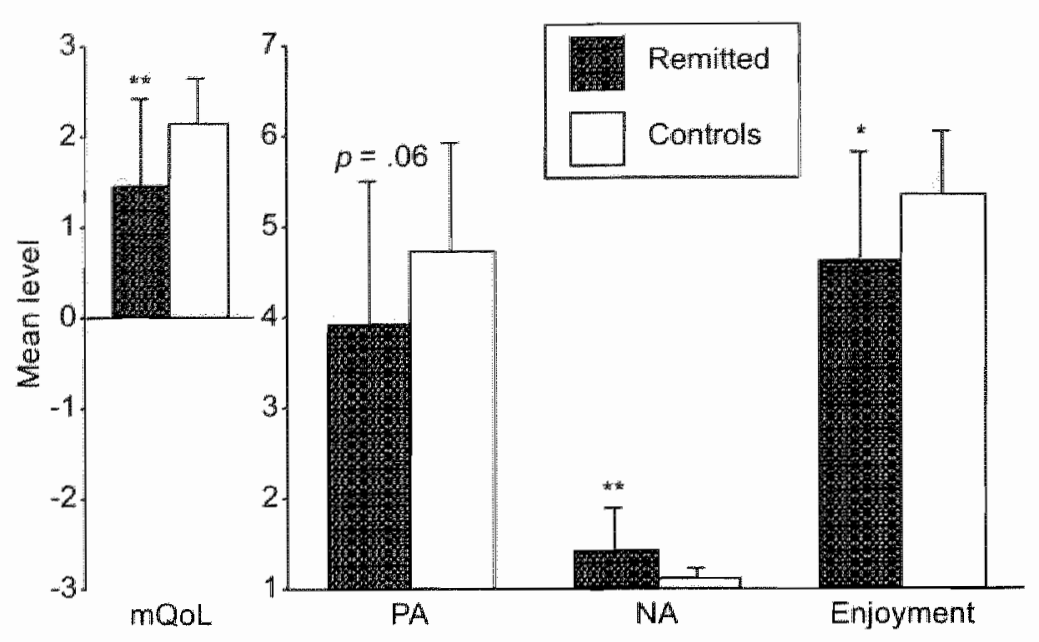

FilGURE 2. Mean levels of ESM wariater in remined pattents atek $18(N=23)$ and in control subjecs $(N=22)$. mQoL: $t=2.8, d f=31, P A: t=1.9, d f=43 . M A=-2.8, d f=24$. Enjoment: $l=2.3 . d f=35 . " p<.05 . " p<.01$.

levels at or above the lower bound $(\mathrm{mQoL}=1.86)$ of the $95 \%$-confidence interval for healthy controls. Mean levels of other daily life measures in remitted patients were also significantly different from those of healthy controls (see Figure 2).

Prior to treatment, a greater percentage of patients than controls had reported at rimes to be doing nothing. In addition, depressed subjects had spent a greater percentage of time in doing nothing than controls (Barge-Schaapveld et al., 1999). At 18 weeks, a similar percentage of remitred patients and controls reported doing nothing at some point during the sampling period $\left(47.8 \%\right.$ versus $50.0 \%$ respectively, $\chi^{2}=0.2, n$ ) . Moreover, the percentage of time in doing nothing no longer differed between the two groups $(4.9 \pm 9.0$ versus $2.2 \pm 3.3$ respectively, $t=-1.3, d f=28, n s)$.

Depressed patients had reported both greater frequency and intensity of physical complaints, even before treatment, than healthy controls (Barge-Schaapveld et al,, 1999). At 18 weeks, significantly more remitted patients than healthy controls still reported dizziness $\left(30.4 \%\right.$ wersus $\left.4.5 \%, \chi^{2}=5.2, p<.05\right)$ or dry mouth $(65.2 \%$ versus $27.3 \%, \chi^{2}=6.5, p<.01$ ) at some point during ESM sampling. None of these remitted parients had reported dizziness, and only six (26.1\%) had reported dry mouth as GP side effecr in that week. Dry mouth and dizziness also occurred with a higher frequency (dry mouth: $42.3 \pm 46.4$ wersus $2.2 \pm 6.1, t=-4.1, d f=23, p<.001$; dizziness: $12.5 \pm$ 26.4 versus $0.4 \pm 2.0, t=-2.2, d f=22, p<.05$ ) and were rated as more severe in the re- 
mitted than in the control group (dry mouth: $2.0 \pm 1.3$ versus $1.0 \pm 0.1, t=-3.6, d f=22$, $p<.01$; dizziness: $1.2 \pm 0.5$ versus $1.0 \pm 0.0, t=-2.1, d f=22, p<.05$ ).

In summary, despite normalized QoL on global retrospective measures, remitted patients still differed from healthy controls in mosr aspects of dailly QoL.

\section{DISCUSSION}

Most antidepressant drug studies rely primarily on clinician measures such as the HDRS. However, self-rating scales can provide important additional information for therapy evaluation as they reflect the patient's personal experience of illness and recovery (Möller, 2000). In the current study, intensive ESM monitoring in the context of daily life revealed effects of depression and antidepressant treatment on well-being, mood states, physical complaints, enjoyment of activities, and patterns of time use information that could not have been obtained with conventional instruments. More specifically, this study provides new information concerning early side effects, changes in daily experience associated with treatment and with clinical improvement, intraindividual variability in the state of well-being, and normalization of daily experience during sustained treatment.

As expected, more IMI than PLA patients reported side effects in the first week of treatment; IMI side effects were also more frequent and more severe. Only a small percentage of patients who showed an increase in specific physical complaints on ESM measures reported these as "side effects" in the same period to the GP. ESM side effects were associated with decrements in $\mathrm{mQoL}$, and parients who reported frequent and severe ESM side effects in the first week were overrepresented among subsequent treatment drop-outs. It is important to note that the study was not designed to determine whether ESM-reported side effects might better predict treatment drop-out than reports to the GP. According to the standard protocol for assessing adverse events in clinical trials, side effects that lead to treatment discontinuation must be registered as GP side effects. This means, by definition, that there is a coupling between GP side effects and subsequent drop-out. Meaningful comparison of the two side effect measures is therefore difficult. However, the lack of any association between mQoL and side effects reported to the GP suggests that clinicians were unaware of side effects of treatment that had a negarive impact on patients' daily quality of life.

Whether or not patients report side effects to the GP also depends to some extent on factors present at the time of the assessment. (Anderson and Testa, 1994) or personality characteristics of the patient (Davis et al., 1995). Based on the current results, we suggest that such problems can be reduced by obtaining self-reports from patients in real time, in their everyday environments, and by asking patients to rate physical complaints (often present prior to any treatment) instead of side effects. In future studies, ESM 
could be useful in describing the side effect profiles of different antidepressant drugs and their relarive impacts on QoL.

The current findings also point to the potential usefulness of ESM measures in understanding treatment adherence. As the decision to prolong trearment was left up to the patient and the GP, it is not surprising that prolongers showed greater clinical improvement and greater increases in $\mathrm{mQoL}$ than non-prolongers. It is noteworthy, however, that prolongers, specifically those on IMI, had experienced more frequent and severe dry mouth (a typical imipramine side effect) in the first week of treatment than non-prolongers. Some authors have questioned the integrity of the double-blind procedure (Antonuccio et al., 1999): if patients can correctly guess the treatment they are receiving due to experienced side effects, they may be more likely to expect positive results. We speculate that these positive expectations might have led patients in our study to opt for a prolongation of treatment.

At 6 weeks, IMI patients showed no greater improvements than PLA patients on the ESM measures of mQoL, mood measures, and enjoyment, even though the active treatment did result in greater clinical improvement on the HDRS. IMI was more effective than PLA in decreasing mQoL within-subject variability and time spent in inactivity. Both the relacively small number of patients in the sample (despite the large number of observations per subject) and the choice of antidepressant may have contributed to the subtle nature of the observed differences between IMI and PLA treatments. Placebo-controlled studies that have reported significant effects of antidepressant treatment on QoL ourcome measures (Dubini et al., 1997; Lydiard et al., 1997; Lenderking et al., 1999) included at least 100 patients per treatment group. Furthermore, although imipramine remains a 'gold standard' for clinical efficacy, other RCT's have been unable to demonstrate an advantage of this drug over placebo in QoL outcomes (see, for example, Phillipp et al., 1999).

Ar 18 weeks, ESM measures still differed in clinically remitted patients from those of healthy individuals, even though QoL had returned to normal on retrospective measures. Normalization in daily life appears to require more time than results obtained with conventional measures would. suggest. It is also possible that the remaining differences in the experience of daily life reflect either 'scars' from the depressive episode or trait-like aspecrs, which may in turn predispose remitted patients to subsequent episodes. The investigation of daily QoL measures in furure recurrence-prevention studies may shed more light on these different possibilities. Even though most of the completers were in clinical remission at 18 weeks, only a minority had achieved normal levels of daily QoL by that time, suggesting that currently used criteria for response in depression may not be sufficient to provide evidence of normalizarion in daily life. These results underscore the need to rethink the current reliance on clinical scales as the sole measure of treatment success in depression (Rush, 1996). 
Aspects of the study design place some limits on the conclusions. Firstly, we assessed momentary quality of life with a single item ( $\mathrm{mQOL}$ ). Although the observed correlations berween average mQoL scores and retrospective QoL measures (see Methods) support the construct validity of mQoL, a multi-item measure would have psychometric advantages in future studies (see Diener, 1984). Furthermore, multilevel regression results as well as the pattern of correlations among ESM measures indicate that $m$ QoL represents more than mood alone (Barge-Schapveld et al. 1999). Secondly, parients provided ESM data during four discrete sampling periods throughout the treatment. Continuous ESM sampling could yield more conclusive information about improvement curves, but the research burden for subjects might become unacceptably high. Future studies should weigh the oprion of sampling less frequently per day over longer periods of time; evidence that continuous long-rerm sampling may be feasible comes from an ESM scudy of migraine patients, in which ESM reports were obtained 6 times a day for 10 weeks (Honkoop et al., 1999). Thirdly, the decision-making process about prolonging rreatment beyond 6 weeks (based on the consensus reached by GP and patient), al though similar to real-life clinical practice, makes it difficult to interpret the findings at 18 weeks.

Experience to date shows that ESM is feasible in the context of a clinical rrial. Depressed patients, with the possible exception of the most severely depressed (Kraan et al., 1992), are willing and able to comply with repeated sampling periods (Barge-Schaapveld et al., 1995; Barge-Schaapveld et al., 1999). Although, in this particular study, the observed advantages of antidepressant treatment over placebo on quality of life measures were subtle, the potential usefulness of ESM measures in understanding treatment compliance, termination, and outcome has been highlighted. In light of the growing interest in QoL in the course and outcome of depressive disorders, we believe that more widespread use of time-sampling methods as a supplement ro conwentional approaches will prowe useful for clinicians as well as researchers.

\section{REFERENCES}

Anderson, I. M., Tomenson, B. M., 1994. The efficacy of elective serotonin re-uptake inhibirors in depression: a meta-analysis of sudies against tricyclic ancidepressants. I Psychopharmacol $8(4), 238-249$.

Anderson, R. B., Testa, M. A. 1994. Symptom distress checklists as a componen of quality oflife measurement: comparing ptompted reports by patient and physician with concurrent adverse cvent reports via the physician. Drug Information Journal $28,89-114$.

Andrews, F. M., Mckennell, A. C., 1980. Measures of self-reported well-being: their affective, cognitive, and other components. Social Indicators Research $8,127-155$.

Antonuccio, D. O., Danton, W. G., DeNelsky, G. Y., Greenberg. R. P., Gordon, I. 5., 1999. Raising questions abour antidepressants. Psychother Psychosom 68(1), 3-14.

Atkinson, M. Zibin, S., Chuang, H. 1997. Characterizing quality of life among partents with chronic mentalillness: a crirical examination of the self-report methodology. Am J Pschiary 154(1).99-105. 
Barge-Schaapveld, D. Q. C. M., Nicalson, N. A., Berkhof, J., deVries, M. W., 1999. Qualiry of life in depression: daily life determinants and variability. Psychiar Res 88, 173-189.

Barge-Schaapveld, D. Q. C. M., Nicolson, N.A., Delespati, P. A. E. G., deVries, M. W., 1997. Assessing daily quality of life with the Experience Sampling Merhod. In: Katschnig. H., Freeman, H., Sartorius, N. (Eds.), Quality of Life in Mental Disorders. John Wiley \& Sons Lid, Chichester, pp. 95-107.

Barge-Schaapveld, D. Q. C.M., Nicolson, N. A., Gerritsen van der Hoop, R., deVries, M. W., 1995. Changes in daily life experience associated with clinical improvement in depression. J Affect Dis 34 , 139-154.

Blackwell, B., 1982. Antidepressant drugs: side effects and compliance. J Clin Psychiarry 43(11. Pt 2), $14-21$.

Cassano, G. B., Toni, C., Perracca, A., Delrito, I. , Benkert, O., Curtis, G., Hippius, H., Maier, W., Shera, D. Kleman, G., 1994. Adverse effects associated with the short-term treatment of panic disorder with imipramine, alprazolam or placebo. Eur Neuropsychopharmacol 4, 47-53.

Cookson. J., 1993. Side-effecrs of antidepressants. Br J Psychiarry 163(Suppl. 20), 20-24.

Corrigan, P. W., Buican, B., 1995. The construct validity of subjective quality of life for the sewerely mentally ill. J Nerv Ment Dis 183, 281-285.

Csikszentmihalyi, M., Larson, R., 1987 . Validity and reliability of the Experience Sampling Method. J Nerv Ment Dis 175(9), 526-537.

Davis, C., Ralevski, E. Kennedy, S. H., Neitzerr, C., 1995. The role of personality factors in the reporting of side effecr complaints ro moclobemide and placebo: a study of healthy male and female volunteers. I Clin Psychopharmacol 15(5), 347-352.

De Lisio, G., Maremmani, I., Perugi, G., Cassano, G. B., Deltiro, J., Akiskal, H. S., 1986. Impairmernt of work and letsure in depressed outpatients: a preliminary communicarion. J Affect Disord 10, 79-84.

deVrues, M. W., 1992. The Experience of Psychopathology: Investigating Mental Disorders in "Their Narural Setrings. Cambridge Uniwersity Press, Cambridge.

deVries, M. W., Delespaul, P. A. E. G., Nicolson, N. A., 1999. Experience Sampling Method (ESM). In: Salek, S. (Ed.), Compendium of Qualiry ofLife Instruments. John Wiley \& Sons, Chichester, pp. 2L:6; 2L:6a.

Diener, E, 1984. Subjective well-being. Psychological Bulletin 95(3), 542-575.

Diener, E., 1994. Assessing subjective well-being: progress and opportunities. Soc Ind Res 31, 103-157.

Diener, E., Emmons, R. A., Larsen, R. J., Griffin, S., 1985. The Satisfaction Wirh Life Scale. Journal of Personaticy Assessment 49(1), 71-75.

Dubini, A., Bosc, M., Polin, V., 1997. Noradrenaline-selective versus serotonin-selective antidepressant therapy: differential effects on social functioning. J Psychopharmacol $\| \mathbb{1}(4), \$ 17-\$ 23$.

Gable, S. L.. Nezlek, J. B., 1998. Level and instability of day-to-day psychological well-being and risk for depression. J Pers Soc Psychol $74(1), 129-138$.

Goethe, J. W., Fischer, E. H., 1995. Funcrional impaiment in depressed inparients. J Affect Disord 33, $23-29$.

Gumnick, J. F., Nemeroff, C. B., 2000. Problems with currently available antidepressants. J Clin Psychiatry $61($ Suppl 10), 5-15.

Guy, W., 1976. ECDEU Assessment Manual for Psychopharmacology. US Department of Health, Education and Welfate, Rockville, MD, pp. 59-70.

Hamilion, M. 1960. A rating scale for depression. J Neurol Neurosurg Psychiar 23, 56-62.

Healy, D., 1999. The three faces of the antidepressants: a critical commentary on the clinical-economic context of diagnosis. J Nerv Ment Dis $187(3), 174-180$.

Honkoop, P. C., Sorbi, M. I., Godaert, G. L., Spierings, E. L., 1999. High-density assessment of the IHS classification criteria for migraine without aura: a prospective study. Cephalalgia 19(4), 201-206. 
Kocsis, J. H., Zisook, S., Davidson, J., Shelton, R., Yonkers, K. Hellerstein, D. J., Rosenbaum, I. Habreich, U., 1997. Double-blind comparison of serraline, imipramine, and placebo in the treatment of dysthymia: psychosocial outcomes. Am I Psycharry 154(3). 390-395.

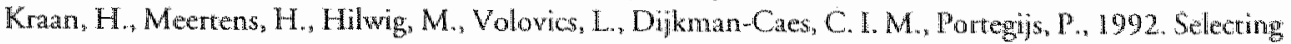
measures, diagnostic validity and scaling in the study of depression. In: deVries, M. W. (Ed), The Experience of Psychopathology: Investigaring Mental Disorders in Their Natural Setrings. Cambridge University Press, Cambridge, pp. 324-338.

Leinonen, E., Skarstein, J., Behnke, K., Agren, H., Helsdingen, J. T., 1999. EfTicacy and tolerabiliry of mirrazapine versus citalopram: a double-blind, randomized study in patients with major depressive disorder. Nordic Antidepressant Study Group. Int Clin Psychopharmacol 14(6), 329-337.

Lenderking, W. R., Tennen, H., Nackley, J. F., Hale, M. S., Turner, R. R., Testa, M. A., 1999. The effecrs of venlafaxine on social acriviry level in depressed outpatients. J Clin Psychiatry 60(3), 157-163.

Lonnqvisc, J., Sintonen, H., Syvalahti, E., Appelberg, B., Koskinen, T., Manmikko, T., Mehtonen, O. P., Naarala, M., Sihwo, S., Auwinen, J., Pirkanen, H., 1994. Antidepressant efficacy and qualiry of life in depression: a double-blind sudy with moclobemide and fuoxerine. Act Pychiar Scand 89, 363-369.

Lydiard, R. B., 1994. Sertraline vs amitriptyline and quality of tife: a double-blind, placebo-controlled study. Neuropsychopharmacol 10(3S/part 2), S163.

Lydiard, R. B., Stahl, S. M., Hertzman, M., Harrison, W. M., 1997. A double-blind, placebo-controlled study comparing the effects of sertraline wersus amitriptyline in the treatment of major depression. J Clin Psychiary 58(11), 484-491.

Moller, H. J., 2000. Raring depressed patients: observer- ws self-assessment. Eur Psychiatry 15(3), 160-172.

Philipp, M., Kohnen, R., Hiller, K. O., 1999. Hypericum extract versus imipramine or placebo in partents with moderate depression: randomised multicentre study of treatment for eight weeks. BM] $319(7224), 1534-1538$.

Pyne, J. M., Parterson, T. L., Kaplan, R. M., Gillin, J. C., Koch, W. L., Grant, I., 1997. Assessment of the quality of life of patients with major depression. Psychiarr Serv 48(2), 224-230.

Ravindran, A. V., Anisman, H., Merali, Z, Charbonneau, Y., Telner, J., Bialik, R. J., Wiens, A., Ellis, I., Griffiths, J., 1999. "Treatment of primary dysthymia with group cognitive therapy and pharmacotherapy; clinical symptoms and functional impairments. Am J Psychiarry 156(10), $1608-1617$.

Rush, A. J., 1996. Assessing outcome in practice: a paradigm shift? Curr Opin Psychiatry 9, 1-2.

Sanders, C., Egger, M., Donovan, J., Tallon, D., Frankel, S., 1998. Reporting on quality of life in randomised controlled trials: bibliographic study. BMJ 317(7167), 1191-1194.

Sechter, D., Troy \&., Parernetti, S., Boyer, P., 1999. A double-blind comparison of sertraline and Auotetine in the treatment of major depressive episode in ourparients. Eur Psychiarry 14(1), 41-48.

Shifman, S., Elash, C. A., Paton, S. M., Gwalney, C. J. Paty, J. A., Clark, D. B., Liu, K. S., Di Marino, M. E., 2000a. Comparative efficacy of 24 -hour and 16 -hour transdermall nicotine patches for reliet of morning craving. Addiction 95(8), 1185-1195.

Shiffman, S., Johnston, I. A. Khayrallah, M., Elash, C.A., Gwaltney, C. J., Pary, J. A., Gnys, M., Evoniuk, G., DeVeaugh-Geiss, J, 2000b. The effect of bupropion on nicotine craving and withdrawal. Psychopharmacology (Berl) 148(1), 33-40.

Smych, J. M., Soefer, M. H., Hurewirz, A., Stone, A. A. 1999. The effect of tape-uecorded relaxation training on well-being, symptoms, and peak expiratory flow rate in adult asthmatics: a pilor study. Psychology and Health 14, 487-501.

Snijders, T. A. B., Bosker, R. I., 1999. Multilewel analysis: an Introduction to Basic and Advanced Multilevel Modeling. SAGE Publications, London.

Song, E., Freemantle, N., Sheldon, T. A., House, A., Watson, P., Long, A., Mason, I., 1993. Selective scrotonin reuprake inhibitors: meta-analysis of efficacy and acceptabilicy. Bmj 306(683), 683-687. 
wander Zee, K. I., Sanderman, R., Heyink, I. W, de Haes, H., 1996. Psychometric qualities of the RAND 36-item health survey 1.0 : a multidimerisional measure of general health starus. International Journal of Behavional Medicine 3(2), 104-122.

Walker, V., Sreiner, D. L., Nowosel, S., Rochi, A. Levine, M. A. H., Dean, D. M., 1995. Health-related quality of life in pationts with major depression who are treated with moclobemide. I Clin Psychophanmacol $15(4.5 \mathrm{sppl}, 2)$ ), 605-675.

Wells, K. B., Stewart, A, Hays, R. D., Burnam, M. A., Rogers, W., Daniels, M., Berry, S., Greenfidd, S. Ware, J., 1989. The functioning and well-being of depressed parients. Results from the Medical Outcones Srudy. Joumal of the American Medical Association 262(7), 914-919. 


\title{
PART \| | |
}

MAIN STUDY (STUDY 2)

\author{
CHAPTER 7 \\ The everyday experience of \\ two depressed patients: A responder and a \\ non-responder to treatment
}

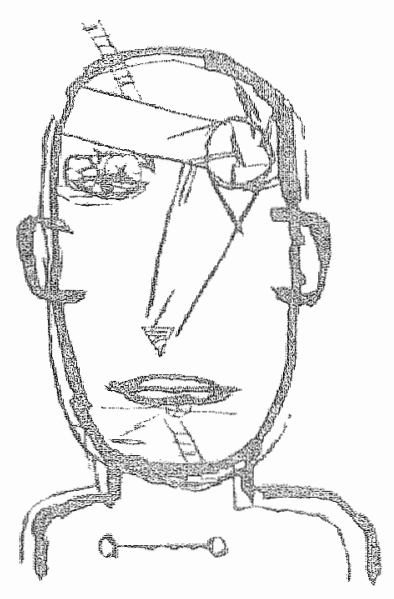




\title{
The everyday experience of two depressed patients: A responder and a non-responder to treatment
}

\author{
INTRODUCTION
}

In spite of traditional prejudices against the case study srategy (e.g., lack of rigor, linte basis for scientific generalization), case examples have obtained a distinctive place in evaluation research (Yin, 1994). The two examples described in this chapter are by no means 'exemplary', but they do illustrate the quantitarive results presented in the foregoing chapters and provide insight into the complexities that can be hidden in group-level results, which are briefly summarized hereafter.

In both Chapters $3 \& 4$, compliance with ESM was described as high across the sampling periods. In addirion, average delay between the beep and the response time was found to decrease over time in responders but not in non-responders to treatment, and in depressed but nor in healthy subjects. In Chapter 6, treatment response was accompanied by an increase in levels and a decrease in fluctuations of mQoL. Moreover, decrements in mQL during the first week of treatment were related to ESM but not to GP side effects and led patients to withdraw from treatment. Overall, there were more ESM than GP side effects reported. Finally, as discussed in Chapter 5 , depressed patients differed from healthy indiwiduals in the percentage of time spent 'doing nothing". Data presented in Chapter 6 showed that responders to treatment reported significant reductions in average time spent 'doing nothing' compared to non-responders.

The main objective of the current chapter is to illustrate the value of ESM in transWating response to treatment into everyday experience, thereby providing clues to a betrer understanding of the impact of depression and its treatment.

\section{METHODS}

\section{Subjects}

The two subjects participated in Study 2 (see Chapters 4-6) and were both randomized ro imipramine treatment. The first case (Suzanne) was chosen as an example of a treatment followed over the course of 18 weeks. The second case concerns a non-responder, Catherine, who was withdrawn from the study due to non-adherence to trearment after 16 days on imipramine. 
Case 1. Suzanne is a 38-year old woman who is suffering from recurtent major depression superimposed on dysthymic disorder. She was 21 at the time of her first episode. Her current episode started about 10 months prior to her participation in the study. She is married and has three children: rwo boys, aged 16 and 12 , and a girl of 5 years old. Her main occupation is homemaker, but she also assists for several hours in the week in a bakery. In addition, Suzanne works as a volunteer at her daughter's primary school.

Case 2. Cacherine is a 35-year old woman who is divorced and liwes with her 8-year-old daughter. As long as she can remember, she has dreaded being alone. After an unhappy marriage that lasted 10 years, Catherine experienced a first depressive episode two years ago, in addition to developing symptoms of panic disorder. She is currently unemployed but receives social benefits. Catherine has a new boyfriend who is 10 years younger than she is. He stays regularly at her place. At the cime of the study, she reports being nervous and depressed most of the time and only occasionally happy or satisfied. Her current episode started quire suddenly a few weeks prior to the study. The only medication she is taking is an oral contraceptive, which she has taken for more than 4 years.

\section{Assesments}

ESM monitoring. The ESM sampling periods were conducted according to the procedure described in Chapter 6 (section 6.2, "Methods"). In addition to the ESM measures described in that chapter (i.e. mQoL, PA, NA, enjoyment and type of activities, frequency and severity of each ESM complaint), other ESM items were also considered here (see Appendix 2). At each beep, subjects were asked whether they were brooding about something, and if so they were requested to describe these thoughts. In response to open questions, subjects also provided a description of where and with whom they were at the time of the beep. Finally, they were asked to report any positive or negative event that had occurred since the last beep.

Clinical monitoring. 'The assessments of parients' clinical response was based on the HDRS (Hamilton, 1960), as rated by the treating physician (GP) at baseline, weel. 6. and week 18. Response to trearment was defined as $50 \%$ or greater reduction from baseline in HDRS scores. Throughout the study, the GP asked wherher the parient had experienced any unusual or unwanted signs or symptoms.

Retrospective QoL monitoring. The overall level of QoL was rated retrospecively ar the end of each ESM sampling period on the QoL VAS, a 100 -m m visual analogue scalle (Andrews and McKennell, 1980). 


\section{Suzanne: a responder to treatment}

Clinical follow mp. At baseline, Suzanne is considered 'markedly ill' by her treating physician, with a rating of 28 on the HDRS. At that time, Suzanne herself reports being completely worn out, often depressed, never calm or satisfied, and only rarely happy. She rates her QoL during the baseline week with a mark at $29 \mathrm{~mm}$ from the "worst QoL you can imagine for yourself on the 100-mm QoL VAS. According to protocol, her dose is increased to $200 \mathrm{mg}$ of imipramine over the course of a week and Suzanne is kept at that dose for the remainder of the study. At the end of the first week, her score on the HDRS decreases to 20 , providing a first hint of response, although she herself reports no change on the QoL VAS (27mm). After 6 weeks, Suzanne has shown a drop of more than $50 \%$ from baseline in her depressive symptoms (HDRS is now 8), and is therefore considered a responder to treatment. Her rating on the QoL VAS now shifts toward the best QoLyou can imagine for yourself $(78 \mathrm{~mm})$. In mutual agreement with her physician, she decides to prolong her participation in the study for another 12 weeks. At the end of this rreatment period, her depressive symptoms show a further reduction (HDRS is now 2). However, no further improvement is seen on the QOL VAS $(79 \mathrm{~mm})$. Throughout the entire study, she has not reported any adverse events to the GP.

ESM data. Suzanne completes an acceprable number of experience sampling report forms across the four sampling periods, with higher completion rates in the first two periods (above $80 \%$ ) than in the last two periods (above $50 \%$ ). In the first sampling period, it takes Suzanne on average $1.78 \mathrm{~min}$ to complete a self-report form. Average response time decreases to $1.47 \mathrm{~min}$ during week 6 and to $0.12 \mathrm{~min}$ in the $18^{\text {rh }}$ week of treatment.

Suzanne s lewels of mQoL throughout the four sampling periods are shown in Figure 1; for comparison purposes QoL VAS scores, transformed to $(-3,3)$ scale as described in Chapter 4 , are also shown. During the pre-treatment baseline week her level of mQoL fluctuates between -2 and 1 . The worst $\mathrm{mQoL}$ moments occur when she is brooding abour her relarionship with her husband. This usually happens when she is doing household chores. During these moments she always reports having a headache. The best mQoL moments during this week occur while Suzanne is engaged in activities she enjoys doing (e.g. reading, dining out, watching T.V.). During these moments, Suzanne has no physical complaints.

During the first week of treatment, Suzanne experiences even more swings in her mQoL states than during the baseline sampling week. The mQoL level is not context-dependent, as she spends most of her time during this period at home doing chores $(73.1 \%)$. Although the percentage of time with headache is reduced from baseline, 

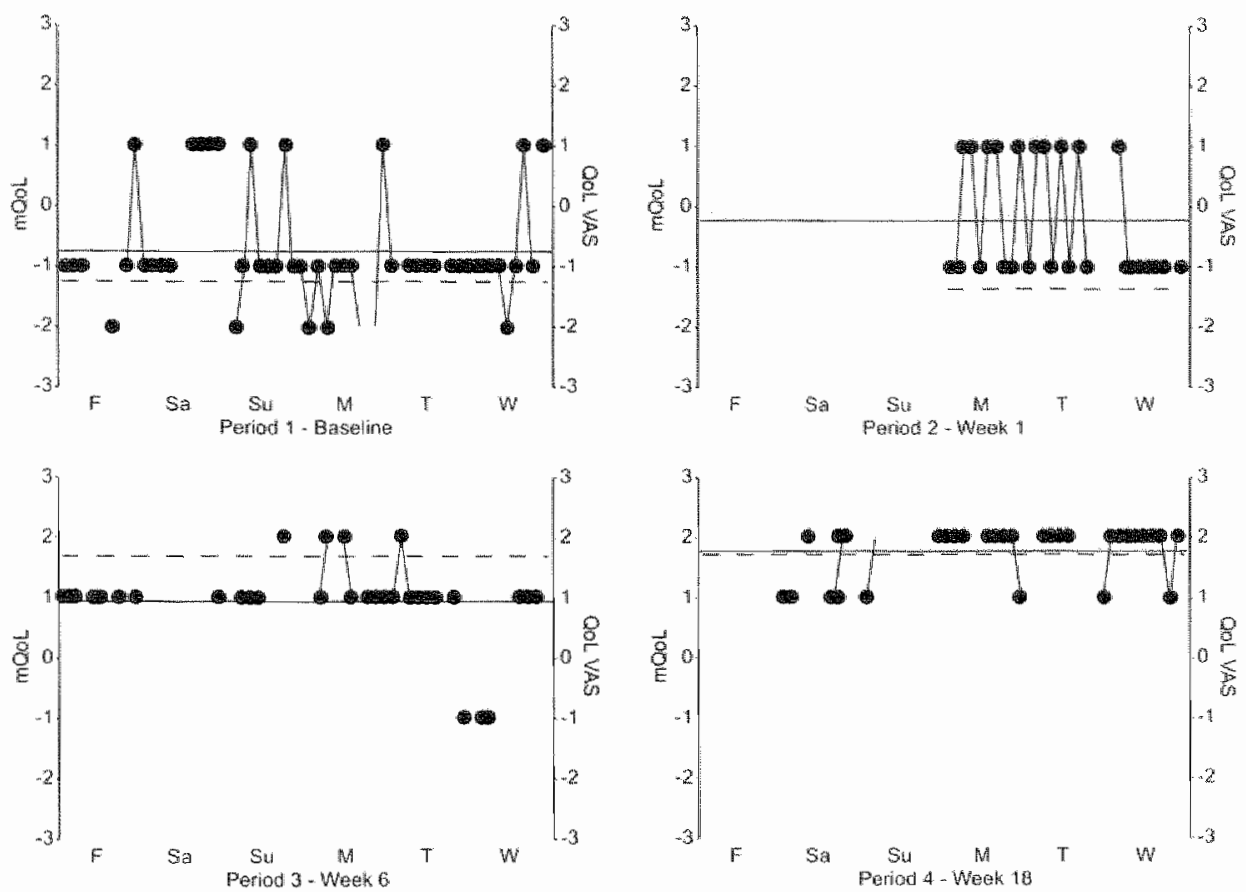

FIGURE 1. Lewels of MQL (--) and QoL. WAS (-...) reported by Suzan ne during the four experience sampling periads ( 6 days pre-rearment, 3 days in the $1^{\text {st }}$ week of treatment, 6 days in the $6^{\text {th }}$ weck of treatment, and 6 dalys in the $18^{\text {th }}$ week of treamenty throughout the study.
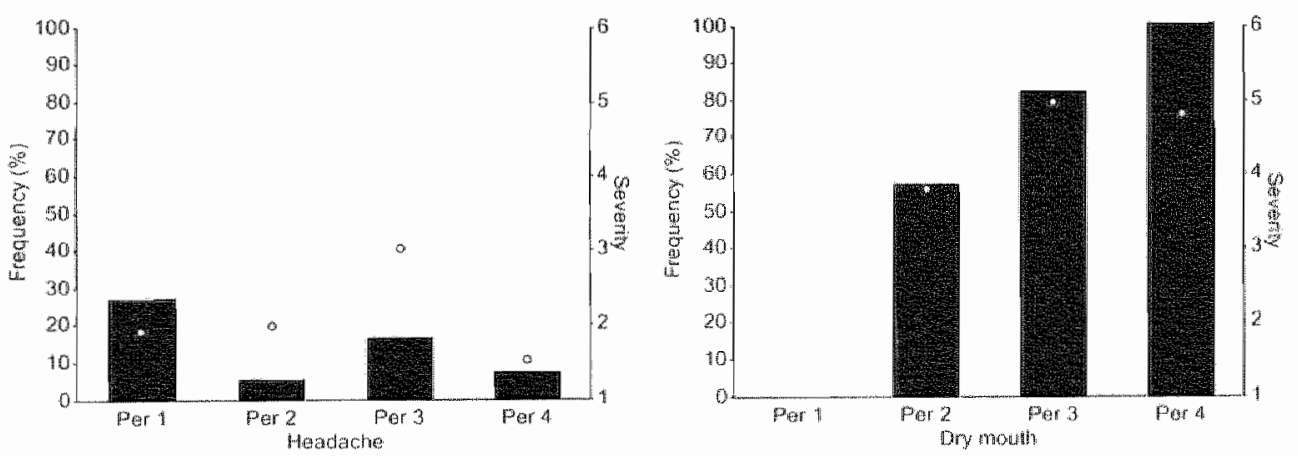

FIGURE 2. Frequency (as of of FSM repors; bar) and mean severity (o) of headache and dry mouth ieporecel by Su-

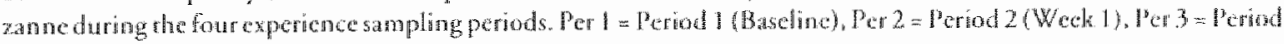
3 (Wek 6). Per $4=$ Period 4 (Wek 18). 
Suzanne experiences moderate levels of dry mouth more than half of the time (56.5\%) (sec Figure 2 for the frequency and severiry of headache and dry mouth across the sampling periods).

In the sixth week of reatment, Suzanne experiences higher average levels of $\mathrm{mQOL}$ than at baselne. During this week, she has four moments of high $\mathrm{mQoL}$, characterized by high levels of posirive affect (PA $>4$ ). However, a negative event may scill precipitate a drop in $\mathrm{mQoL}$, as is the case on $\mathrm{T}$ uesday evening when Suzanne has an argument with her husband. While watching T.V., Suzanne reports very severe headache and dry mouth, and experiences high levels of negative affect. This carries over to the following day, as she broods about her relationship with her husband while doing chores alone at home.

After 18 weeks of treatment, Suzanne's awerage level of mQoL approaches 'normal' (the lower bound of the 95\%-confidence interval for healthy controls $=1.86$, see Chapter 6). Even though her marital problems are not resolved, she manages to cope with them. Negarive interactions with her husband no longer precipitate low $\mathrm{mQoL}$. On Monday evening, for example, she has an argument with her husband but rates her mQoL as 2. Suzanne continues to experience dry mouth throughout the entire week.

\section{Catherine: a non-responder to treatment}

Clinical follow-up. At baseline, Catherine is reported to be "markedly ill' by her GP and is rated 25 on the HDRS. When asked to rate her QoL ower the past week on the VAS, Catherine marks $9 \mathrm{~mm}$ from the worst QoL you can imagine for yourself. This rating seems to be influenced by events of the previous day (as can be seen in Figure 3) and may not be representative for the entire week. She starts with $50 \mathrm{mg}$ of imipramine in the evening. But from that first day she reports excessive transpiration, accompanied three days later by vomiting; both complaints last until the end of her participation in the study. In both instances, the physician regards the relationship with the drug to be probable. Therefore, instead of increasing the dose of imipramine over the course of the First week to $200 \mathrm{mg}$ as per protocol, the physician decides to keep Catherine on a dose of $50 \mathrm{mg} / \mathrm{day}$. Although her HDRS is unchanged (24), she rates her QoL as slightly betrer $(24 \mathrm{~mm})$ from baseline. At the end of this first week, Catherine does not return any capsule of study medication to the physician, stating that she has thrown all remaiming capsules away. During the second week, the dose is gradually increased to $100 \mathrm{mg}$ of imipramine, which Catherine receives according to the physician for another 8 days. However, as Catherine returns only $14(35 \%)$ capsules instead of the $24(60 \%)$ that are expected on the basis of the dosage schedule, she is withdrawn from the study due to non-adherence with the prescribed medication.

ESM dam. Catherine is compliant with respect to ESM, completing $63.3 \%$ of the reports pre-treatment and $80 \%$ in the first week of treatment. The mean time she 

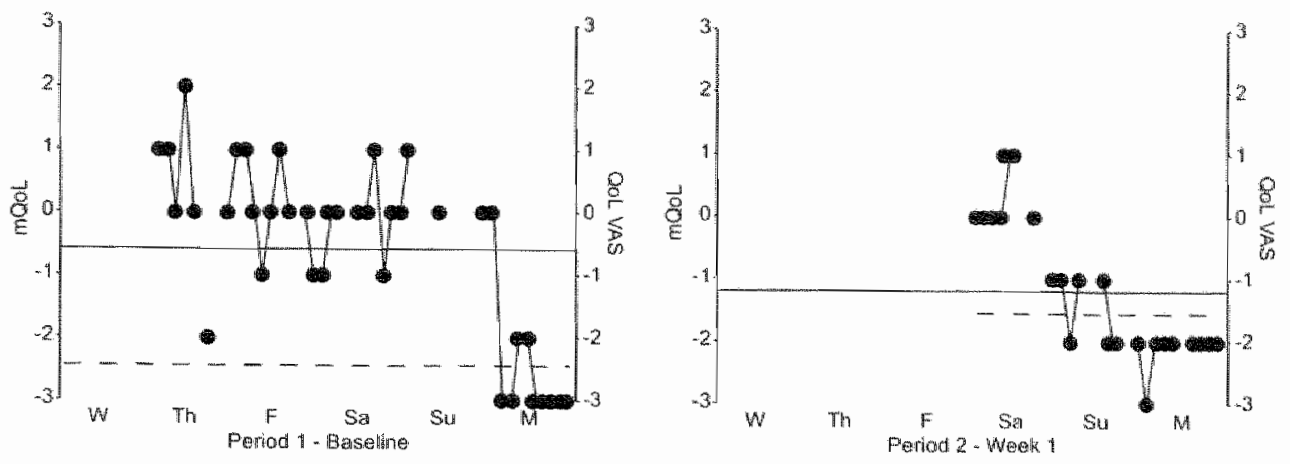

FICURE 3. Levels of mQoL (--) and QoL VAS (- - ) reported by Catherine during the wo experience sampling periods $\left(6\right.$ days pre-reatment, 3 days in the $1^{\text {sh }}$ week of treament) throughour the study.
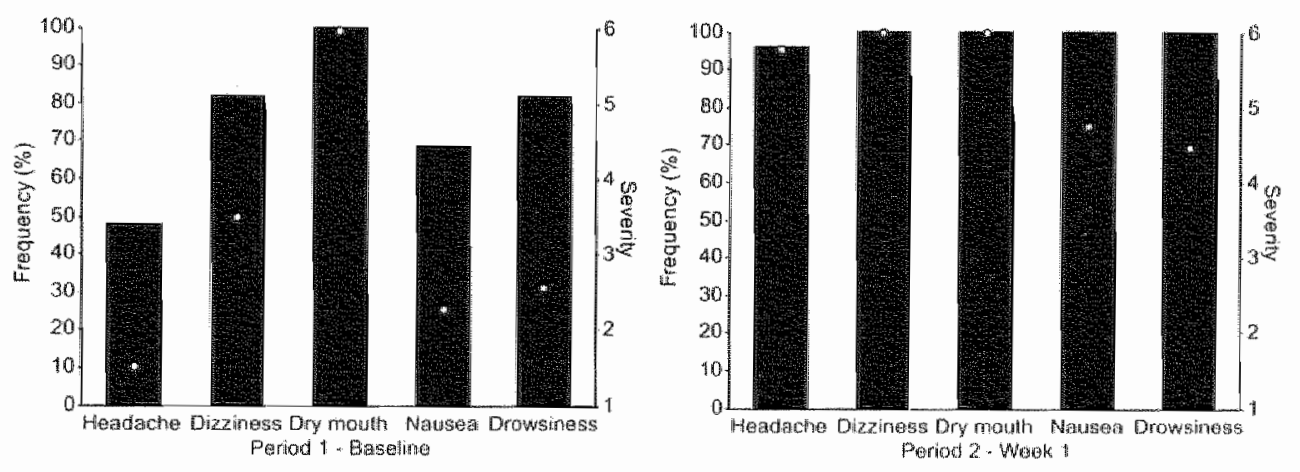

FIGURE 4 . Frequency (as 0 of ESM reports; baly and mean severicy (o) of complaints that Catherine reported during the rwo experience sampling periods throughout the study.

requires to respond to a self-report is 1.21 min pre-treatment and does not change over time (1.25 min on treatment).

Catherine's levels of mQoL during the sampled days are shown in Figure 3. On average, Catherine experiences a lower level of $\mathrm{mQoL}$ on treatment than prior to treatment. Her best moment pre-treatment occurs on Thursday afternoon, when she is chatring at her girl friend's house. Later that day, Catherine also reports a low level of mQoL while sitting in the car with her boyfriend and daughter. They are having trouble finding the way to a shop. Catherine is stressed, insecure, and very irritated. In addition to dry 
mouth, which she experiences most of the time, she also reports other complaints, such as dizxiness and nausea. The following days show a fairly stable partern, with Catherine's level of mQoL fluctuating between -1 and 1 , very much depending on whether she is alone or with orhers, respecrively. On Sunday, her daughter receives Holy Communion for the first time, which is reported by Catherine as a pleasant event. That evening, as she lies in bed, Catherine is concerned by the fact that she seems so calm in spite of all the excitement of the day. It makes her quite anxious. After a sleepless night, Catherine reports her lowest levels of mQoL the following day. She worries abour her daughter's health (she is hyperactive), as well as her own psychic health. Her visit to the GP does not brighten her spirits much. She feels down for the rest of the day. She takes her first capsule of imipramine $(50 \mathrm{mg})$ that evening.

Althougln complaints were already present pre-treatment, both the frequency and the severiry show further increases during the first week of rreatment (see Figure 4), in spite of the fact that Carherine is kept at a low dose of imipramine $(50 \mathrm{mg}$, taken in the evening). Her sleep improves. She describes this as follows: I sleep very well and I find this great. All my problems are gone. That is a very good feeling, which I haven't felt in years.' However, her levels of $\mathrm{mQoL}$ gradually decrease over the three days, as she feels more and more depressed and experiences more and more nausea. Her best moment in these three days occurs while she is shopping on Saturday with her boyfriend and daughter. Her worst moment occurs early Monday morning, when she is at home alone thinking about what she has ro do that day. At that moment, she describes the quality of her sleep as a positive event, but at the same time she reports the fact that she has had to get up as a negative event. During the two ESM sampling periods, Catherine spends more than $10 \%$ of her time 'doing nothing', a typical partern for depressed patients.

\section{DISCUSSION}

The results reported here were derived from the intensive study of nwo cases and were meant to unravel the complexiries of group-level results to obtain a better understanding of how response to treatment is translated to everyday experience.

What these two depressed women in their mid-thirties had in common was their average level of mQoL pre-treatment and the fact that they were both regarded as "modcrately ill' by their treating physician. However, based on their experiences on treatment, Suzanne was considered a responder, whereas Catherine did not adhere to the prescribed medication regimen, and was thus per definition a non-responder. As seen in Chapters $3 \& 4$, compliance with ESM was acceptable (above $50 \%$ ) in both cases across the sampling periods, although Suzanne had a higher number of ESM self-reports in the first two periods. The cases illustrate the finding that average response time decreases over time in responders but not in non-responders to treatment. As reported 
in Chapter 6 for responders, Suzanne's response to treatment over time was accompanied by an increase in average mQoL and a decrease in mQoL fluctuations, as she learns to cope with her marital problems. In contrast, Catherine's mean level of $\mathrm{mQoL}$ was lower in the first week of treatment than pre-treatment, even though her depressive symptoms were unchanged. As described in Chapter 6, treatment-related increases in frequency or severity of physical complaints may be associared with decrements in $\mathrm{mQoL}$ and lead subsequently to withdrawal. This appears to have been the case for Carherine. Borh women experienced side effects, which they eicher did not report to their GPs, or their GPs failed to write them down. Suzanne had more frequent and more severe dry mouth as time progressed. During the last week of treatment, she actually experienced moderately severe levels of dry mourh all the time (this complaint was not present prior to treatment). Surprisingly, dry mouth was not reported as an adverse event by the GP! Catherine reported excessive transpiration and vomiting, both of moderate intensity, as adverse events to the GP. According to the ESM self-reports, Carherine experienced headache, dizziness, dry mouth, nausea and drowsiness as side effects of treatment. With the possible exception of nausea, none of these ESM side effects was reported by the GP. Even before treatment, Catherine experienced nausea half of the time, but it was mild in severity. During her week on trearment, she reported quite severe levels of nausea all of the time. Moreover, of all the side effects she experienced, nausea had the highest negarive association with $\mathrm{mQoL}$ from moment to moment. It is possible this relationship, which cannot be established retrospectively from GP reports, may explain her non-adherence to treatment. Finally, as discussed in Chapter 5, depressed patients differ from healthy individuals in the percentage of time spent 'doing nothing'. Catherine is a good example, as she spends more than $10 \%$ of her time 'doing nothing'.

Although the causal relations identified in these two cases between treatment changes and everyday experience may well be very different in other cases, they shed light on clinically relevant differences between ESM dara and uraditional measures and point ro the relevance of measures that should be incorporated in dynamic models of QoL. Clinicians should be made more aware of the relationship berween early side effecrs and non-adherence, as evidenced by case 'Catherine'. Early side effects should be monitored more carefully and their impact on mQoL should be assessed thoroughly in order to better monitor trearment adherence. Clinicians should also be careful in depending on retrospective assessments of patients' QoL, as these might be biased by the most recent experience (case 'Catherine', baseline week). On the basis of the two case descriptions, it seems relevant in future daily Qo models to incorporate those negative events that are most frequently associated with low $\mathrm{mQoL}$, and to determine wherher the patient learns to cope with these. Furthermore, measures that are likely to contribute to a better understanding of non-adherence (c.g. attribution of side effects) should also be considered in future models of daily QoL. 
These two cases ill ustrate how information obtained with ESM can extend understanding of how antidepressant treatment affects daily life experiences. In addition to a betrer insight into the changes in daily life experiences that accompany response to treatment (as in case "Suzanne"), ESM data can also provide new information about treatment non-response, intolerance, or non-adherence (as in case 'Catherine'). In conclusion, not only does ESM yield detailed quantitative information, but the self-reports are also arich source of qualitarive description of patients' everyday experience.

\section{REFERENCES}

Andrews, F. M. Mclkennell, A. C., 1980. Measures of self-reported well-being: their affecrive, cognirive, and ocher componenrs. Social Indicators Research 8, 127-155.

Hamilton, M., 1960. A rating scale for depression. I Neurol Neturosurg Psychiat 23, 56-62.

Yin, R. K., 1994. Case study research. Design and methods. Second Edition. (Vol. 5). Sage Publications, Thousand Oaks, Calliforna. 


\title{
PART IV \\ DISCUSSION
}

\begin{abstract}
CHAPTER 8
Impact of depression and antidepressant treatment in daily life: Conclusions and general discussion
\end{abstract}

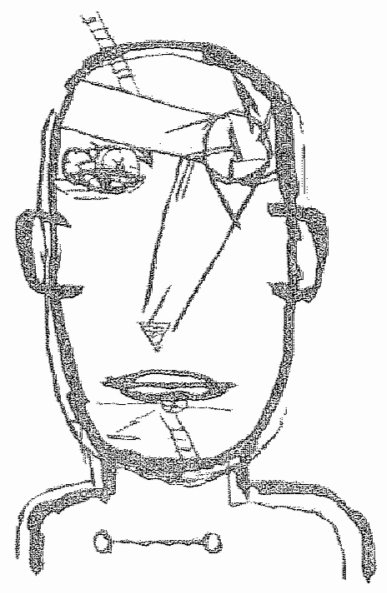




\section{Impact of depression and antidepressant treatment in daily life: Conclusions and general discussion}

Major depression is both a common and a chronic condition with a high risk of suicidality. Depression imposes significant annual costs on society, not only in terms of direct costs of diagnosis and treatment, but also, and perhaps mainly in terms of lost productiviry. At a micro level, the consequences of depression can dramatically affect the lives of those interacting with afflicted individuals. Studies have shown that relatives have difficulties coping with the mood disturbance of their family member because they understand so little of the impact it has in everyday acrivities. Depressed parients experience an inability to enjoy life. They feel impaired or unable to handle the demands of everyday life. A quantitarive description of the impact of depression in daily life is required, however, for a better understanding of what it actually means to be depressed.

Since the 1950s, effective and specific pharmacological treatments, such as tricyclic drugs, have been available. Literature on RCTs in depression that include QoL assessments support the hyporhesis that antidepressants, in general, enhance QoL in depressed patients as a consequence of clinical improvement. But little is known about how QoL improvements translate to changes in daily life experiences and in patterns of acrivities over time.

The down side of antidepressants is their side effects. In clinical trials, the determination of side effects relies upon the physician to detect signs of illness or injury that appear or worsen during treatment, and upon the patient to volunteer information to the physician. A side effects profile is then compiled on the basis of a greater percentage of patients reporting the side effect ar any time on treatment than on placebo. Although this convention may work for regulatory purposes, parient and physician are found to filter and pertaps to distort information (Anderson and Testa, 1994). In addition to the unreliability of conventional assessments, they provide litrle insight into how side effects impinge on daily life.

The current research was intended to provide a quantitative description of the impact of depression in daily life, to clarify the changes in daily life experiences and parterns of activities that are associated with clinical improvement over time, and to investigate how side effecrs are experienced in daily life. For this purpose, an ecologically valid method such as ESM was needed that captures subjective experiences prospectively in real-life setrings. Such a method had not been used to assess the effects of a pharmacological intervention at the outset of the current research. 


\section{CONCLUSIONS}

The main conclusions of the present research can be briefly summarized with respect ro the two main objectives of this thesis, as follows:

I. Feasibility and utility of ESM in clinical drug trials:

- ESM is feasible in the context of a clinical trial in depression, as a majority of depressed subjects complied with ESM and remained compliant over time (Chapters $3 \&$ 4);

- ESM is useful in the context of a clinical trial, in that new insights on the effects of active treatment in daily life are obtained. These new insights are gained by measuring repearedly and prospectively in reall-life setrings. So far, however, ESM has not been found to be quantitatively superior to conventional approaches in detecting statisrically significant advantages of antidepressant treatment over placebo (Chapters 4 \& 6 ).

II. New insights into the impact of depression and antidepressant treatment in daily life:

- Daily life experiences in depressed patients differ from that of healthy controls both in intensity and variation, even though similar daily life variables are associated with QoL changes from moment to moment (Chapter 5);

- Inactivity in daily life is a more common occurrence in depressed than in healthy individuals. The percentage of time 'doing nothing' is likely to decrease following clinical improvement (Chapters 3, $\&$ \&);

- Clinical improvement in a depression trial is accompanied by changes in daily life experiences, both in quanticative estimates of time use and in emotional states occurring in daily life situations and activities (Chapters $3,6 \& 7$ );

- Instability in subjective well-being, a chancteristic of psychiatric disorders including depression, is a temporary phenomenon that can be reduced by active treatment, independently of the level of well-being (Chapters 5, $6 \& 7$ );

- Severity - and to a lesser extent frequency - of side effects, which are very often not reported as adverse events to the physician, are associated with decrements in levels of daily QoL during the first week of treatment. (Chapters $6 \& 7$ ). 


\section{Application of ESM in clinical drug trials}

In the present research, ESM was applied for the first time in the context of a clinical drug trial. In achieving the aim of describing the impact of depression and antidepressant treatment in daily life, ESM was found to be feasible and useful in the clinical trials context. The two clinical trials were conducted in outpatients; as over $90 \%$ of clinical trials in depression in Europe are done in outpatients ${ }^{\dagger}$, data on ESM compliance can thus be generalized to most studies conducted in depression in Europe. Based on the results of the two clinical studies, however, some methodological issues remain.

First, the choice of a sampling procedure requires further thought. The sampling strategy in the current research (10 times a day for 6 days) was chosen on the basis of previous experience (Delespaul, 1995). Although the sampling strategy used was effecrive in obtaining the maximum standardized treatment effect size for ESM measures (see Chapter 4), other sampling strategies (with fewer beeps per day) would have been more efficient in this respect. However, caution should prevail in decreasing the number of beeps per day as this could reduce the possibility of assessing within-person variability (Chapter 5).

In order to assess pre- versus post-trearment differences in the two studies, a sampling period was conducted in the baseline week and in the sixth week of treatment. In Study 2 , an additional sampling period of three days was included at the end of the first week of treatment in order to study the impact of side effects in daily life. As prolongation of treatment was offered as a possibility after 6 weeks, another sampling period of 6 days was conducted in the $18^{\text {th }}$ week of treatment. Ideally, sampling should have been done throughout the baseline week and the entire treatment period, but in light of the additional burden on subjects a compromise was sought berween compliance and sampling requirements. However, it is possible that other sampling procedures may be better suired for obtaining insight into the improvement curve of various aspects of daily life over time or into the differential effects of treatment. For instance, in a recent application of ESM in a clinical trial, two transdermal nicotine patches were compared for relief of morning craving (Shiffman et al., 2000). ESM measures for craving (e.g. urge to smoke) were assessed between 8 and 10 times a day for 4 to 7 baseline days, while smoking ad libitum, and for two weeks after quitting and subsequent randomization to either a 16 -hour or a 24 -hour transdermal parch. ESM results showed that, besides reducing average craving intensity significantly more than the 16 -hour parch, the

1 This information is obtained from Data Edge/ Fast Track. Systems and is based on a survey of over 140,000 grants covering all therapeuric areas. 
24-hour patch cut by at least one-third the rime that participants experienced craving and reduced the frequency of temptations by $50 \%$. Thus, the sampling strategy used by Shiffman and colleagues was effective in differentiating rwo types of nicotine patches. However, with only a handful of intervention studies using ESM that have been published to date, the design of optimal sampling strategies should be studied more thoroughly, possibly as an objective in itself.

In addition, with a growing number of long-term depression studies, there is a need to sample over longer periods of time. An ESM study of migraine patients, in which ESM reports were obtained 6 times a day for 10 weeks (Honkoop et al., 1999) supports the notion that continuous sampling over longer periods of time may be feasible. The finding in the current research that compliant subjects remained compliant over time (see Chapter 4) also suggests that ESM can be used with success over exrended periods of time.

A second methodological consideration regards the sensitivity of ESM in a clinical trial setting. In Chapter 4, sensitivity was defined in two ways: quantitatively and qualitatively. The current focus is on the quantitative perspecrive; that is, can ESM reduce the number of subjects required to differenciate active treatment from placebo, when compared with conventional retrospective measures, by increasing STES? By using repeated measurements over the day and across days instead of one-time measurement, the sampling strategy used in the current research (i.e. 10 times a day for 6 days) increased STES of ESM measures, thereby increasing the likelihood of detecting true treatment differences. In Study 1, ESM once-a-day measures of sleep quality were found to be more sensitive to differences berween responders and non-responders than a SIP module on sleep (see Chapter 3). In Study 2, an ESM measure (mQoL) was not found to be more sensitive than a retrospecrive measurement (QOL VAS) in detecting differences berween imipramine and placebo (see Chapter 4). Although the variance of mQoL was, as expected, smaller than the variance of QoL VAS, the group mean difference for mQoL was, unexpectedly, also smaller. "Two speculative explanations for this unexpected finding are suggested. First, the correlation between the two scales was possibly not sufficient to make such a comparison. In other words, retrospective and moment-to-moment assessments may measure intrinsically different concepts. Kahneman (Kahneman, 1999) makes a fundamental distinction between what he defines as the "objective" (based on moment to moment states) versus the 'subjective' (evaluated retrospectively) happiness. It could be argued that both 'objective' and 'subjective' QoL (i.e., how is it experienced in real time and how is it assessed retrospectively) are important in determining the effects of treatment on parients QoL, and that future studies should investigate both aspects of QoL. Second, in the current debate on the integrity of the double-blind procedure in depression trials due to side effects (Greenberg and Fisher, 1997; Quitkin et al., 2000), some authors have suggested that 
patients report enhanced improvement as a result of experiencing anticipated side effects (Antonuccio et al., 1999). As the frame of reference in ESM assessment is the description of patients' immediate emotions and behaviors, ESM may be less vulnerable to such cognirive judgmental processes and thus capture a more 'objective' (although possibly smaller) difference between treatments.

However, from the perspectives of the pharmaceutical industry and regulatory agencies, the question of whether or not ESM measures are more sensitive than retrospective measures will, in the end, determine wherher ESM will be accepted in furure regulatory studies as a possible substitute for primary outcome measures such as HDRS. The issue is complex. As pointed out in Chapter 2, comparisons between ESM and conventional methods are subject to discrepancies berween: (1) observer-ratings versus self-ratings, (2) one-time measurement versus repeated measurement, (3) retrospective versus prospective ratings, and (4) clinical symptom versus QoL measures. Future ESM applicarions in depression trials should address the question of whether a relevant ESM index can be developed that is more sensitive in detecting trearment differences than commonly used primary outcome measures like the HDRS. Results of the current research suggest that such an index should consist of affective (PA, NA), cognitive-appraisal ( $\mathrm{mQoL}$, enjoyment of activities), and behavioral components (percentage of time doing nothing), but other aspects such as cognitive disturbances, social interactions, and coping mechanisms should also be considered. Until then, ESM should be regarded as a supplement to conventional methods in clinical trials, which can go beyond nosological and clinical perspectives to clarify the impact of treatment from an experiential perspective.

Finally, the feasibility and utility of ESM in assessing the impact of depression and antidepressant treatment in daily life will depend on its cost-benefit rario. Facrors that should be aken into account on the cost-side of the equation include costs of the equipment used (e.g. wrist-watch, booklers) and of the data management involved; time required for training of personnel in ESM procedures as well as the time involved in briefing and debriefing sessions. On the benefit-side of the equation, new insights into personal experience of illness and recovery, not obtainable via conventional measures, should be included. Based on expected costs and benefits, future studies should evaluate the incremental costs in using ESM, either in addition to or as a substitute for conventional measures. 


\section{New insights into depression and antidepressant treatment in daily life}

\section{Burden of depression in daily life}

ESM offers a supplement to the approaches taken by the numerous retrospective studies that have explored the burden of depression, in that it collects systematic data prospectively about the ongoing impact of the illness in daily life. In comparison to a control group similar in sociodemographic characteristics, depressed patients studied in the current research experienced nor only lower levels of momentary QoL, but also greater variability. The burden of depression was also assessed in terms of the rypes of activities subjects engaged in, and the pleasure they derived from them. Results showed that depressed individuals spent a greater percentage of time doing nothing than control subjects. In addition, a greater proportion of the depressed group reported daily periods of 'doing nothing'. In spire of few other differences in time use, depressed individuals did report significantly less enjoyment than control subjects in al most all activities they engaged in. Finally, depressed individuals experienced more frequent and severe levels of physical complaints than healthy controls. Within subjects, complaints were positively associated with negative affect from moment-to-moment. Ir remains undear whether the experience of complaints is a cause or a consequence of reporting negarive affect, but the current results suggest that both variables make independent contributions to momentary Qol..

In general, the current research has shown that state aspects of $Q D L$ are as important as the trait-like aspects of QoL in understanding the burden of depression in daily life. Future studies investigating QoL in depression should incorporate both aspects of QoL.

\section{Clinical improvement and daily life experiences}

In the two clinical studies undertaken in the context of the present research, responders to six weeks of treatment improved more than non-responders in levels of momentary QoL and positive mood states. To a lesser extent, responders also experienced lower levels of negative mood states than non-responders. These mood differences were found across all activities, except for active leisure. In terms of rime use, responders did show greater increase in productive activities, such as houschold chores, and greater decrease in passive leisure, such as 'doing nothing' than non-responders. Furthermore, in line with studies on self-esteem and daily events, current results showed that instability in well-being may be a marker of vulnerability to depression (see Chapter 5). At six weeks of treatment, imipramine patients, who showed a greater clinical response, experienced less variability in momentary QoL than did parients on placebo (see Chaprer 6). Based on these results, it would seem that instability in well-being is more likely a remporary phenomenon than a pre-existing trait in depressed parients; instability may possibly be even more sensitive than levels of subjective well-being to drug treatment differences. 
Conclusions regarding the impact of different classes of effecrive antidepressants are limited to the extent that few differences in daily life variables were found between different active treatments (e.g.; fluvoxamine versus amitriptyline, see Chapter 3 ). In recent years, there is increased interest in distinguishing changes in positive and negative affect occurring as a result of antidepressant trearments. For example, pharmacological theories predict that drugs that target noradrenaline will perform better when outcome measures tap into the domain of positive affects, whereas drugs with serotonergic activity will do better on measures that assess reducrion in negative affects (Healy, 1998). Anorher hyporhesis postulates that changes in positive affect underly treatment-related changes in social activities (Lenderking et al., 1999). In the absence of a specific noradrenergic drug in the current studies, the independent roles of PA and NA could not be investigated. However, results point to independent and large effects of both PA and NA on momentary QoL. Given the salience of low PA in the phenomenology of depression, in particular (Watson er al., 1988), and the relevance of borh PA and NA to the concept of well-being, in general (Diener, 1984), it is suggested that psychological models of affect in daily life should be incorporated into clinical trials more often. Inclusion of daily process models in future trials, specifically those comparing the effects of a selective serotonergic versus a selective noradrenergic drug, is expected to provide new insights into the differential effects of treatment.

\section{The experience of side effects in daily life}

Unfortunately, no currently available antidepressant is without side effects. An improved adverse event profile is considered to be one of several imporrant targers in the search for the ideal antidepressant (DeVane, 2000). Information on the expected drug side effects profile stems from the pharmacological mode of action of the drug. However, a description of the potential side effects in the labelling is ultimately based on the data generated in a clinical trials context. Conventionally, these data are based on physician reports. Results of the current research and others (Anderson and Testa, 1994) have shown that this method of reporting may not be sufficient to obtain a good understanding of how side effects impinge on daily life, and hence, how well side effects are tolerated by patients. For this purpose, time sampling methods such as ESM are important additions to the traditional measures used in clinicall trials. Dry mouth, a typical anticholinergic side effect, is a good example. The incidence of anticholinergic side effects with tricyclic antidepressant trearment usually ranges between $15 \%$ and $30 \%$ (Lader, 1983). In Study 2, however, 41.4\% of imipramine-treated patients reported dry mouth to the GP (see Chapter 6). This greater percentage may have been a consequence of cueing patients on complaints with ESM, although even greater percentages have been reported in other trials without ESM (e.g. 63\% imipramine-treated patients experiencing dry mouth; (Cohn et al., 1990). But what does this actually mean in the daily life of individual parients? At week 1, the average time spent with dry mourh 
increased from baseline by one-third on imipramine compared to only one-tenth on placebo treatment. In addition, severity increased from baseline on average by one point (on a 7-point scale) on imipramine versus one-third of a point on placebo treatment. More importantly, an increase from baseline in either severity or frequency of dry mouth, although not reported as an adverse event by the physician, was significantly relared to a decrease in average momentary QOL. A second example of how ESM offers new insights into how side effects impinge on daily life comes from the second case study in Chapter 7. Even before treatment, Catherine experienced nausea half of the time, bur it was mild in severity. During her week on treatment, she reported quire severe levels of nausea all of the time. Moreover, of all the side effects she experienced, nausea had the highest negative association with momentary QoL. This relationship, which could not be established retrospectively from GP reports, may have explained her non-adherence to treatment. By providing a means to obtain more descriptive information on the experience of side effects in daily life, ESM data potentially provide a better understanding of patients' difficulties with and expectation of treatment.

A disadvantage of cueing complaints in daily life may be that a greater number of patients will report side effects more frequently. Controlling for baseline levels and including placebo arms should help to overcome these impediments. With the goal of developing safe, tolerable and effective drugs, and increasing non-adherence to drug regimens, it seems essential to enhance our understanding of how side effects are experienced in daily life, even if this occurs with methods that may increase the overall incidences of reported side effects.

Furthermore, the finding that physical complaints were still present in clinical responders ar 18 weeks raises the issue of whether these are lingering side effects of treatment or a pre-existing trait, marking a certain vulnerability for depression. For many antidepressants, side effects are bellieved to occur mainly in the first two weeks and to disappear over time, partly due to true colerance and partly as a result of the parient complaining less as the depression lifts (Lader, 1983). But do we teally know? Long-term studies should address this question by invesrigating the side effects over time, both as reported by the GP and experienced by the patients in daily life.

As stated earlier, recent discussions on the reporting of typical, drug-related side effects have questioned the integrity of the double-blind in clinical trials (Antonuccio et al., 1999). In line with these concerns, current results suggested that the experience of early side effects in daily life, associated with active trearment, increased the likelihood of further prolongation of treatment (see Chapter 6). As ESM is focused on the description of the immediate personal experience, it is less likely to be affected by cognitive judgmental processes, such as taking into consideration the presence or absence of anticipared side effects. Future studies should address the role of cognitive judgmental processes (expectarions and beliefs) in patients' responses. 
Finally, further investigations should indicate whether the findings with respect to the experience of early side effecrs only hold true for conventional antidepressants such as imipramine, or also for the more specific serotonergic and noradrenergic drugs, which are believed in general to have fewer side effects.

\section{Concluding remark}

In summary, further research on the use of ESM in investigating the impact of illness and associated treatment is required. The present research focused on the impacr of depression and different antidepressant treatments in daily life. Some new insights in the effects of depression and antidepressant treatment in daily life, not obrainable via conventional measures, have been gained. Daily life variables that have an independent contribution to momentary QoL have been identified. Although we have come a little further in understanding what it means in daily life to be clinically depressed and what it means in daily life to be receiving antidepressant drug treatment, much work still needs to be done in order to obtain a model of daily QoL. In this context, the role of unmeasured aspects of depression (e.g., cognitive disturbances, difficulty in coping with daily stressors) and of treatment adherence (e.g. attributions with respect to side effects) will need to be investigated in future studies. For the pharmaceutical industry, clinical trials in a broader range of disorders can assess whether ESM is a beneficial supplement to conventional approaches, as a means both of understanding the impact of drugs in daily life (early phase of development) and of differentiating drugs from competitors in terms of daily life effects (post-markering phase).

T.S. Eliott once remarked: 'We've had the experience, but we missed the meaning'. As a general critique of conventional clinical studies in depression, we may have had the meaning, but we missed the experience. 


\section{REFERENCES}

Anderson, R. B., Testa, M.A., 1994 . Symptom discress checklists as a component of qualigy of life measurement: comparing prompted teports by patient and physician with concurrent adverse event reports via the physician. Drug Information Journal 28, 89-114.

Antonuccio, D. O., Danton, W. G., DeNewky, G. Y., Greenberg, R. P., Gordon, J. S. 1999. Raising questions about anridepressants. Psychother Psychosom 68(1), 3-14.

Cohn, J. B., Crowder, J. E., Wilcox, C.S., Ryan, P.J., 1990. A placebo-and inipramine-controlled study of paroxetine. Psychopharmacol Bull 26(2), 185-189.

Delespaul, P.A. E. G., 1995. Assessing Schizophrenia in Daily Life: The Experience Sampling Merhod; Ph.D. dissertation, Maastricht Universiry, Universitaire Pers, Maastricht.

DeVane, C. L., 2000. Pharmacologic characteristics of ideal antidepressants in the 21 st century, 1 Clin Psychiatry 61(Suppl 11), 4-8.

Diener, E., 1984. Subjective well-being. Psychological Bullerin 95(3), 542-575.

Greenberg, R. P., Fisher, S., 1997. Mood-mending medicines: probing drug, psychotherapy, and placebo solutions. In: Fisher, S., Greenberg. R. P. (Eds.), From Placebo to Panacea: Putring Psychatric Drugs to the Test. Wiley \& Sons, New York, pp. 115-172.

Healy, D., 1998. Reboxetine, fluoxerine and social functioning as an outcome measure in antidepressant trials: implications. Primary Care Psychiatry 4(2), 81-89.

Honkoop, P. C., Sorbi, M. J., Godaert, G. L., Spierings, E. L., 1999. High-densiry assessment of the IHS classification criteria for migraine without aura: a prospective study. Cephalalgia 19(4), 201-206.

Kahneman, D., 1999. Objecriwe happiness. In: Kahneman, D., Diener, E., Schwar, N. (Eds.), Well-being: the foundations of hedonic psychology. Russell Sage Foundation, New York, pp. 3-25.

Lader, M., 1983. The problems of safery and compliance wirh conventional ancidepressant drugs. Acta Psychiar Scand Suppl 308(5), $91-95$.

Lenderking, W. R., Tennen, H., Nackley, J. F. Hale, M. S., Turner, R. R., Testa, M. A., 1999. The effects of venlafaxine on social activity level in depressed outpatients. J Clin Psychiarry 60(3), 157-163.

Quirkin, F. M., Rabkin, J. G., Gerald, J., Davis, J. M., Klein, D. F., 2000. Validity of clinical trials of antidepressants. Arn J Psychiatry 157(3), 327-337.

Shiffman, S., Elash, C. A., Paton, S. M., Gwalney, C. J., Pary J. A., Clark, D. B., Liu, K. S., Di Marino, M. E., 2000. Comparative efficacy of 24-hour and 16 -hour transdermal nicotine patches for relief of moming craving. Addiction 95(8), 1185-1195.

Watson, D., Clark, L. A., Carey, G. 1988. Posirive and negative affectivity and their relation to anxiety and depressive disorders, Journal of Abnomal Psychology $97(3), 346-353$. 



\section{APPENDICES}

$$
\text { APPENDIX } 1
$$

A. Study 1 ESM self-report beep level (Dutch)

B. Study 1 ESM self-report beep level (English)

C. Study 1 ESM self-report day level (Dutch)

D. Study 1 ESM self-report day level (English)

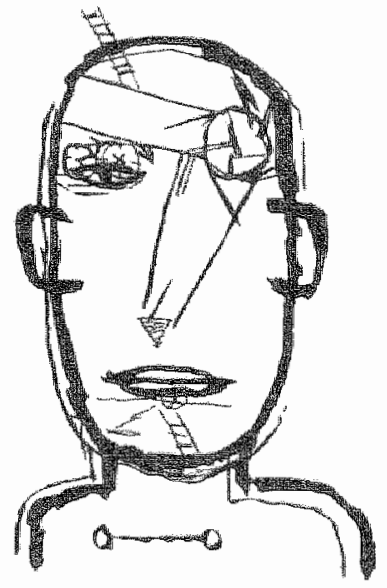




\section{A. STUDY I ESM SELF-REPORT BEEP LEVEL (DUTCH)}

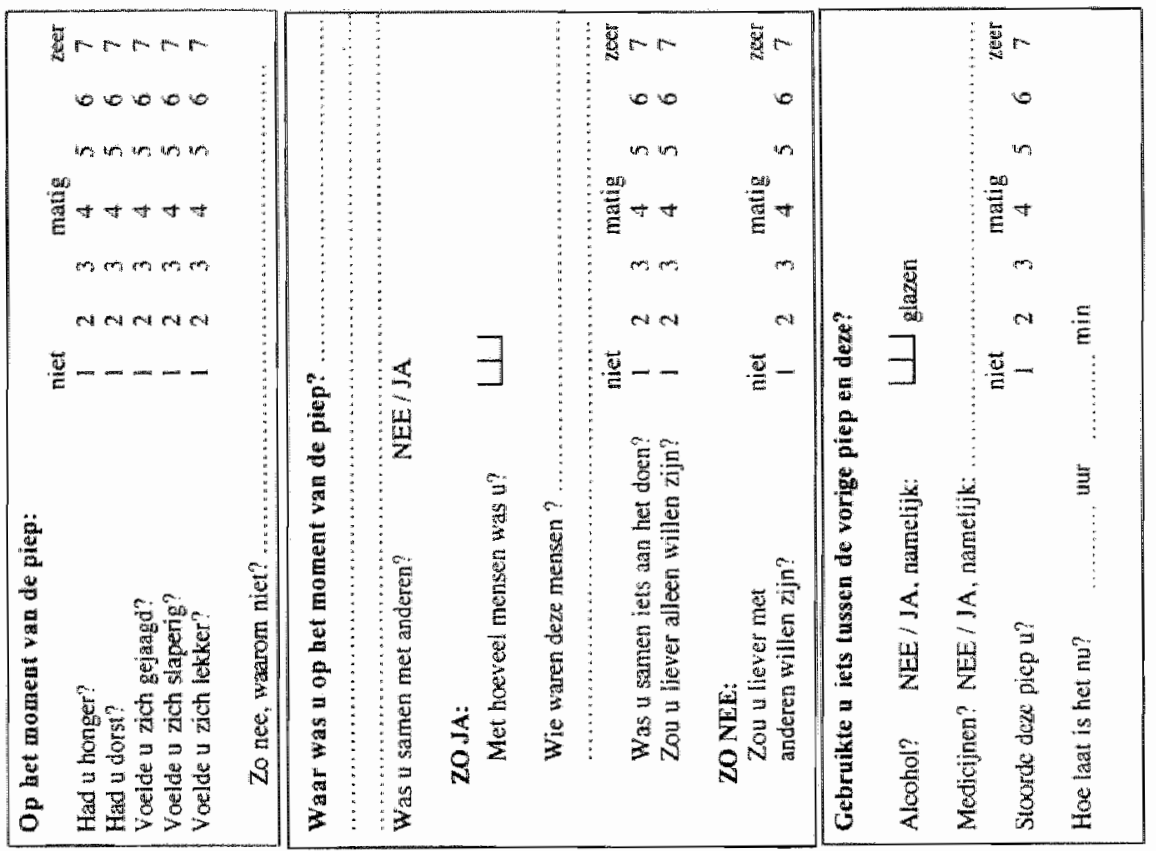
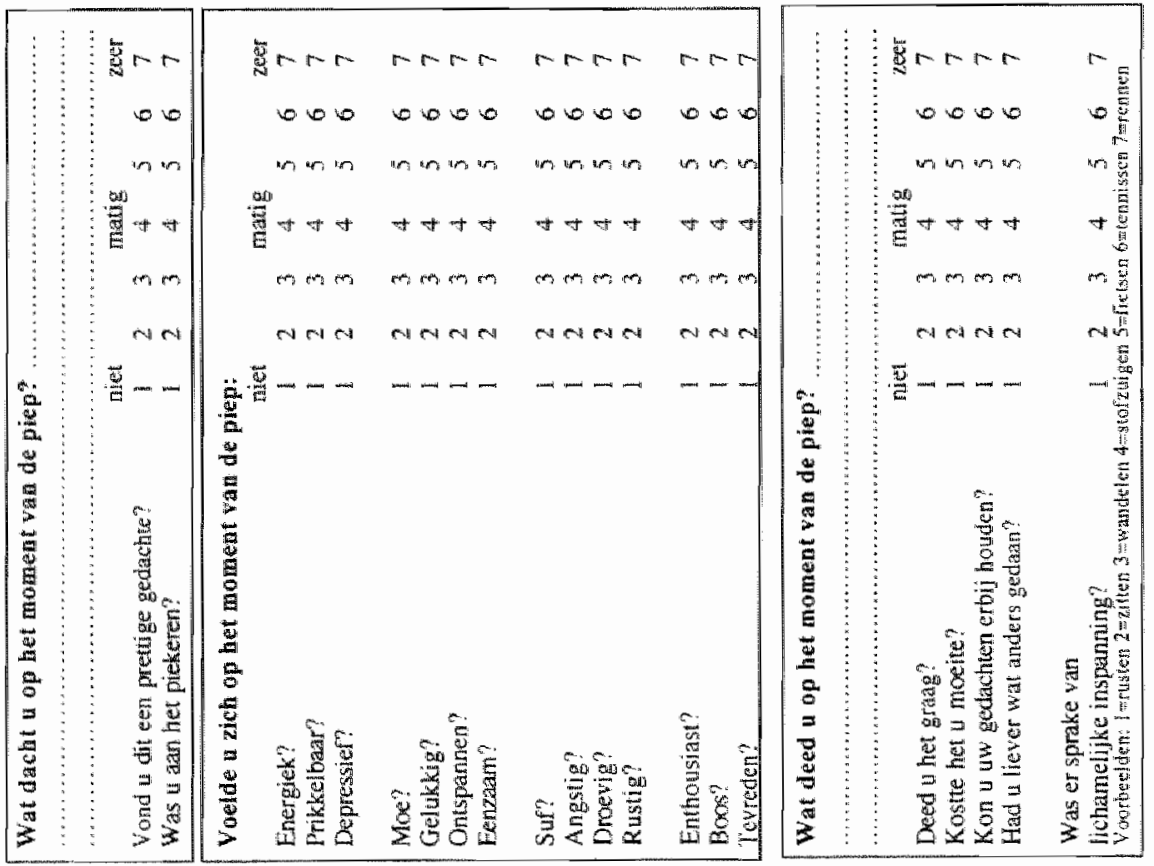


\section{B. STUDY I ESM SELF-REPORT BEEP LEVEL (ENGLISH)}
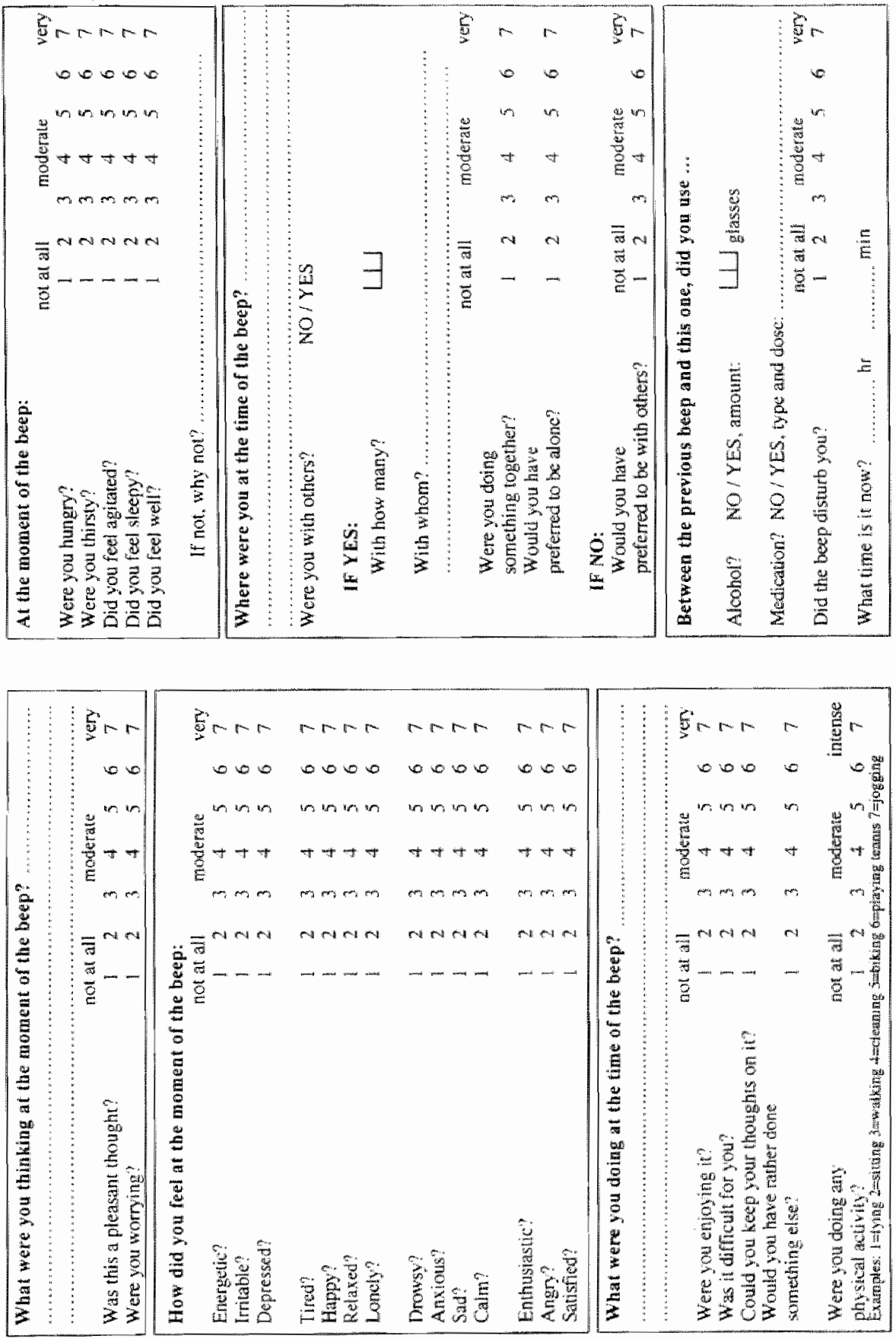


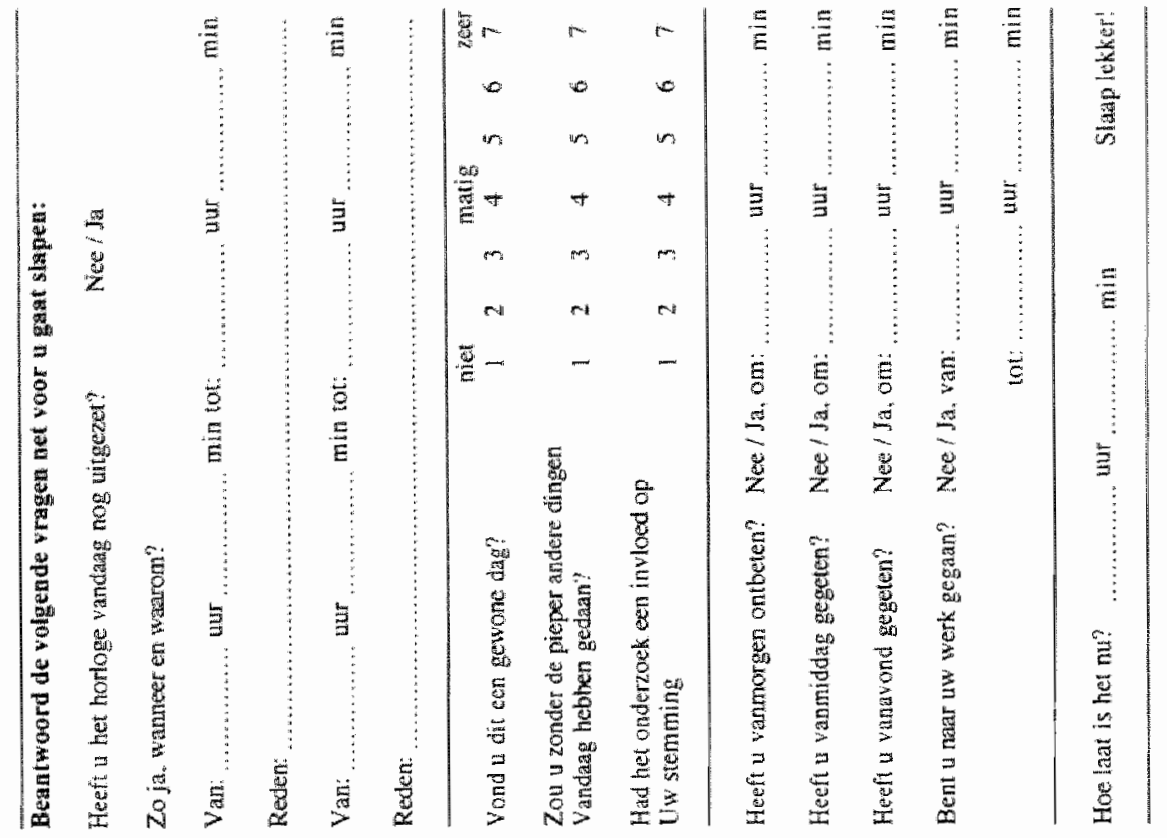

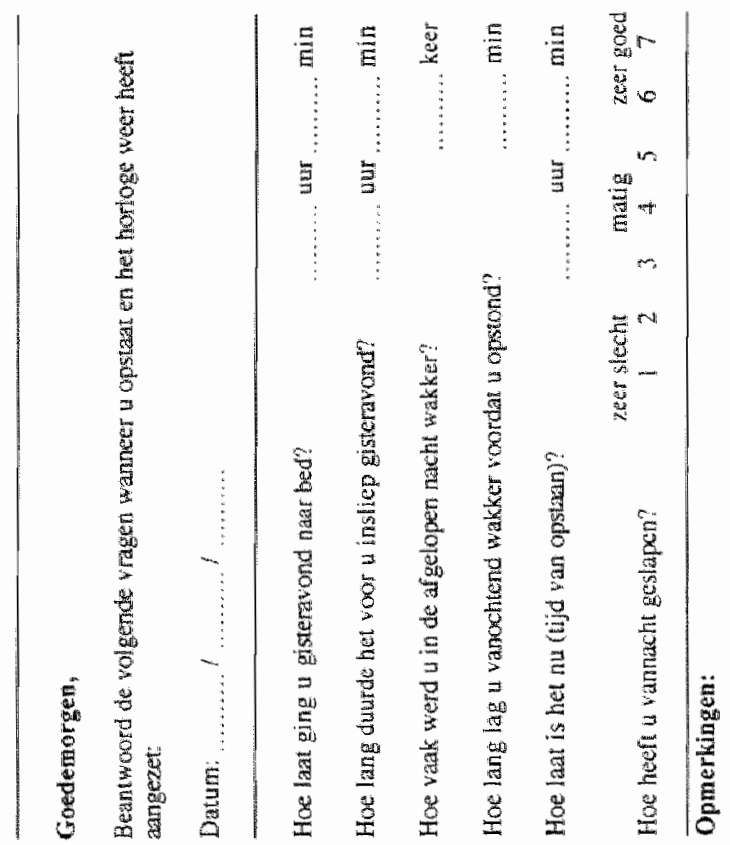


D. STUDY 1 ESM SELF-REPORT DAY LEVEL (ENGLISH)
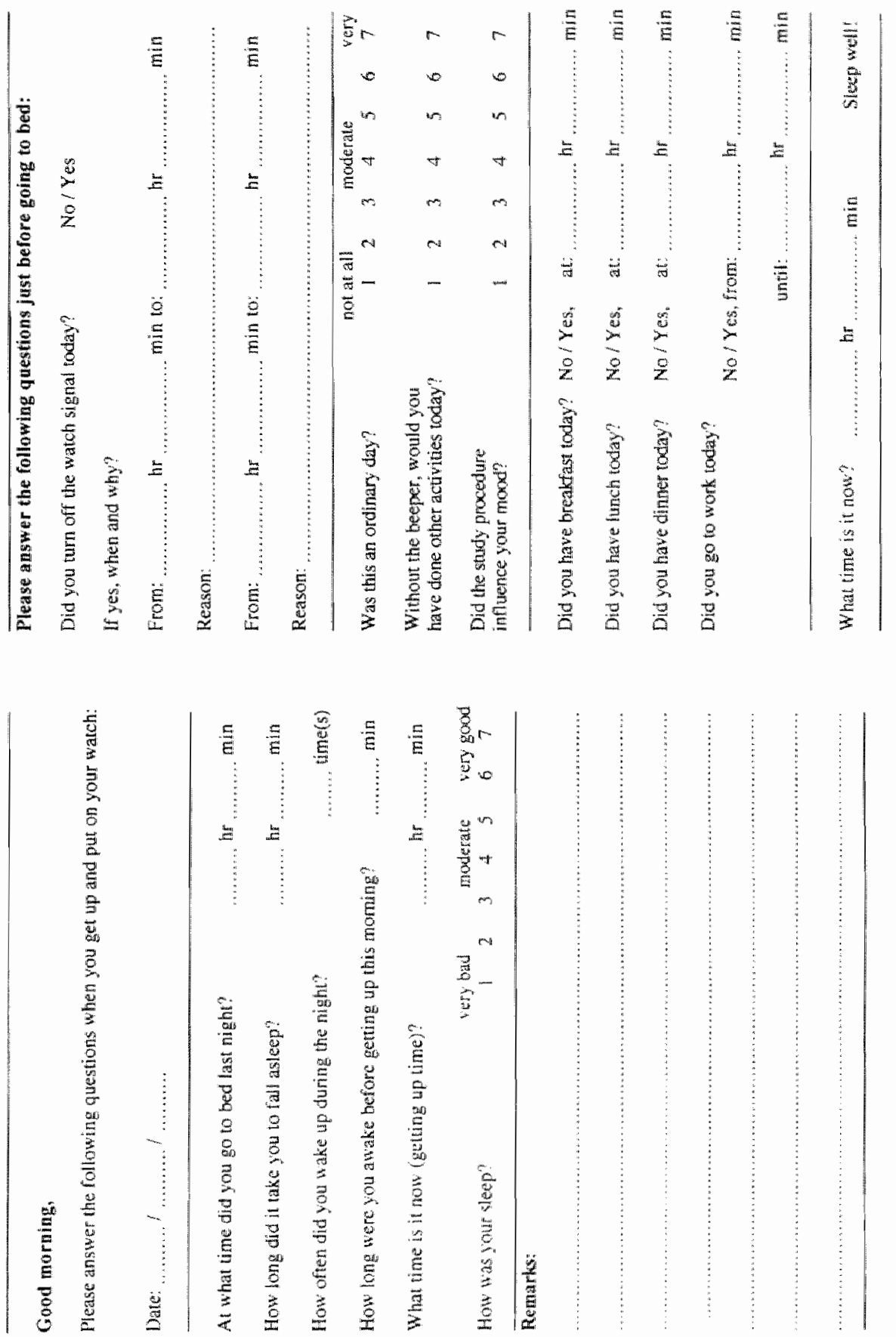



\section{APPENDICES}

$$
\text { APPENDIX } 2
$$

A. Study 2 ESM self-report beep level (Dutch)
B. Study 2 ESM self-report beep level (English)

C. Study 2 ESM self-report day level (Dutch)

D. Study 2 ESM self-report day level (English)

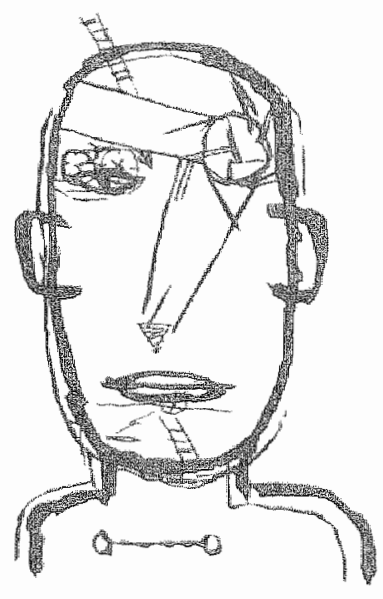


A. STUDY 2 ESM SELF-REPORT BEEP LEVEL (DUTCH)
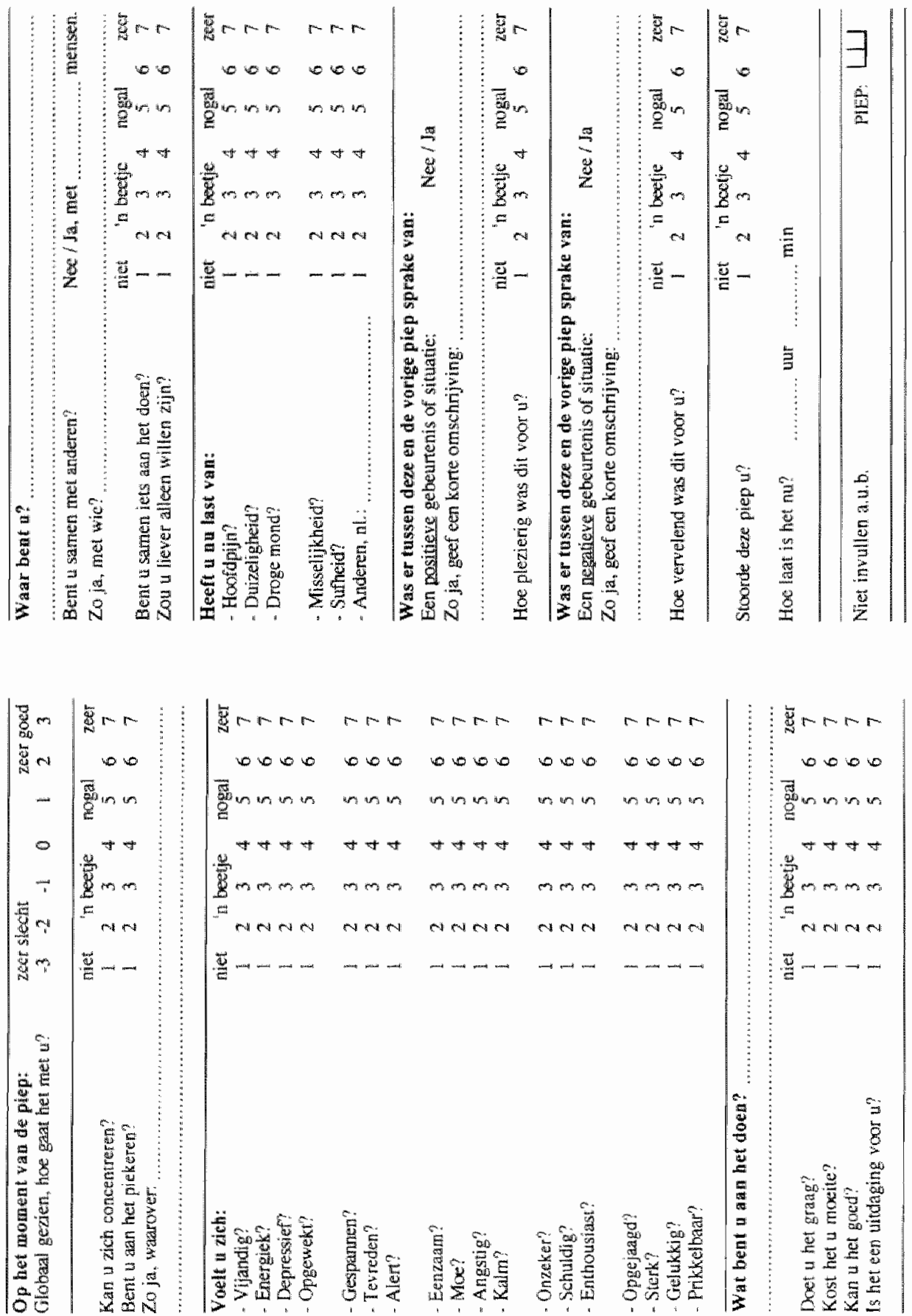


\section{B. STUDY 2 ESM SELF-REPORT BEEP LEVEL (ENGLISH)}
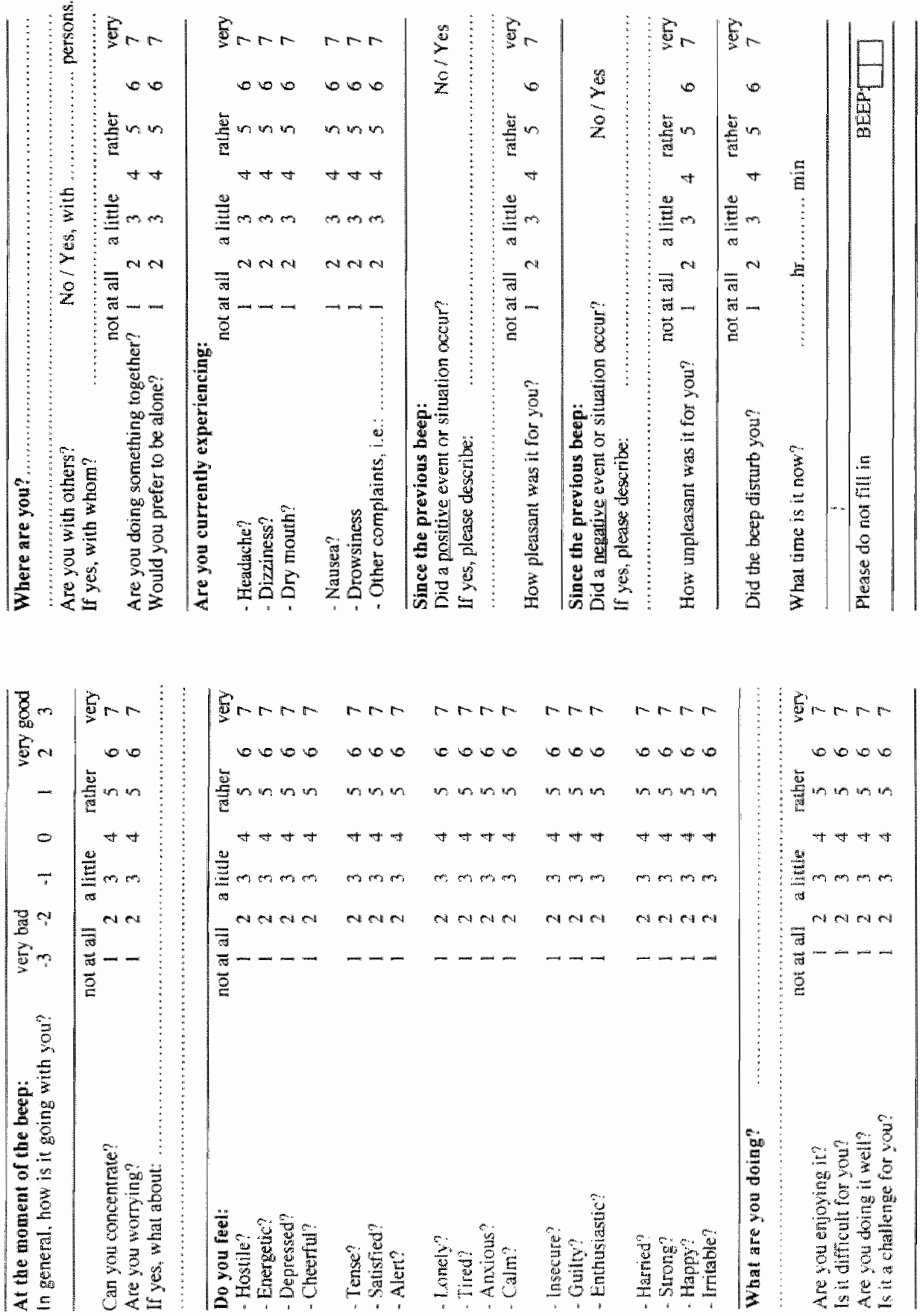
162

C. STUDY 2 ESM SELF-REPORT DAY LEVEL (DUTCH)

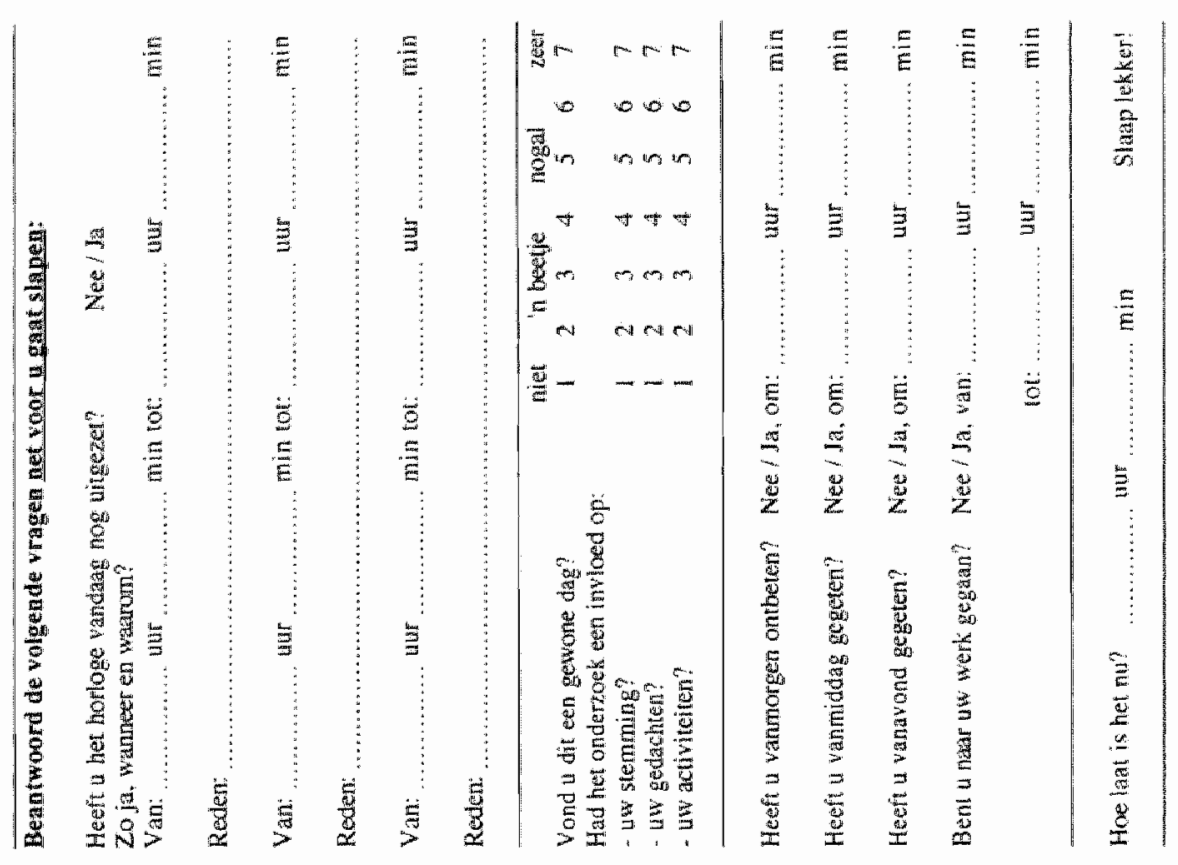

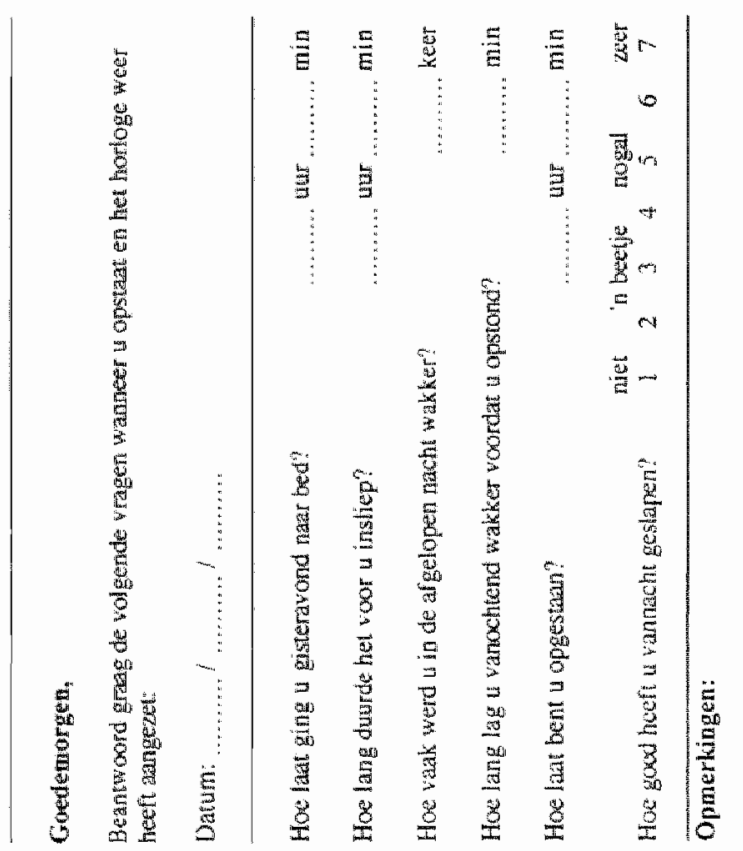


D. STUDY 2 ESM SELF-REPORT DAY LEVEL (ENGLISH)

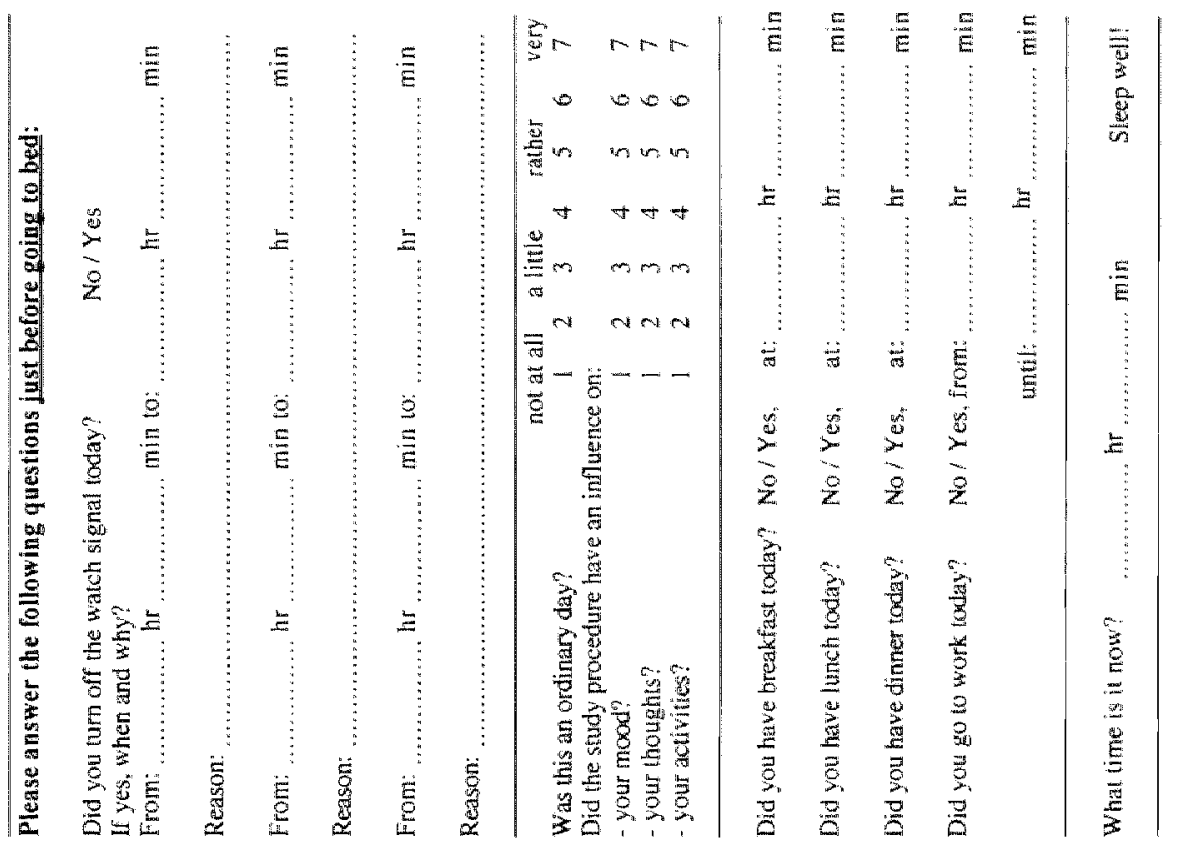

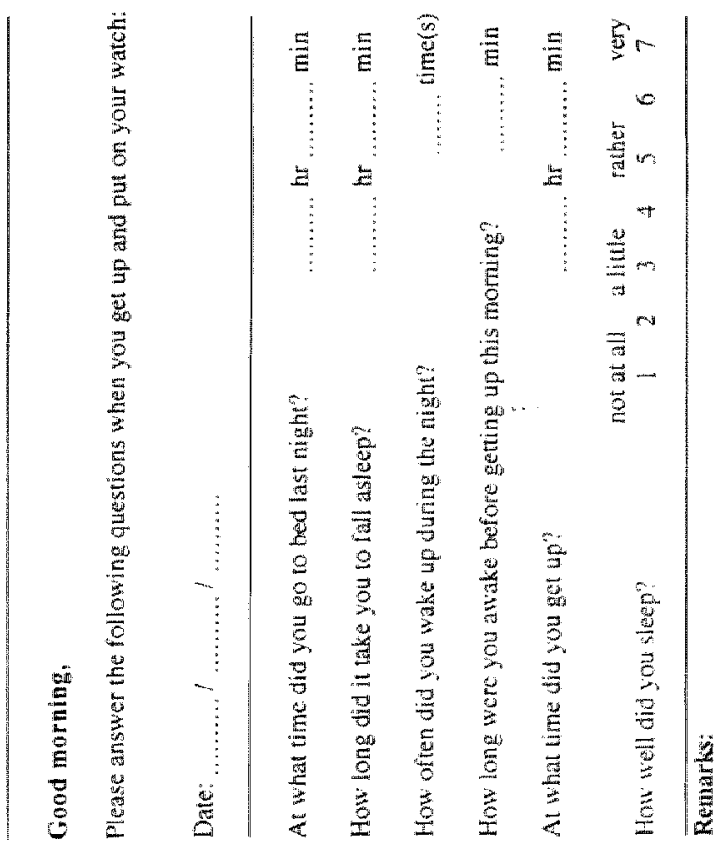





\section{Summary}

This thesis explores the effects of depression as well as of antidepressant treatment in daily life. In Chapter 1, the burden of depression is described and treatment issues surrounding antidepressants are outlined. Furthermore, the introduction of the Qualicy of Life (QoL) concept in clinical research is reviewed. In light of the limitations of the currently used QoL instruments in depression, Chapter 2 describes the Experience Sampling Method (ESM) as a way to investigate the impact of depression and the effects of antidepressant treatment prospectively in real life setrings. Chapter 3 presents the results of Study 1 , a first exploration of the use of ESM in a clinical trial context. Here, a sample of 21 depressed patients who were randomized to either fluvoxamine or amitriptyline treatment (single-blind) for 6 weeks, completed ESM booklers for 6 days pre-treatment and again for 6 days in the last week of trearment. Compliance with ESM was good in both sampling periods, with $81 \%$ of self-reports responded to within 15 min. On a retrospective generic QoL measure (Sickness Impact Profile), clinical responders were found to improve relative to non-responders in the domains of household chores, leisure and social acriviries. ESM results further clarified the improvement in these three areas of life with: (1) responders increasing time spent on chores and reducing time spent on passive leisure, (2) responders experiencing greater changes in average mood states across the life domains than non-responders, and (3) responders reporting highly positive mood states more often than non-responders. The next four chapters describe results obtained in Study 2. In this study, 63 patients were randomized to either imipramine or placebo, which they received (double-blind) for 6 weeks, with a possible prolongarion to 18 weeks. A control group of 22 healthy individuals provided normative data. ESM was conducted pre-treatment, and in the $1 \mathrm{st}$, $6 \mathrm{th}$, and 18 th week of treatment. Chapter 4 addresses a number of methodological issues concerning the feasibility and the utillity of using ESM in depression and in a clinical trial. It appeared that depressed patients complied with ESM over time as well as healthy individuals, despite more initial difficulty and disturbance. The results further suggested that patients were able to provide a valid and reliable representation of their daily lives with ESM. By using repeated measurements over the day and across days instead of one-rime measurement, the current sampling strategy (i.e. 10 rimes a day for 6 days) increased the standardized trearment effect size (STES) of ESM measures, thereby increasing the likelihood of detecting true treatment differences. Although the sampling strategy used was effecrive in obraining the maximum STES for ESM measures, other sampling strategies (with a lower number of beeps per day) may be more efficient in this respect. Surprisingly, ESM measures were not found to be more sensitive than 
conceptual y related retrospective measures in detecting differences berween drug and placebo. Two speculative explanations are proposed. Chapter 5 uses ESM dara to invesrigate differences between depressed and control groups. Depressed subjects reported Nower levels in positive mood and enjoyment of actiwity, higher negative mood, and more frequent and severe complaints than the healthy individuals. In addition, depressed subjects were more likely than control subjects to be doing nothing and less likely to be engaged in work. Moreover, moment to moment QoL (mQoL) in depressed subjects was found to be lower and more variable within the day than in controls. Mulvilevel regression analysis showed that mQoL was more influenced by transient states and daily experiences than a conceptually related retrospective measure, underscoring the potential value of the ESM approach as a tool in understanding changes in QoL during the course of antidepressant treatment. This aspect is investigated in Chapter 6. Results showed that treatment-related increases in frequency or severity of physical complaints including those not reported to the general practirioner as side effects, were associated with decrements in $\mathrm{mQOL}$, which may have led to subsequent treatment drop-out. Results further indicated that six weeks of im ipramine treatment had a stronger stabilizing effect on $\mathrm{mQoL}$ than placebo treatment. Changes in measures of daily functioning (i.e. rime spent doing nothing) were also observed after six weeks. However, at 18 weeks, the majority of parients, including those who responded to treatment, still showed deficits on daily life measures relative to healthy controls; even though QoL had returned to normal on retrospective measures. In Chapter 7, two case examples are presented to illustrate the quantitative findings of Chapters 4,5 and 6 . The case of Suzanne, a responder to imipramine treatment, demonstrates the value of ESM in providing better insight into changes in daily life experiences that accompany reatment response. The case of Catherine illustrates ESM as a means for obtaining a better understanding of non-response, drug incolerance, or non-adherence. Chapter 8 summarizes the main findings of the two studies and discusses them in terms of the application of ESM in clinical drug trials and the new insights, obtained via ESM, into the burden of depression in daily life, clinical improvement and daily life experiences, and the experiences of side effects in daily life. Implicarions for practice and future research are suggested. 


\section{Samenvatting}

Dit proefschrift onderzoekt de gevolgen van een depressie en de effecten van het gebruik van antidepressiva op her dagelijks leven. In Hoofdstuk 1 worden de negatieve gevolgen van een depressie en problemen die verband houden met het gebruik van de huidige antidepressiva in hoofdlijnen beschreven. Vervolgens wordt er een overzicht gegeven van de introductie van het begrip 'Kwaliteit van Leven' (Quality of Life, QoL) in het klinisch onderzoek. In het licht van de beperkingen van de huidige gebruikte QoL instrumenten bij depressie onderzoek geeft Hoofdstuk 2 een beschrijving van de Experience Sampling Method (ESM). ESM is een onderzoeksmethode waarmee het mogelijk is om prospectief en op basis van herhaalde observaties de invloed van depressie en de effecten van antidepressiva te meten in de natuurlijke omgeving. In Hoofdstuk 3 worden de resultaten van de eerste toepassing van ESM in een klinische studie (Studie 1) gepresenteerd. In deze studie hebben 21 depressieve patiènten, die gedurende 6 weken fluvoxamine of amitriptyline voorgeschreven kregen, 6 dagen ESM boekjes ingevuld vóó behandeling en nog eens 6 dagen in de laarste week van de behandeling. Tijdens beide periodes werden de boekjes goed ingevuld; $81 \%$ van alle vragenlijsten werd binnen 15 minuten ingevuld. Gemeten met een retrospectieve generische QoL-maat (Sickness Impact Profile) verbeterde de toestand van de mensen die positief reageerden op de behandeling (responders) zich meer dan de mensen die niet of nauwelijks reageerden (non-responders) op het gebied van huishoudelijke taken, vrijetijdsbesteding en sociale activireiren. ESM-resultaten verhelderden deze bevindingen doordat: (1) responders meer tijd gingen besteden aan huishoudelijke activiteiten en minder aan passieve vrijetijdsbestedingen, (2) responders een grotere verbetering in hun stemming constateerden gedurende de diverse activiteiten dan non-fesponders, en (3) responders frequenter dan non-tesponders momenten van exrreem positieve stemming rapporteerden. De volgende vier hoofdstukken (Hoofdstuk 4, 5, 6 en 7) beschrijven de resultaten die verkregen zijn in Studie 2. In deze studie hebben 63 patiënten op aselecte wijze het antidepressivum imipramine of placebo voorgeschreven gekregen gedurende 6 weken (dubbel-blind), met een mogelijke verlenging tot 18 weken. Tweeënrwintig gezonde individuen zorgden voor normatieve gegevens. ESM werd uirgevoerd in de week voorafgaand aan de behandeling en in de eerste, zesde en achtriende week van de behandeling. Hoofdstuk 4 behandelt verscheidene methodologische kwesties die betrekking hebben op de uitvoerbaarheid en het nut van ESM in een klinisch onderzoek naar depressie. Depressieve patiënten voldeden even goed als gezonde vrijwilligers aan ESM ondanks het feit dat ze in het begin meer moeite en storing ondervonden. Verder lieten de resultaten zien dat 
parienten in star waren cen valide en representatief beeld te geven van hun dagelijks leven mer behulp van ESM. Door herhaaldelijke metingen gedurende de dag en over cen periode van meerdere dagen verhoogde de huidige ESM-sampling strategie (te weten tien keer per dag gedurende zes dagen) de genormaliseerde effectgrootte (standardized treatment effect size, STES) van de ESM maten, waardoor de kans op het vinden wan een echt behandelingsverschil vergroot werd. Alhoewel de gebruikte sampling strategie effectief bleek in het verkrijgen van een maximum STES voor de ESM maten, zou het toch mogelijk kunnen zijn dat andere sampling strategieën nog efficiënter blijken. Tegen de verwachting in bleken ESM maten niet gevoeliger te zijn voor verschillen tussen actief (imipramine) en placebo dan conceptueel gerelateerde retrospectieve maten. Op zoek naar een oorzaak worden twee speculatieve verklaringen gegeven. Hoofdstuk 5 maakt gebruik van de ESM-gegevens om verschillen tussen de depressieve en de controlegroep te onderzoeken. Depressieve patiënten rapporteerden een lagese positieve stemming, minder plezier in de activiteiten die zij ondernamen, een hogere negatieve stemming en tevens frequentere en ernstiger klachten dan gezonde mensen. Verder bleken depressieve patiënten minder vaak dan gezonde mensen te werken en vaker inactief te zijn. Bovendien, was de kwaliteit van lewen van moment tot moment (gedefinieerd als mQoL) lager en meer variabel gedurende de dag dan bij gezonde mensen. Een multilevel regressie-analyse bracht aan het licht dat mQoL meet beïnvloed wordt door kortdurende momenten en dagelijkse ervaringen dan een conceptueel gerelateende retrospectieve maat. Hiermee wordt de potentiële waarde van ESM belicht om een beter inzicht te krijgen in veranderingen in QoL die optreden gedurende een behandeling met antidepressiva. Deze veranderingen worden verder onderzocht in Hoofdstuk 6. De resultaten (van het onderzoek) lieten zien dat een verhoging in de frequentie of de ernst van klachten, waaronder ook die klachten die niet als bijwerking an de arts gerapporteerd waren, geassocieerd was met een vermindering van $\mathrm{mQoL}$, hetgeen geleid kan hebben tot vervroegde beëindiging wan deelname aan het onderzoek. Verder bleek bij de meting na 6 weken dar imipramine een sterker stabiliserend effect had op mQoL dan het placebo. Veranderingen in het dagelijks funcrioneren (met name de rijd besteed aan het inactief zijn) werden ook na 6 weken wargenomen. Echter na 18 weken behandeling bleek de meerderheid van de patiènten, ook diegenen die een goede respons hadden vertoond, erop basiswan $E S M$ in het dagelijks lewen nog steeds slechter an roe te zijn dan gezonde mensen, terwijl dit op basis wan retrospectieve maten niet langer her geval bleek te zijn. In Hoofdstuk 7 worden twee casus gepresenteerd om de kwantitatieve bevindingen uit de hoofdstukken 4, 5 en 6 te illustreren. De casus 'Suzanne', die een goede respons heeft op de behandeling, laat zien dat ESM een mogelijkheid biedt om een beter inzicht te krijgen in de veranderingen die zich voordoen in het dagelijks leven als gevolg van een goede respons. De casus 'Catherine' illustreert ESM als een manier om een beter inzicht te krijgen in gevallen waar een respons uitblijf, het geneesmiddel niet wordt verdragen, 
of er sprake is van onvoldoende therapietrouw. Hoofdstuk 8 vat de belangrijkste bevindingen samen en bespreekt deze ten aanzien van de toepassing van ESM in klinische studies en ten aanzien van de - door middel van ESM - nieuw verkregen inzichten in de gevolgen van depressie voor her dagelijks leven, de klinische verbetering en de daarmee gepaard gaande dagelijkse erwaringen en tenslotte de invloed van de bijwerkingen van antidepressiva op het dagelijkse leven. Gevolgen woor de praktijk en suggesties voor toekomstig onderzoek komen eveneens aan de orde. 


\section{Acknowledgments}

A 'Dissociative Identiry Disorder', better known as a 'Split-type Personality Disorder' is characterized by the presence of two distinct personality states in one individual, which are perceived by the individual's environment. Working in two distinct locations, borh geographically (Amsterdam/Maastricht) and funcrionally (industry/academia) can be compared to a 'Dissociative Identity Disorder', which is only perceived by the individual concerned. There are many people I am indebred to for the fact that this disorder has never become applicable to me.

First of all I thank Dr. Roland Gerritsen van der Hoop. The idea of doing this research was born on our way back by train from a work visit to the Department of Psychiatry and Neuropsychology in Maastricht in June 1991. Thanks to his infectious enthusiasm, he helped rally support for the project within Solvay Pharmaceuticals. Since then, even after he was appointed to Solvay Pharmaceuticals in the USA, Roland has continued to remain involved with the project by providing helpful comments on the various manuscripts.

Professor Marten deVries has helped me broaden my scientific horizon by his never-ending, stimularing thoughts and his multidisciplinary approach. Although initially I was not always able to appreciate the value of Marten's original ideas, I have actually come to miss the challenging discussions as they became less frequent over the years. II would like to acknowledge Marten's flexibility in accepting an 'honorary $\mathrm{OIO}^{\prime}$ ' (as he himself put it), who would always place her work for Solvay Pharmaceuticals as her first priority over her thesis.

I could never have managed without the extensive and highly qualified support of Dr. Nancy Nicolson. I thank Nancy for the innumerable hours she has spent on my project, the countless comments she has provided on my manuscripts, and the invaluable scienrific knowledge she has imparted to me. In view of the time constraints we always experienced, our discussions were to the point and efficient, thereby even allowing some time to keep track of each other personally. In short, I experienced that as inspiring reamwork!

Over the years, I have been able to exchange thoughts with many of my colleagues in Maastricht. In this context, I mention Dr. Philippe Delespaul, a sincere person, who was always there for me and who gave me great deal of support in setting-up and imple- 
menting the ESM studies. Dr. Hans Berkhof provided inestimable statistical input when it came to hierarchical linear models. I am grateful to Truda Driesen and Frieda Delespaul-Goethem for helping me become acquainted with the practical aspects of the Experience Sampling Method and for their diligence in coding and entering the data. Furthermore, I thank the secretaries from the Department, especially Trees Soute, who made it possible to conduct this research project from such a distance.

My gratitude goes to Solvay Pharmaceuticals, for having provided me the opportunity of carrying out my research project. In this context, I thank Marianne Mak for her critical concerns about my personal well-being. Jos Nauta's advice and involvement in. Chapter 4 in particular and his willingness to discuss thorny issues have strengthened me in my conviction that no sound research can be done without statisticians. At the same time, I acknowledge the help that Jeroen Tolboom and Frank Kok gave with specific statistical calculations. It is a good thing that I have not kept track of all the literarure requests I have made over the years. I realize they presented a lot of work to my excolleagues from BWI and thank them for it. Especially Rob van Spronsen made it his personal responsibility to ensure that the availability of the arricles would not become a rate-limiting step in my research. Finally, I thank all my ex-colleagues, with whom I have enjoyed working over the years, for their understanding of my 'double' life.

I am indebted to the depressed patients and healthy volunteers, who took part in the two clinical trials, that have provided the data for this dissertation. The studies could not have taken place without the well-organized group of general practitioners, i.e. M.F.J. Bemelmans, R.H.J. Brouwers, G. Costongs, A.C.J. Schlösser, J.J.M. Theunissen, P.G.J. van Aubel, D.J.M. van der Voort, and M. Weijts, and their incredibly motivated research assistants, Loes Stokkermans, Pauline Versteeg, and Toos van der Voort.

Furthermore, I gratefully acknowledge Agnes Charlemagne for the graphical design on the cover, which is her personal reflection of the contents of this thesis.

In the summer of 1992, I spent time in Maastricht to become acquainted with the Experience Sampling Method. During this time, I stayed with Désirée Brenninkmejert and her children. I gratefully appreciate how they introduced me to the 'Mestreechse" way of life.

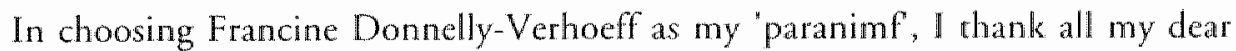
friends, who have kept confidence in me over the years. Through her ability to finalize her thesis under more penurious circumstances, Francine has set an example for me.

My orher 'paranimf is Benedikte Bruijs-Schaapveld, in whom I thank all my brothers, sisters, and in-laws for their support and encouragement, but also for helping me 
keep my feet on the ground. Benedikte convinced me to opt for a sabbatical leave in order to finalize this thesis. I thank her for persuading me.

Two individuals have kept me going over the years. First of all Radboud Schaapveld, who would have been the first in the family to obtain his doctor's degree and would have pointed this out to me, if he were still amongst us. And second, Professor Jan Naura, or rather 'oom' Jan, who pictured the development of a $\mathrm{Ph}$. D. thesis as such a nightmare that the reality was actually a pleasant surprise.

I thank my parents for all the time, patience and effort they have put into my education, and all the opportunities they gave me. In this context, I thank them especially for the high level of self-discipline, which they helped me acquire. Furthermore, I am grateful to Leticia Paraiso-Alencar for her flexibility in taking care of Ludovic and Céline. Without her, Frederic and I would not have been able to develop our professional careers over the past 5 years. Finally, I am deeply indebted to Frederic for his unconditional love and support throughout the 'double' life I have led since 1993. He also made me realize that a master's degree in information management does not say anything about the person's ability to work on a computer!

Amsterdam, 2001

Daniela Q.C.M. Barge-Schaapveld 


\section{Curriculum vitae}

Daniela Quirina Carola Maria Barge-Schaapveld was born on July 23, 1966, in New York (USA). She followed her secondary education (Baccalauréat C) at the Lycée Français de Londres in London (UK), via the Cours par Correspondance from Brasilia (Brazil), and finally at the Ecole Française de La Haye in The Hague (The Netherlands). In 1983, she started a degree in medical information management at the University of Leiden (The Netherlands), which she completed in 1989. She was subsequently employed by Solvay Pharmaceuticals (previously Duphar), where she worked for 11 years in clinical research and international marketing. As a Clinical Research Director, she was responsible for the clinical development of psychopharmacologic drugs. She has been affiliared with the Department of Psychiatry and Neuropsychology at Maastricht University (The Netherlands) since 1993, conducting her dissertation research with financial and logistical support from Solvay Pharmaceuticals. In 1994, she obtained a 'propedeuse' in psychology at the University of Amsterdam (The Netherlands). In $1995 / 1996$, she completed requirements for the European Certificate in Anxiety \& Mood Disorders (Erasmus Programme, Maastricht/Caen). 